\title{
Modeling nitrogen chemistry in combustion
}

\section{Glarborg, Peter; Miller, James A.; Ruscic, Branko; Klippenstein, Stephen J.}

\section{Published in:}

Progress in Energy and Combustion Science

Link to article, DOI:

10.1016/j.pecs.2018.01.002

Publication date:

2018

Document Version

Peer reviewed version

Link back to DTU Orbit

Citation $(A P A)$ :

Glarborg, P., Miller, J. A., Ruscic, B., \& Klippenstein, S. J. (2018). Modeling nitrogen chemistry in combustion. Progress in Energy and Combustion Science, 67, 31-68. https://doi.org/10.1016/j.pecs.2018.01.002

\section{General rights}

Copyright and moral rights for the publications made accessible in the public portal are retained by the authors and/or other copyright owners and it is a condition of accessing publications that users recognise and abide by the legal requirements associated with these rights.

- Users may download and print one copy of any publication from the public portal for the purpose of private study or research.

- You may not further distribute the material or use it for any profit-making activity or commercial gain

- You may freely distribute the URL identifying the publication in the public portal

If you believe that this document breaches copyright please contact us providing details, and we will remove access to the work immediately and investigate your claim 


\section{Modeling Nitrogen Chemistry in Combustion}

Peter Glarborg ${ }^{1}$, James A. Miller ${ }^{2}$, Branko Ruscic ${ }^{2}$, and Stephen J.

Klippenstein ${ }^{2}$

${ }^{1}$ Department of Chemical and Biochemical Engineering, Technical University of Denmark, DK-2800 Kgs. Lyngby, Denmark

${ }^{2}$ Chemical Sciences and Engineering Division, Argonne National Laboratory, Argonne, IL, $60439, U S A$

Keywords: nitric oxide, thermal NO, prompt-NO, fuel-NO, kinetic model

Understanding of the chemical processes that govern formation and destruction of nitrogen oxides $\left(\mathrm{NO}_{\mathrm{x}}\right)$ in combustion processes continues to be a challenge. Even though this area has been the subject of extensive research over the last four decades, there are still unresolved issues that may limit the accuracy of engineering calculations and thereby the potential of primary measures for $\mathrm{NO}_{\mathrm{x}}$ control. In this review our current understanding of the mechanisms that are responsible for combustion-generated nitrogen-containing air pollutants is discussed. The thermochemistry of the relevant nitrogen compounds is updated, using the Active Thermochemical Tables (ATcT) approach. Rate parameters for the key gas-phase reactions of the nitrogen species are surveyed, based on available information from experiments and high-level theory. The mechanisms for thermal and prompt-NO, for fuel-NO, and NO formation via $\mathrm{NNH}$ or $\mathrm{N}_{2} \mathrm{O}$ are discussed, along with the chemistry of NO removal processes such as reburning and Selective Non-Catalytic Reduction of NO. Each subset of the mechanism is evaluated against experimental data and the accuracy of modeling predictions 
is discussed.

\section{Introduction}

Emission of oxides of nitrogen from combustion and high temperature industrial processes continues to be an environmental concern. Nitrogen oxides, collectively termed $\mathrm{NO}_{\mathrm{x}}$, are formed in essentially all combustion processes, mostly as nitric oxide (NO) with smaller amounts of nitrogen dioxide $\left(\mathrm{NO}_{2}\right)$ and nitrous oxide $\left(\mathrm{N}_{2} \mathrm{O}\right)$. Nitric oxide is subsequently oxidized to $\mathrm{NO}_{2}$ in the atmosphere. Nitric oxide and nitrogen dioxide are acid rain precursors and participate in the generation of photochemical smog, while nitrous oxide is a greenhouse gas.

Several separate mechanisms have been identified that can lead to formation of nitrogen oxides in significant quantities. These mechanisms involve either fixation of the molecular nitrogen contained in the combustion air or oxidation of organic nitrogen chemically bound in the fuel. Figure 1 provides an overview of the most important sources of NO in combustion.

For gaseous fuels with no or negligible amounts of fuel-bound nitrogen (e.g., natural gas), as well as for fuels with a low nitrogen content (oil, woody biomass, plastic waste), formation of $\mathrm{NO}$ arises from fixation of $\mathrm{N}_{2}$ in the combustion air. Homogeneous mechanisms for fixation of $\mathrm{N}_{2}$ involve the attack of reactive radicals $\left(\mathrm{O}, \mathrm{CH}_{\mathrm{n}}, \mathrm{H}\right)$ on the triple bond in molecular nitrogen [1-4]. These reactions form either $\mathrm{NO}$ or a reactive nitrogen intermediate $\left(\mathrm{N}_{2} \mathrm{O}\right.$, cyanides, $\left.\mathrm{NNH}\right)$ that may subsequently be oxidized to NO. For fuels with a considerable content of organically bound nitrogen, i.e., most solid fuels, oxidation of fuel-bound nitrogen constitutes the dominant source of nitrogen oxides. Here, formation of NO will depend on the partitioning of fuel-N between volatiles and char. The chemistry of the volatile nitrogen is complicated, since it may involve oxidation of tar- $\mathrm{N}$, soot-N, cyclic compounds, and light species such as $\mathrm{HCN}$ and $\mathrm{NH}_{3}$. 
Volatile-N from coal is mostly released with tar, emerging subsequently mainly as $\mathrm{HCN}$, while for biomass and low rank coals, significant amounts of $\mathrm{NH}_{3}$ may be released directly from the solid matrix during devolatilization [3].

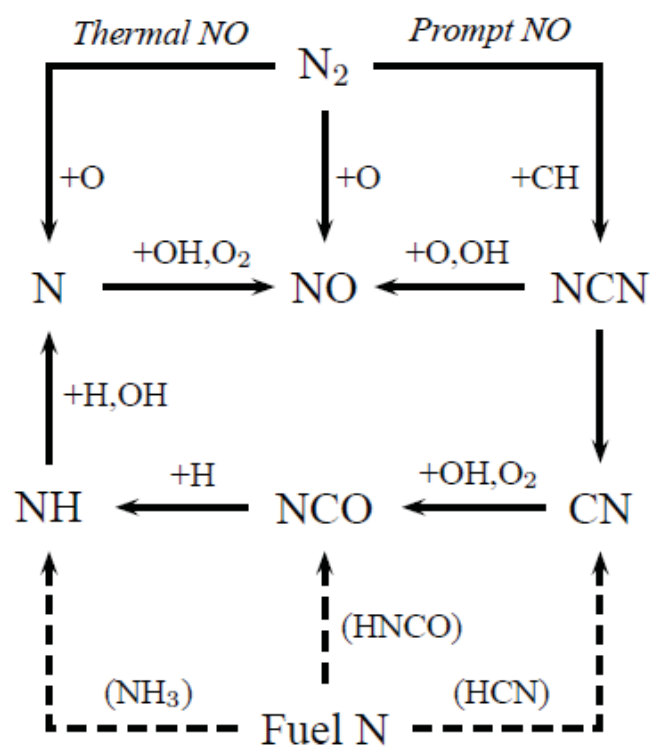

Figure 1: Simplified reaction path diagram illustrating the major steps in the formation of thermal NO, prompt $\mathrm{NO}$, and fuel $\mathrm{NO}$. Recycling of $\mathrm{NO}$ to $\mathrm{N}_{2}$ through reaction with atomic nitrogen or to cyanides through reaction with hydrocarbon radicals is not shown.

A large amount of work has been devoted to improve the understanding of $\mathrm{NO}_{\mathrm{x}}$ formation mechanisms in combustion and to develop control strategies to reduce emissions $[1-3,5,6]$. Restrictions on $\mathrm{NO}_{\mathrm{x}}$ emissions that used to apply only to large combustion systems such as power plants are now implemented on ever smaller scales: they continue to be a driving force for research and development in many industrial high temperature processes. In large power plants and for certain engines, emissions are typically controlled by catalytic flue gas cleaning. However, this technology can be challenging to use for fuels such as biomass and waste due to poisoning issues or undesirable due to comparatively high costs. For this reason there is still an incentive to control $\mathrm{NO}_{\mathrm{x}}$ emissions by primary means 
or by in-situ techniques such as Selective Non-Catalytic Reduction (SNCR) or reburning. To achieve this aim, it is important to have access to reliable and versatile chemical kinetic models for formation and consumption of NO in high temperature processes. The use of detailed reaction mechanisms together with engineering models such as Computational Fluid Dynamics (CFD) has, with the strongly enhanced computational power now available, become an important tool in designing low- $\mathrm{NO}_{\mathrm{x}}$ combustion systems.

The objective of the present work is to establish and evaluate a state-of-the-art, non-optimized chemical kinetic model for homogeneous nitrogen chemistry in combustion. It is based on the work on nitrogen chemistry reported over the last decades, drawing also on recent advances in the knowledge of thermochemistry and reaction rates from theoretical work. The different mechanisms for formation and consumption of NO are discussed and the key reaction steps are evaluated. Different subsets of the model are validated against experimental data and the predictive capability of the mechanism is assessed.

To limit the scope of the review, we emphasize nitrogen chemistry in combustion of light hydrocarbons, mostly $\mathrm{CH}_{4}$, and/or light fuel-nitrogen species ( $\left.\mathrm{HCN}, \mathrm{NH}_{3}, \mathrm{HNCO}\right)$ at atmospheric or sub-atmospheric pressure. Oxidation of heterocyclic nitrogen compounds, which may be formed in combustion of more complex fuels, or of energetic materials such as nitroalkanes are not addressed in the current work. Furthermore, we focus on experimental conditions that are sufficiently well-defined for kinetic interpretation and refrain from modeling practical combustion systems, partly due to the fact that turbulent flow characteristics and turbulence/chemistry interactions may play a significant role, and partly due to the need for simplified chemistry when used in computational fluid dynamics calculations.

In this review, a wide range of experimental data has been selected for model validation, including results from laminar premixed flames at low and atmospheric pressure, from shock tube experiments, and from jet-stirred reactors. 
Modeling predictions have also been compared extensively to data obtained in laminar flow reactors. However, data from flow reactors are prone to uncertainties in initial conditions, either due to conditioning (mixing, preheating) or interference from reactions on the reactor surface, even for fairly inert materials such as quartz and alumina. For this reason, care must be taken when interpreting the results [7]. In App. A, it is discussed how quartz surfaces may interact with the gas phase chemistry in flow and batch reactors. In reality, all experimental approaches suffer from complications that must be kept in mind when used for model development and evaluation.

\section{Detailed Chemical Kinetic Model}

A chemical kinetic model consists of a reaction mechanism along with thermodynamic properties and transport coefficients for the involved species. A reaction mechanism for nitrogen chemistry in combustion will have to include submechanisms for hydrocarbon oxidation, oxidation of reactive nitrogen species (amines, cyanides, etc.), and interactions between the hydrocarbon and nitrogen chemistry (e.g., prompt NO, reburning). The model established in this review is based on work on nitrogen chemistry published over the last 40 years. However, the thermochemistry and the rate constants for reactions important for formation and consumption of NO are re-evaluated based on recent high-level theory work. The full model in Chemkin input format is available as Supplementary Material. Specific aspects of the model are discussed in detail in the following.

\subsection{Thermodynamic properties}

Table 1 lists thermodynamic properties for selected species in the model. The data for these species were reevaluated in the present work using the Active Thermochemical Tables (ATcT) approach [8,9]. Particular emphasis was on the 
thermochemistry of selected hydrocarbon radicals and reactive nitrogen species. Where relevant, these are discussed in more detail in the sections below. Heats of formation for the $\mathrm{CH}_{\mathrm{n}}$ hydrocarbon radicals are entirely consistent with the recent evaluation of Ruscic [10], which was based on ver. 1.122 of the ATcT Thermochemical Network (TN) [11]. The listed values are based on the updated progeny ATcT TN ver. 1.122b, which was augmented with new determinations during a subsequent effort to extract the best currently available energy difference between $\mathrm{HCN}$ and $\mathrm{HNC}$, as well as the enthalpies of formation of these two species and their positive and negative ions [12]. ATcT TN ver. 1.122b was also used to develop and benchmark new high-level composite electronic structure methods known as ANLn [13]. In order to obtain the requisite NASA thermodynamic polynomials for the species listed in Table 1, JANAF-style tabular ATcT outputs based on the results from TN ver. 1.122b (containing temperatures, isobaric heat capacities, entropies, enthalpy increments, and enthalpies of formation, using $50 \mathrm{~K}$ increments) were fitted using the gold-standard NASA PAC program of McBride and Gordon [14].

The thermodynamic properties for other species were mostly adopted from the Ideal Gas Thermochemical Database by Goos, Burcat and Ruscic [15] (which is periodically updated with available ATcT enthalpies of formation).

\subsection{Reaction mechanism}

The core of the reaction mechanism is based on recent work by the authors on the chemistry of $\mathrm{C}_{1}-\mathrm{C}_{2}$ hydrocarbons [16-18], amines [19], cyanides [20], and hydrocarbon/nitrogen interactions [21-23]. However, many features of the model date back to work in the 1980's $[1,24]$. The nitrogen chemistry subsets of the mechanism will be discussed in the following sections. In this section we discuss briefly the reactions in the fuel oxidation subset that are of particular importance for the nitrogen chemistry. 


\begin{tabular}{|c|c|c|c|c|c|c|c|c|c|}
\hline Species & $\mathrm{H}_{298}$ & $\mathrm{~S}_{298}$ & $\mathrm{C}_{\mathrm{p}, 300}$ & $\mathrm{C}_{\mathrm{p}, 400}$ & $\mathrm{C}_{\mathrm{p}, 500}$ & $\mathrm{C}_{\mathrm{p}, 600}$ & $\mathrm{C}_{\mathrm{p}, 800}$ & $\mathrm{C}_{\mathrm{p}, 1000}$ & $\mathrm{C}_{\mathrm{p}, 1500}$ \\
\hline $\mathrm{NH}_{3}$ & -10.89 & 46.07 & 8.53 & 9.24 & 10.04 & 10.81 & 12.22 & 13.44 & 15.76 \\
\hline $\mathrm{NH}_{2}$ & 44.46 & 46.57 & 8.05 & 8.24 & 8.51 & 8.81 & 9.50 & 10.19 & 11.64 \\
\hline $\mathrm{NH}$ & 85.75 & 43.32 & 6.97 & 6.97 & 6.99 & 7.04 & 7.22 & 7.47 & 8.07 \\
\hline $\mathrm{N}$ & 112.92 & 36.64 & 4.97 & 4.97 & 4.97 & 4.97 & 4.97 & 4.97 & 4.97 \\
\hline NNH & 59.70 & 53.65 & 8.22 & 8.62 & 9.11 & 9.61 & 10.52 & 11.26 & 12.36 \\
\hline $\mathrm{NO}$ & 21.78 & 50.37 & 7.14 & 7.16 & 7.29 & 7.47 & 7.83 & 8.12 & 8.55 \\
\hline $\mathrm{NO}_{2}$ & 8.14 & 57.40 & 8.90 & 9.68 & 10.44 & 11.09 & 12.05 & 12.67 & 13.49 \\
\hline $\mathrm{NO}_{3}$ & 17.72 & 61.76 & 12.28 & 13.73 & 14.94 & 15.91 & 17.23 & 18.04 & 19.13 \\
\hline $\mathrm{N}_{2} \mathrm{O}$ & 19.73 & 52.58 & 9.25 & 10.21 & 10.96 & 11.59 & 12.54 & 13.20 & 14.15 \\
\hline $\mathrm{HCN}$ & 30.90 & 48.24 & 8.59 & 9.38 & 9.98 & 10.47 & 11.31 & 12.01 & 13.23 \\
\hline $\mathrm{HNC}$ & 45.98 & 49.13 & 9.64 & 10.20 & 10.60 & 10.94 & 11.56 & 12.10 & 13.11 \\
\hline $\mathrm{CN}$ & 105.17 & 48.43 & 6.97 & 7.03 & 7.16 & 7.33 & 7.69 & 8.00 & 8.52 \\
\hline $\mathrm{NCN}$ & 107.74 & 53.92 & 9.88 & 10.77 & 11.52 & 12.12 & 12.96 & 13.45 & 14.00 \\
\hline $\mathrm{HNO}$ & 25.56 & 52.79 & 8.09 & 8.45 & 8.96 & 9.51 & 10.52 & 11.36 & 13.17 \\
\hline $\mathrm{HON}$ & 51.28 & 55.21 & 8.44 & 9.07 & 9.66 & 10.16 & 10.91 & 11.48 & 12.46 \\
\hline HONO & -18.80 & 60.70 & 11.08 & 12.42 & 13.51 & 14.39 & 15.67 & 16.56 & 17.90 \\
\hline $\mathrm{HNO}_{2}$ & -10.55 & 57.02 & 9.28 & 10.58 & 11.85 & 12.98 & 14.72 & 15.95 & 17.69 \\
\hline $\mathrm{HONO}_{2}$ & -32.07 & 63.78 & 12.98 & 15.33 & 17.22 & 18.69 & 20.71 & 21.93 & 23.41 \\
\hline $\mathrm{CH}_{4}$ & -17.81 & 44.54 & 8.55 & 9.71 & 11.14 & 12.61 & 15.32 & 17.63 & 21.72 \\
\hline $\mathrm{CH}_{3}$ & 34.98 & 46.37 & 9.11 & 9.76 & 10.38 & 10.97 & 12.08 & 13.07 & 14.76 \\
\hline${ }^{3} \mathrm{CH}_{2}$ & 93.57 & 46.58 & 8.53 & 9.01 & 9.46 & 9.90 & 10.82 & 11.79 & 14.05 \\
\hline${ }^{1} \mathrm{CH}_{2}$ & 102.54 & 45.25 & 8.11 & 8.37 & 8.71 & 9.10 & 9.93 & 10.73 & 12.28 \\
\hline $\mathrm{CH}$ & 142.48 & 43.75 & 6.97 & 6.99 & 7.03 & 7.11 & 7.37 & 7.68 & 8.46 \\
\hline $\mathrm{C}$ & 171.34 & 37.79 & 4.98 & 4.97 & 4.97 & 4.97 & 4.97 & 4.97 & 4.97 \\
\hline
\end{tabular}

Table 1: Thermodynamic properties of selected species in the reaction mechanism from ATcT TN ver. 1.122b (see text). Units are $\mathrm{kcal} \mathrm{mol}^{-1}$ for $\mathrm{H}$, and cal $\mathrm{mol}^{-1} \mathrm{~K}^{-1}$ for $\mathrm{S}$ and $\mathrm{C}_{\mathrm{p}}$. Temperatures are in $\mathrm{K}$.

Formation and consumption of nitric oxide in combustion are strongly dependent on the radical pool. Formation of NO through the thermal NO mechanism, or through $\mathrm{N}_{2} \mathrm{O}$ or $\mathrm{NNH}$, is dependent on the $\mathrm{O} / \mathrm{H}$ radical pool, which is typically controlled by the fuel oxidation chemistry. To the extent the kinetic model is able to provide a satisfactory description of the fuel oxidation chemistry, it would be expected to predict the $\mathrm{O} / \mathrm{H}$ radical pool fairly accurately. However, under some conditions trace species chemistry has an impact on the radical pool. For instance, the presence of nitrogen oxides may serve to promote or inhibit fuel oxidation, depending on the conditions [4].

A more direct interaction between the nitrogen chemistry and the fuel oxidation chemistry involves reactions of hydrocarbon radicals with $\mathrm{N}_{2}$ (forming prompt NO), with NO (reburn type reactions), or with other reactive nitrogen species (for instance, converting amines to cyanides). Almost any fuel derived radical, 
e.g., $\mathrm{CH}_{3},{ }^{3} \mathrm{CH}_{2},{ }^{1} \mathrm{CH}_{2}, \mathrm{CH}$, and $\mathrm{C}$ among the $\mathrm{C}_{1}$-radicals and $\mathrm{C}_{2} \mathrm{H}, \mathrm{C}_{2}, \mathrm{HCCO}$, and $\mathrm{C}_{2} \mathrm{O}$ from the $\mathrm{C}_{2}$-radical pool, may be involved in this interaction. Among these radicals, methylidyne $(\mathrm{CH})$ is of special interest since it is sufficiently reactive to attack even molecular nitrogen and initiate prompt NO formation.

In the present review, we limit our scope to nitrogen chemistry in combustion of small hydrocarbons, mostly methane. In oxidation of methane, the $\mathrm{CH}$ and $\mathrm{C}$ radicals are largely formed from the sequence

$$
\mathrm{CH}_{3} \stackrel{+\mathrm{H}, \mathrm{OH}}{\longrightarrow} \mathrm{CH}_{2} \stackrel{+\mathrm{H}, \mathrm{OH}}{\longrightarrow} \mathrm{CH} \stackrel{+\mathrm{H}, \mathrm{OH}}{\longrightarrow} \mathrm{C}
$$

In App. B, we take a look at the reactions that determine the levels of the small hydrocarbon radicals and evaluate this part of the reaction mechanism. Compared to previous modeling efforts, an important feature in the present mechanism is the use of a more accurate rate constant for $\mathrm{CH}+\mathrm{H}_{2} \mathrm{O}$. 


\section{Formation mechanisms for $\mathrm{NO}$}

\subsection{Thermal NO}

The thermal NO or Zeldovich mechanism [25] is the most important source of NO in high-temperature gas combustion. The mechanism of thermal NO formation is well established. The initiating step is attack of an oxygen atom on the triple bond in $\mathrm{N}_{2}$,

$$
\mathrm{O}+\mathrm{N}_{2} \rightleftarrows \mathrm{NO}+\mathrm{N}
$$

This reaction has a high activation energy, about $75 \mathrm{kcal} \mathrm{mol}^{-1}$ [26], and it is the rate limiting step in thermal NO formation. Once formed, the nitrogen atom is rapidly oxidized to $\mathrm{NO}$ by reaction with $\mathrm{OH}$ or $\mathrm{O}_{2}$,

$$
\begin{aligned}
& \mathrm{N}+\mathrm{OH} \rightleftarrows \mathrm{NO}+\mathrm{H} \\
& \mathrm{N}+\mathrm{O}_{2} \rightleftarrows \mathrm{NO}+\mathrm{O}
\end{aligned}
$$

The remaining issues in modeling thermal NO formation involve mainly the accuracy of the rate constant for reaction R1, discussed below.

\subsubsection{Reaction subset for thermal NO}

Table 2 lists the rate constants for the reactions in thermal NO formation. The rate constant for the rate limiting step (R1b) has been measured directly in shock tube studies $[27,28]$ and inferred from a number of flame studies [29-36]. In addition, the reverse reaction,

$$
\mathrm{N}+\mathrm{NO} \rightleftarrows \mathrm{O}+\mathrm{N}_{2}
$$


has been characterized experimentally over a wide range of temperature $[26,37-$ 46]. The $\mathrm{N}+\mathrm{NO}$ reaction is expected to have little if any pressure dependence because the minimum energy path on the ground electronic surface is purely attractive with no minimum [47].

Figure 2 shows an Arrhenius plot for reaction R1. Data for the $\mathrm{O}+\mathrm{N}_{2}$ reaction (R1b) are converted through the equilibrium constant. Baulch et al. [26] estimated the uncertainty in the rate constant to be a factor of two, providing a recommendation for $\mathrm{k}_{1 \mathrm{~b}}$ that is $50-70 \%$ larger than their value for $\mathrm{k}_{1}$ divided by the equilibrium constant.

\begin{tabular}{llrrrr}
\hline & & $\mathrm{A}$ & $\beta$ & $\mathrm{E}$ & Source \\
& & & & & \\
\hline & & & & & \\
1. & $\mathrm{N}+\mathrm{NO} \rightleftarrows \mathrm{O}+\mathrm{N}_{2}$ & $9.4 \mathrm{E} 12$ & 0.140 & 0 & {$[46]$} \\
2. & $\mathrm{N}+\mathrm{OH} \rightleftarrows \mathrm{NO}+\mathrm{H}$ & $3.8 \mathrm{E} 13$ & 0.000 & 0 & {$[48]$} \\
3. & $\mathrm{~N}+\mathrm{O}_{2} \rightleftarrows \mathrm{NO}+\mathrm{O}$ & $5.9 \mathrm{E} 09$ & 1.000 & 6280 & {$[49]$} \\
& & & & & \\
\hline
\end{tabular}

Table 2: Reactions involved in thermal NO formation. Parameters for use in the modified Arrhenius expression $\mathrm{k}=\mathrm{AT}^{\beta} \exp (-\mathrm{E} /[\mathrm{RT}])$. Units are mol, $\mathrm{cm}$, s, cal.

We have adopted the rate constant for reaction $\mathrm{R} 1$ from the recent study of Abian et al. [46]. They determined $\mathrm{k}_{1}$ from flow reactor experiments, measuring NO formation from $\mathrm{N}_{2} / \mathrm{O}_{2}$ mixtures at $1700-1800 \mathrm{~K}$, and extrapolated the rate constant to a wider temperature range taking literature data into account. Their resulting value is $25 \%$ above the recommendation of Baulch et al. for $\mathrm{k}_{1}$, while it corresponds to a value $\mathrm{k}_{1 \mathrm{~b}} 25 \%$ below the Baulch et al. evaluation, reconciling the data for the forward and reverse rate constant (Fig. 2). 


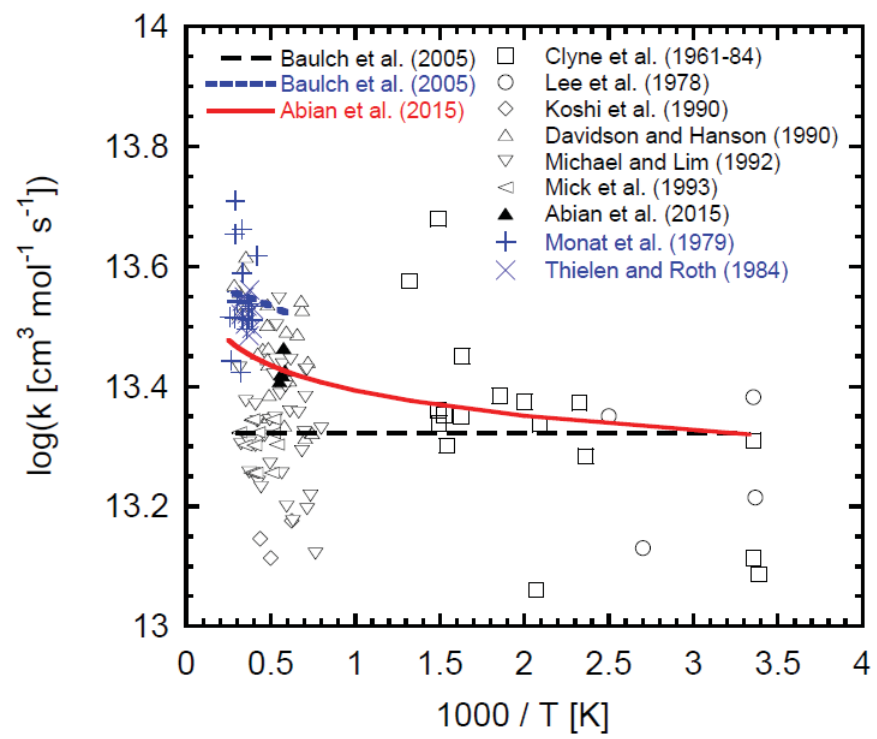

Figure 2: Arrhenius plot for the reaction $\mathrm{N}+\mathrm{NO} \rightleftarrows \mathrm{O}+\mathrm{N}_{2}$ (R1). The black symbols denote measurements of the forward reaction while the blue symbols denote data obtained from measurements of the reverse step, converted using the thermodynamic properties. Data for $\mathrm{k}_{1}$ : Clyne et al. [37-40], Lee et al. [41], Koshi et al. [42], Davidson and Hanson [43], Michael and Lim [44], Mick et al. [45], and Abian et al. [46]. Data derived from measurements of $\mathrm{k}_{1 \mathrm{~b}}$ : Monat et al. [27] and Thielen and Roth [28]. The long-dashed line shows the recommendations of Baulch et al. [26] for $\mathrm{k}_{1}$, while the short-dashed line is the value of $\mathrm{k}_{1}$ derived from their recommendation of $\mathrm{k}_{1 \mathrm{~b}}$. The solid line is the rate constant recommended by Abian et al., adopted in the present work.

\subsubsection{Modeling thermal NO formation}

Comparatively little experimental work, reviewed in $[46,50,51]$, has been conducted to characterize thermal NO formation under well-controlled conditions. Following Abian et al. [46], we have selected the flow reactor data of Arai et al. [52] and the flame data from Homer and Sutton [53] for comparison with modeling predictions.

Arai et al. [52] conducted an experimental study of the $\mathrm{O}_{2} / \mathrm{N}_{2}$ system in an isothermal laminar flow reactor, investigating the effect of the $\mathrm{O}_{2}$ mole fraction (0.05-0.95) and the temperature (1550-1750 K) on the formation of NO. Figure 3 
compares the measured NO concentrations reported by Arai et al. with modeling predictions. Interference of the quartz reactor surface with the NO formation in these experiments is expected to be negligible. Loss of atomic oxygen at the reactor wall, which could be a concern (App. A), can be disregarded since $\mathrm{O}$ is rapidly equilibrated with $\mathrm{O}_{2}$ under these conditions [46].

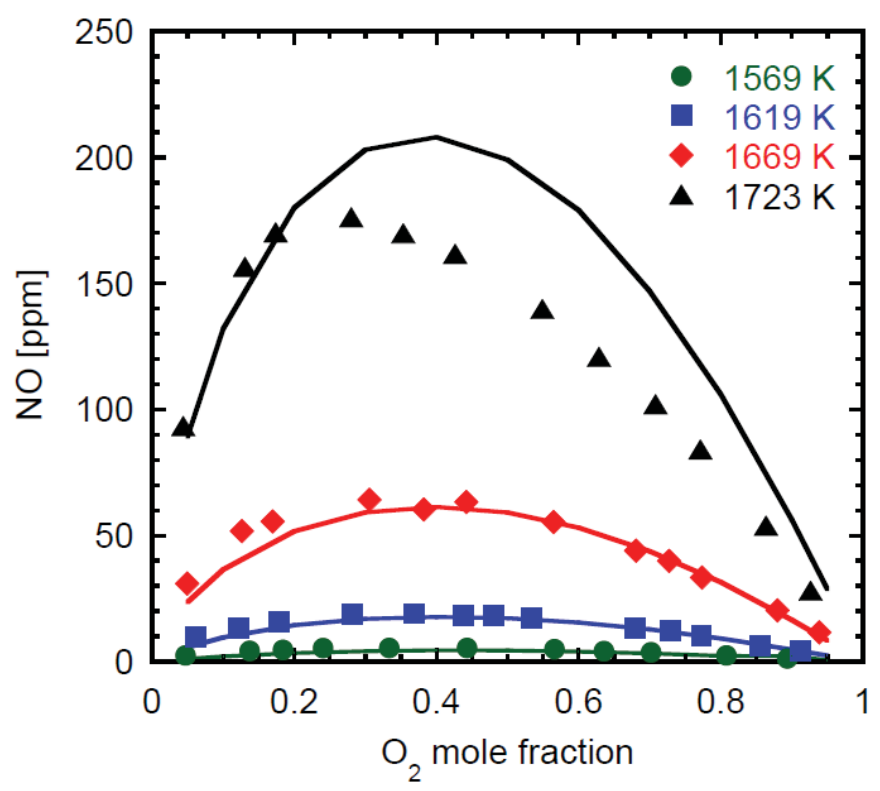

Figure 3: Comparison between experimental data [52] and modeling predictions for formation of $\mathrm{NO}$ from $\mathrm{N}_{2}$ and $\mathrm{O}_{2}$ in a flow reactor as a function of temperature and mole fraction of $\mathrm{O}_{2}$ in the $\mathrm{O}_{2} / \mathrm{N}_{2}$ reactant gas mixture. Experimental data are shown as symbols, while modeling predictions are shown as lines.

The agreement is within $20 \%$ or better. The differences are most pronounced for the highest temperature at $\mathrm{O}_{2}$ levels above $30 \%$, where the predicted NO levels exceed the measurements. As pointed out by Abian et al. [46], the observed NO profile at this temperature has a different shape from those measured at other temperatures, with $\mathrm{NO}$ peaking at a lower $\mathrm{O}_{2}$ concentration, and the difference may be partly attributed to an experimental artifact.

Homer and Sutton [53] reported measurements of NO concentration profiles in atmospheric-pressure premixed hydrogen-oxygen-nitrogen flames over a range of 
stoichiometries and temperatures. Figure 4 compares their experimental data with modeling predictions. The flames of Homer and Sutton were heavily stabilized on the burner and conceivably the burner surface affected the flames by removing heat and radicals from the flame zone. Most of the NO formation reported by Homer and Sutton occurs very early in the flame, i.e. in a region where the flame may interact with the burner surface. Following Abian et al. [46], we choose in the calculations to fix the NO level at the measured value at about $0.25 \mathrm{~cm}$ above the burner and model the NO formation only in the post-flame region to minimize the uncertainty.

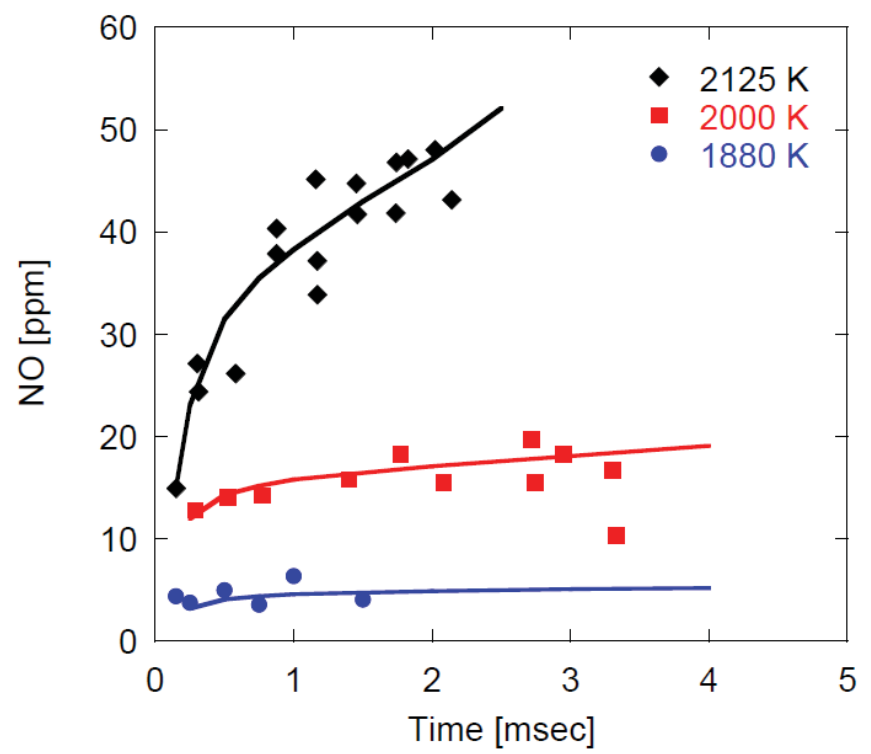

Figure 4: Comparison of measured and predicted mole fractions of NO in the post-flame zone of an atmospheric pressure $\mathrm{H}_{2} / \mathrm{O}_{2} / \mathrm{N}_{2}$ premixed laminar flame. The symbols denote experimental data from Homer and Sutton [53], while the lines denote calculated values. Flame $1: \mathrm{T}=2125 \mathrm{~K}$, inlet composition $25 \%$ $\mathrm{H}_{2}, 17.5 \% \mathrm{O}_{2}, 57.5 \% \mathrm{~N}_{2}$. Flame 2: $\mathrm{T}=2000 \mathrm{~K}$, inlet composition $23 \% \mathrm{H}_{2}$, $16.1 \% \mathrm{O}_{2}, 60.9 \% \mathrm{~N}_{2}$. Flame $3: \mathrm{T}=1880 \mathrm{~K}$, inlet composition $21.1 \% \mathrm{H}_{2}, 14.7 \%$ $\mathrm{O}_{2}, 64.2 \% \mathrm{~N}_{2}$.

The flame data are scattered and there is some uncertainty in the measured flame temperatures. However, the agreement between observed and calculated NO concentrations in the post-flame region is good. 
Even though the thermal NO subset can only be validated to a limited extent due to the scarcity of suitable experimental data, the uncertainty of calculations for this NO formation mechanism would be expected to be small. The accuracy in the rate constant for the rate limiting step (R1) is probably of the order of $25 \%$ at high temperatures and modeling predictions for thermal NO formation under well-controlled conditions are likely to have a similar accuracy. In practical systems, the accuracy of the calculations would be limited to a greater extent by uncertainties in temperature and/or in turbulence-chemistry interactions. 


\subsection{Prompt-NO}

The mechanism initiated by attack of $\mathrm{CH}_{\mathrm{n}}$-radicals on $\mathrm{N}_{2}$ is termed prompt NO $[29,54]$. Prompt NO is an important, perhaps dominating, source of NO in turbulent hydrocarbon/air diffusion flames [55], which is the most common practical flame configuration. Early modeling studies $[1,24]$ identified the reaction of $\mathrm{CH}$ with $\mathrm{N}_{2}$ as the most important initiation step. For a long time, this reaction was believed to form $\mathrm{HCN}+\mathrm{N}$, but it is now known to proceed via insertion of $\mathrm{CH}$ into the $\mathrm{N}_{2}$ triple bond, yielding $\mathrm{NCN}+\mathrm{H}[56,57]$ :

$$
\mathrm{CH}+\mathrm{N}_{2} \rightleftarrows \mathrm{NCN}+\mathrm{H}
$$

Other hydrocarbon radicals have also been proposed to attack molecular nitrogen. The reactions of both triplet and singlet methylene $\left({ }^{3} \mathrm{CH}_{2},{ }^{1} \mathrm{CH}_{2}\right)$ with $\mathrm{N}_{2}$ have been shown to have too high barriers to contribute to prompt NO formation $[1,24,58]$. Also, the $\mathrm{C}_{2} \mathrm{O}+\mathrm{N}_{2}$ reaction, discussed in several publications [59-62], has a prohibitively high barrier [63]. The $\mathrm{C}_{2}+\mathrm{N}_{2}$ reaction (R6) could be a candidate $[64,65]$, but the low $\mathrm{C}_{2}$ concentration, typically two orders of magnitude below the $\mathrm{CH}$ concentration in premixed flames [66], prevents this step from being significant. Only the $\mathrm{C}+\mathrm{N}_{2}$ reaction to form $\mathrm{CN}+\mathrm{N}$ (R5b) or $\mathrm{NCN}$ (R7b) is sufficiently fast to compete with $\mathrm{CH}+\mathrm{N}_{2}$ (R4). The direct step to form $\mathrm{CN}+\mathrm{N}(\mathrm{R} 5 \mathrm{~b})$ has a higher activation energy than reaction $\mathrm{R} 4$ and becomes more competitive as the combustion temperature increases, but also the sequence $\mathrm{C}+\mathrm{N}_{2}(+\mathrm{M}) \rightarrow \mathrm{NCN}(+\mathrm{M})(\mathrm{R} 7 \mathrm{~b})$, followed by reaction of NCN, may contribute to NO formation. The $\mathrm{C}+\mathrm{N}_{2}(+\mathrm{M}) \rightarrow \mathrm{NCN}(+\mathrm{M})$ reaction (R7b) is exothermic (by $63.6 \mathrm{kcal} \mathrm{mol}^{-1}$ at $298 \mathrm{~K}$ ) and is exergonic up to $2100 \mathrm{~K}$, becoming endergonic at higher temperatures, while $\mathrm{C}+\mathrm{N}_{2} \rightarrow \mathrm{CN}$ $+\mathrm{N}$ (R5b) is both endothermic (by $17.4 \mathrm{kcal} \mathrm{mol}^{-1}$ at $298 \mathrm{~K}$ ) and endergonic, with its endergonicity gradually growing as the temperature rises.

The NCN radical formed by $\mathrm{CH}+\mathrm{N}_{2}(\mathrm{R} 4)$ or $\mathrm{C}+\mathrm{N}_{2}$ (R7b) feeds into the 
cyanide pool and is eventually oxidized to $\mathrm{NO}$ or $\mathrm{N}_{2}$. Recent modeling studies [60-62,67-72] have successfully included and refined the NCN chemistry in the reaction mechanism for prompt NO formation. However, there are still unresolved issues, as discussed below.

\subsubsection{Heat of formation of $\mathrm{NCN}$}

The thermodynamic properties for NCN are important in modeling prompt-NO formation since they affect the branching fraction of the $\mathrm{NCN}+\mathrm{H}$ reaction towards $\mathrm{CH}+\mathrm{N}_{2}(\mathrm{R} 4 \mathrm{~b})$ and $\mathrm{HCN} / \mathrm{HNC}+\mathrm{N}(\mathrm{R} 8, \mathrm{R} 9)$. Values for the heat of formation of NCN used in modeling studies $[61,62,67,71,72]$ vary more than three $\mathrm{kcal} \mathrm{mol}^{-1}$; differences that have a significant impact on modeling predictions.

Table 3 lists reported values of the heat of formation of NCN. Clifford et al. [73] estimated $\Delta_{\mathrm{f}} \mathrm{H}_{298}^{0}(\mathrm{NCN})$ to $107.9 \pm 4.0 \mathrm{kcal} \mathrm{mol}^{-1}$ from electron affinity measurements measurements on NCN and a computed (CBS-4, CBS-Q, and CBSAPNO) gas-phase acidity of HNCN. Bise et al. [74,75] studied the photodissociation dynamics of NCN using beam photofragment spectroscopy leading to $\Delta_{\mathrm{f}} \mathrm{H}_{298}^{0}=111.1 \pm 0.7 \mathrm{kcal} \mathrm{mol}^{-1}$. Canneaux et al. [76] computed a value of $\Delta_{\mathrm{f}} \mathrm{H}_{298}^{0}=107.2 \pm 0.8 \mathrm{kcal} \mathrm{mol}^{-1}$ using CBS-QB3, CBS-APNO, G3B3, G3, and G4 calculated atomization energies.

\begin{tabular}{lll}
\hline $\begin{array}{c}\Delta \mathrm{H}_{\mathrm{f} 298}^{0}(\mathrm{NCN}) \\
\mathrm{kcal} \mathrm{mol}\end{array}$ & Method & Ref. \\
\hline $107.9 \pm 4.0$ & Experimental & Clifford et al. [73] \\
$111.1 \pm 0.7$ & Experimental & Bise et al. [74, 75] \\
$109.4 \pm 2.0$ & Theory & Harding et al. [77] \\
$107.2 \pm 0.8$ & Theory & Canneaux et al. [76] \\
$109.4 \pm 0.5$ & ATcT (localized TN ver. 1.112 bis) & Goos et al. [71] \\
$107.5^{+1.4}$ & Experimental, indirect & Fassheber et al. [78] \\
$107.7 \pm 0.2$ & Theory, ATcT (TN ver. 1.122b) & See text \\
\hline
\end{tabular}

Table 3: Reported values for the heat of formation of NCN. 
Recently, Goos et al. [71] re-examinated the heat of formation of NCN based on a detailed analysis of available experimental and theoretical thermochemical data combined with two Active Thermochemical Tables analyses. As discussed at length by these authors, the initial ATcT analysis using TN ver. 1.112, which included the experimental and theoretical data available at the time, suggested a tentative value of $106.5 \pm 0.4 \mathrm{kcal} \mathrm{mol}^{-1}$ [79]. The value was reflecting an irreconcilable discord between available experimental data and was thus significantly influenced by several mid-level electronic structure results, such as those of Canneaux et al. [76] (CBS-QB3, CBS-APNO, G3B3, G3, G4), which appeared to be mutually consistent. Upon repetition and further scrutiny of these (and other) single-reference computations, Goos et al. [71] established that these theoretical results for NCN (which is a ${ }^{3} \Sigma^{-}$biradical in the ground state) suffer from significant spin contamination, a problem that escaped notice by both Canneaux et al. [76] and Clifford et al. [73]. The value proposed by Goos et al., $109.4 \pm 0.5 \mathrm{kcal} \mathrm{mol}^{-1}$, was obtained by solving a small (localized) TN (ver. 1.112 bis) that included the conflicting experimental data from Clifford et al. [73] and Bise et al. [74,75], together with a couple of multi-reference results of Harding et al. [77], but excluded all spin-contaminated single-reference theoretical results. As discussed by Goos et al., the data available at the time produced a rather sparse $\mathrm{TN}$, which subtended very few thermochemical cycles involving NCN that would normally be exploited by ATcT to check the individual determinations for consistency. As a consequence, the ATcT statistical analysis of the TN could not find clear fault with either of the two experimental studies and thus produced a result that was more-or-less mid-way between the two discordant experiments, which turned out to be in reasonable accord with the value implied by the (included) multi-reference results of Harding et al. [77]. (Parenthetically, when the content of the localized TN is conjoined with the full TN, such as in ver. 1.118 [80], the NCN-related local sparsity of the TN largely remains unchanged, and thus the result changes rather insignificantly, to $109.1 \mathrm{kcal} \mathrm{mol}^{-1}$.) Since the proposed result deviates significantly from previous values used in modeling studies, Goos et al. [71] tested its im- 
pact on prompt NO formation, and concluded that the value obtained from the localized TN did appear to somewhat improve the modeling of NCN and NO mole fraction profiles in a fuel-rich methane flame when compared to the high value of Bise et al. In addition, by separately examining which range of values could be accommodated in their modeling efforts, Goos et al. concluded that a feasible enthalpy of formation of NCN should fall between 106.4 and $108.3 \mathrm{kcal}$ $\mathrm{mol}^{-1}$ - somewhat lower than the ATcT result from the localized TN - but also indirectly suggesting that the experimental value of Clifford at al. appears more acceptable than the high value of Bise et al.

Other previous modeling studies of prompt-NO have also employed values for $\Delta_{\mathrm{f}} \mathrm{H}_{298}^{0}(\mathrm{NCN})$ that were varying by 3 or more $\mathrm{kcal} \mathrm{mol}^{-1}$. Konnov [61] preferred the high value of $111 \mathrm{kcal} \mathrm{mol}^{-1}$ from Bise and coworkers [74,75]. Desgroux and coworkers $[62,67]$ initially adopted the value of $107.9 \mathrm{kcal} \mathrm{mol}^{-1}$ from Clifford et al. [73], but in their most recent work [72] they find that the best agreement with flame measurements is obtained with an even lower $\Delta_{\mathrm{f}} \mathrm{H}_{298}^{0}(\mathrm{NCN})=106.1$ kcal mol ${ }^{-1}$.

In the present work, we use the current ATcT value of $\Delta_{\mathrm{f}} \mathrm{H}_{298}^{0}(\mathrm{NCN})=107.7 \pm 0.2$ $\mathrm{kcal} \mathrm{mol}^{-1}$ (see section 2.1). The value is partially based on new experimental and theoretical information. The relevant new theoretical information emanates from recent high-accuracy computational results at the ANL1 level of theory [13], and was added to the TN as appropriate isodesmic reactions; the new experimental information is based on the 2nd and 3rd law interpretation of the studies of Fassheber et al. [78]. The recent shock tube study by Fassheber et al. on the $\mathrm{NCN}+\mathrm{H}$ reaction supports a value of $\Delta_{\mathrm{f}} \mathrm{H}_{298}^{0}(\mathrm{NCN})$ of approximately $107.5 \mathrm{kcal} \mathrm{mol}^{-1}$, with an upper limit of $108.9 \mathrm{kcal} \mathrm{mol}^{-1}$. The provenance of the current ATcT enthalpy of formation (based on species-specific variance decomposition analysis [81]) indicates that it indeed relies heavily on the new ANL1 results (which cumulatively contribute $76.5 \%$ to the provenance), followed by the experimental study of Fassheber et al. (the 2nd and 3rd law contributing 
together 5.6\%). Of note is also that the individual enthalpies of formation implied on one hand by the ANL1 computational results alone and on the other by the experimental study of Fassheber et al. agree rather closely, and thus it is perhaps no surprise that the current ATcT value is in excellent agreement both with the latter experimental result and with ANL1 computations. The current ATcT value is also in admirable agreement with the earlier result of Clifford et al. [73], but is outside the error bounds of the determination of Bise et al. [74,75], reinforcing the conclusion that the latter is too high. The current ATcT result is lower than the previous ATcT result from a small localized TN reported by Goos et al., but it falls comfortably in the middle of their deduced 'feasible range' for the enthalpy of formation. Perhaps somewhat surprising is that the current ATcT value also agrees well with the results obtained from mid-level computations of Canneaux et al., given that these veritably suffer from spin contamination in nearly every computational step of their composite sequences.

\subsubsection{Reaction subset for prompt NO formation}

Selected reactions in the prompt NO subset are listed in Table 4. Other important steps are formation and consumption of hydrocarbon radicals, discussed in App. B, and reactions in the cyanide and amine subsets, discussed in the following sections.

The rate constant for the key reaction in prompt NO formation,

$$
\mathrm{CH}+\mathrm{N}_{2} \rightleftarrows \mathrm{NCN}+\mathrm{H}
$$

has been derived both experimentally $[87,88]$ and theoretically $[77,82,89,90]$. Figure 5 shows an Arrhenius plot for the reaction. Dean et al. [87] and Vasudevan et al. [88] used the perturbation in the $\mathrm{CH}$ profile upon adding $\mathrm{N}_{2}$ to the initial reaction mixture to infer the rate coefficients of the $\mathrm{CH}+\mathrm{N}_{2}$ reaction in the 2500-3800 $\mathrm{K}$ temperature range. Their results are in good agreement, 


\begin{tabular}{rlrrrl}
\hline & & $\mathrm{A}$ & $\beta$ & $\mathrm{E}$ & Source \\
& & & & & \\
\hline & & & & & \\
4. & $\mathrm{CH}+\mathrm{N}_{2} \rightleftarrows \mathrm{NCN}+\mathrm{H}$ & $5.3 \mathrm{E} 09$ & 0.790 & 16770 & {$[82], a$} \\
5. & $\mathrm{CN}+\mathrm{N} \rightleftarrows \mathrm{C}+\mathrm{N}_{2}$ & $5.9 \mathrm{E} 14$ & -0.400 & 0 & {$[26]$} \\
6. & $\mathrm{C}_{2}+\mathrm{N}_{2} \rightleftarrows \mathrm{CN}+\mathrm{CN}$ & $1.5 \mathrm{E} 13$ & 0.000 & 41730 & {$[64]$} \\
7. & $\mathrm{NCN}+\mathrm{M} \rightleftarrows \mathrm{C}+\mathrm{N}_{2}+\mathrm{M}$ & $8.9 \mathrm{E} 14$ & 0.000 & 62100 & {$[83]$} \\
8. & $\mathrm{NCN}+\mathrm{H} \rightleftarrows \mathrm{HCN}+\mathrm{N}$ & $2.2 \mathrm{E} 11$ & 0.710 & 5321 & {$[82], a$} \\
9. & $\mathrm{NCN}+\mathrm{H} \rightleftarrows \mathrm{HNC}+\mathrm{N}$ & $4.3 \mathrm{E}-4$ & 4.690 & 2434 & {$[82], a$} \\
10. & $\mathrm{NCN}+\mathrm{O} \rightleftarrows \mathrm{CN}+\mathrm{NO}$ & $2.5 \mathrm{E} 13$ & 0.170 & -34 & {$[84]$} \\
11. & $\mathrm{NCN}+\mathrm{OH} \rightleftarrows \mathrm{HCN}+\mathrm{NO}$ & $2.6 \mathrm{E} 08$ & 1.220 & 3593 & {$[82], a$} \\
12. & $\mathrm{NCN}+\mathrm{OH} \rightleftarrows \mathrm{NCO}+\mathrm{NH}$ & $1.7 \mathrm{E} 18$ & -1.830 & 4143 & {$[82], a$} \\
13. & $\mathrm{NCN}+\mathrm{O} \rightleftarrows \mathrm{NO}+\mathrm{NCO}$ & $1.3 \mathrm{E} 12$ & 0.000 & 23167 & {$[85]$} \\
14. & $\mathrm{NCN}+\mathrm{NO} \rightleftarrows \mathrm{CN}+\mathrm{N}_{2} \mathrm{O}$ & $1.9 \mathrm{E} 12$ & 0.000 & 6280 & {$[86]$} \\
& & & & & \\
& & & & & \\
\hline
\end{tabular}

a: $1 \mathrm{~atm}$ (for pressure dependence, see Supplementary Material)

Table 4: Selected reactions important for prompt NO formation. Parameters for use in the modified Arrhenius expression $\mathrm{k}=\mathrm{AT}^{\beta} \exp (-\mathrm{E} /[\mathrm{RT}])$. Units are mol, cm, s, cal.

but the data from Vasudevan et al. show less scatter. Lindackers et al. [91] also reported measurements for the $\mathrm{CH}+\mathrm{N}_{2}$ reaction from shock tube experiments. However, they monitored formation of atomic N, which is now known to be a product of secondary reactions, and their results were disregarded in the present evaluation.

Harding et al. [77] reported a high level theoretical study of the $\mathrm{CH}+\mathrm{N}_{2}$ reaction. They determined a value for $\mathrm{k}_{4}$ with an uncertainty of a factor of two, owing mostly to the uncertainty in the heat of formation for NCN. Recently, Klippenstein et al. [82] reanalyzed the reactions on the HNCN potential energy surface. They obtained a value for $\mathrm{k}_{4}$, adopted in the present work, that is slightly higher than the rate constant from Harding et al. and the measurements of Vasudevan et al. (Fig. 5).

Knowledge of the subsequent reactions of the NCN radical has improved con- 


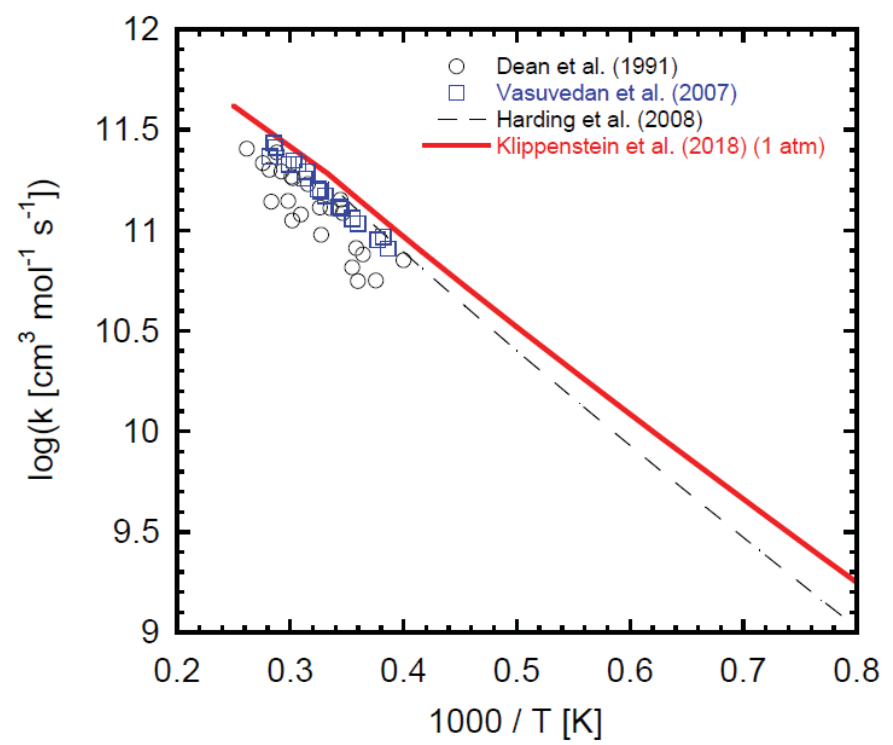

Figure 5: Arrhenius plot for the reaction $\mathrm{CH}+\mathrm{N}_{2} \rightleftarrows \mathrm{NCN}+\mathrm{H}$ (R4). The symbols denote measurements of the rate constant while lines denote calculated values. Data are obtained from Dean et al. [87], Vasudevan et al. [88], Harding et al. [77], and Klippenstein et al. [82].

siderably in recent years, owing to a large degree to the shock tube work of Friedrichs and coworkers who determined rate constants for several of the NCN reactions, i.e., $\mathrm{NCN}+\mathrm{M}(\mathrm{R} 7)$ [83], $\mathrm{NCN}+\mathrm{H}$ [78], $\mathrm{NCN}+\mathrm{O}(\mathrm{R} 9)$ [83], $\mathrm{NCN}$ $+\mathrm{O}_{2}$ (R13) [85], and NCN $+\mathrm{NO}$ (R14) [86]. In addition, Lin and coworkers have studied theoretically a number of reactions, including $\mathrm{NCN}+\mathrm{H}$ [92], $\mathrm{NCN}+\mathrm{O}[84], \mathrm{NCN}+\mathrm{OH}[93]$ and $\mathrm{NCN}+\mathrm{O}_{2}$ [94]. Very recently, Klippenstein et al. [82] reported a theoretical study of $\mathrm{NCN}+\mathrm{H}$ and $\mathrm{NCN}+\mathrm{OH}$. The present subset for NCN relies mostly on the experimental results of Friedrichs and coworkers and the theoretical work of Klippenstein et al.

Prompt NO formation is most important under slightly reducing conditions and the reaction with atomic hydrogen is a key step in the NCN subset. In addition to recombination to form $\mathrm{HNCN}$, this reaction has three product channels,

$$
\mathrm{NCN}+\mathrm{H} \rightleftarrows \mathrm{CH}+\mathrm{N}_{2}
$$




$$
\begin{gathered}
\mathrm{NCN}+\mathrm{H} \rightleftarrows \mathrm{HCN}+\mathrm{N} \\
\mathrm{NCN}+\mathrm{H} \rightleftarrows \mathrm{HNC}+\mathrm{N}
\end{gathered}
$$

Fassheber et al. [78] measured the overall rate constant for $\mathrm{NCN}+\mathrm{H}$ in a shock tube in the temperature range 962-2425 K, while Vasudevan et al. [88] derived a rate constant for the sum of the channel to $\mathrm{HCN}+\mathrm{N}(\mathrm{R} 8)$ and $\mathrm{HNC}+\mathrm{N}(\mathrm{R} 9)$ at $2300-2500 \mathrm{~K}$ from measured time histories of the NCN radical concentration. In addition, the $\mathrm{NCN}+\mathrm{H}$ reaction has been studied theoretically by Teng et al. [92] and by Klippenstein et al. [82].

In Fig. 6 the measurements of Fassheber et al. and Vasudevan et al. for NCN $+\mathrm{H}$ are compared with the high-level calculations of Klippenstein et al. [82] for $\mathrm{k}_{4 \mathrm{~b}}, \mathrm{k}_{8}+\mathrm{k}_{9}$, and $\mathrm{k}_{\mathrm{NCN}+\mathrm{H} \text {,total }}$ The $\mathrm{NCN}+\mathrm{H}$ reaction is dominated by the channel to $\mathrm{CH}+\mathrm{N}_{2}(\mathrm{R} 4 \mathrm{~b})$ at low to medium temperatures, while $\mathrm{HCN}+$ $\mathrm{N}$ (R8) becomes competitive at high temperatures. Since $\mathrm{k}_{4 \mathrm{~b}}$ has a negative temperature dependence while $\mathrm{k}_{8}$ increases with temperature, the overall rate constant for $\mathrm{NCN}+\mathrm{H}$ has an inflection point, which occurs at temperatures between 1000 and $1500 \mathrm{~K}$.

Teng et al. calculated a rate constant for reaction $\mathrm{R} 8$ in good agreement with the measurements of Vasudevan et al., finding formation of $\mathrm{HNC}+\mathrm{N}$ (R9) to be of little importance due to a high barrier. The analysis of Klippenstein et al. confirms that the channel to HNC $+\mathrm{N}$ (R9) is minor, even though there may be a contribution from inter-system crossing from ${ }^{2} \mathrm{HNCN}$ to ${ }^{4} \mathrm{HNCN}$.

The value of $\mathrm{k}_{8}\left(+\mathrm{k}_{9}\right)$ inferred by Fassheber et al. from their experiments is about a factor of two higher than indicated by the data from Vasudevan et al. and the theoretical studies. However, their overall rate constant for $\mathrm{NCN}+\mathrm{H}$ is in good agreement with the prediction of Klippenstein et al., in particular at high temperatures.

In the present work, we have adopted the rate constants for the reactions on the 


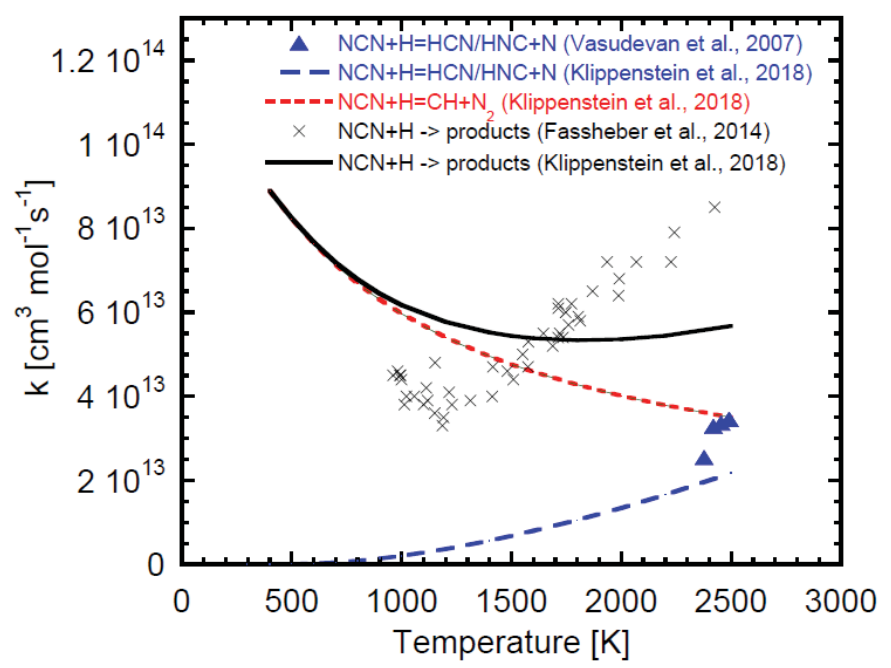

Figure 6: Arrhenius plot for the $\mathrm{NCN}+\mathrm{H}$ reaction. The symbols denote measurements of the overall rate constant from Fassheber et al. [78] and for reaction $\mathrm{R} 8$ from Vasudevan et al. [88]. Lines denote values of rate constants calculated by Klippenstein et al. [82].

HNCN potential energy surface from Klippenstein et al. [82]. Their calculated values of $\mathrm{k}_{8}+\mathrm{k}_{9}$ are below those derived by Fassheber et al. [78] by more than a factor of two at $2000 \mathrm{~K}$. This difference has implications for modeling predictions of prompt NO formation and more work is required to resolve this issue. The accuracy of the theoretical values is affected by uncertainty in the prediction of the inter-system crossing probability for $\mathrm{NCN}+\mathrm{H}$ and in the thermodynamic properties for $\mathrm{NCN}$ and $\mathrm{CH}$ when extrapolated to high temperatures [82].

Both experiment [83] and theory [84] support that the reaction of NCN with $\mathrm{O}$ (R10) is fast and it is important for prompt NO formation. The NCN + $\mathrm{OH}$ reaction ( $\mathrm{R} 11, \mathrm{R} 12)$ has only been studied theoretically [82,93]; this step is slower and thus less important for NO formation. 


\subsubsection{Modeling prompt NO formation}

The model for prompt-NO formation is evaluated by comparison to data from low-pressure premixed flames [62,72,95-99] and from jet-stirred reactors [100]. The most comprehensive experimental work on prompt NO formation in flames has been conducted by Desgroux and coworkers in a series of publications $[62,72$, 96-99]. Data from laminar, premixed flames are often very reliable, in particular if obtained by non-intrusive methods. Concerns include the accuracy of the measured temperature profile and possible interactions with the burner surface. The well-stirred reactor device is characterized by intense turbulent mixing, high concentrations of free radicals and short residence times. These conditions favor prompt-NO formation and make it the dominant source of NO at equivalence ratios ranging from stoichiometric to fuel-rich. However, data from jet-stirred reactors are prone to be mixing influenced, in particular at high temperatures where the chemistry is fast

Following Glarborg et al. [24] and Miller and Bowman [1], we compare modeling predictions with the measurements of Bartok et al. [100] on NO formation in combustion of $\mathrm{CH}_{4}$ in a jet-stirred reactor (Fig. 7). In the calculations we have used the measured temperatures, which peak at about $2000 \mathrm{~K}$ at slightly fuel-rich conditions. Due to the concerns about mixing influence, the uncertainty in the experimental results is presumably considerable. With this in mind, the agreement between the experimental data and the modeling predictions is good, except at very fuel-rich conditions where the NO concentration is underpredicted.

Analysis of the calculations for Fig. 7 provides information on how the dominating NO formation mechanism is controlled by the stoichiometry and the temperature. It is seen from the figure that if the prompt-NO initiation reactions are deleted from the reaction mechanism (dashed line), NO is still predicted well under lean conditions, but under stoichiometric and reducing conditions 


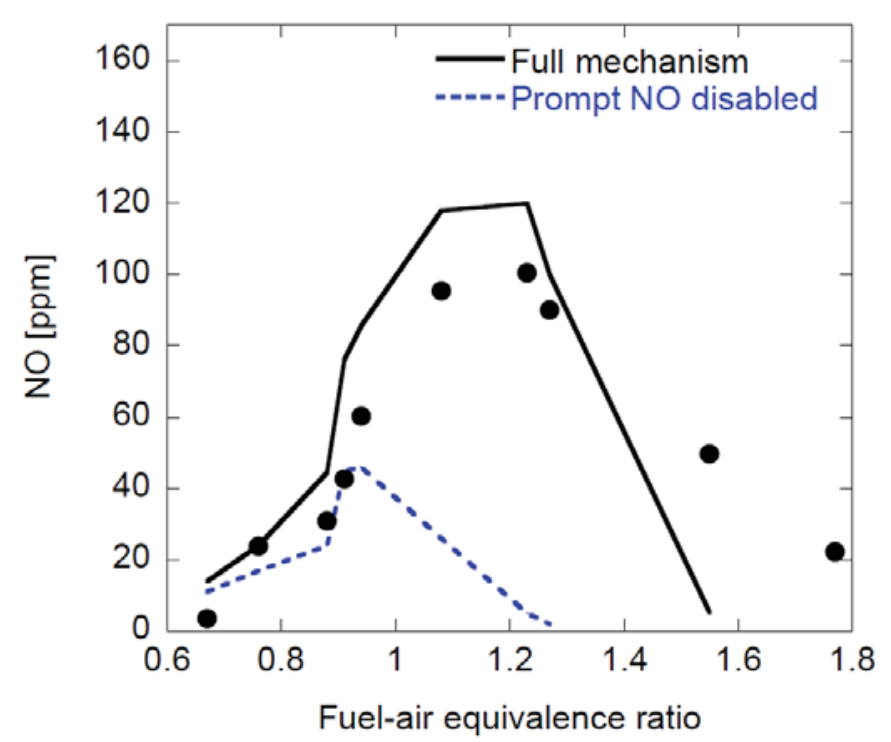

Figure 7: Comparison of measured [100] and predicted mole fractions of NO as a function of the fuel-air equivalence ratio $\phi$ in methane/air combustion in a jet-stirred reactor. The symbols denote experimental data, while the solid lines denote calculated values. Predictions with the full model are shown as a solid line, while the dashed line denotes calculations with prompt NO initiating reactions disabled. The nominal residence time and the pressure in the reactor were $3.0 \mathrm{~ms}$ and $1.0 \mathrm{~atm}$, respectively.

it is severely underpredicted. Thermal NO dominates under slightly lean conditions, while NO formation through the nitrous oxide mechanism, discussed in section 3.3, becomes more important as the amount of excess air increases and the temperature decreases. Under stoichiometric conditions thermal NO and prompt NO contribute with similar amounts of nitric oxide, but prompt NO rapidly becomes the dominating source of NO for fuel-air equivalence ratios larger than 1.0 .

Figure 8 shows a reaction path diagram for prompt NO formation under slightly fuel-rich conditions. Prompt-NO formation involves three overall steps $[1,24]$ :

- formation of $\mathrm{CH}_{\mathrm{n}}$-radicals, in particular $\mathrm{CH}$

- molecular nitrogen fixation 


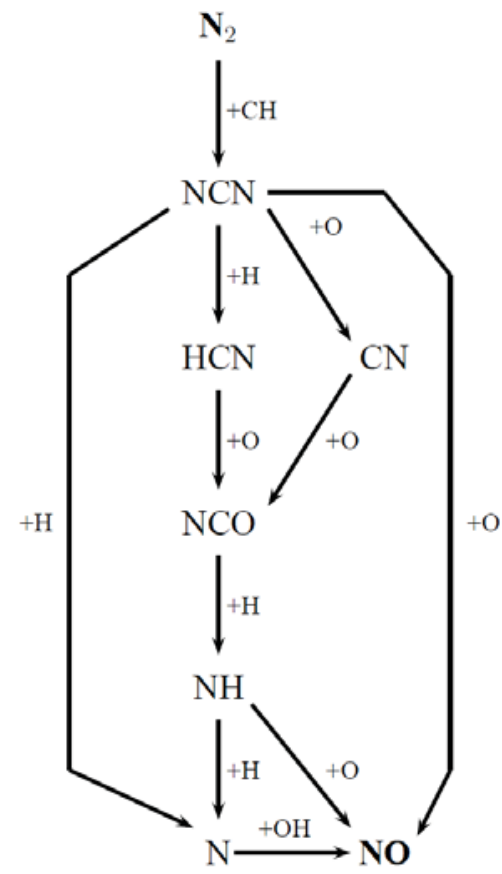

Figure 8: Reaction path diagram for prompt NO formation under slightly fuelrich conditions under the conditions of the jet-stirred reactor experiments of Bartok et al. [100] . Not shown is a sequence leading from NCN through HNC to the amine pool.

- interconversion between fixed nitrogen species

The fixation of $\mathrm{N}_{2}$ occurs mainly through the $\mathrm{CH}+\mathrm{N}_{2}$ reaction (R4), even though recombination of $\mathrm{C}$ and $\mathrm{N}_{2}$ (R7b) also contributes. Up to a fuel-air equivalence ratio of approximately 1.2 the $\mathrm{NCN}$ and $\mathrm{N}$ formed in these reactions are oxidized rapidly to NO, principally by the sequence:

$$
\begin{aligned}
& \mathrm{NCN}+\mathrm{H} \rightleftarrows \mathrm{HCN}+\mathrm{N} \\
& \mathrm{HCN}+\mathrm{O} \rightleftarrows \mathrm{NCO}+\mathrm{H} \\
& \mathrm{NCO}+\mathrm{H} \rightleftarrows \mathrm{NH}+\mathrm{CO}
\end{aligned}
$$




$$
\begin{gathered}
\mathrm{NH}+\mathrm{H} \rightleftarrows \mathrm{N}+\mathrm{H}_{2} \\
\mathrm{~N}+\mathrm{OH} \rightleftarrows \mathrm{NO}+\mathrm{H}
\end{gathered}
$$

A minor alternative pathway involves the sequence $\mathrm{NCN} \stackrel{+\mathrm{H}}{\longrightarrow} \mathrm{HNC} \stackrel{+\mathrm{OH}}{\longrightarrow} \mathrm{HNCO}$ $\stackrel{+\mathrm{H}}{\longrightarrow} \mathrm{NH}_{2}$.

At conditions richer than $\phi=1.2$ the concentration of HCN increases rapidly, while NO decreases. The shift in fixed nitrogen partition from NO to HCN is caused by the combination of several factors. The conversion of HCN to NO by reaction ( $\mathrm{R} 26)$ is no longer rapid due to the decrease in O-atom concentration. Furthermore, recycling of amine radicals and NO back to HCN through reaction with hydrocarbon radicals becomes dominant. At richer conditions the reactions of $\mathrm{CH}_{3}$ leading to $\mathrm{CH}_{\mathrm{n}}$-radicals are favored compared to the oxidation pathways leading to formaldehyde. Reactions between the $\mathrm{CH}_{\mathrm{n}}$-radicals and NO then efficiently convert NO to cyanides and isocyanides. These steps are discussed in more detail in section 4.2 on reburning. Recycling of amine radicals into the cyanide pool occurs mainly through the fast reactions,

$$
\begin{gathered}
\mathrm{CH}_{3}+\mathrm{N} \rightleftarrows \mathrm{H}_{2} \mathrm{CN}+\mathrm{H} \\
\mathrm{CH}_{3}+\mathrm{NH} \rightleftarrows \mathrm{CH}_{2} \mathrm{NH}+\mathrm{H}
\end{gathered}
$$

Figure 9 shows a sensitivity analysis for NO for the conditions of the experiments of Bartok et al. (Fig. 7). Results for three selected fuel-air equivalence ratio are shown. Under slightly lean conditions $(\phi=0.91)$, thermal NO contributes to formation of $\mathrm{NO}$ and the prediction is sensitive to the $\mathrm{O}+\mathrm{N}_{2}$ reaction $(\mathrm{R} 1)$. Under slightly fuel-rich conditions $(\phi=1.08)$, the importance of this step is diminished and under even more reducing conditions $(\phi=1.27)$, it proceeds in the reverse direction $\left(\mathrm{N}+\mathrm{NO} \rightarrow \mathrm{N}_{2}+\mathrm{O}\right)$ and shows a negative coefficient.

Prompt NO is an important source of NO under all three conditions. The 


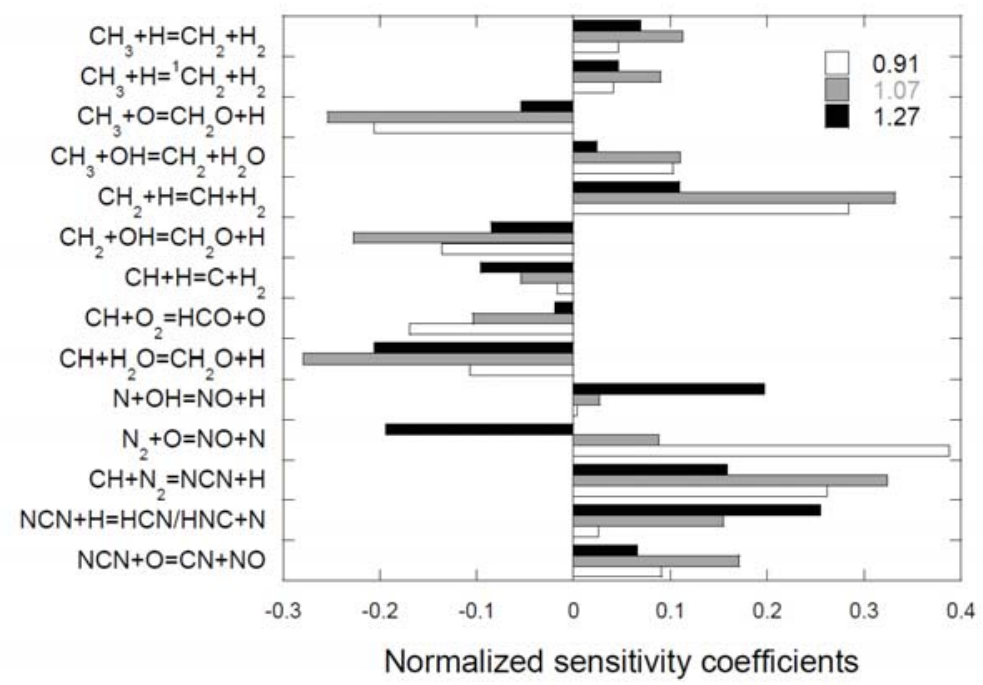

Figure 9: Sensitivity coefficients for prediction of NO under the conditions of the jet-stirred reactor experiments of Bartok et al. [100] at three fuel-air equivalence ratios.

key reactions in the prompt $\mathrm{NO}$ mechanism, $\mathrm{CH}+\mathrm{N}_{2}(\mathrm{R} 4), \mathrm{NCN}+\mathrm{H}(\mathrm{R} 8$, R9) and NCN $+\mathrm{O}$ (R10) exhibit positive sensitivity coefficients. Reactions that promotes formation of $\mathrm{CH}$ through the sequence $\mathrm{CH}_{3} \rightarrow{ }^{3} \mathrm{CH}_{2} \rightarrow \mathrm{CH}$, i.e., $\mathrm{CH}_{3}+\mathrm{H}$ (R99, R100b), $\mathrm{CH}_{3}+\mathrm{OH}$ (R103) and ${ }^{3} \mathrm{CH}_{2}+\mathrm{H}$ (R106), also show positive sensitivity coefficients, while steps breaking this sequence (mainly $\mathrm{CH}_{3}$ $+\mathrm{O}$ (R101) and ${ }^{3} \mathrm{CH}_{2}+\mathrm{OH}(\mathrm{R} 107)$ ) and steps competing with $\mathrm{CH}+\mathrm{N}_{2}(\mathrm{R} 4)$ (primarily $\mathrm{CH}+\mathrm{O}_{2}$ (R113) and $\mathrm{CH}+\mathrm{H}_{2} \mathrm{O}$ (R115)) inhibit NO formation. Under reducing conditions, the reaction $\mathrm{N}+\mathrm{OH}$ (R3) also becomes important for NO formation.

Modeling predictions were compared to concentration profiles for NO and relevant precursors from a series of low-pressure, laminar premixed methane-air flames. The experimental data were obtained by Berg et al. [95] who detected $\mathrm{CH}$ and NO, and by Desgroux and coworkers [62,72,96-99], who in addition to $\mathrm{CH}$ and $\mathrm{NO}$ reported concentration profiles for $\mathrm{HCN}, \mathrm{NCN}, \mathrm{CN}$, and NCO. In both flame studies methane was used as fuel, at pressures of 25-30 and 40 torr, 
respectively, and over a range of equivalence ratios.

Figure 10 compares measured NO concentration profiles with modeling predictions for six flames from Lamoureux et al. and Berg et al. Despite differences between the two sets of flames, some common trends are seen. The measured NO increases with fuel-air equivalence ratio in these flames, ranging from about $5 \mathrm{ppm}$ in the lean flames $(\phi=0.80)$ to $25-40 \mathrm{ppm}$ in the fuel-rich flames $(\phi$ $=1.25-1.28)$. This is expected, since prompt NO is the controlling NO formation mechanism in these flames, with temperatures in the range 1750-1980 K. The model predicts the NO profile quite accurately under slightly lean conditions, but underpredicts NO under stoichiometric and reducing conditions. In the fuel-rich flames where we see the largest discrepancy, the calculated NO is about a factor of two below measurements.

Figure 11 compares the measured and calculated CH-profiles from the two sets of flames. Even though the equivalence ratios investigated in the studies of Lamoureux et al. and Berg et al. are similar, differences in pressure and temperature mean that the flames are not directly comparable. Modeling predictions are generally in satisfactory agreement with measurements. The only important difference is observed for the fuel-rich flame of Berg et al., where $\mathrm{CH}$ is underpredicted by a factor of two. However, in the similar flame from Lamoureux et al., $\mathrm{CH}$ is predicted quite accurately.

Figure 12 shows results for the key nitrogen intermediates in prompt NO formation for the flames of Lamoureux et al. The concentrations of HCN, NCN, and $\mathrm{CN}$ are all captured well by the model. The largest discrepancy is seen for $\mathrm{NCO}$, which is underpredicted in the stoichiometric and the fuel-rich flame.

To bring the present modeling predictions in agreement with the measured NO profile in the rich flame, the rate constant for the reaction $\mathrm{NCN}+\mathrm{H} \rightarrow \mathrm{HCN}$ $+\mathrm{N}$ (R8) needs to be increased by more than a factor of four, bringing it roughly in agreement with the determination from Fassheber et al. [78] and the 


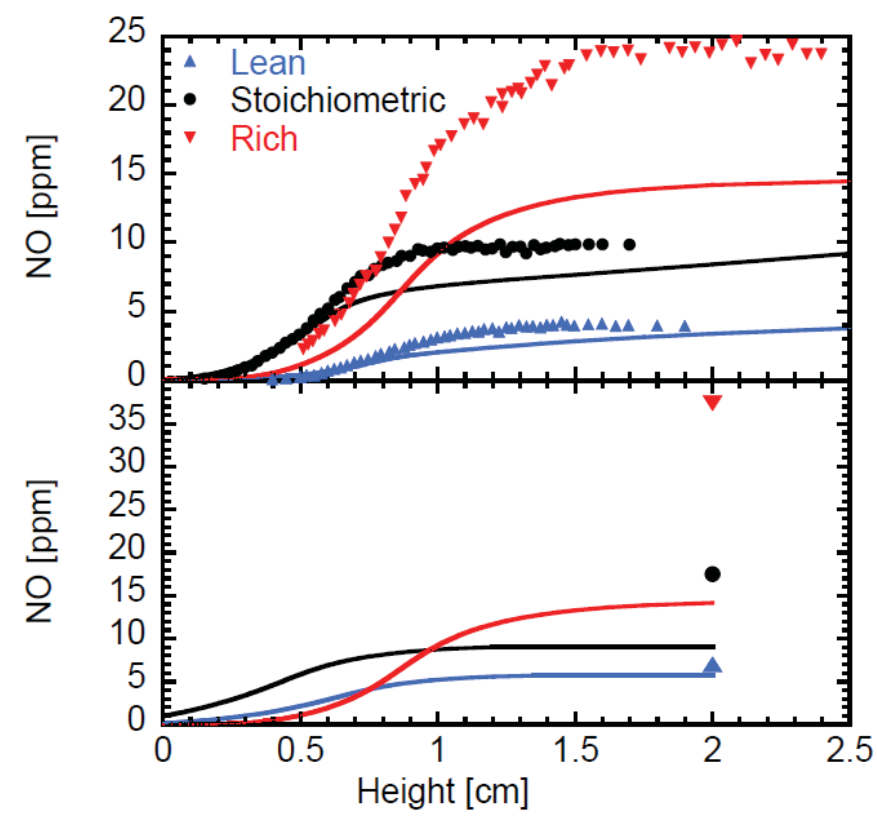

Figure 10: Comparison of measured [62,72,95,97] and predicted mole fractions of NO low-pressure premixed methane/oxygen/nitrogen flames as a function of fuel-air equivalence ratio. The symbols denote experimental data, while the solid lines denote calculated values. Conditions for the flames of Lamoureux et al. [62,72,97]: fuel-air equivalence ratios of 0.80 (lean, $\mathrm{T}_{\max }=1825 \mathrm{~K}$ ), 1.0 (stoichiometric, $\mathrm{T}_{\max }=1875 \mathrm{~K}$ ) and 1.25 (rich, $\mathrm{T}_{\max }=1845 \mathrm{~K}$ ); pressure 40 torr. Conditions for the flames of Berg et al. [95]: fuel-air equivalence ratios of 0.81 (lean, 25 torr, $\mathrm{T}_{\max }=1750 \mathrm{~K}$ ), 1.07 (stoichiometric, 25 torr, $\mathrm{T}_{\max }=1920$ $\mathrm{K}$ ) and 1.28 (rich, 30 torr, $\mathrm{T}_{\max }=1980 \mathrm{~K}$ ).

optimized rate constant used by Lamoureux et al. [72]. Such a change would be outside the estimated $2 \sigma$ uncertainty of a factor of 1.5 for the theoretical rate constant [82]. While a high value for $\mathrm{k}_{8}$ is not supported by theory, it is evident that the predictions of the present model deteriorates under reducing conditions and more work is desirable to resolve the differences.

Prediction of prompt NO formation requires an accurate rate constant for the $\mathrm{CH}+\mathrm{N}_{2}$ reaction ( $\left.\mathrm{R} 4\right)$, as well as the ability to predict both the $\mathrm{CH}$ concentration and the selectivity in the oxidation of $\mathrm{NCN}$ to form $\mathrm{NO}$ or $\mathrm{N}_{2}$. The value of $\mathrm{k}_{4}$ is known better than a factor of two, but the rate constants for important 


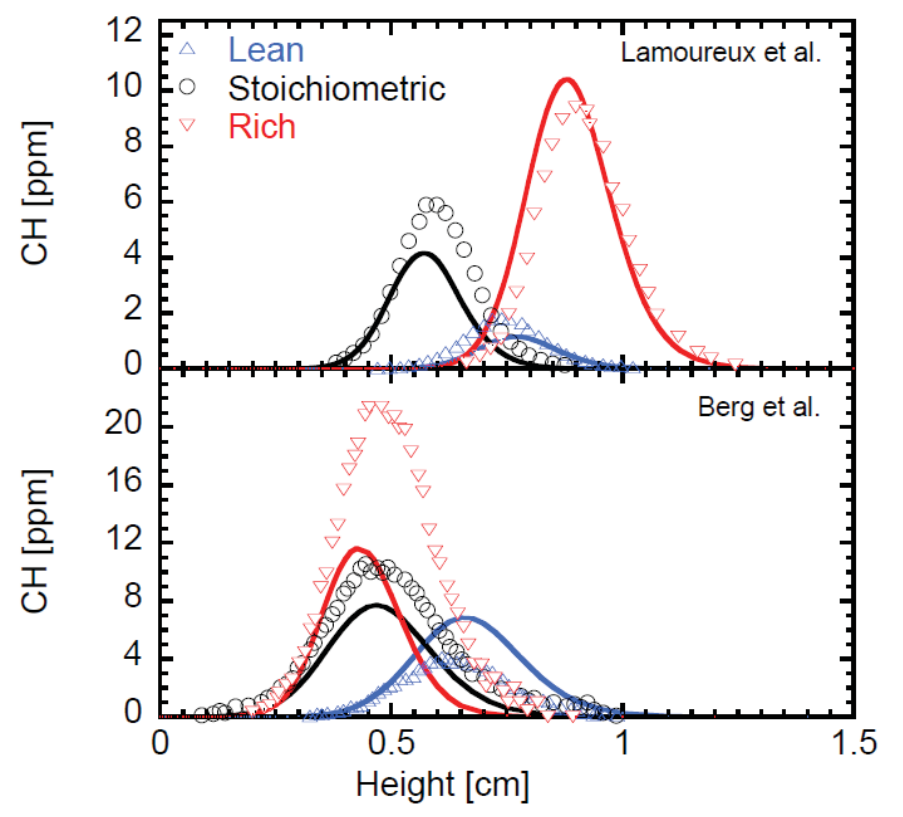

Figure 11: Comparison of measured [72,95] and predicted mole fractions of $\mathrm{CH}$ in low-pressure premixed methane/oxygen/nitrogen flame as a function of fuel-air equivalence ratio. The symbols denote experimental data, while the solid lines denote calculated values. Conditions for the flames of Lamoureux et al. [72]: fuel-air equivalence ratios of 0.80 (lean), 1.0 (stoichiometric) and 1.25 (rich); pressure 40 torr. Conditions for the flames of Berg et al. [95]: fuel-air equivalence ratios of 0.81 (lean, 25 torr), 1.07 (stoichiometric, 25 torr) and 1.28 (rich, 30 torr).

$\mathrm{NCN}$ reactions, in particular $\mathrm{NCN}+\mathrm{H}$, are still in discussion. Consequently, the accuracy in predicting prompt NO formation in the combustion of methane or natural gas is probably not better than a factor of two. The uncertainty in predictions for other hydrocarbon fuels may be even larger, due to concerns about predicting accurately the concentration of $\mathrm{CH}[70]$. 


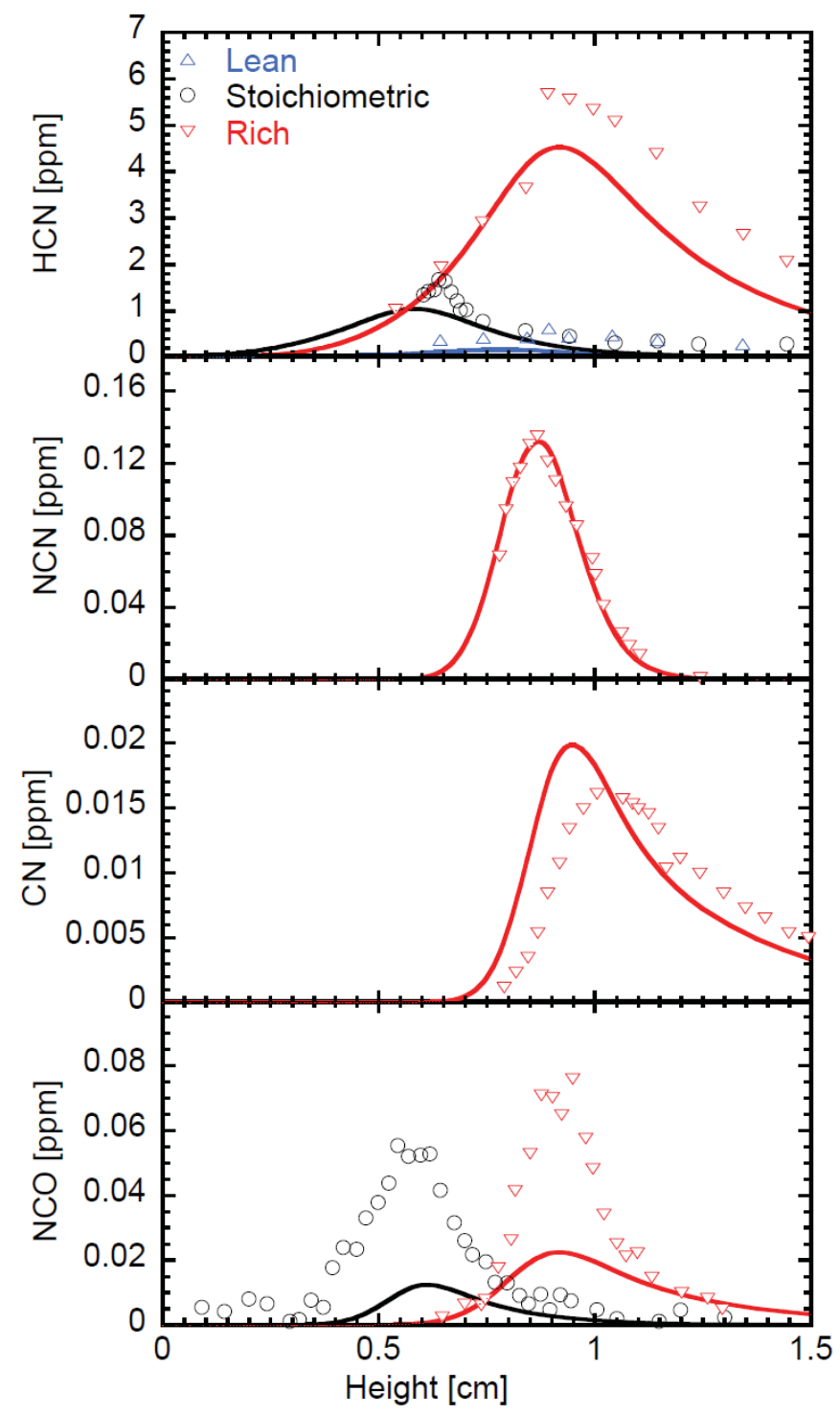

Figure 12: Comparison of measured $[62,72,97]$ and predicted mole fractions of $\mathrm{HCN}, \mathrm{NCN}, \mathrm{CN}$, and $\mathrm{NCO}$ in low-pressure premixed methane/air flames. The symbols denote experimental data, while the solid lines denote calculated values. Conditions: fuel-air equivalence ratios of 0.80 (lean), 1.0 (stoichiometric) and 1.25 (rich); pressure 40 torr. 


\subsection{The $\mathrm{N}_{2} \mathrm{O}$ and $\mathrm{NNH}$ Mechanisms}

Additional reaction paths to NO from atmospheric nitrogen are initiated by recombination of $\mathrm{N}_{2}$ with atomic oxygen, $\mathrm{O}+\mathrm{N}_{2}(+\mathrm{M}) \rightarrow \mathrm{N}_{2} \mathrm{O}(+\mathrm{M})$ [101], or atomic hydrogen, $\mathrm{H}+\mathrm{N}_{2}(+\mathrm{M}) \rightarrow \mathrm{NNH}(+\mathrm{M})$ [102], followed by oxidation of the nitrogen intermediate to $\mathrm{NO}$. The $\mathrm{N}_{2} \mathrm{O}$ scheme may be important under lean conditions at high pressure and moderate temperatures, while the NNH mechanism is most significant at slightly reducing conditions and higher temperatures, perhaps in particular in diffusion flames where NNH may form on the fuel-rich side of the flame sheet and then react with $\mathrm{O}$ inside the flame sheet [103]. While the $\mathrm{N}_{2} \mathrm{O}$ mechanism is quite well established, the importance of NO formation through NNH remains controversial, as discussed below.

\subsubsection{Reaction subset for $\mathrm{NO}$ formation via $\mathrm{N}_{2} \mathrm{O}$}

The $\mathrm{N}_{2} \mathrm{O}$ mechanism was proposed by Malte and Pratt [101]. It involves the steps

$$
\begin{gathered}
\mathrm{O}+\mathrm{N}_{2}(+\mathrm{M}) \rightleftarrows \mathrm{N}_{2} \mathrm{O}(+\mathrm{M}) \\
\mathrm{N}_{2} \mathrm{O}+\mathrm{H} \rightleftarrows \mathrm{NO}+\mathrm{NH} \\
\mathrm{N}_{2} \mathrm{O}+\mathrm{O} \rightleftarrows \mathrm{NO}+\mathrm{NO}
\end{gathered}
$$

The $\mathrm{NH}$ radical may react with $\mathrm{OH}$ or $\mathrm{O}_{2}$ to form $\mathrm{NO}$, or react with $\mathrm{NO}$ to form $\mathrm{N}_{2}$ or $\mathrm{N}_{2} \mathrm{O}$. The $\mathrm{NO}$ forming reactions compete with steps recycling $\mathrm{N}_{2} \mathrm{O}$ to $\mathrm{N}_{2}$,

$$
\begin{aligned}
& \mathrm{N}_{2} \mathrm{O}+\mathrm{H} \rightleftarrows \mathrm{N}_{2}+\mathrm{OH} \\
& \mathrm{N}_{2} \mathrm{O}+\mathrm{O} \rightleftarrows \mathrm{N}_{2}+\mathrm{O}_{2}
\end{aligned}
$$

The $\mathrm{N}_{2} \mathrm{O}$ subset of the mechanism is listed in Table 5. Data on the association reaction between $\mathrm{N}_{2}$ and $\mathrm{O}(\mathrm{R} 15 \mathrm{~b})$ are very limited, but the reverse reaction, 
dissociation of $\mathrm{N}_{2} \mathrm{O}$ (R15), has been studied experimentally over a wide range of conditions. The data, reviewed by Baulch et al. [26], are in very good agreement. The selectivity for forming $\mathrm{NO}$ or $\mathrm{N}_{2}$ from $\mathrm{N}_{2} \mathrm{O}$ is largely controlled by the branching fractions of the reactions of $\mathrm{N}_{2} \mathrm{O}$ with $\mathrm{H}$ and $\mathrm{O}$, respectively.

\begin{tabular}{llrrrl}
\hline & & A & $\beta$ & E & Source \\
& & & & & \\
\hline & & & & & \\
15. & $\mathrm{~N}_{2} \mathrm{O}(+\mathrm{M}) \rightleftarrows \mathrm{O}+\mathrm{N}_{2}(+\mathrm{M})$ & $9.9 \mathrm{E} 10$ & 0.000 & 57901 & {$[26]$} \\
& Low pressure limit: & $6.0 \mathrm{E} 14$ & 0.000 & 57444 & \\
16. & $\mathrm{~N}_{2} \mathrm{O}+\mathrm{H} \rightleftarrows \mathrm{N}_{2}+\mathrm{OH}$ & $6.4 \mathrm{E} 07$ & 1.835 & 13492 & {$[19]$} \\
17. & $\mathrm{NH}+\mathrm{NO} \rightleftarrows \mathrm{N}_{2} \mathrm{O}+\mathrm{H}$ & $2.7 \mathrm{E} 15$ & -0.780 & 20 & See text \\
18. & $\mathrm{~N}_{2} \mathrm{O}+\mathrm{O} \rightleftarrows \mathrm{NO}+\mathrm{NO}$ & $9.2 \mathrm{E} 13$ & 0.000 & 27679 & {$[104]$} \\
19. & $\mathrm{~N}_{2} \mathrm{O}+\mathrm{O} \rightleftarrows \mathrm{N}_{2}+\mathrm{O}_{2}$ & $9.2 \mathrm{E} 13$ & 0.000 & 27679 & See text \\
& & & & & \\
\hline
\end{tabular}

Table 5: Reactions involved in the $\mathrm{N}_{2} \mathrm{O}$ mechanism. Parameters for use in the modified Arrhenius expression $\mathrm{k}=\mathrm{AT}^{\beta} \exp (-\mathrm{E} /[\mathrm{RT}])$. Units are mol, $\mathrm{cm}, \mathrm{s}$, cal.

The $\mathrm{N}_{2} \mathrm{O}+\mathrm{H}$ reaction was studied theoretically by Klippenstein et al. [19]. Their calculated rate constant is in excellent agreement with the measurements of Marshall et al. [105]. The reaction yields predominantly $\mathrm{N}_{2}+\mathrm{OH}$ (R16), except at very low temperatures where addition occurs. The product channel to form $\mathrm{NH}+\mathrm{NO}(\mathrm{R} 17 \mathrm{~b})$ is only minor and reliable data for the forward reaction are scarce. However, the NH + NO reaction has been studied extensively. The reaction has two major product channels:

$$
\begin{aligned}
& \mathrm{NH}+\mathrm{NO} \rightleftarrows \mathrm{N}_{2} \mathrm{O}+\mathrm{H} \\
& \mathrm{NH}+\mathrm{NO} \rightleftarrows \mathrm{N}_{2}+\mathrm{OH}
\end{aligned}
$$

Reported results for the overall rate constant for $\mathrm{NH}+\mathrm{NO}$ are summarized in Fig. 13. The low temperature measurements agree to within a factor of two, and the data of Lillich et al. [106] and Romming and Wagner [107], which are in good agreement, serve to extrapolate the data up to about $2200 \mathrm{~K}$. Also the 
theoretical rate constant from Klippenstein et al. [19] and the evaluation by Baulch et al. [26] are shown, both for $\mathrm{k}_{17}+\mathrm{k}_{71}$.

Experimental [106, 108-112] and theoretical [19] data for the branching ratio of the reaction show that $\mathrm{N}_{2} \mathrm{O}+\mathrm{H}(\mathrm{R} 17)$ is dominating in the $300-2200 \mathrm{~K}$ range, contributing $70-90 \%$ of the total rate. The $\mathrm{N}_{2}+\mathrm{OH}$ channel (R71) accounts for 10-30\%; according to theory this value increases only slightly with temperature [19].

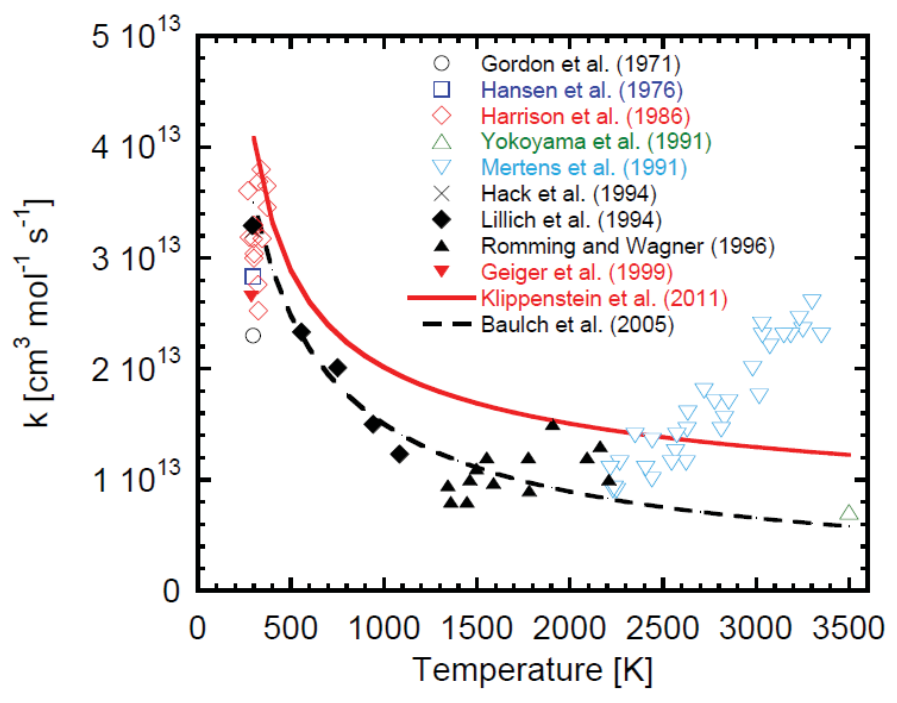

Figure 13: Arrhenius plot for the reaction $\mathrm{NH}+\mathrm{NO} \rightarrow$ products. The symbols denote measurements of the rate constant, while lines denote theoretical values (solid line) or evaluations (dashed line). The data are drawn from Gordon et al. [113], Hansen et al. [114], Harrison et al. [115], Yokoyama et al. [108], Mertens et al. [109], Hack et al. [116], Lillich et al. [106], Romming and Wagner [107], Geiger et al. [117], Klippenstein et al. [19] $\left(\mathrm{k}_{17}+\mathrm{k}_{71}\right)$ and Baulch et al. [26] $\left(\mathrm{k}_{17}+\mathrm{k}_{71}\right)$.

At temperatures above $2200 \mathrm{~K}$ there are only two reported studies of $\mathrm{NH}+$ $\mathrm{NO}$, both conducted in a shock tube using $\mathrm{HNCO}$ as a source of NH. Mertens et al. [109] report overall rate measurements in the 2200-3350 K range, while Yokoyama et al. [108] report a single measurement at $3500 \mathrm{~K}$. The data from Mertens et al., which are in good agreement with those of Romming and Wagner 
in the overlapping temperature range, indicate an increase in the rate constant for $\mathrm{NH}+\mathrm{NO}$ above $2200 \mathrm{~K}$. The upturn in the rate constant is not consistent with the measurement of Yokoyama et al. Their result for $\mathrm{k}_{\mathrm{NH}+\mathrm{NO}}$ at $3500 \mathrm{~K}$ is about a factor of three lower than the data of Mertens et al., but in excellent agreement with the recommendation of Baulch et al. for $\mathrm{k}_{17}+\mathrm{k}_{71}$.

Baulch et al. [26] attributed the high temperature increase detected by Mertens et al. in the rate constant for $\mathrm{NH}+\mathrm{NO}$ to a third product channel,

$$
\mathrm{NH}+\mathrm{NO} \rightleftarrows \mathrm{NNH}+\mathrm{O}
$$

This would require a rate constant for $\mathrm{NNH}+\mathrm{O}$ (R23) close to collision frequency at high temperatures. While this would be in agreement with early estimates $[102,118,119]$, theoretical work $[19,120]$ indicates a value about an order of magnitude lower, making the $\mathrm{NNH}+\mathrm{O}$ channel (R23) insignificant for the overall rate of $\mathrm{NH}+\mathrm{NO}$. Reaction R23 is discussed in detail in section 3.3.2 below.

We have adopted the value for $\mathrm{k}_{17}+\mathrm{k}_{71}$ and the branching fraction $\mathrm{k}_{71} /\left(\mathrm{k}_{17}\right.$ $+\mathrm{k}_{71}$ ) from Baulch et al. [26]; these rate coefficients are in agreement with the theoretical work [19] withín the uncertainty, but provide a slightly better agreement with the experiments of Lillich et al. and Romming and Wagner in the temperature range of interest in this study.

For the $\mathrm{N}_{2} \mathrm{O}+\mathrm{O}$ reaction, the rate constant for forming $\mathrm{NO}+\mathrm{NO}$ (R18), measured both in the forward and reverse directions, and at high temperatures also the overall rate constant are well established $[26,104]$. However, the predicted formation of $\mathrm{NO}$ from $\mathrm{N}_{2} \mathrm{O}$ is sensitive to the branching fraction of the $\mathrm{N}_{2} \mathrm{O}+\mathrm{O}$ reaction between $\mathrm{NO}+\mathrm{NO}(\mathrm{R} 18)$ and $\mathrm{N}_{2}+\mathrm{O}_{2}$ (R19) and the value of $\mathrm{k}_{19}$ has significant error limits at intermediate temperatures [26]. In early evaluations by Baulch et al. [121] and Hanson and Salimian [122], it was concluded that $\mathrm{k}_{18}$ and $\mathrm{k}_{19}$ were similar over a wide temperature range. More recently, this 
finding was questioned by Meagher and Anderson [104]. From a reevaluation of the available experimental results, they concluded that most likely reaction R19 had a significantly smaller activation energy than R18, causing formation of $\mathrm{N}_{2}+\mathrm{O}_{2}$ to dominate at lower temperatures, while $\mathrm{NO}$ formation dominated at temperatures above $1900 \mathrm{~K}$.

Reported experimental results obtained at lower temperatures do not support

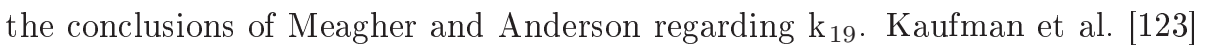
conducted a batch reactor study of decomposition of $\mathrm{N}_{2} \mathrm{O}$ and formation of NO at temperatures of 876-1031 K. Their data indicate that the NO producing channel (R18) constitutes at least 50\% under these conditions. Meagher and Anderson discarded the batch reactor results due to concern about surface effects. However, according to Kaufman et al. an increase in the surface/volume ratio resulted in a decrease, not an increase, in formation of NO. The decrease in NO formation would be consistent with loss of atomic oxygen on the quartz surface (see App. A). In the present work, we have adopted the rate constant for reaction R18 from the review of Meagher and Anderson [104], but tentatively assumed that $\mathrm{k}_{18}=\mathrm{k}_{19}$ based on the results of Kaufman et al. [123], Dindi et al. [124], and Rohrig et al. [125]. A high activation energy for reaction R19 is consistent with theoretical work [126], but more work on this reaction is desirable.

\subsubsection{Reaction subset for NO formation via NNH}

The reaction subset for NNH is listed in Table 6. The mechanism for forming NO via NNH consists of the reaction sequence [102],

$$
\begin{gathered}
\mathrm{H}+\mathrm{N}_{2}(+\mathrm{M}) \rightleftarrows \mathrm{NNH}(+\mathrm{M}) \\
\mathrm{NNH}+\mathrm{O} \rightleftarrows \mathrm{NH}+\mathrm{NO}
\end{gathered}
$$


followed by oxidation of $\mathrm{NH}$.

\begin{tabular}{llrrrr}
\hline & & $\mathrm{A}$ & $\beta$ & $\mathrm{E}$ & Source \\
& & & & & \\
\hline & & & & & \\
20. & $\mathrm{NNH} \rightleftarrows \mathrm{N}_{2}+\mathrm{H}$ & $1.0 \mathrm{E} 09$ & 0.000 & 0 & {$[19]$} \\
21. & $\mathrm{NNH}+\mathrm{O} \rightleftarrows \mathrm{N}_{2} \mathrm{O}+\mathrm{H}$ & $1.9 \mathrm{E} 14$ & -0.274 & -22 & {$[19]$} \\
22. & $\mathrm{NNH}+\mathrm{O} \rightleftarrows \mathrm{N}_{2}+\mathrm{OH}$ & $1.2 \mathrm{E} 13$ & 0.145 & -217 & {$[19]$} \\
23. & $\mathrm{NNH}+\mathrm{O} \rightleftarrows \mathrm{NH}+\mathrm{NO}$ & $5.2 \mathrm{E} 11$ & 0.381 & -409 & {$[19]$} \\
24. & $\mathrm{NNH}+\mathrm{O}_{2} \rightleftarrows \mathrm{N}_{2}+\mathrm{HO}_{2}$ & $5.6 \mathrm{E} 14$ & -0.385 & -13 & {$[19]$} \\
& & & & & \\
\hline
\end{tabular}

Table 6: Selected reactions from the NNH subset. Parameters for use in the modified Arrhenius expression $\mathrm{k}=\mathrm{AT}^{\beta} \exp (-\mathrm{E} /[\mathrm{RT}])$. Units are mol, $\mathrm{cm}, \mathrm{s}$, cal.

The rate constant for NNH dissociation (R20) is discussed in more detail in section 4.1.1. With a lifetime of $\mathrm{NNH}$ of about $10^{-9} \mathrm{~s}$ [19], the NNH $\rightleftarrows \mathrm{N}_{2}$ $+\mathrm{H}$ reaction equilibrates rapidly. Thereby, the yield of NO from the NNH mechanism becomes directly proportional to the rate constant for $\mathrm{NNH}+\mathrm{O} \rightleftarrows$ $\mathrm{NH}+\mathrm{NO}$ (R23), as well as to the equilibrium constant $\mathrm{K}_{\mathrm{C}, 20 \mathrm{~b}}$ for reaction $\mathrm{R} 20 \mathrm{~b}$ $[19,127]$. The equilibrium constant $\mathrm{K}_{\mathrm{C}, 20 \mathrm{~b}}$ depends on the heat of formation of $\mathrm{NNH}$, which is now well established at a value of $\Delta_{\mathrm{f}} \mathrm{H}_{298}^{0}(\mathrm{NNH})=59.7 \mathrm{kcal}$ $\mathrm{mol}^{-1}$ [19]. Contrary to this, reported rate constants for the NNH $+\mathrm{O} \rightarrow \mathrm{NH}$ + NO reaction (R23) vary by more than an order of magnitude, as shown in Fig. 14.

There are no direct measurements of $\mathrm{k}_{23}$. The data shown from Mertens et al. are calculated from their shock tube measurements of $\mathrm{k}_{\mathrm{NH}+\mathrm{NO}}$ by subtracting $\mathrm{k}_{17}+\mathrm{k}_{71}$ and then converting the resulting value for $\mathrm{k}_{23 \mathrm{~b}}$ to $\mathrm{k}_{23}$ through the equilibrium constant. Hayhurst and Hutchinson reported values of $\mathrm{k}_{23} \cdot \mathrm{K}_{\mathrm{C}, 20 \mathrm{~b}}$, derived from flame measurements, with error limits of a factor of five; we have used the present thermochemistry to obtain $\mathrm{k}_{23}$. Konnov and De Ruyck [128] based their recommendation for $\mathrm{k}_{23}$ on a re-interpretation of flame data from Harrington et al. [129] at $1200 \mathrm{~K}$. Their value is compatible with the results from Hayhurst and Hutchinson (1800-2500 K) and from Mertens et al. 


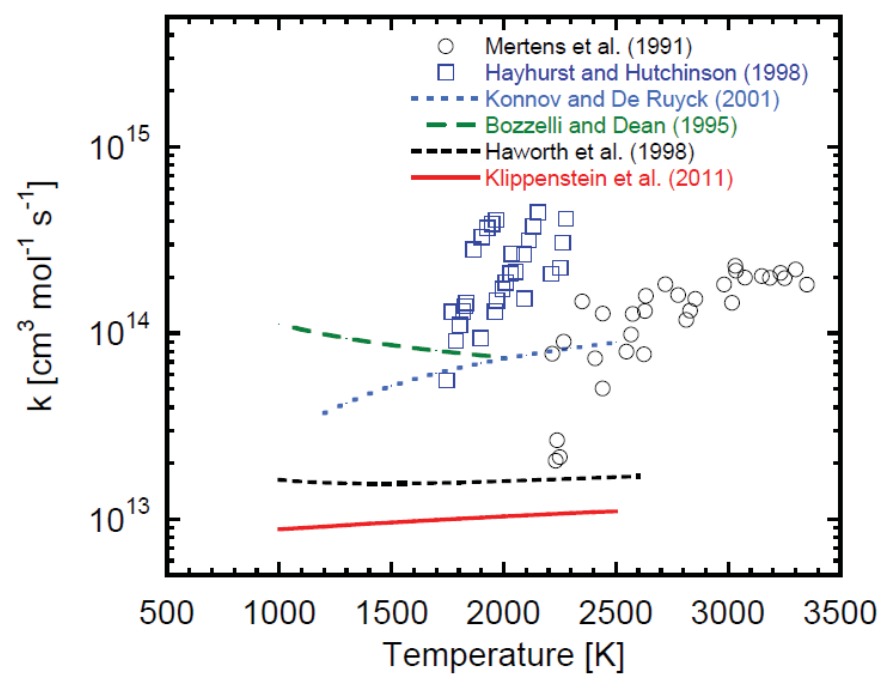

Figure 14: Arrhenius plot for the reaction $\mathrm{NNH}+\mathrm{O} \rightarrow \mathrm{NH}+\mathrm{NO}(\mathrm{R} 23)$. The data are drawn from the following sources: Mertens et al. [109] (shock tube study), Bozzelli and Dean [102], Hayhurst and Hutchinson [127] (flame study), Konnov and De Ruyck [128] (flame study), Haworth et al. [120] (theory), and Klippenstein et al. [19] (theory). The data from Mertens et al. are derived from their overall measurements of $\mathrm{k}_{\mathrm{NH}+\mathrm{NO}}$, subtracting $\mathrm{k}_{17}+\mathrm{k}_{71}$ and converting through the equilibrium constant. The data from Hayhurst and Hutchinson are derived from their reported values of $\mathrm{k}_{23} \cdot \mathrm{K}_{\mathrm{C}, 20 \mathrm{~b}}$, using the present thermochemistry.

These indirect experimental determinations of $\mathrm{k}_{23}$ all support a value close to collision frequency. However, the theoretical studies by Haworth et al. [120] and Klippenstein et al. [19] indicate a much lower rate constant for reaction R23 (Fig. 14). In the present work, we have drawn $\mathrm{k}_{23}$ from the theoretical study of Klippenstein et al. [19]. This value has an estimated $2 \sigma$ uncertainty of a factor of two. The implications of this choice for predicting NO formation through the NNH mechanism is discussed below.

\subsubsection{Modeling $\mathrm{NO}$ formation from the $\mathrm{N}_{2} \mathrm{O}$ and $\mathrm{NNH}$ mechanisms}

Under most conditions, formation of $\mathrm{NO}$ via $\mathrm{N}_{2} \mathrm{O}$ or $\mathrm{NNH}$ is a minor source of nitric oxide compared to thermal NO and prompt NO. For this reason experi- 
ments where the $\mathrm{N}_{2} \mathrm{O}$ or $\mathrm{NNH}$ mechanisms dominate $\mathrm{NO}$ formation are scarce. To exclude the possibility of prompt-NO formation, we select validation data only from non-hydrocarbon systems, i.e. with $\mathrm{H}_{2}$ or $\mathrm{H}_{2} / \mathrm{CO}$ mixtures as fuel.

Following Haworth et al. [120] and Klippenstein et al. [19], we have selected the low-pressure, fuel-rich flames of Harrington et al. [129] and the lean jetstirred reactor experiments of Steele et al. [130] for comparison with modeling predictions. The $\mathrm{H}_{2}$ /air flames of Harrington et al. were designed to minimize formation of $\mathrm{NO}$ through thermal $\mathrm{NO}$ and $\mathrm{N}_{2} \mathrm{O}$ mechanisms while yielding measurable quantities of NO from NNH. To obtain this condition, the flames were operated at comparatively low temperature (about $1200 \mathrm{~K}$ ) and under reducing conditions.

In Fig. 15, the measured NO profile from the 38 torr flame of Harrington et al. is compared with modeling predictions. The amount of NO formed is very low, below $1 \mathrm{ppm}$. Even so, the model underpredicts NO in the flame by almost an order of magnitude. We currently cannot explain the difference between the observed and calculated NO levels for this flame. With a value of $\mathrm{k}_{23}$ of about $10^{14} \mathrm{~cm}^{3} \mathrm{~mol}^{-1} \mathrm{~s}^{-1}$, the NO predictions become in agreement with experiment. However, such a fast step appears to be incompatible with the theoretical work $[19,120]$, which clearly indicates that $\mathrm{NH}+\mathrm{NO}$ is only a minor channel of the $\mathrm{NNH}+\mathrm{O}$ reaction.

Malte and co-workers $[101,130]$ have conducted a range of jet-stirred reactor experiments to characterize NO formation in lean, premixed combustion. While $\mathrm{NO}$ is mostly formed via $\mathrm{N}_{2} \mathrm{O}$ under these conditions, the $\mathrm{CO} / \mathrm{H}_{2}$ oxidation data of Steele et al. [130] is sensitive also to NO formation from the NNH mechanism [19,120]. Figure 16 compares measured and predicted $\mathrm{NO}$ and $\mathrm{N}_{2} \mathrm{O}$ concentrations as a function of temperature. The model predicts both NO and $\mathrm{N}_{2} \mathrm{O}$ within about $20 \%$. Analysis of the calculations indicates that the $\mathrm{N}_{2} \mathrm{O}$ mechanism dominates under the conditions of these experiments. However, augmented by the high levels of radicals in the reactor, the NNH mechanism is 


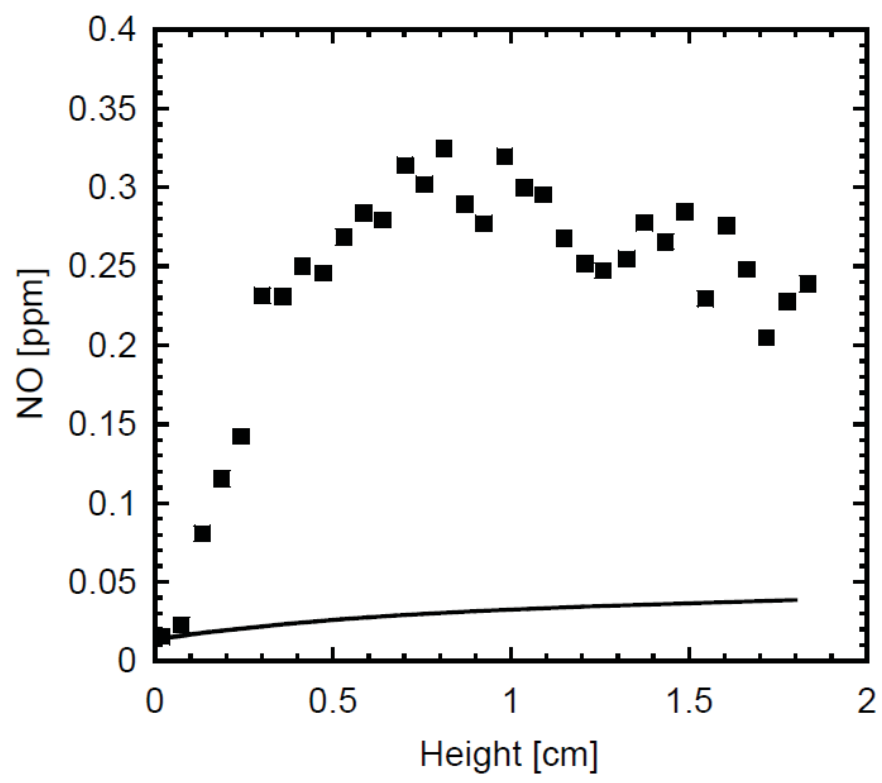

Figure 15: Comparison of measured [129] and predicted mole fractions of NO in a low-pressure premixed hydrogen/air flame. The symbols denote experimental data, while the solid lines denote calculated values. Conditions: pressure of 38 torr, fuel-air equivalence ratio of $\phi=1.5$, and flame temperatures of the order of $1200 \mathrm{~K}$.

also active, contributing about $25 \%$ to the formation of NO. It is noteworthy that modeling predictions with a high rate constant for the $\mathrm{NNH}+\mathrm{O} \rightleftarrows \mathrm{NH}$ + NO reaction (R23) leads to a substantial overprediction of NO under these conditions $[19,120]$.

The $\mathrm{N}_{2} \mathrm{O}$ mechanism is well established and predictions of NO formed from this scheme would be expected to be quite accurate at relevant temperatures and pressures. The main uncertainty relates to the activation energy for $\mathrm{N}_{2} \mathrm{O}+\mathrm{O}$ $\rightarrow \mathrm{N}_{2}+\mathrm{O}_{2}$ (R19), which particularly at lower temperatures has some impact on the calculated NO.

The prediction of NO from NNH is significantly more uncertain. High level theoretical results for $\Delta_{\mathrm{f}} \mathrm{H}_{298}^{0}(\mathrm{NNH})$ [19] and for the $\mathrm{NNH}+\mathrm{O}$ reaction $[19,120]$ indicate that the NNH mechanism may be less important than indicated by early 


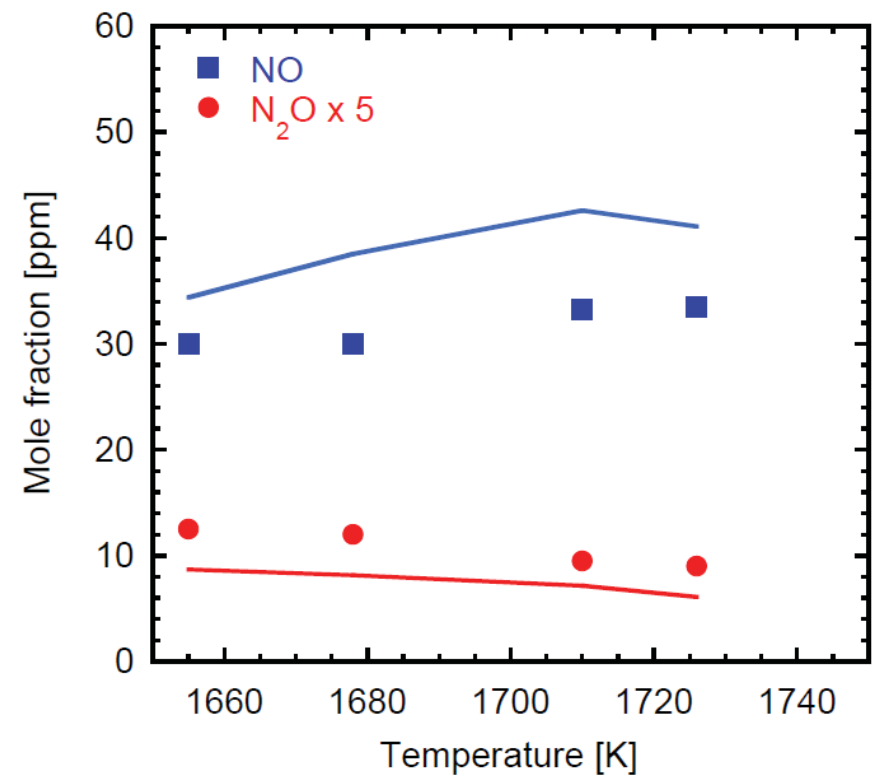

Figure 16: Comparison of measured [130] and predicted mole fractions of NO and $\mathrm{N}_{2} \mathrm{O}$ in $\mathrm{CO} / \mathrm{H}_{2} /$ air combustion in a jet-stirred reactor. The symbols denote experimental data, while the solid lines denote calculated values. Results are shown as a function of temperature with the following inlet composition: $17.4 \%$ $\mathrm{CO}, 82 \%$ air, $0.69-0.25 \% \mathrm{H}_{2}$ (decreasing with increasing temperature). The nominal residence time was about $4.0 \mathrm{~ms}$.

modeling studies. Experimental results $[129,130]$ are inconclusive and additional experimental work is called for to validate this subset. 


\subsection{Oxidation of $\mathrm{HCN}$}

In combustion processes, cyanides may be formed from reaction of $\mathrm{CH}$ and $\mathrm{C}$ with $\mathrm{N}_{2}$ (the initiating steps in prompt NO formation), from reaction of reactive nitrogen species such as NO or amines with hydrocarbon radicals, from decomposition of hydrocarbon amines, or from devolatilization of fuels with organically bound nitrogen [1-4,131]. The predominant cyanide species in combustion is hydrogen cyanide $(\mathrm{HCN})$ and the oxidation chemistry of this component has been studied extensively over the years [132-143]. Much of this work was reviewed by Dagaut et al. [20]. Recently the chemistry was re-examined by Glarborg and Marshall [143], who emphasized the role of the hydrogen isocyanide isomer $\mathrm{HNC}$. The key issue in HCN chemistry is the selectivity towards forming other nitrogen species during oxidation, i.e., $\mathrm{NH}_{3}, \mathrm{HNCO}, \mathrm{NO}, \mathrm{N}_{2} \mathrm{O}$, and $\mathrm{N}_{2}$.

\subsubsection{Reaction subset for HCN oxidation}

Table 7 lists selected reactions from the HCN subset of the chemical kinetic model. It is based on the work of Dagaut et al. [20], adopting the modifications suggested by Glarborg and Marshall [143]. The major consumption steps for HCN are the reactions with $\mathrm{O}$ (R27-R29) and $\mathrm{OH}$ (R30-R33). Both of these reactions are complicated processes that involve multiple potential wells and multiple product channels [1]. While rate constant and product channels are fairly well established for the $\mathrm{HCN}+\mathrm{O}$ reaction [1,20,144], few experimental data are available for $\mathrm{HCN}+\mathrm{OH}$. Only the $\mathrm{H}$-abstraction reaction $\mathrm{R} 30$ is well characterized experimentally [143]. For the other product channels of HCN + $\mathrm{OH}$ (R31-33), rate constants are drawn from BAC-MP4 calculations by Miller and Melius [145].

Hydrogen isocyanide (HNC) has been proposed as an important intermediate in oxidation of HCN in combustion [154]. At higher temperatures, HCN and HNC equilibrate rapidly through isomerization (R25), and, being more reactive than 


\begin{tabular}{llrrrl}
\hline & & & & & \\
& & $\mathrm{A}$ & $\beta$ & $\mathrm{E}_{a}$ & Source \\
& & & & \\
25. & $\mathrm{HCN}+\mathrm{M} \rightleftarrows \mathrm{HNC}+\mathrm{M}$ & $1.6 \mathrm{E} 26$ & -3.230 & 54900 & {$[146]$} \\
26. & $\mathrm{CN}+\mathrm{H}_{2} \rightleftarrows \mathrm{HCN}+\mathrm{H}$ & $1.1 \mathrm{E} 05$ & 2.600 & 51908 & {$[26]$} \\
27. & $\mathrm{HCN}+\mathrm{O} \rightleftarrows \mathrm{NCO}+\mathrm{H}$ & $1.4 \mathrm{E} 04$ & 2.640 & 4980 & {$[1]$} \\
28. & $\mathrm{HCN}+\mathrm{O} \rightleftarrows \mathrm{NH}+\mathrm{CO}$ & $3.5 \mathrm{E} 03$ & 2.640 & 4980 & {$[1]$} \\
29. & $\mathrm{HCN}+\mathrm{O} \rightleftarrows \mathrm{CN}+\mathrm{OH}$ & $4.2 \mathrm{E} 10$ & 0.400 & 20665 & {$[146]$} \\
30. & $\mathrm{HCN}+\mathrm{OH} \rightleftarrows \mathrm{CN}+\mathrm{H}_{2} \mathrm{O}$ & $3.9 \mathrm{E} 06$ & 1.830 & 10300 & {$[147]$} \\
31. & $\mathrm{HCN}+\mathrm{OH} \rightleftarrows \mathrm{HOCN}+\mathrm{H}$ & $5.9 \mathrm{E} 04$ & 2.430 & 12500 & {$[145]$} \\
32. & $\mathrm{HCN}+\mathrm{OH} \mathrm{HNCO}+\mathrm{H}$ & $2.0 \mathrm{E}-03$ & 4.000 & 1000 & {$[145]$} \\
33. & $\mathrm{HCN}+\mathrm{OH} \mathrm{NH}+\mathrm{CO}$ & $7.8 \mathrm{E}-04$ & 4.000 & 4000 & {$[145]$} \\
34. & $\mathrm{HNC}+\mathrm{H} \rightleftarrows \mathrm{HCN}+\mathrm{H}$ & $7.8 \mathrm{E} 13$ & 0.000 & 0 & {$[148]$} \\
35. & $\mathrm{HNC}+\mathrm{O} \rightleftarrows \mathrm{NH}+\mathrm{CO}$ & $4.6 \mathrm{E} 12$ & 0.000 & 2200 & {$[146]$} \\
36. & $\mathrm{HNC}+\mathrm{OH} \rightleftarrows \mathrm{HNCO}+\mathrm{H}$ & $3.6 \mathrm{E} 12$ & 0.000 & -479 & {$[143,149]$} \\
37. & $\mathrm{CN}+\mathrm{O}_{2} \rightleftarrows \mathrm{NCO}+\mathrm{O}$ & $5.8 \mathrm{E} 12$ & 0.000 & -417 & {$[26,150]$} \\
38. & $\mathrm{CN}+\mathrm{O}_{2} \rightleftarrows \mathrm{NO}+\mathrm{CO}$ & $1.4 \mathrm{E} 12$ & 0.000 & -417 & {$[26,150]$} \\
39. & $\mathrm{NCO}+\mathrm{H} \rightleftarrows \mathrm{NH}+\mathrm{CO}$ & $7.2 \mathrm{E} 13$ & 0.000 & 1000 & {$[26]$} \\
40. & $\mathrm{NCO}+\mathrm{O} \rightleftarrows \mathrm{NO}+\mathrm{CO}$ & $2.0 \mathrm{E} 15$ & -0.500 & 0 & {$[151]$} \\
41. & $\mathrm{NCO}+\mathrm{O}_{2} \rightleftarrows \mathrm{NO}+\mathrm{CO} 2$ & $2.0 \mathrm{E} 12$ & 0.000 & 20000 & {$[152]$ est } \\
42. & $\mathrm{NCO}+\mathrm{NO} \rightleftarrows \mathrm{N}_{2} \mathrm{O}+\mathrm{CO}$ & $4.0 \mathrm{E} 19$ & -2.190 & 1743 & {$[153]$} \\
43. & $\mathrm{NCO}+\mathrm{NO} \rightleftarrows \mathrm{N}_{2}+\mathrm{CO} \mathrm{C}_{2}$ & $1.5 \mathrm{E} 21$ & -2.740 & 1824 & {$[153]$} \\
& & & & & \\
& & & & &
\end{tabular}

Table 7: Selected reactions in the HCN oxidation subset. Parameters for use in the modified Arrhenius expression $\mathrm{k}=\mathrm{AT}^{\beta} \exp (-\mathrm{E} /[\mathrm{RT}])$. Units are mol, $\mathrm{cm}, \mathrm{s}$, cal.

HCN, HNC offers an alternative route of oxidation for cyanides. The major issues regarding $\mathrm{HNC}$ have been the energy separation to $\mathrm{HCN}$, important for the predicted concentration of $\mathrm{HNC}$ when equilibrated with $\mathrm{HCN}$, and the rate constants for the reactions of $\mathrm{HNC}$ with $\mathrm{OH}$ and $\mathrm{O}_{2}$. Both the thermodynamic properties of $\mathrm{HNC}$ and the key $\mathrm{HNC}$ reactions are known more accurately due to recent work. Nguyen et al. [12] determined the energy difference between $\mathrm{HCN}$ and $\mathrm{HNC}$ at $298 \mathrm{~K}$ to be $15.1 \pm 0.1 \mathrm{kcal} \mathrm{mol}^{-1}, 2.2 \mathrm{kcal} \mathrm{mol}^{-1}$ higher than that proposed in the early study by Lin et al. [154] and $0.3 \mathrm{kcal} \mathrm{mol}^{-1}$ higher than the recommendation of Dagaut et al. [20]. Reactions of $\mathrm{HNC}$ with $\mathrm{OH}$ (R36) [149] and $\mathrm{O}_{2}$ [143] have been characterized theoretically and both steps appear to be slower at relevant temperatures than assumed in earlier modeling 
studies. In particular, Glarborg and Marshall [143] report a high barrier of 44 $\mathrm{kcal} \mathrm{mol}{ }^{-1}$ for the latter reaction, making it irrelevant under most conditions of interest.

Compared to the HCN subset from previous work [20,143], only a few changes have been made. The most important of these concerns the reaction of the $\mathrm{CN}$ radical with $\mathrm{O}_{2}$. This step is fast and the overall rate constant is well established. However, the branching fraction to the two product channels NCO $+\mathrm{O}$ (R37) and $\mathrm{NO}+\mathrm{CO}$ (R38) has been in discussion. Measurements of the branching fraction $[150,155,156]$ are in good agreement at room temperature. Recently, Feng and Hershberger [150] verified that the NO + CO channel (R38) constituted $20 \%$ with little or no temperature dependence over the range 296$475 \mathrm{~K}$, in contrast to earlier results from the same group [156], and we have adopted their recommendation.

\subsubsection{Modeling HCN oxidation}

In the following, modeling predictions for HCN oxidation are compared to experimental results from flames (high temperature, reducing conditions) and flow reactors (intermediate temperatures, oxidizing conditions).

Following Glarborg and Marshall [143], we compare modeling predictions for the post-flame zone with measurements from a rich ethylene flame doped with ammonia (Fig. 17). The conditions are representative of the high-temperature region in fuel-rich combustion prior to the rich-lean transition. The experimental data are from Haynes [157] who investigated the decay of hydrogen cyanide in the burnt gases of a number of fuel-rich, atmospheric pressure hydrocarbon flames, using nitrogen additives (ammonia or pyridine) as a source of $\mathrm{HCN}$. In the reaction zone of the flame, the additive would be converted to HCN, with smaller amounts of NO. In the post-flame zone, HCN was slowly converted to $\mathrm{NH}_{3}$. The temperature of the burnt gases was $2000 \mathrm{~K}$. In the modeling, 
it was assumed that both ethylene and oxygen were depleted in the reaction zone, resulting in an equilibrium mixture of $\mathrm{CO}, \mathrm{H}_{2}, \mathrm{CO}_{2}$, and $\mathrm{H}_{2} \mathrm{O}$ entering the post-flame zone together with measured concentrations of $\mathrm{HCN}, \mathrm{NH}_{3}$, and NO [143].

The modeling predictions are in good agreement with the measurements for $\mathrm{HCN}, \mathrm{NH}_{3}$, and NO. Hydrogen cyanide is consumed through a two step sequence,

$$
\begin{gathered}
\mathrm{HCN}+\mathrm{M} \rightleftarrows \mathrm{HNC}+\mathrm{M} \\
\mathrm{HNC}+\mathrm{OH} \rightarrow \mathrm{HNCO}+\mathrm{H}
\end{gathered}
$$

Under the conditions in the flame, HCN equilibrates rapidly with HNC. Atomic hydrogen and to a lesser extent $\mathrm{OH}$ are the dominant radicals in the flame but they consume little $\mathrm{HCN}$ because the reactions $\mathrm{HCN}+\mathrm{H} \rightleftarrows \mathrm{CN}+\mathrm{H}_{2}$ (R26b) and $\mathrm{HCN}+\mathrm{OH} \rightleftarrows \mathrm{CN}+\mathrm{H}_{2} \mathrm{O}$ (R30) are both rapidly equilibrated. The HNCO formed in reaction R36 feeds rapidly into the amine pool, eventually forming $\mathrm{NH}_{3}$ :

$$
\begin{gathered}
\mathrm{HNCO}+\mathrm{H} \rightleftarrows \mathrm{NH}_{2}+\mathrm{CO} \\
\mathrm{NH}_{2}+\mathrm{H}_{2} \rightleftarrows \mathrm{NH}_{3}+\mathrm{H}
\end{gathered}
$$

A smaller fraction of the $\mathrm{NH}_{2}$ is converted to $\mathrm{NH}$ and $\mathrm{N}$ through the sequence $\mathrm{NH}_{2} \stackrel{+\mathrm{H}}{\longrightarrow} \mathrm{NH} \stackrel{+\mathrm{H}}{\longrightarrow} \mathrm{N}$. The $\mathrm{NH}$ and $\mathrm{N}$ radicals may be oxidized to $\mathrm{NO}$ by reaction with $\mathrm{OH}$ or react with $\mathrm{NO}$ to form $\mathrm{N}_{2} \mathrm{O}$ or $\mathrm{N}_{2}$. This competition results overall in a small decrease in NO concentration.

In combustion, $\mathrm{HCN}$ is oxidized to $\mathrm{NO}$ and $\mathrm{N}_{2}$ under excess air conditions, typically in the presence of combustibles. Figure 18 compares flow reactor results from Hulgaard and Dam-Johansen [136] and Glarborg and Miller [137] on lean oxidation of HCN with modeling predictions. The upper figure shows results for HCN oxidation in the absence of combustibles [137], while the lower figure shows the impact of adding $\mathrm{CO}$ as a reactant [136]. The agreement between 


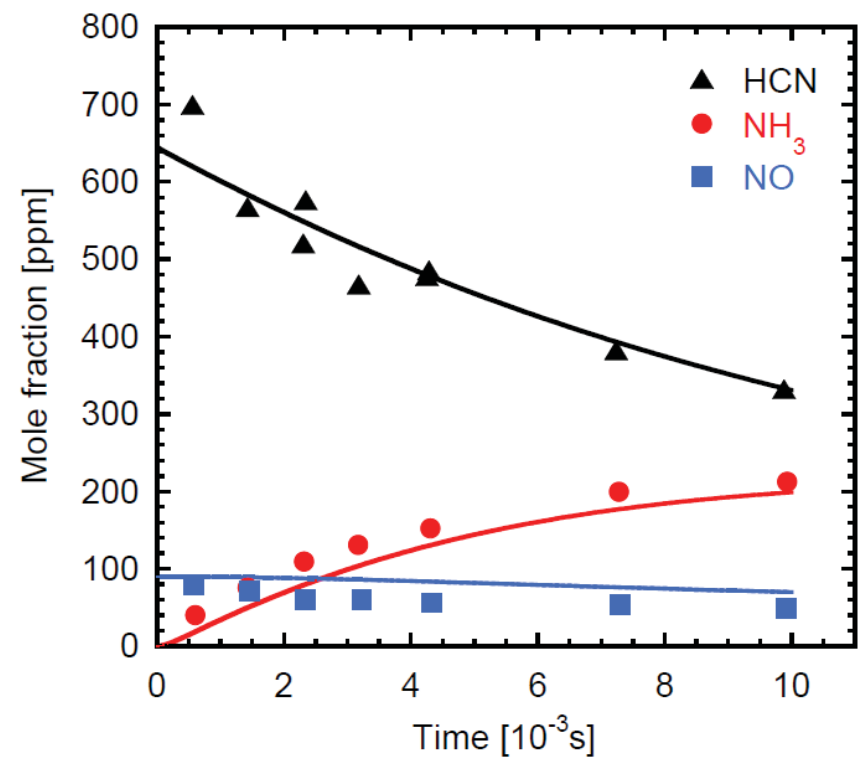

Figure 17: Comparison between experimental data [157] and modeling predictions for $\mathrm{HCN}$ oxidation in the post-flame region of an atmospheric pressure, premixed, fuel-rich ethylene-air flame doped with $680 \mathrm{ppm}$ ammonia. Symbols denote experimental data while lines denote modeling predictions. Fuel-air equivalence ratio $\phi=1.66$; temperature $2000 \mathrm{~K}$.

model and experiment is good. In the absence of $\mathrm{CO}$, the conversion of HCN to $\mathrm{HNCO}$ is underpredicted at lower temperatures, while predicted concentrations of $\mathrm{NO}$ and $\mathrm{N}_{2} \mathrm{O}$ at higher temperatures are slightly too high.

Figure 19 shows a reaction path path diagram for HCN oxidation under the conditions of Fig. 18. In the absence of $\mathrm{CO}$, predictions are sensitive to the generation of radicals. Due to the abundance of $\mathrm{O}_{2}$ and $\mathrm{H}_{2} \mathrm{O}$ in the flow reactor experiments, representative of the burnout region in combustion systems, $\mathrm{H}$ and $\mathrm{O}$ atoms are efficiently converted to $\mathrm{OH}$, which becomes the dominant chain carrier. This occurs through the chain branching sequence $\mathrm{H}+\mathrm{O}_{2} \rightarrow \mathrm{O}$ $+\mathrm{OH}, \mathrm{O}+\mathrm{H}_{2} \mathrm{O} \rightarrow \mathrm{OH}+\mathrm{OH}$. Consequently, removal of $\mathrm{HCN}$ is controlled primarily by reaction with $\mathrm{OH}(\mathrm{R} 30)$, followed by a fast reaction of $\mathrm{CN}$ with $\mathrm{O}_{2}$ to form $\mathrm{NCO}+\mathrm{O}(\mathrm{R} 37)$. The subsequent reactions of NCO largely determine 
the fate of the $\mathrm{N}$ atom in the $\mathrm{HCN}$ oxidation process. Under the conditions of Fig. 18(upper), NCO reacts primarily with $\mathrm{H}_{2} \mathrm{O}$ (R48b) at lower temperatures, thereby converting $\mathrm{HCN}$ to HNCO. Due to low radical concentrations, consumption of $\mathrm{HNCO}$ is very slow below $1150 \mathrm{~K}$. As the temperature increases, the $\mathrm{NCO}+\mathrm{H}_{2} \mathrm{O} \rightarrow \mathrm{HNCO}+\mathrm{OH}$ reaction is reversed at longer reaction times. In this way, reaction $\mathrm{R} 48$ becomes the main consumption channel for $\mathrm{HNCO}$ as well as the main source.

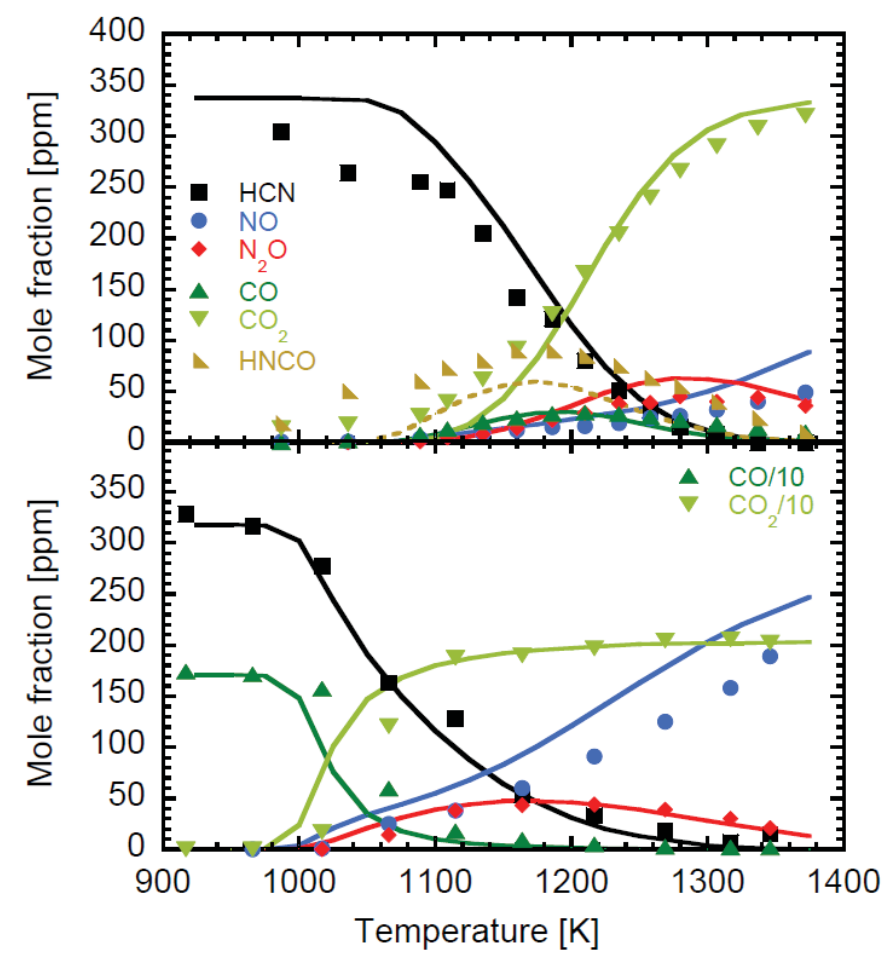

Figure 18: Comparison of experimental data $[136,137]$ and modeling predictions for HCN oxidation in quartz a flow reactor, without (upper figure) and with (lower figure) $\mathrm{CO}$ in the inlet. Experimental data are shown as symbols, modeling predictions as lines. Inlet mole fractions: upper figure $\mathrm{HCN}=337 \mathrm{ppm}, \mathrm{O}_{2}=2.6 \%, \mathrm{H}_{2} \mathrm{O}=3.1 \%$; lower figure $\mathrm{HCN}=318$ ppm, $\mathrm{CO}=1710 \mathrm{ppm}, \mathrm{O}_{2}=2.4 \%, \mathrm{H}_{2} \mathrm{O}=2.8 \%$; balance $\mathrm{N}_{2} . \mathrm{P}=1.05 \mathrm{~atm}$. Reaction times are 0.149 (upper) and $0.071 \mathrm{sec}$ at $900 \mathrm{~K}$ (constant mass flow). Surface/volume ratios were $4.4 \mathrm{~cm}^{-1}$ (upper) and $8.0 \mathrm{~cm}^{-1}$ (lower).

In the presence of combustibles, here CO (Fig. 18 lower), the generation of chain carriers becomes less sensitive to reactions in the HCN subset. The sequence CO $+\mathrm{OH} \rightarrow \mathrm{CO}_{2}+\mathrm{H}, \mathrm{H}+\mathrm{O}_{2} \rightarrow \mathrm{O}+\mathrm{OH}$ acts as a source of radicals and shifts 
the HCN oxidation chemistry towards lower temperatures. It also suppresses the formation of $\mathrm{HNCO}$. Since $\mathrm{OH}$ reacts rapidly with $\mathrm{CO}$, atomic oxygen now assumes a more important role in the HCN oxidation. Reaction of HCN with $\mathrm{O}(\mathrm{R} 27, \mathrm{R} 28)$ becomes competitive with $\mathrm{HCN}+\mathrm{OH}$ (R30) in removing $\mathrm{HCN}$, and a minor oxidation route now proceeds through the amine pool via reaction R28. The increased O-atom concentration also shifts the balance between the $\mathrm{NCO}+\mathrm{O}$ and $\mathrm{NCO}+\mathrm{NO}$ reactions and causes a comparatively larger fraction of $\mathrm{HCN}$ to be oxidized to NO at higher temperatures.

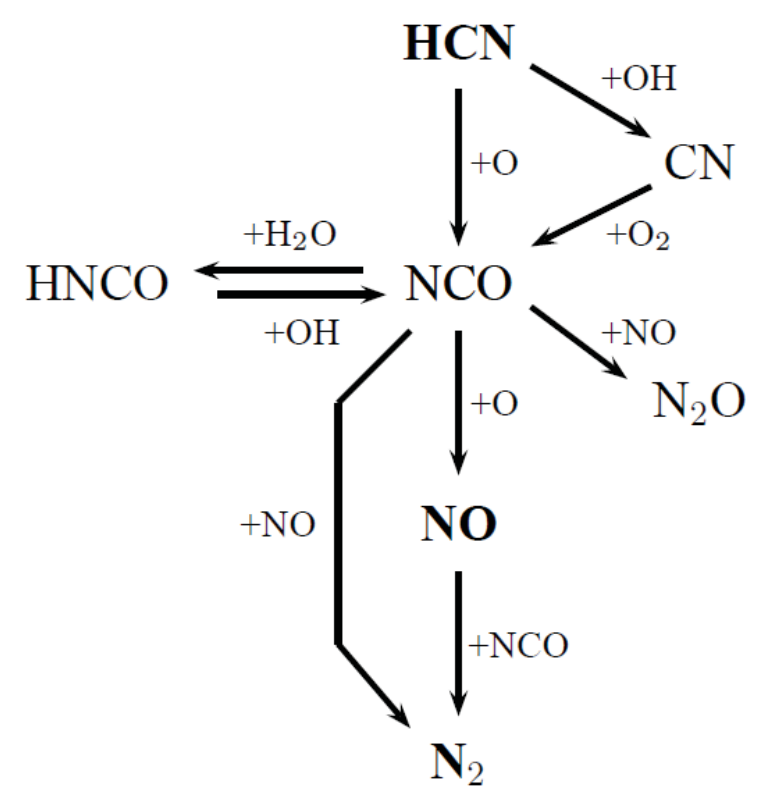

Figure 19: Reaction path diagram for oxidation of HCN under lean conditions.

For most practical purposes, the HCN oxidation chemistry is sufficiently well established. Hydrogen cyanide is very seldom a stand-alone combustible and the radical pool will typically be controlled by the oxidation of the main fuel or fuel intermediates, not by the HCN chemistry. The selectivity in HCN oxidation for forming $\mathrm{NO}, \mathrm{HNCO}, \mathrm{NH}_{3}, \mathrm{~N}_{2} \mathrm{O}$, or $\mathrm{N}_{2}$ is predicted fairly accurately by the present model. 


\subsection{Oxidation of $\mathrm{HNCO}$}

Isocyanic acid (HNCO) is an important intermediate in fuel nitrogen oxidation $[1,3,20,137-139]$. It is also important in selective non-catalytic reduction of NO with cyanuric acid and urea, as it is a primary decomposition product of both these agents $[152,158]$. Previous modeling studies of HNCO oxidation [159] and reduction of NO by HNCO $[1,152,159,160]$ have provided an understanding of the $\mathrm{HNCO}$ chemistry, but efforts to develop a reliable prediction tool have to some extent been hampered by the limited availability of suitable experimental data.

\subsubsection{Reaction subset for HNCO oxidation}

Table 8 lists selected reactions from the HNCO subset of the chemical kinetic model. The subset is mostly based on previous modeling studies by the authors $[1,20,21,152,159]$, as well as on the evaluation by Baulch et al. [26]. Rate constants for several of the HNCO consumption reactions are fairly well established due to the low temperature work of Perry and coworkers $[161,162]$, the mediumto-high temperature work of Lin's group [163-166], the high temperature work of Hanson and coworkers [167-170], and theoretical work, e.g., [171, 172].

The main consumption step for $\mathrm{HNCO}$ is the reaction with $\mathrm{OH}$ [159],

$$
\mathrm{HNCO}+\mathrm{OH} \rightleftarrows \mathrm{NCO}+\mathrm{H}_{2} \mathrm{O}
$$

The rate constant for this reaction has been measured both at low [162] and high [170] temperatures and the results are in good agreement. Both experimental studies show that $\mathrm{NCO}+\mathrm{H}_{2} \mathrm{O}$ is the major product channel. The importance of a secondary product channel to $\mathrm{NH}_{2}+\mathrm{CO}_{2}$ has been in discussion, but the theoretical study of Sengupta and Nguyen [172] indicates that this channel is negligible. 
A $\quad \beta \quad \mathrm{E}_{a} \quad$ Source

$\begin{array}{lllrll}\text { 44. } & \mathrm{HNCO}+\mathrm{H} \rightleftarrows \mathrm{NH}_{2}+\mathrm{CO} & 3.6 \mathrm{E} 04 & 2.490 & 2345 & {[26]} \\ \text { 45. } & \mathrm{HNCO}+\mathrm{H} \rightleftarrows \mathrm{NCO}+\mathrm{H}_{2} & 9.0 \mathrm{E} 07 & 1.660 & 13900 & {[26]} \\ \text { 46. } & \mathrm{HNCO}+\mathrm{O} \rightleftarrows \mathrm{NH}+\mathrm{CO}_{2} & 9.6 \mathrm{E} 07 & 1.410 & 8520 & {[26]} \\ \text { 47. } & \mathrm{HNCO}+\mathrm{O} \rightleftarrows \mathrm{NCO}+\mathrm{OH} & 2.2 \mathrm{E} 06 & 2.110 & 11430 & {[26]} \\ \text { 48. } & \mathrm{HNCO}+\mathrm{OH} \rightleftarrows \mathrm{NCO}+\mathrm{H}_{2} \mathrm{O} & 3.5 \mathrm{E} 07 & 1.500 & 3600 & {[170]} \\ \text { 49. } & \mathrm{HNCO}+\mathrm{O}_{2} \rightleftarrows \mathrm{HNO}+\mathrm{CO}_{2} & 2.0 \mathrm{E} 13 & 0.000 & 58900 & \text { See text } \\ \text { 50. } & \mathrm{HNCO}+\mathrm{H}_{2} \mathrm{O} \rightleftarrows \mathrm{NH}_{3}+\mathrm{CO}_{2} & 2.0 \mathrm{E} 13 & 0.000 & 48500 & {[173,174], \text { est }} \\ \text { 51. } & \mathrm{HNCO}+\mathrm{HNCO} \rightleftarrows \mathrm{HNCNH}^{\mathrm{HNCO}} \mathrm{CO}_{2} & 6.9 \mathrm{E} 11 & 0.000 & 42100 & {[164]}\end{array}$

Table 8: Selected reactions in the HNCO oxidation subset. Parameters for use in the modified Arrhenius expression $\mathrm{k}=\mathrm{AT}^{\beta} \exp (-\mathrm{E} /[\mathrm{RT}])$. Units are mol, $\mathrm{cm}, \mathrm{s}$, cal.

The reaction between $\mathrm{HNCO}$ and $\mathrm{O}_{2}$,

$$
\mathrm{HNCO}+\mathrm{O}_{2} \rightleftarrows \mathrm{HNO}+\mathrm{CO}_{2}
$$

was proposed by Glarborg et al. [159] to explain the oxidation behavior of HNCO in the absence of other combustibles. They assumed an activation energy for reaction $\mathrm{R} 49$ of $35 \mathrm{kcal} \mathrm{mol}^{-1}$. In the present work we estimate the barrier for the addition of triplet $\mathrm{O}_{2}$ to $\mathrm{HNCO}$ to be about $58.9 \mathrm{kcal} \mathrm{mol}^{-1}$. The overall barrier for reaction R49 might be even higher. Such a high barrier to reaction means that the $\mathrm{HNCO}+\mathrm{O}_{2}$ reaction is insignificant under the conditions of interest here.

Alternative reactions of $\mathrm{HNCO}$ include the self-reaction and the reaction with $\mathrm{H}_{2} \mathrm{O}$. Both of these reactions possibly yield $\mathrm{CO}_{2}$,

$$
\begin{gathered}
\mathrm{HNCO}+\mathrm{HNCO} \rightleftarrows \mathrm{HNCNH}+\mathrm{CO}_{2} \\
\mathrm{HNCO}+\mathrm{H}_{2} \mathrm{O} \rightleftarrows \mathrm{NH}_{3}+\mathrm{CO}_{2}
\end{gathered}
$$

Reaction R51 has been studied both experimentally [164] and theoretically [164, 175] and data are in good agreement. The reaction is too slow to contribute 
to $\mathrm{HNCO}$ consumption under most conditions of interest. The rate constant for formation of the HNCO dimer is predicted to be 1-2 orders of magnitude faster [175], but the dimer is not expected to be stable at elevated temperatures.

Hydrogenation of HNCO has been reported to occur readily in liquid phase [176], but there are no measurements of the gas-phase step. The reaction has been studied theoretically both in gas phase $[173,174,177]$ and aqueous phase [178]. Wei et al. [173] and Cheng et al. [174] calculated barriers for R50 of 48.4 and 48.7 kcal $\mathrm{mol}^{-1}$, respectively; significantly higher than the value of $35.3 \mathrm{kcal} \mathrm{mol}^{-1}$ predicted for the direct bimolecular reaction in aqueous phase [178]. Following Wei et al. [173] and Cheng et al. [174], we have included the reaction with an activation energy of $48.5 \mathrm{kcal} \mathrm{mol}^{-1}$.

\subsubsection{Modeling HNCO oxidation}

The only experimental study of HNCO oxidation is the flow reactor work of Glarborg et al. [159]. However, results for the reduction of NO by HNCO $\left(\right.$ RapReNO$\left._{\mathrm{x}}\right)$ are also of importance for understanding the HNCO chemistry; these are discussed in section 4.1.2. Glarborg et al. investigated HNCO oxidation in the absence and presence of $\mathrm{CO}$ in the temperature range 1025-1425 $\mathrm{K}$ at atmospheric pressure. Figure 20 compares experimental results and predictions with the present model. Unfortunately, the source of $\mathrm{HNCO}$ in the experiments - saturation of a nitrogen stream at $195 \mathrm{~K}$ - was not completely stable, but the scatter in the data is limited. In order to facilitate interpretation, the experimental results are presented on a normalized basis in the figure, using the calculated concentrations of inlet HNCO. The corresponding calculations are carried out for each set with a fixed inlet composition.

Figure 20 (upper) shows results on HNCO oxidation in the absence of combustibles. Consumption of HNCO proceeds very slowly at temperatures below $1250 \mathrm{~K}$. Above $1250 \mathrm{~K}$ the HNCO decay is faster, but even at $1400 \mathrm{~K}$ only of 


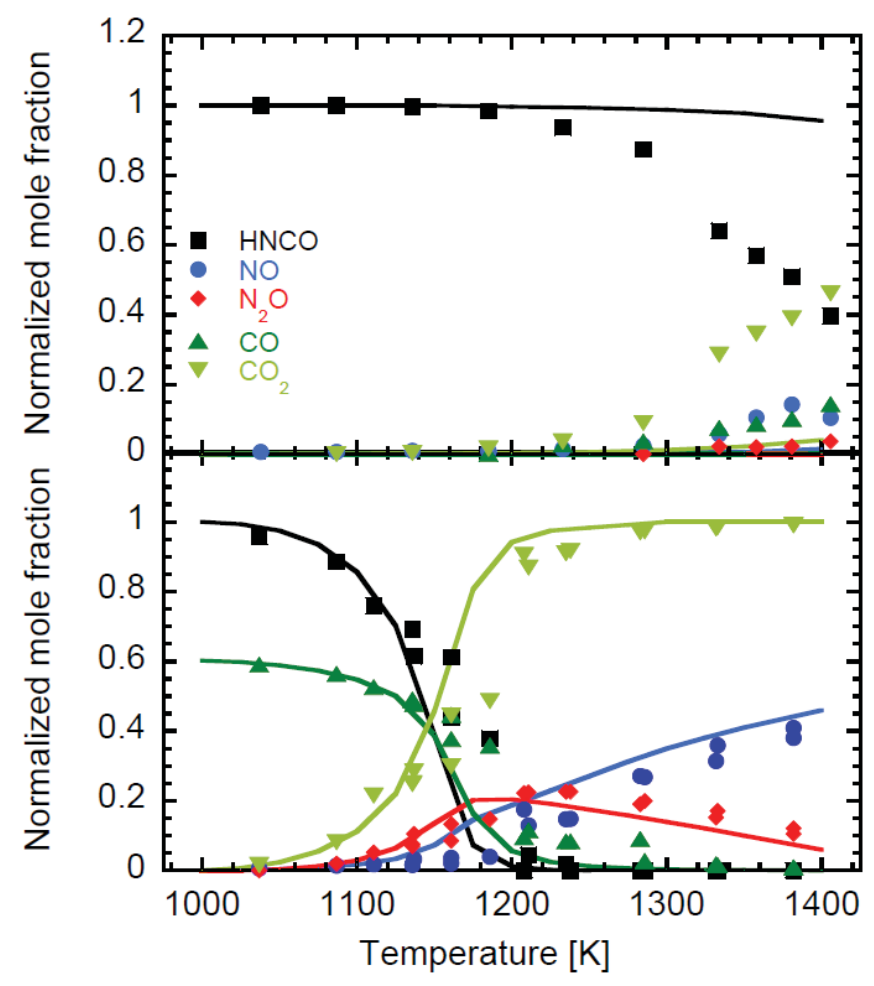

Figure 20: Comparison of experimental data [159] and modeling predictions for $\mathrm{HNCO}$ oxidation in a quartz flow reactor, without (upper figure) and with (lower figure) $\mathrm{CO}$ in the inlet. Experimental data are shown as symbols, modeling predictions as lines. The data have been normalized by the inlet HNCO concentration, calculated from a carbon balance $\left(\mathrm{HNCO}+\mathrm{CO}+\mathrm{CO}_{2}\right)$. Inlet mole fractions: upper figure $\mathrm{HNCO}=228-336 \mathrm{ppm}(320 \mathrm{ppm}$ in the calculations), $\mathrm{O}_{2}=5.6 \%, \mathrm{H}_{2} \mathrm{O}=0.5 \%$; lower figure $\mathrm{HNCO}=343-516 \mathrm{ppm}(480 \mathrm{ppm}$ in the calculations), $\mathrm{CO}=730 \mathrm{ppm}, \mathrm{O}_{2}=5.5 \%, \mathrm{H}_{2} \mathrm{O}=0.5 \%$; balance $\mathrm{N}_{2} \cdot \mathrm{P}$ $=1.05 \mathrm{~atm}$. Reaction time $=0.10 \mathrm{sec}$ at $1200 \mathrm{~K}$ (constant mass flow). The reactor surface/volume ratio was $4.4 \mathrm{~cm}^{-1}$.

the order of $50 \%$ of the inlet HNCO is consumed. Oxidation of HNCO leads to concentrations of $\mathrm{CO}_{2}$ that are consistently larger than those of $\mathrm{CO}$. Nitric oxide and $\mathrm{N}_{2} \mathrm{O}$ constitute a comparatively small fraction of the products.

The model severely underpredicts the consumption rate of $\mathrm{HNCO}$. The low predicted oxidation rate for $\mathrm{HNCO}$ even at high temperature is due to the fact that the major oxidation route for HNCO under these conditions is chain terminat- 
ing. The $\mathrm{OH}$ radical is the main chain carrier, and $\mathrm{HNCO}$ is mainly consumed by the $\mathrm{HNCO}+\mathrm{OH}$ reaction (R48), forming $\mathrm{NCO}$ and $\mathrm{H}_{2} \mathrm{O}$. The $\mathrm{NCO}$ radical is consumed by reaction with $\mathrm{O}(\mathrm{R} 40)$ and, at higher temperatures, possibly also $\mathrm{O}_{2}$ (R41). These reactions are chain terminating and inhibit the oxidation process. Isocyanide oxidation is negligible even at $1400 \mathrm{~K}$, if it proceeds exclusively through this sequence. The observed consumption of HNCO, and the formation of $\mathrm{CO}_{2}$ rather than $\mathrm{CO}$, support the importance of a reaction between $\mathrm{HNCO}$ and another stable species, i.e., $\mathrm{O}_{2}$ (R49), $\mathrm{H}_{2} \mathrm{O}$ (R50), or HNCO (R51). However, all of these steps appear to be too slow to account for the observed reaction. Formation of isomers of HNCO could potentially enhance oxidation, similarly to what is observed for HCN (see section 3.4). The isomerization pathways for HNCO have been studied theoretically by several groups [108, 179,180] who find the pathway to HOCN to be energetically the most favorable. However, the overall barrier height is of the order of $90 \mathrm{kcal} \mathrm{mol}^{-1}$, which is too high for the process to be significant at the present temperatures. Even though quartz surfaces are believed to be inert towards HNCO [158, 160, 181], it cannot be excluded that oxidation is promoted by heterogenous reactions on the surface.

Figure 20 (lower) shows results for HNCO oxidation in the presence of CO. The impact of $\mathrm{CO}$ on $\mathrm{HNCO}$ oxidation is similar to the effect it has on HCN oxidation, discussed in section 3.4. The presence of $\mathrm{CO}$ enhances the consumption rate of HNCO significantly and isocyanic acid is completely oxidized already at $1200 \mathrm{~K}$, forming considerable amounts of $\mathrm{NO}$ and $\mathrm{N}_{2} \mathrm{O}$, in addition to $\mathrm{N}_{2}$. The model describes the observations well. The predicted onset of reaction is slightly premature, but the product concentrations are in good agreement with experiment.

The $\mathrm{CO}$ oxidation chemistry acts to replenish the radical pool and shifts the chemistry towards lower temperatures. Similar to what was seen for HCN oxidation, this happens through the chain branching sequence $\mathrm{CO}+\mathrm{OH} \rightleftarrows \mathrm{CO}_{2}$ 
$+\mathrm{H}, \mathrm{H}+\mathrm{O}_{2} \rightleftarrows \mathrm{O}+\mathrm{OH}, \mathrm{O}+\mathrm{H}_{2} \mathrm{O} \rightleftarrows \mathrm{OH}+\mathrm{OH}$. Oxidation of $\mathrm{CO}$ is slightly inhibited by the presence of $\mathrm{HNCO}$ due to the chain terminating $\mathrm{NCO}$ reactions and the competition for $\mathrm{OH}-$ radicals between $\mathrm{CO}$ and $\mathrm{HNCO}$. For this reason, $\mathrm{CO}$ enters the rapid oxidation regime only after most of the HNCO is depleted.

Figure 21 shows a pathway diagram for oxidation of $\mathrm{HNCO}$ in the presence of $\mathrm{CO}$. Isocyanuric acid is consumed primarily by reaction with $\mathrm{OH}$ (R49), forming NCO. The NCO radical subsequently reacts either with $\mathrm{O}$ to form NO (R40) or with $\mathrm{NO}$ to form $\mathrm{N}_{2} \mathrm{O}$ (R42) and $\mathrm{N}_{2}$ (R43). At temperatures above $1250 \mathrm{~K}$ formation of $\mathrm{N}_{2} \mathrm{O}$ diminishes while consumption reactions, in particular thermal dissociation, become competitive, causing a decrease in $\mathrm{N}_{2} \mathrm{O}$.

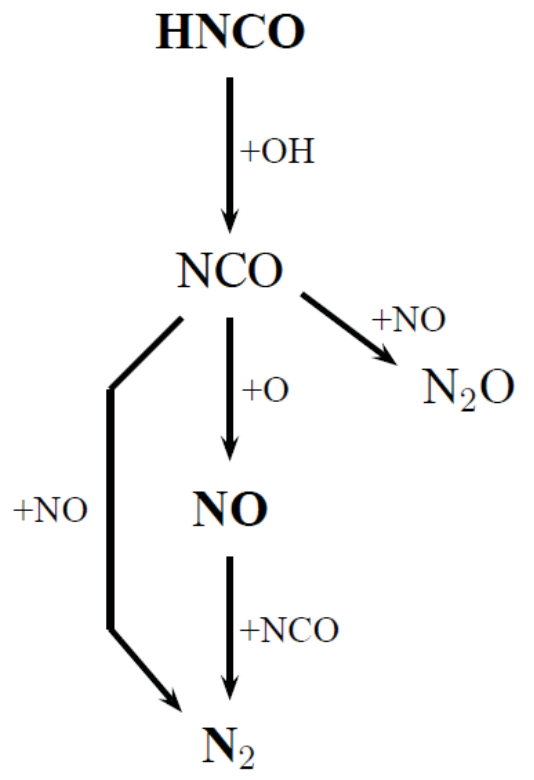

Figure 21: Reaction path diagram for oxidation of HNCO under lean conditions.

Similar to HCN, the reliability of the HNCO oxidation subset of the model is sufficient for most practical purposes. In combustion systems, HNCO is only a minor reactive nitrogen species, formed either in devolatilization of solid fuels or from partial oxidation of cyanides. The uncertainty in the HNCO oxidation chemistry is mainly related to the slow oxidation occurring in the absence of 
other combustibles. However, as discussed in more detail in section 4.1.2, selective non-catalytic reduction of NO by cyanuric acid or urea is sensitive to the $\mathrm{HNCO}$ subset, and here the uncertainties in this chemistry limit the predictive capability of the model. 


\subsection{Oxidation of $\mathrm{NH}_{3}$}

Ammonia is the key volatile-N species in combustion. It is formed in devolatilization of solid fuels [3] or from conversion of cyanides at higher temperatures $[1,3,131,157]$. At the rich-lean transition in staged combustion processes, $\mathrm{NH}_{3}$ rather than $\mathrm{HCN}$ governs the nitrogen chemistry and controls the selectivity for forming $\mathrm{NO}$ and $\mathrm{N}_{2}$ [182].

A number of modeling studies and reviews on ammonia oxidation chemistry have been reported, e.g. $[1,19,48,146,183-185]$. In addition, the chemistry of selective non-catalytic reduction of NO by reaction with ammonia has been studied extensively (see section 4.1.1). However, the development of reliable models for ammonia oxidation in combustion and flue gas cleaning has been hampered partly by issues concerning key reactions, in particular the branching fraction of the $\mathrm{NH}_{2}+\mathrm{NO}$ reaction and the lifetime of $\mathrm{NNH}[1,19]$, and partly by the strong sensitivity of ammonia to surfaces, potentially limiting the accuracy of reactor experiments (see App. A).

\subsubsection{Reaction subset for $\mathrm{NH}_{3}$ oxidation}

Table 9 lists selected reactions in the amine subset of the chemical kinetic model. This subset was based mostly on the recent work by Klippenstein et al. [19], which again drew on previous modeling studies [22, 48, 186-189]. For many of the key reactions in the ammonia subset, rate constants have been calculated by Klippenstein and coworkers using high-level theory. These include $\mathrm{NH}_{2}+$ $\mathrm{NO}[190,191]$ and $\mathrm{NH}_{2}+\mathrm{NO}_{2}$ [192], reactions on the ONNH potential energy surface $\left(\mathrm{NH}+\mathrm{NO}, \mathrm{NNH}+\mathrm{O}, \mathrm{N}_{2} \mathrm{O}+\mathrm{H}\right)$ [19], reactions of $\mathrm{NH}_{2}$ and $\mathrm{NNH}$ with $\mathrm{O}_{2}[19]$, and $\mathrm{NH}_{2}+\mathrm{OH}[193]$.

In the absence of hydrocarbons, ammonia is largely consumed by H-abstraction reactions with the $\mathrm{O} / \mathrm{H}$ radical pool (R53-R55); these steps are all characterized 


\begin{tabular}{|c|c|c|c|c|c|}
\hline & & $\mathrm{A}$ & $\beta$ & $\mathrm{E}$ & Source \\
\hline \multirow[t]{3}{*}{52.} & $\mathrm{NH}_{2}+\mathrm{H}(+\mathrm{M}) \rightleftarrows \mathrm{NH}_{3}(+\mathrm{M})$ & $1.6 \mathrm{E} 14$ & 0.000 & 0 & {$[194]$} \\
\hline & Low pressure limit: & $3.6 \mathrm{E} 22$ & -1.760 & 0 & \\
\hline & Troe parameters: 0.5 1.0E-30 & $1.0 \mathrm{E} 30$ & & & \\
\hline 53. & $\mathrm{NH}_{3}+\mathrm{H} \rightleftarrows \mathrm{NH}_{2}+\mathrm{H}_{2}$ & $6.4 \mathrm{E} 05$ & 2.390 & 10171 & {$[195]$} \\
\hline 54. & $\mathrm{NH}_{3}+\mathrm{O} \rightleftarrows \mathrm{NH}_{2}+\mathrm{OH}$ & $9.4 \mathrm{E} 06$ & 1.940 & 6460 & {$[196]$} \\
\hline 55 . & $\mathrm{NH}_{3}+\mathrm{OH} \rightleftarrows \mathrm{NH}_{2}+\mathrm{H}_{2} \mathrm{O}$ & $2.0 \mathrm{E} 06$ & 2.040 & 566 & {$[197]$} \\
\hline 56. & $\mathrm{NH}_{2}+\mathrm{HO}_{2} \rightleftarrows \mathrm{NH}_{3}+\mathrm{O}_{2}$ & 1.7E04 & 1.550 & 2027 & [198] \\
\hline 57. & $\mathrm{NH}+\mathrm{H}_{2} \rightleftarrows \mathrm{NH}_{2}+\mathrm{H}$ & $2.1 \mathrm{E} 13$ & 0.000 & 15417 & [199] \\
\hline 58. & $\mathrm{NH}_{2}+\mathrm{O} \rightleftarrows \mathrm{HNO}+\mathrm{H}$ & $6.6 \mathrm{E} 14$ & -0.500 & 0 & See text \\
\hline 59. & $\mathrm{NH}_{2}+\mathrm{O} \rightleftarrows \mathrm{NH}+\mathrm{OH}$ & 7.0E12 & 0.000 & 0 & See text \\
\hline 60. & $\mathrm{NH}_{2}+\mathrm{OH} \rightleftarrows \mathrm{NH}+\mathrm{H}_{2} \mathrm{O}$ & $3.3 \mathrm{E} 06$ & 1.949 & -217 & {$[19,193]$} \\
\hline 61. & $\mathrm{NH}_{2}+\mathrm{HO}_{2} \rightleftarrows \mathrm{H}_{2} \mathrm{NO}+\mathrm{OH}$ & $2.5 \mathrm{E} 17$ & -1.280 & 1166 & [198] \\
\hline 62. & $\mathrm{NH}_{2}+\mathrm{O}_{2} \rightleftarrows \mathrm{H}_{2} \mathrm{NO}+\mathrm{O}$ & $2.6 \mathrm{E} 11$ & 0.487 & 29050 & {$[19]$} \\
\hline 63. & $\mathrm{NH}_{2}+\mathrm{O}_{2} \rightleftarrows \mathrm{HNO}+\mathrm{OH}$ & $2.9 \mathrm{E}-2$ & 3.764 & 18185 & {$[19]$} \\
\hline 64. & $\mathrm{NH}_{2}+\mathrm{HNO} \rightleftarrows \mathrm{NH}_{3}+\mathrm{NO}$ & $5.9 \mathrm{E} 02$ & 2.950 & -3469 & {$[200]$} \\
\hline 65. & $\mathrm{NH}_{2}+\mathrm{NO} \rightleftarrows \mathrm{NNH}+\mathrm{OH}$ & 4.3E10 & 0.294 & -866 & {$[201]$} \\
\hline 66. & $\mathrm{NH}_{2}+\mathrm{NO} \rightleftarrows \mathrm{N}_{2}+\mathrm{H}_{2} \mathrm{O}$ & $2.6 \mathrm{E} 19$ & -2.369 & 870 & {$[201]$} \\
\hline 67. & $\mathrm{NH}_{2}+\mathrm{NO}_{2} \rightleftarrows \mathrm{N}_{2} \mathrm{O}+\mathrm{H}_{2} \mathrm{O}$ & $2.2 \mathrm{E} 11$ & 0.110 & -1186 & See text \\
\hline 68. & $\mathrm{NH}_{2}+\mathrm{NO}_{2} \rightleftarrows \mathrm{H}_{2} \mathrm{NO}+\mathrm{NO}$ & $8.6 \mathrm{E} 11$ & 0.110 & -1186 & See text \\
\hline 69. & $\mathrm{NH}+\mathrm{O}_{2} \rightleftarrows \mathrm{HNO}+\mathrm{O}$ & $4.6 \mathrm{E} 05$ & 2.000 & 6500 & {$[202]$} \\
\hline 70. & $\mathrm{NH}+\mathrm{O}_{2} \rightleftarrows \mathrm{NO}+\mathrm{OH}$ & $1.3 \mathrm{E} 06$ & 1.500 & 100 & {$[202]$} \\
\hline 71. & $\mathrm{NH}+\mathrm{NO} \rightleftarrows \mathrm{N}_{2}+\mathrm{OH}$ & $6.8 \mathrm{E} 14$ & -0.780 & 20 & See text \\
\hline 72 . & $\mathrm{H}_{2} \mathrm{NO}+\mathrm{O}_{2} \rightleftarrows \mathrm{HNO}+\mathrm{HO}_{2}$ & $2.3 \mathrm{E} 02$ & 2.994 & 16500 & See text \\
\hline 73. & $\mathrm{HNO}+\mathrm{O}_{2} \rightleftarrows \mathrm{NO}+\mathrm{HO}_{2}$ & $2.0 \mathrm{E} 13$ & 0.000 & 16000 & {$[146]$} \\
\hline
\end{tabular}

Table 9: Selected reactions in the $\mathrm{NH}_{3}$ oxidation subset. Additional reactions are listed in Table 6. Parameters for use in the modified Arrhenius expression $\mathrm{k}=\mathrm{AT}^{\beta} \exp (-\mathrm{E} /[\mathrm{RT}])$. Units are mol, cm, s, cal.

experimentally over a wide temperature range. The subsequent reactions of the $\mathrm{NH}_{2}$ radical have a large impact on the consumption rate for $\mathrm{NH}_{3}$ and on the selectivity for forming $\mathrm{NO}$ and $\mathrm{N}_{2}$. Owing to the low reactivity of $\mathrm{NH}_{2}$ towards $\mathrm{O}_{2}$, the key step in the presence of even small amounts of $\mathrm{NO}$ is the fast $\mathrm{NH}_{2}$ + NO reaction. Due to the importance of this reaction in the SNCR process (section 4.1.1), it has been studied extensively in the past [203]. An Arrhenius plot for the overall reaction between $\mathrm{NH}_{2}$ and $\mathrm{NO}$ is shown in Fig. 22. The reaction has been measured over a wide temperature range, and data agree 
roughly within a factor of two. The experimentally based value of Song et al. [204] and the theoretical rate constant from Klippenstein [191], which both provide an accurate representation of available measurements, are slightly lower than the value of Miller and Glarborg [188] used in our recent modeling work [19].

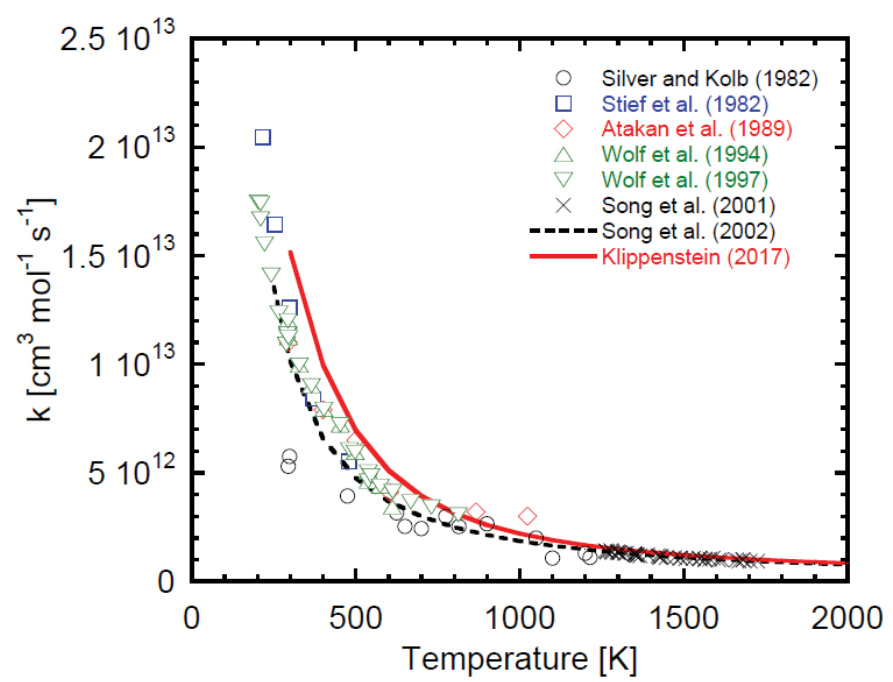

Figure 22: Arrhenius plot for the reaction $\mathrm{NH}_{2}+\mathrm{NO} \rightarrow$ products. The symbols denote measurements of the rate constant while lines denote theoretical values. The data are drawn from Silver and Kolb [205], Stief et al. [206], Atakan et al. [207], Wolf et al. [208, 209], Song et al. [201, 204], and Klippenstein [191].

The $\mathrm{NH}_{2}+$ NO reaction has two product channels,

$$
\begin{gathered}
\mathrm{NH}_{2}+\mathrm{NO} \rightleftarrows \mathrm{NNH}+\mathrm{OH} \\
\mathrm{NH}_{2}+\mathrm{NO} \rightleftarrows \mathrm{N}_{2}+\mathrm{H}_{2} \mathrm{O}
\end{gathered}
$$

Reaction R65 is chain branching while R66 is terminating, and for this reason, modeling predictions are very sensitive to the branching fraction for the reaction, defined as $\alpha=\mathrm{k}_{65} /\left(\mathrm{k}_{65}+\mathrm{k}_{66}\right)$. Figure 23 compares experimental data for the branching fraction with the theoretical ratio from Miller and Klippenstein [190] and Klippenstein [191]. The recent experimental data [201, 204,210-213] and 
the theoretical values are in very good agreement.

In the present work, we have adopted the rate constants for reactions R65 and R66 from Song et al. [201]. Their branching ratio was chosen to match the theoretical value from Miller and Klippenstein [190]. In the temperature window for the Thermal DeNO ${ }_{x}$ process (around $1250 \mathrm{~K}$ ), this value is slightly lower than the value of the CASPT2 calculation from Klippenstein [191] (see Fig. 23). Due to the very high sensitivity to $\alpha$ in modeling predictions for Thermal $\mathrm{DeNO}_{\mathrm{x}}$, even a very small change has a significant impact (see section 4.1.1).

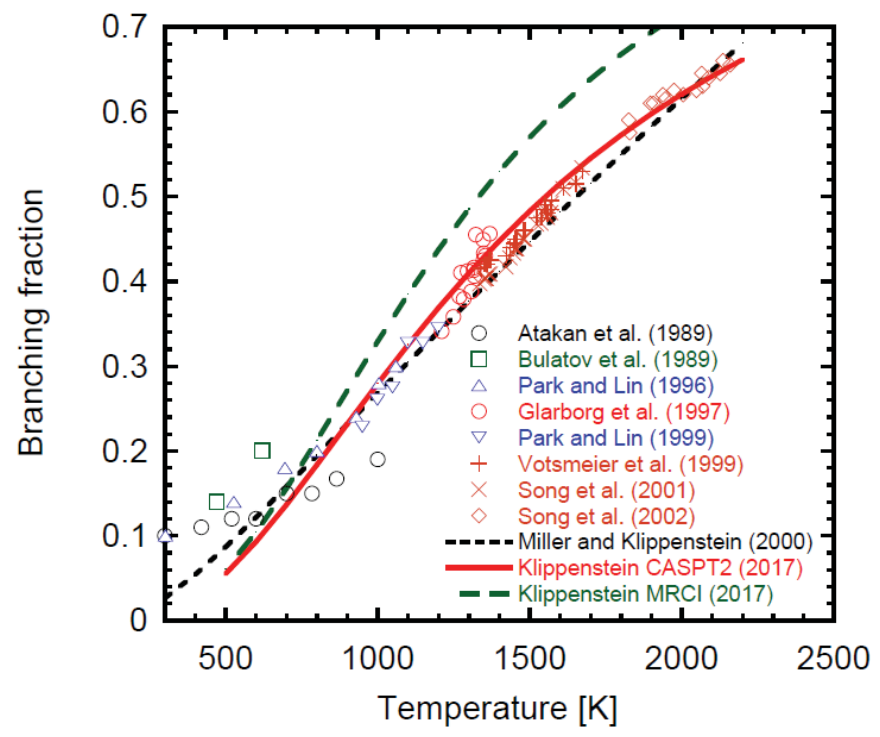

Figure 23: Arrhenius plot for the branching fraction of the reaction $\mathrm{NH}_{2}+\mathrm{NO}$ $\rightarrow$ products, defined as $\alpha=\mathrm{k}_{65} /\left(\mathrm{k}_{65}+\mathrm{k}_{66}\right)$. The symbols denote measurements of the rate constant while lines denote theoretical values. The data are drawn from Atakan et al. [207], Bulatov et al. [214], Park and Lin [210,211], Glarborg et al. [212], Votsmeier et al. [213], Song et al. [201,204], Miller and Klippenstein [190], and Klippenstein [191]. The Klippenstein branching fractions are based on the following rate constants: $\mathrm{k}_{65}=6.2 \cdot 10^{15} \mathrm{~T}^{-1.150} \exp (-1267 / \mathrm{T}) ; \mathrm{k}_{66}=$ $1.2 \cdot 10^{20} \mathrm{~T}^{-2.576} \exp (-365 / \mathrm{T})(\mathrm{CASPT} 2) ; \mathrm{k}_{65}=1.3 \cdot 10^{16} \mathrm{~T}^{-1.216} \exp (-1360 / \mathrm{T}) ;$ $\mathrm{k}_{66}=3.3 \cdot 10^{21} \mathrm{~T}^{-3.029} \exp (-588 / \mathrm{T})(\mathrm{MRCI}+\mathrm{Q})$.

At large excess air ratios, the $\mathrm{HO}_{2}$ radical may be formed in significant quan- 
tities, promoting oxidation of $\mathrm{NO}$ to $\mathrm{NO}_{2}$. This occurs via the reaction $\mathrm{NO}+$ $\mathrm{HO}_{2} \rightleftarrows \mathrm{NO}_{2}+\mathrm{OH}$, which is well characterized both in the forward [26, 215] and reverse [216] direction. The $\mathrm{NH}_{2}+\mathrm{NO}_{2}$ reaction has been studied over a wide range of temperature. Similar to $\mathrm{NH}_{2}+\mathrm{NO}$, it has two major product channels,

$$
\begin{gathered}
\mathrm{NH}_{2}+\mathrm{NO}_{2} \rightleftarrows \mathrm{N}_{2} \mathrm{O}+\mathrm{H}_{2} \mathrm{O} \\
\mathrm{NH}_{2}+\mathrm{NO}_{2} \rightleftarrows \mathrm{H}_{2} \mathrm{NO}+\mathrm{NO}
\end{gathered}
$$

Values for the overall rate constant have been reported over a wide range of conditions [192,217-226], but the scatter in the data is considerable. However, even though data at $500 \mathrm{~K}$ differ by more than an order of magnitude (Fig. 24), most recent determinations are in fairly good agreement. The rate constant calculated by Klippenstein et al. [192] provides a good description of most of the data below $1000 \mathrm{~K}$, but it is a factor of three below the high temperature (1300-1600 K) shock tube determination of Song et al. [226]. In the present work, we have adopted the overall rate constant from Glarborg et al. [223], which is compatible with the rate constants from both Song et al. and Klippenstein et al. within their uncertainties.

Also the branching fraction for the $\mathrm{NH}_{2}+\mathrm{NO}_{2}$ reaction, defined as $\mathrm{k}_{67} /\left(\mathrm{k}_{67}\right.$ $+\mathrm{k}_{68}$ ), has been in discussion but most studies support a value around $20 \%$ [223, 225-229], in agreement with the theoretical analysis of Klippenstein et al. [192].

Competing consumption steps of $\mathrm{NH}_{2}$ include reactions with the $\mathrm{O} / \mathrm{H}$ radical pool (R57-R61), with amine radicals leading to formation of $\mathrm{N}_{2}$-amines, and, at high excess oxygen levels, with $\mathrm{O}_{2}$ (R62, R63). The $\mathrm{NH}_{2}+\mathrm{H}$ reaction (R57b) has been measured both in the forward $[230,231]$ and reverse $[199,232]$ direction at elevated temperatures. The data for the $\mathrm{NH}+\mathrm{H}_{2}$ reaction [199,232] is in excellent agreement over an extended temperature range and consistent with the only low temperature measurement of $\mathrm{k}_{57 \mathrm{~b}}$ [233]. The $\mathrm{NH}_{2}+\mathrm{O}$ reaction ( $\mathrm{R} 58$, 


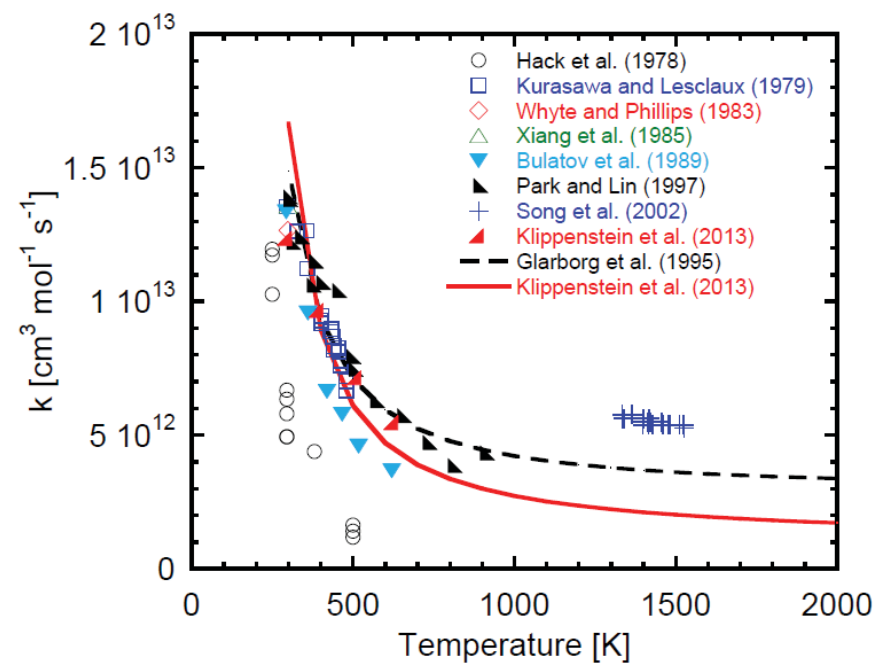

Figure 24: Arrhenius plot for the reaction $\mathrm{NH}_{2}+\mathrm{NO}_{2} \rightarrow$ products. The symbols denote measurements of the rate constant while lines denote theoretical values. The data are drawn from Hack et al. [217], Kurasawa and Lesclaux [218], Whyte and Phillips [219], Xiang et al. [220], Bulatov et al. [221], Park and Lin [225], Song et al. [226], Klippenstein et al. [192], and Glarborg et al. [223].

R59) has only been measured at low temperature where the overall rate constant has been shown to be fast [234-236] and HNO $+\mathrm{H}$ (R58) is the dominating product channel, with a minor contribution from $\mathrm{NH}+\mathrm{OH}(\mathrm{R} 59)[234,235]$. Based on unpublished data by Temps (cited by Miller et al. [183]), we have assumed a $\mathrm{T}^{-0.5}$ temperature dependence for reaction $\mathrm{R} 58$. Since the $\mathrm{NH}_{2}+$ $\mathrm{O}$ reaction is important for formation of $\mathrm{NO}$ from $\mathrm{NH}_{3}$ at high temperatures, a measurement of the rate of this step at elevated temperature is desirable. The $\mathrm{NH}_{2}+\mathrm{OH}$ reaction ( $\mathrm{R} 60$ ) was studied experimentally and theoretically by Klippenstein et al. [193].

The NH radical, formed by hydrogen atom abstraction from $\mathrm{NH}_{2}$, may react with $\mathrm{NO}$ to form $\mathrm{N}_{2} \mathrm{O}$ (R17) or $\mathrm{N}_{2}$ (R71), as discussed in section 3.3.1, or with $\mathrm{O}_{2}$ leading to formation of $\mathrm{NO}$,

$$
\mathrm{NH}+\mathrm{O}_{2} \rightleftarrows \mathrm{NO}+\mathrm{OH}
$$




$$
\mathrm{NH}+\mathrm{O}_{2} \rightleftarrows \mathrm{HNO}+\mathrm{O}
$$

The competition between the different consumption reactions of $\mathrm{NH}$ is important for the overall selectivity for forming $\mathrm{NO}$ or $\mathrm{N}_{2}$ in ammonia oxidation, in particular at higher temperatures.

Under conditions with high $\mathrm{O}_{2}$ concentrations [19] or high pressure [237], nitroxide $\left(\mathrm{H}_{2} \mathrm{NO}\right)$ may be formed in significant quantities from reaction of $\mathrm{NH}_{2}$ with $\mathrm{HO}_{2}$ or $\mathrm{NO}_{2}$. The $\mathrm{H}_{2} \mathrm{NO}$ subset of the reaction mechanism is not well established and consists largely of reactions with estimated rate constants. The most important reaction of $\mathrm{H}_{2} \mathrm{NO}$ is that with $\mathrm{O}_{2}$,

$$
\mathrm{H}_{2} \mathrm{NO}+\mathrm{O}_{2} \rightleftarrows \mathrm{HNO}+\mathrm{HO}_{2}
$$

There are no experimental data available for this reaction. Recently, it was studied theoretically by Song et al. [237] who calculated the rate constant from ab initio theory. To facilitate modeling predictions of $\mathrm{NH}_{3}$ oxidation and Thermal $\mathrm{DeNO}_{\mathrm{x}}$ at high oxygen concentrations, we have lowered the activation energy for reaction ( $\mathrm{R} 72$ ) by $2.5 \mathrm{kcal} \mathrm{mol}^{-1}$; this change is within the estimated uncertainty in the calculated barrier height.

Also for $\mathrm{HNO}$, reaction with $\mathrm{O}_{2}$ (R73) is an important consumption step. For this reaction we rely on a rate constant derived from QRRK theory [146]. Experimental determinations of the rate constants for both $\mathrm{HNO}+\mathrm{O}_{2}$ and $\mathrm{H}_{2} \mathrm{NO}$ $+\mathrm{O}_{2}$ are desirable.

\subsubsection{Modeling $\mathrm{NH}_{3}$ oxidation}

Oxidation of ammonia has been studied extensively in the past, both experimentally and through modeling. The experimental work include studies in flames [238-245], shock tubes [185,246-253] and flow reactors [136, 140, 237, 254, 255]. 
Due to the potential impact of surface reactions on the induction time in $\mathrm{NH}_{3}$ oxidation even for quartz (see [254] and App. A), flow and batch reactor experiments can be used only cautiously for model validation. For this reason, we supplement flow reactor data with results from experiments conducted in premixed flames and shock tubes for validation of the $\mathrm{NH}_{3}$ oxidation subset.

Following Miller and Bowman [1], we evaluate the model against the lowpressure flame data of Bian et al. [244]. They measured the structure of a flame burning in a near equimolar ammonia-oxygen mixture at reduced pressure (35 Torr), using using a molecular beam sampling technique coupled with a mass spectrometer. Figure 25 compares the measured species profiles with modeling predictions.

Overall, the agreement between the experimental results and the modeling predictions is good. The concentrations of both reactants $\left(\mathrm{NH}_{3}, \mathrm{O}_{2}\right)$ and products (NO, $\mathrm{N}_{2} \mathrm{O}, \mathrm{N}_{2}$, and $\mathrm{H}_{2} \mathrm{O}$ ) are predicted quite accurately, while calculations for the amine radicals $\mathrm{NH}_{2}$ and $\mathrm{NH}$ are within the experimental uncertainty. The only major discrepancies, not shown, occur for HNO and N, which are both severely overpredicted.

Figure 26 shows a reaction path diagram for oxidation of $\mathrm{NH}_{3}$. Ammonia is converted to $\mathrm{NH}_{2}$ by reaction with the radical pool. The $\mathrm{NH}_{2}$ radical may be converted to $\mathrm{NH}$ and $\mathrm{N}$ in the sequence $\mathrm{NH}_{2} \stackrel{+\mathrm{OH}_{3} \mathrm{H}}{\longrightarrow} \mathrm{NH} \stackrel{+\mathrm{OH}_{3} \mathrm{H}}{\longrightarrow} \mathrm{N}$; these reactions become more competitive with increasing temperature. Subsequently, the $\mathrm{NH}_{\mathrm{i}}$ radicals may react with $\mathrm{NO}$, leading to $\mathrm{N}_{2}$, or with $\mathrm{O}, \mathrm{OH}$, or $\mathrm{O}_{2}$, forming $\mathrm{NO}$. The selectivity for forming $\mathrm{NO}$ or $\mathrm{N}_{2}$ in oxidation of ammonia is determined by the competition of the amine radicals for reacting with $\mathrm{NO}$ or with the $\mathrm{O} / \mathrm{H}$ radical pool (or $\mathrm{O}_{2}$ ).

Mathieu and Petersen [185] measured the ignition delay for $\mathrm{NH}_{3}$ as a function of stoichiometry and pressure. In Fig. 27, their results for a pressure of 1.4 atm are compared with modeling predictions. The calculations are in good 


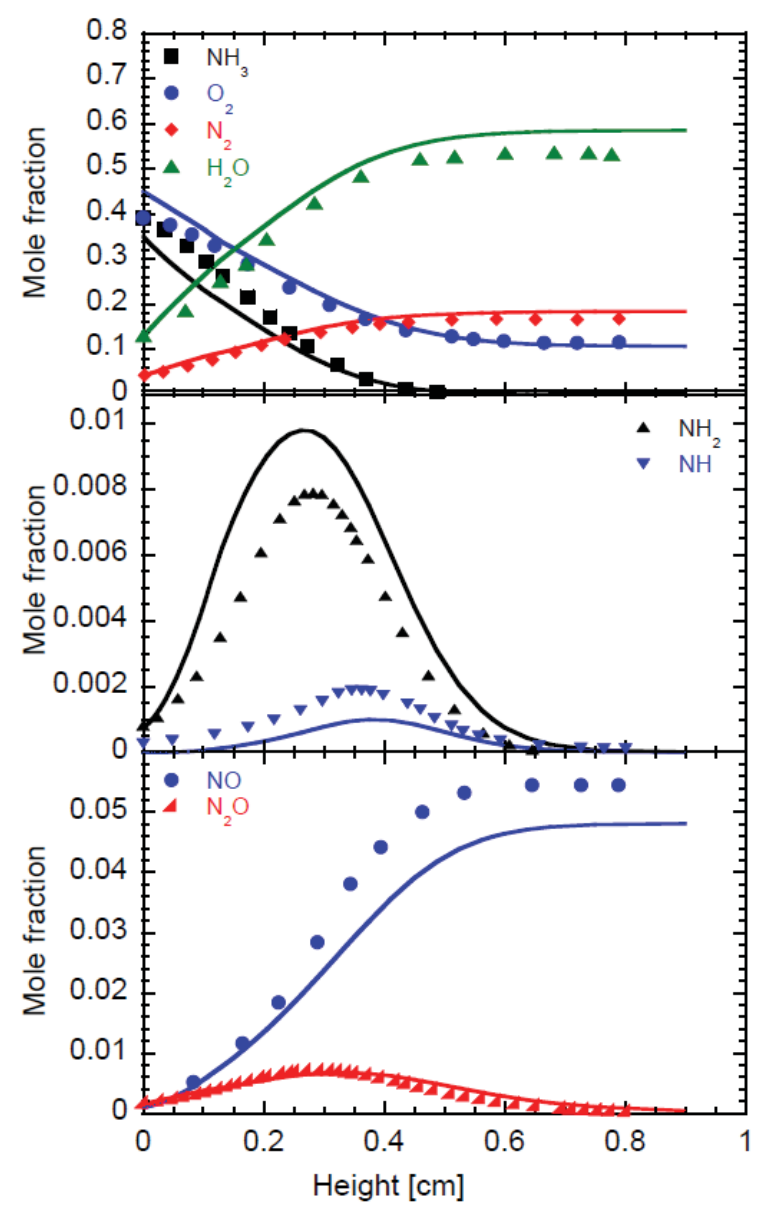

Figure 25: Comparison of measured [244] and predicted mole fractions of stable species and selected radicals in a low-pressure premixed ammonia/oxygen flame. The symbols denote experimental data, while the solid lines denote calculated values. Conditions: pressure of 35 torr; inlet composition $48 \% \mathrm{NH}_{3}, 51 \% \mathrm{O}_{2}$, and $1 \% \mathrm{Ar}$. The gas velocity was $60.8 \mathrm{~cm} \mathrm{~s}^{-1}$ and the peak flame temperature was about $2250 \mathrm{~K}$.

agreement with measurements at lean and rich conditions, but curiously show a larger deviation at stoichiometric conditions. As pointed out by Mathieu and Petersen, the predicted ignition delays for $\mathrm{NH}_{3}$ are sensitive to the $\mathrm{N}_{2} \mathrm{H}_{\mathrm{x}}$ subset of the mechanism. This subset is quite uncertain and more work on the $\mathrm{N}_{2}$-amine chemistry is desirable. 


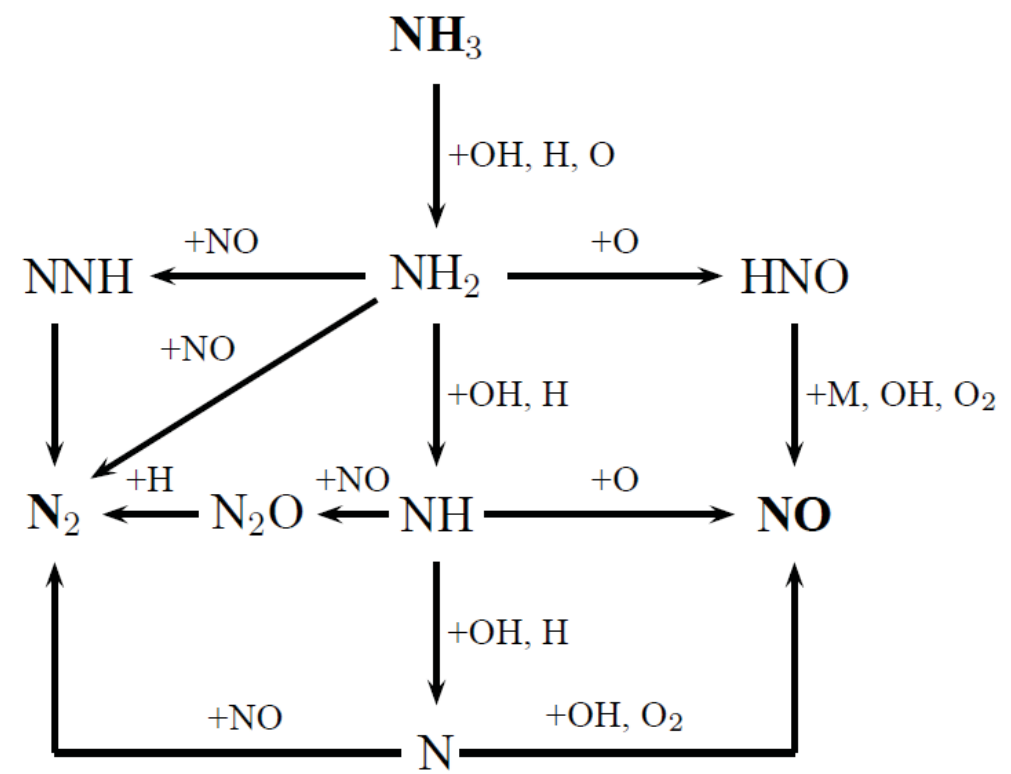

Figure 26: Reaction path diagram for oxidation of $\mathrm{NH}_{3}$.

In the presence of even small amounts of $\mathrm{NO}, \mathrm{NH}_{3}$ oxidation becomes insensitive to initiation reactions and the impact of the surface in flow reactor experiments is minimized $[1,159]$. Figure 28 shows results for $\mathrm{NH}_{3}$ oxidation in the presence of $\mathrm{NO}$ varying in the range 25-100 ppm, with the $\mathrm{NH}_{3}$ and $\mathrm{O}_{2}$ inlet levels maintained at $1000 \mathrm{ppm}$ and $40 \%$, respectively [256]. The onset temperature for reaction is independent of the NO level. Even at the smallest NO concentration of $25 \mathrm{ppm}$, a minimum in NO is observed just above the initiation temperature, and inspection of the data shows that the fractional conversion of NO at the minimum is quite similar over the range of NO levels from 25 to $100 \mathrm{ppm}$. At higher temperatures ( $>1200 \mathrm{~K}$ ), the exit NO concentration asymptotically approaches a value, which is independent of the inlet level. A similar observation was reported by Lyon and Benn [257]. The modeling predictions capture all these trends well.

The comparisons with the flame structure data (Fig. 25), the shock tube ignition delays (Fig. 27), and the flow reactor data (Fig. 28) indicate that the important 


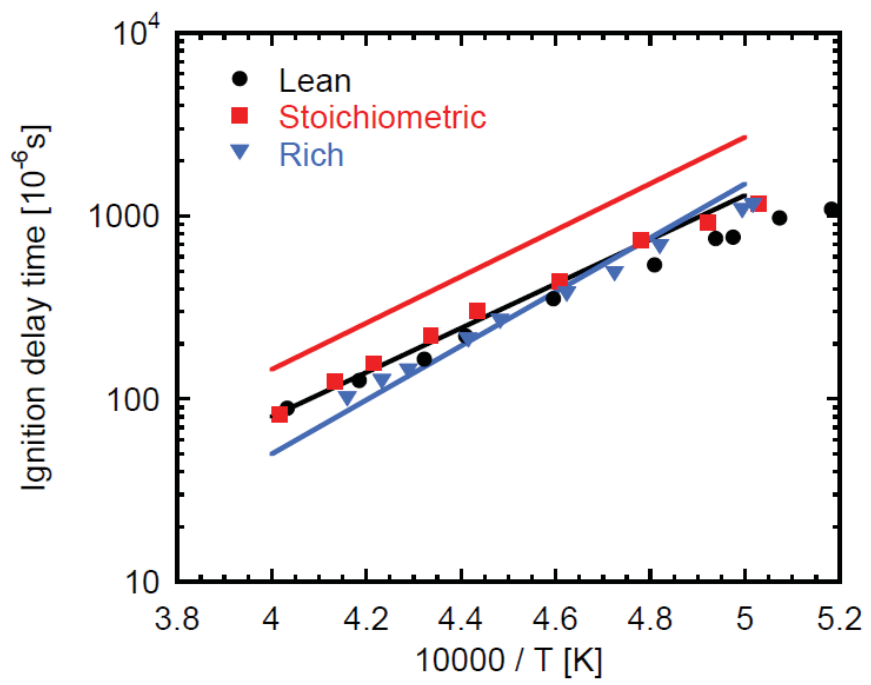

Figure 27: Experimental [185] and predicted ignition delays for mixtures of $\mathrm{NH}_{3}$ and $\mathrm{O}_{2}$ in $\mathrm{Ar}(99 \%)$ as a function of fuel-air equivalence ratio (lean $(\phi=0.5)$, stoichiometric $(\phi=1.0)$, and rich $(\phi=2.0))$ and temperature. The data were obtained in a shock tube at a pressure of 1.4 bar. Symbols denote experimental data, while solid lines denote modeling predictions.

features of $\mathrm{NH}_{3}$ oxidation, including the selectivity for forming $\mathrm{NO}$ and $\mathrm{N}_{2}$, are described well by the model. However, in combustion processes ammonia formed from fuel-nitrogen will typically be present only in small amounts compared to other combustibles. The oxidation chemistry of these combustibles will control the generation of chain carriers, and, particularly under reducing conditions, hydrocarbon/amine interactions may be important.

Figure 29 compares modeling predictions with the experimental results from Mendiara and Glarborg [22] for oxidation of $\mathrm{CH}_{4}$ doped with $\mathrm{NH}_{3}$ in a flow reactor as a function of temperature and stoichiometry. The conditions of these experiments are expected to be more representative of practical combustion systems. The methane inlet level was about 2500 ppm, with about $500 \mathrm{ppm}$ $\mathrm{NH}_{3}$. The stoichiometry is seen to have a major impact on the NO formation. Under fuel-rich conditions, the amount of NO formed is negligible. Carbon monoxide is formed above $1230 \mathrm{~K}$ and reaches a plateau level at a temperature 


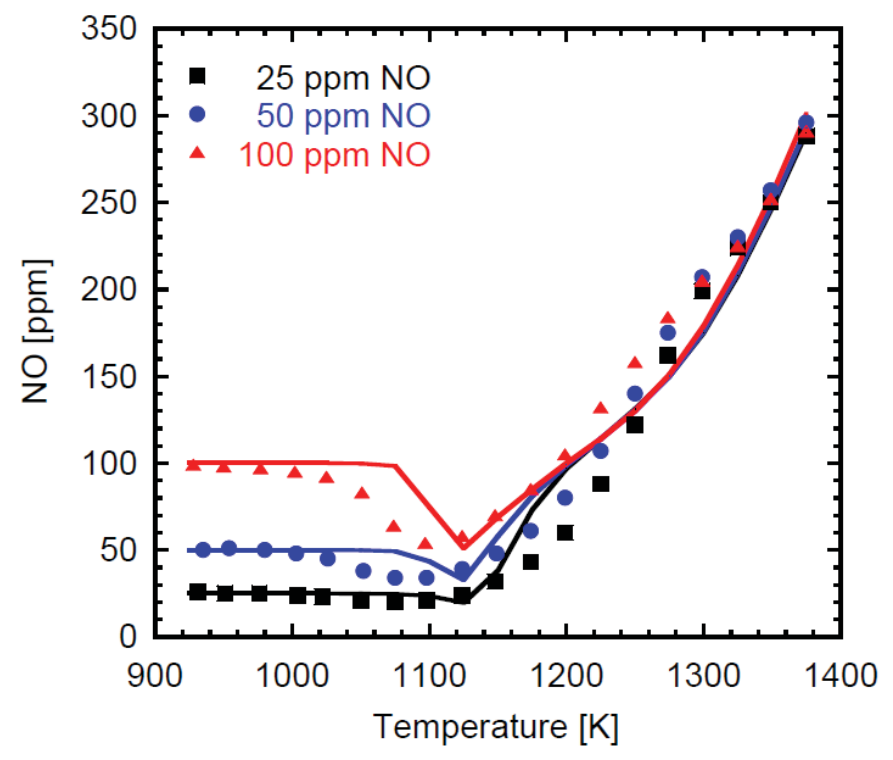

Figure 28: Comparison of experimental data [256] and modeling predictions for oxidation of $\mathrm{NH}_{3}$ in a quartz flow reactor: effect of inlet $\mathrm{NO}$ concentration. Symbols denote experimental data, while solid lines denote modeling predictions. Inlet concentrations: $\mathrm{NH}_{3}=1000 \pm 100 \mathrm{ppm}, \mathrm{O}_{2}=40 \pm 1.2 \%, \mathrm{H}_{2} \mathrm{O}=$ trace, $\mathrm{NO}$ varying $(25,50,100 \mathrm{ppm})$; balance $\mathrm{N}_{2}$. Residence time $(\mathrm{s})=48.7 / \mathrm{T}[\mathrm{K}]$.

close to $1300 \mathrm{~K}$. Ammonia oxidation is initiated at $1130 \mathrm{~K}$, but the consumption rate of $\mathrm{NH}_{3}$ is slow until $\mathrm{CH}_{4}$ is completely converted to $\mathrm{CO}$. For stoichiometric conditions, the initiation of the reaction occurs at a slightly lower temperature. Nitric oxide is formed following the disappearance of $\mathrm{NH}_{3}$, reaching a level of $180 \mathrm{ppm}$ at $1400 \mathrm{~K}$ and then leveling out. Carbon monoxide exhibits a peak at $1230 \mathrm{~K}$ and then reaches a plateau. For fuel-lean conditions, reaction is initiated at much lower temperatures. Carbon monoxide peaks already at $1030 \mathrm{~K}$, and no $\mathrm{CO}$ is observed above $1075 \mathrm{~K}$. Following the depletion of $\mathrm{NH}_{3}$ at about 1050 $\mathrm{K}, \mathrm{NO}$ is formed. The NO concentration increases with temperature up to 1250 $\mathrm{K}$ and then levels out.

Modeling predictions are generally in good agreement with experiments. The model captures well the initiation of methane and ammonia oxidation and the onset of NO formation, except under lean conditions where the onset tempera- 


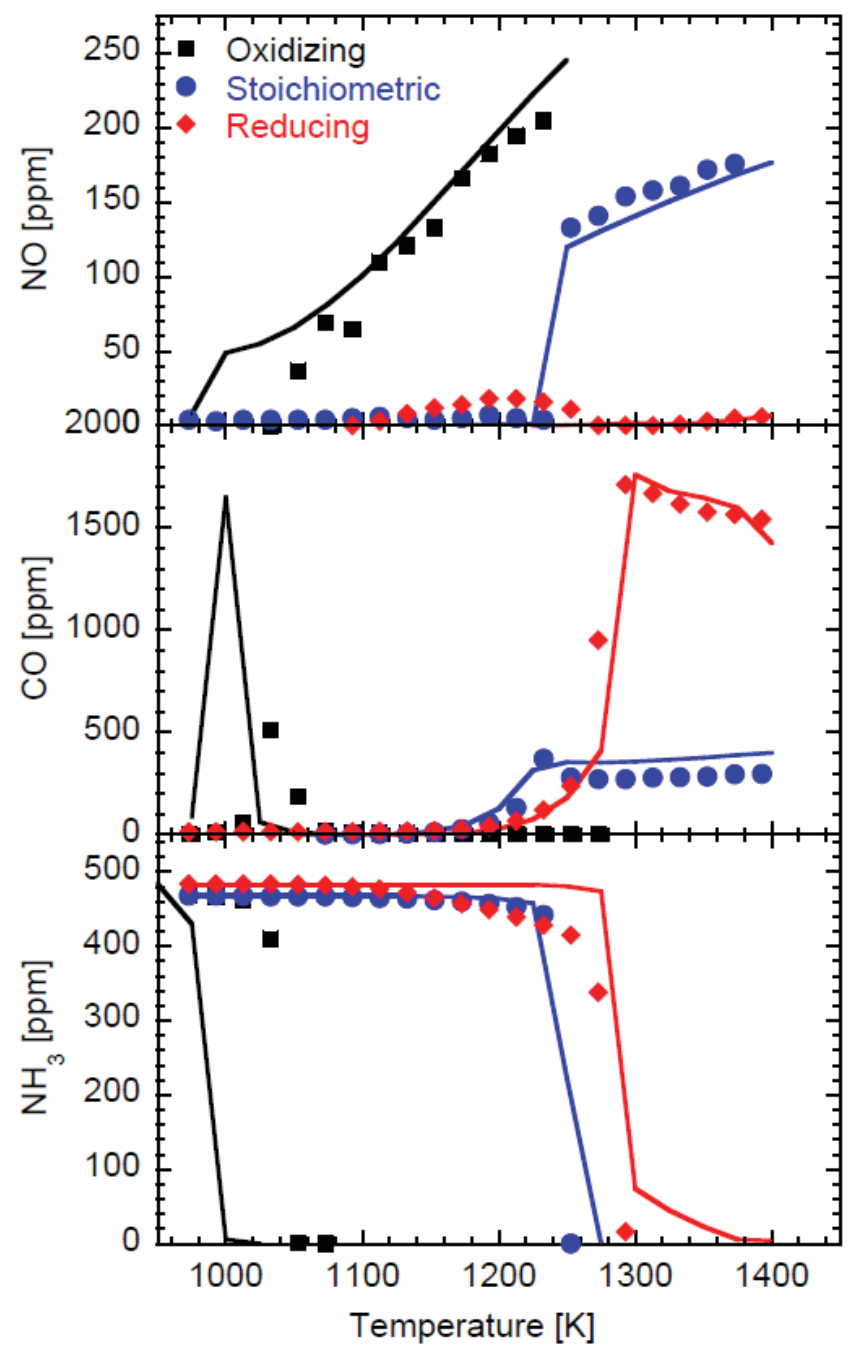

Figure 29: Comparison of experimental data [22] and modeling predictions for oxidation of a mixture of $\mathrm{CH}_{4}$ and $\mathrm{NH}_{3}$ as a function of stoichiometry and temperature. Symbols denote experimental data, while solid lines denote modeling predictions. Inlet concentrations (reducing $(\phi=1.55) /$ stoichiometric $(\phi=$ 1.07) / oxidizing $(\phi=0.13)): \mathrm{CH}_{4}=2508 / 2513 / 2515 \mathrm{ppm}, \mathrm{O}_{2}=3480 /$ $5040 / 40100 \mathrm{ppm}, \mathrm{NH}_{3}=484 / 468 / 468 \mathrm{ppm}$; balance $\mathrm{N}_{2}$. All experiments were conducted in a $12 \mathrm{~mm}$ inner diameter alumina reactor at $1.05 \mathrm{~atm}$ with a residence time in the isothermal zone of $1296 / \mathrm{T}(\mathrm{K})$. 
ture is underpredicted. The amount of NO formed is predicted quite accurately over the range of temperature and stoichiometry.

The presence of hydrocarbons opens up additional oxidation pathways for $\mathrm{NH}_{3}$, compared to the diagram in Fig. 26. These interactions are discussed in more detail elsewhere $[22,131,189]$. In particular the methyl radical plays an active role, converting amine radicals to hydrocarbon amines,

$$
\begin{gathered}
\mathrm{CH}_{3}+\mathrm{NH}_{2}(+\mathrm{M}) \rightleftarrows \mathrm{CH}_{3} \mathrm{NH}_{2}(+\mathrm{M}) \\
\mathrm{CH}_{3}+\mathrm{NH} \rightleftarrows \mathrm{CH}_{2} \mathrm{NH}+\mathrm{H}
\end{gathered}
$$

and hydrogen cyanide to acetonitrile,

$$
\mathrm{CH}_{3}+\mathrm{HCN} \rightleftarrows \mathrm{CH}_{3} \mathrm{CN}+\mathrm{H}
$$

The level of accuracy shown in Fig. 29 is presumably representative of the reliability of the model in simulating ammonia oxidation, in particular the selectivity for forming $\mathrm{NO}$ and $\mathrm{N}_{2}$, in most practical systems. This is encouraging, as $\mathrm{NH}_{3}$ can be considered the most important fuel-nitrogen species in the gas-phase. However, the interaction of $\mathrm{NH}_{3}$ with the hydrocarbon oxidation chemistry, particularly under reducing conditions, is quite complicated $[22,131,189]$ and uncertainties in this chemistry may limit the accuracy of modeling predictions under reducing conditions. 


\section{In-situ reduction of $\mathrm{NO}$}

As legislation on nitrogen oxide emissions becomes increasingly stringent, primary measures based on staged combustion may become inadequate, making it necessary to employ either catalytic flue gas cleaning or in-situ control technologies such as selective non-catalytic reduction (SNCR) or reburning. Both SNCR $[1,152,258,259]$ and reburning $[21,260-273]$ have been studied extensively. They are available as commercial technologies, typically offering $\mathrm{NO}_{\mathrm{x}}$ reductions of the order of $50 \%$ [274]. In the following sections, the chemistry of these processes are outlined and the reliability of the model in describing the NO reduction is evaluated.

\subsection{Selective Non-Catalytic Reduction of NO}

Selective, non-catalytic reduction of $\mathrm{NO}$ (SNCR) is widely used for $\mathrm{NO}_{\mathrm{x}}$ control in combustion of fuels such as biomass and waste, where catalytic cleaning may be prohibitive due to poisoning of the catalyst. The reducing agents used to react with NO are ammonia, urea and cyanuric acid. Also ammonium sulfate has been proposed [274], but little is known about the performance of this agent.

\subsubsection{SNCR with $\mathrm{NH}_{3}$ (Thermal DeNO ${ }_{\mathrm{x}}$ )}

Selective, non-catalytic reduction of $\mathrm{NO}$ using $\mathrm{NH}_{3}$ as the reducing agent was developed by Lyon [258] who termed the process Thermal DeNO $_{x}$. The chemistry of Thermal DeNO ${ }_{x}$ has been studied extensively $[1,19,187,188,258,259,275-277]$. Characteristic of the process is that nitric oxide removal is possible only in a narrow temperature range centered at $1250 \mathrm{~K}$ and only in the presence of oxygen. At temperatures below $1100 \mathrm{~K}$, reaction is too slow to be significant, and above $1400 \mathrm{~K}$ the $\mathrm{NH}_{3}$ is oxidized to $\mathrm{NO}$ rather than to $\mathrm{N}_{2}$. 
The kinetic model for Thermal DeNO $\mathrm{x}_{\mathrm{x}}$ is the same as that for the $\mathrm{H} / \mathrm{N} / \mathrm{O}$ chemistry discussed in previous sections. The major difference between the present subset, adopted largely from Klippenstein et al. [19], and previous kinetic models for Thermal DeNO ${ }_{x}$, e.g., $[1,188]$, is that the chain branching in the process is now mainly restricted by the small value of the branching fraction $\alpha$ of the $\mathrm{NH}_{2}+\mathrm{NO}$ reaction, rather than by reactions of $\mathrm{NNH}$ with $\mathrm{O}_{2}$ or NO. Following Klippenstein et al. [19], we use a value for the NNH lifetime of $10^{-9} \mathrm{~s}$, much lower than values commonly used in modeling. This value corresponds to $\mathrm{k}_{20}$ $=1 \times 10^{9} \mathrm{~s}^{-1}$. A lower limit rate for prompt dissociation can be estimated to around $2 \times 10^{8} \mathrm{~s}^{-1}$. An accurate determination of the dissociation rate for $\mathrm{NNH}$ (R20) would be very valuable for modeling ammonia oxidation and selective non-catalytic reduction of NO.

Figure 30 compares experimental and modeling results for the Thermal $\mathrm{DeNO}_{\mathrm{x}}$ process. The upper figure shows data obtained in a laminar flow reactor [278], while the results in the lower figure were obtained in a jet-stirred reactor [276]. Despite the difference in reaction conditions, the temperature window for the process is similar in the two reactor configurations. Presence of water vapor is seen to have only a limited impact on the process.

The present model provides a satisfactory prediction of the experimental results, even though it predicts a larger impact of $\mathrm{H}_{2} \mathrm{O}$ than observed experimentally. While NO is predicted fairly accurately in the presence of water vapor, in particular for the flow reactor conditions, the model tends to underpredict the temperature for onset of reaction in the absence of $\mathrm{H}_{2} \mathrm{O}$. The reason for this discrepancy is not clear. Loss of atomic oxygen on the reactor wall under dry conditions could conceivably play a role; this is discussed in App. A. The predicted inhibition by water vapor is mostly caused by its high collider efficiency in the reaction $\mathrm{H}+\mathrm{O}_{2}+\mathrm{M} \rightarrow \mathrm{HO}_{2}+\mathrm{M}$. Presently, the collider efficiency is based on low temperature measurements, but there is likely a considerable temperature dependence to it. 


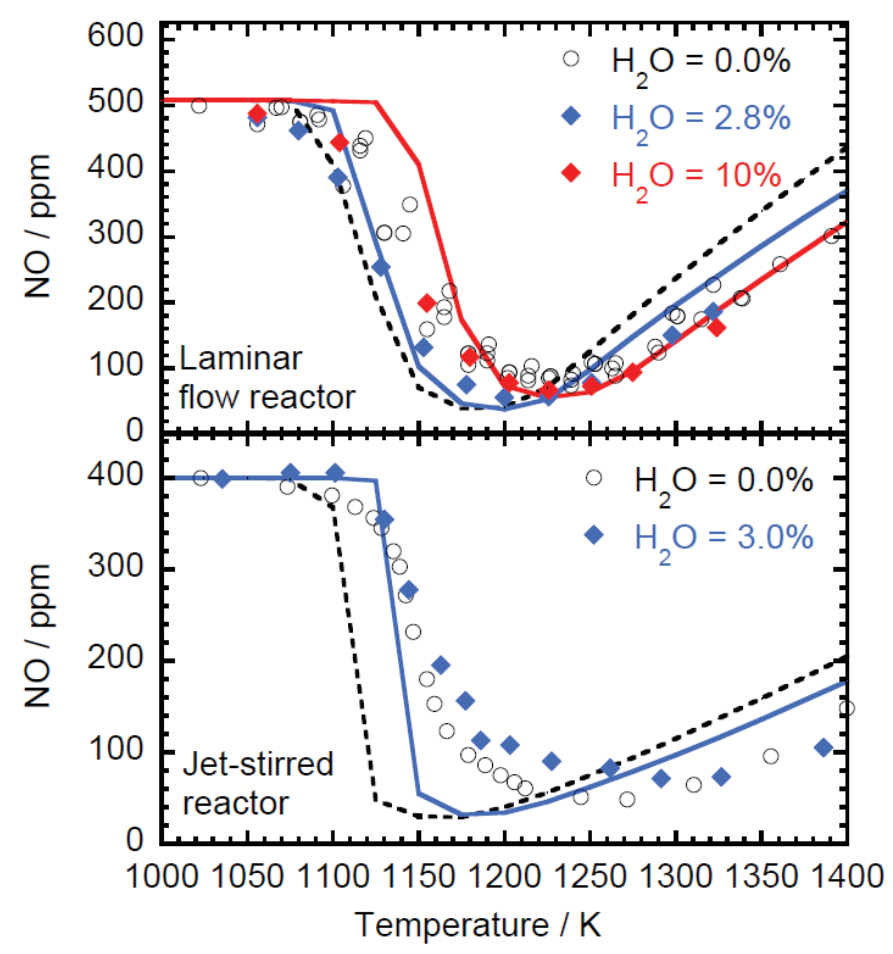

Figure 30: Comparison of experimental data [276,278] and modeling predictions for reduction of $\mathrm{NO}$ by $\mathrm{NH}_{3}$ : effect of $\mathrm{H}_{2} \mathrm{O}$ concentration. Symbols denote experimental data, while solid lines denote modeling predictions. Upper figure (laminar quartz flow reactor [278]): Inlet concentrations: $\mathrm{NH}_{3}=832 \mathrm{ppm}, \mathrm{NO}$ $=507 \mathrm{ppm}, \mathrm{O}_{2}=4.0 \%, \mathrm{H}_{2} \mathrm{O}=0 \%$ or $2.8 \%$ or $10 \%$, balance $\mathrm{N}_{2}$. Residence time $(\mathrm{s})=92.7 / \mathrm{T}(\mathrm{K})$. Lower figure (jet-stirred reactor [276]): Inlet concentrations: $\mathrm{NH}_{3}=960$ ppm, $\mathrm{NO}=400$ ppm, $\mathrm{O}_{2}=0.8 \%, \mathrm{H}_{2} \mathrm{O}=0 \%$ or $3 \%$, balance $\mathrm{N}_{2}$. Nominal residence time $(\mathrm{s})=370 / \mathrm{T}(\mathrm{K})$.

Figure 31 shows a pathway diagram for the Thermal DeNO $\mathrm{D}_{\mathrm{x}}$ process in the presence of water vapor. Ammonia is converted to $\mathrm{NH}_{2}$ by reaction with the $\mathrm{O} / \mathrm{H}$ radical pool, primarily $\mathrm{OH}$ ( $\mathrm{R} 55)$. The subsequent reaction between $\mathrm{NH}_{2}$ and NO is the key step in the process. This reaction must simultaneously remove NO and produce free radicals to sustain reaction $[1,19]$. As discussed above, it has two product channels

$$
\mathrm{NH}_{2}+\mathrm{NO} \rightleftarrows \mathrm{NNH}+\mathrm{OH}
$$




$$
\mathrm{NH}_{2}+\mathrm{NO} \rightleftarrows \mathrm{N}_{2}+\mathrm{H}_{2} \mathrm{O}
$$

Dissociation of NNH initiates a reaction sequence, which secures that reaction (R65) leads to a net formation of three hydroxyl radicals [1,19]:

$$
\begin{gathered}
\mathrm{NNH} \rightleftarrows \mathrm{N}_{2}+\mathrm{H} \\
\mathrm{H}+\mathrm{O}_{2} \rightleftarrows \mathrm{O}+\mathrm{OH} \\
\mathrm{O}+\mathrm{H}_{2} \mathrm{O} \rightleftarrows \mathrm{OH}+\mathrm{OH}
\end{gathered}
$$

For the overall process to be self-sustainable, it is required that the branching fraction of the $\mathrm{NH}_{2}+\mathrm{NO}$ reaction, $\alpha=\mathrm{k}_{65} /\left(\mathrm{k}_{65}+\mathrm{k}_{66}\right)$, must be at least $25 \%$. Early experiments $[207,279]$ indicated a smaller branching fraction, but it is now well established that $\alpha$ attains values of $0.3-0.4$ in the 1100-1400 K range (Fig. 23).

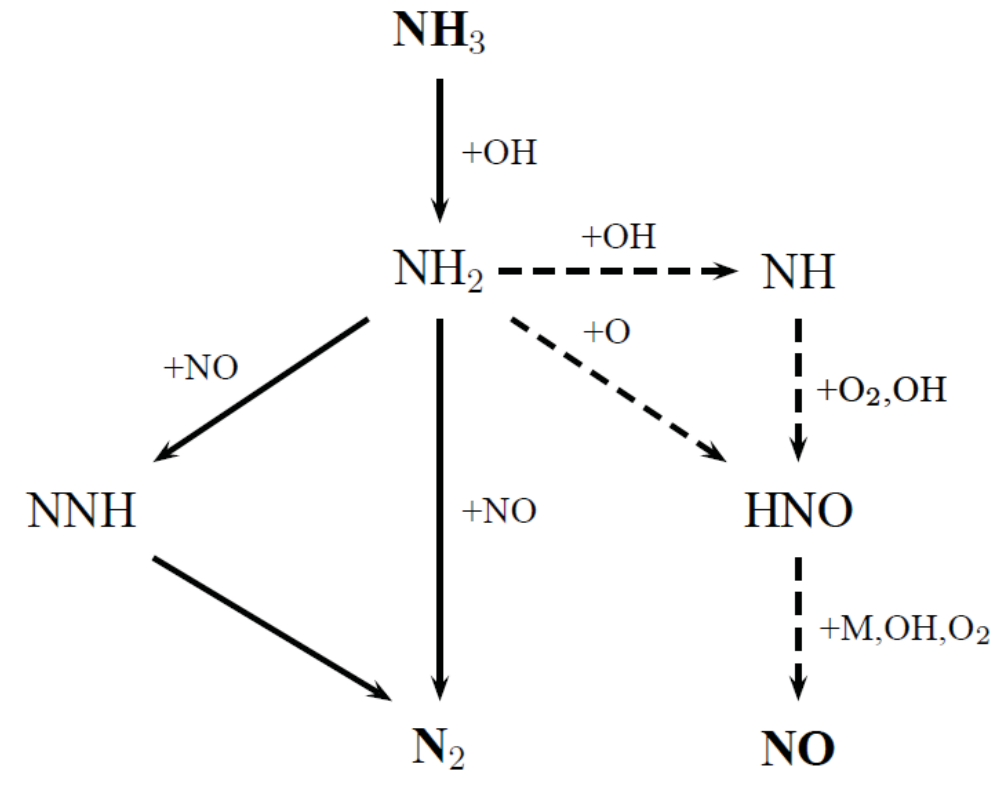

Figure 31: Reaction path diagram for the Thermal DeNO $\mathrm{x}_{\mathrm{x}}$ process. Dashed lines denote pathways only important at high temperatures.

The process is limited in the high temperature end by the chain branching cycle 
occurring too rapidly, thus leading to a strong growth in the $\mathrm{O} / \mathrm{H}$ radical pool. This promotes conversion of $\mathrm{NH}_{2}$ to $\mathrm{NH}$,

$$
\mathrm{NH}_{2}+\mathrm{OH} \rightleftarrows \mathrm{NH}+\mathrm{H}_{2} \mathrm{O}
$$

which becomes competitive with the $\mathrm{NH}_{2}+\mathrm{NO}$ reaction. The $\mathrm{NH}$ formed is partly oxidized to $\mathrm{NO}$ through the sequence $\mathrm{NH} \stackrel{+\mathrm{O}_{2}}{\longrightarrow} \mathrm{HNO} \stackrel{+\mathrm{M}, \mathrm{OH}, \mathrm{O}_{2}}{\longrightarrow} \mathrm{NO}$. Also the $\mathrm{NH}_{2}+\mathrm{O}$ reaction (R58, R59) contributes to formation of NO. At sufficiently high temperatures, typically around $1400 \mathrm{~K}$, these reactions lead to a net formation of $\mathrm{NO}$.

Figure 32 shows a sensitivity analysis for NO for the conditions of the experiments of Duo (Fig. 30). Results for three water vapor concentrations are shown for temperatures slightly above the onset temperature for the process and below the optimum temperature for NO reduction. Chain branching processes enhance the reduction, whereas termination processes inhibit it. Reaction R65, $\mathrm{NH}_{2}+\mathrm{NO} \rightarrow \mathrm{NNH}+\mathrm{OH}$, is favorable to NO reduction, and reaction R66, $\mathrm{NH}_{2}+\mathrm{NO} \rightarrow \mathrm{N}_{2}+\mathrm{H}_{2} \mathrm{O}$, is equally unfavorable. Similarly, but with much lower sensitivity coefficients, $\mathrm{H}+\mathrm{O}_{2} \rightarrow \mathrm{O}+\mathrm{OH}$ promotes reaction while $\mathrm{H}+$ $\mathrm{O}_{2}(+\mathrm{M}) \rightarrow \mathrm{HO}_{2}(+\mathrm{M})$ inhibits reduction of NO.

The sensitivity coefficients for the $\mathrm{NH}_{2}+\mathrm{NO}$ reaction, and in particular for the branching fraction for the reaction, $\alpha=\mathrm{k}_{65} /\left(\mathrm{k}_{65}+\mathrm{k}_{66}\right)$, are very large, showing the unusually large sensitivity of modeling predictions for Thermal $\mathrm{DeNO}_{\mathrm{x}}$ to this parameter. Apart from the $\mathrm{H}+\mathrm{O}_{2}$ reaction, no other steps in the mechanism are nearly as important.

Figures 33 and 34 compare modeling predictions for NO with experimental data from Kasuya et al. [280]. They performed a series of flow reactor experiments where they investigated the effect of $\mathrm{O}_{2}$ concentration from close to zero to $50 \%$ on the Thermal DeNO ${ }_{x}$ process, measuring both $\mathrm{NO}, \mathrm{NO}_{2}$, and $\mathrm{N}_{2} \mathrm{O}$.

Figures 33 shows results for NO. An increase in the oxygen concentration shifts 


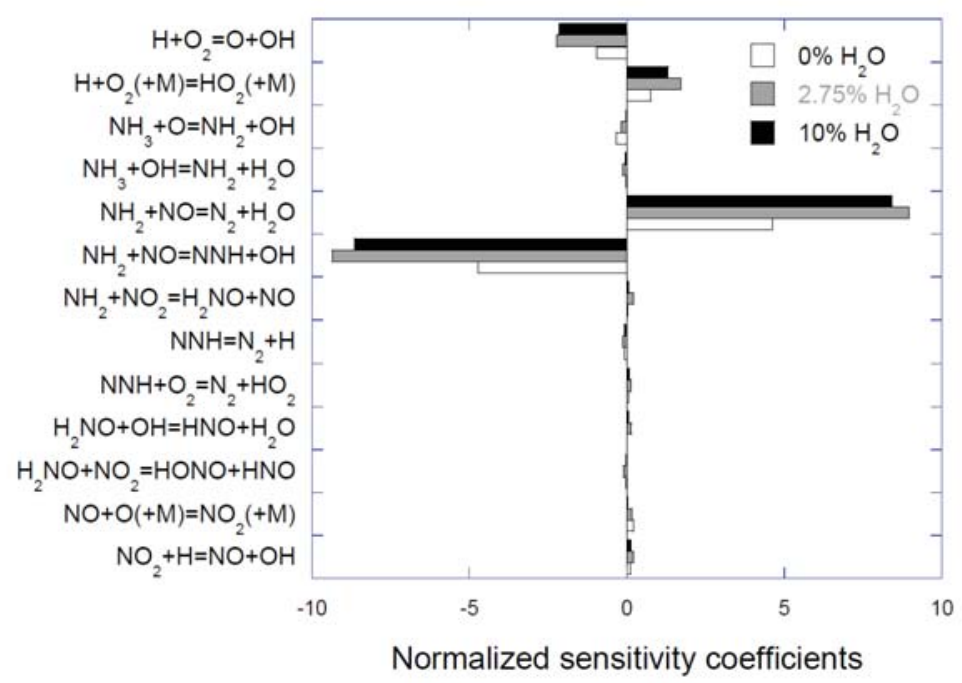

Figure 32: Sensitivity coefficients for prediction of NO in Thermal DeNO ${ }_{x}$ for the conditions of the experiments of Duo [278] as a function of the water vapor concentration at a temperature slightly above the temperature for onset of reaction: $0 \%(1100 \mathrm{~K}), 2.75 \%(1125 \mathrm{~K})$, and $10 \%(1150 \mathrm{~K})$.

the window towards lower temperatures and widens it. At the same time, the maximum amount of NO removal decreases. Similar results were reported by $\mathrm{Lu}$ and $\mathrm{Lu}$ [277]. These characteristics are described well by the model. Similar to what was observed by Klippenstein et al. [19], the predicted temperature for onset of reaction is slightly shifted for some conditions. The very short NNH lifetime of the present mechanism causes the predicted onset temperature to be less sensitive to the $\mathrm{O}_{2}$ level than observed experimentally, but the difference is probably within experimental uncertainty.

Figure 34 compares predicted and observed concentrations of $\mathrm{NO}_{2}$ and $\mathrm{N}_{2} \mathrm{O}$ for the conditions of Fig. 33. Kasuya et al. were the first to report detection of $\mathrm{NO}_{2}$ in the Thermal DeNO ${ }_{\mathrm{x}}$ process; $\mathrm{NO}_{2}$ is now believed to be a key intermediate in the process $[19,187,188]$. Nitrogen dioxide is seen to form in significant quantities at high concentrations of $\mathrm{O}_{2}$, but the level drops off rapidly as $\mathrm{O}_{2}$ decreases. 


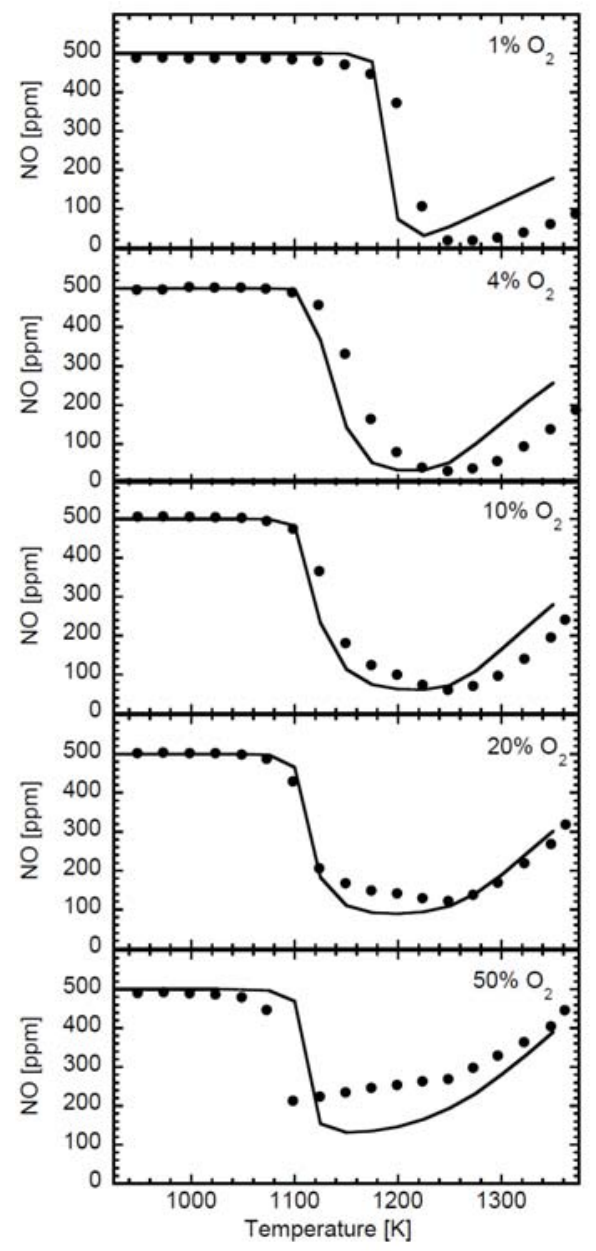

Figure 33: Comparison of experimental data [280] and modeling predictions for reduction of $\mathrm{NO}$ by $\mathrm{NH}_{3}$ in a quartz flow reactor: effect of $\mathrm{O}_{2}$ concentration. Symbols denote experimental data, while solid lines denote modeling predictions. Inlet concentrations: $\mathrm{NH}_{3}=1000 \pm 60 \mathrm{ppm}, \mathrm{NO}=500 \pm 30 \mathrm{ppm}, \mathrm{H}_{2} \mathrm{O}=$ $5 \%$, balance $\mathrm{N}_{2}$. Residence time $(\mathrm{s})=88.0 / \mathrm{T}(\mathrm{K})$. The reactor surface/volume ratio was $7.8 \mathrm{~cm}^{-1}$.

The modeling predictions are in qualitative agreement with the measurements, but the predicted window for $\mathrm{NO}_{2}$ extends to higher temperatures than observed experimentally. Nitrogen dioxide is formed through the sequence,

$$
\mathrm{NNH}+\mathrm{O}_{2} \rightleftarrows \mathrm{N}_{2}+\mathrm{HO}_{2}
$$




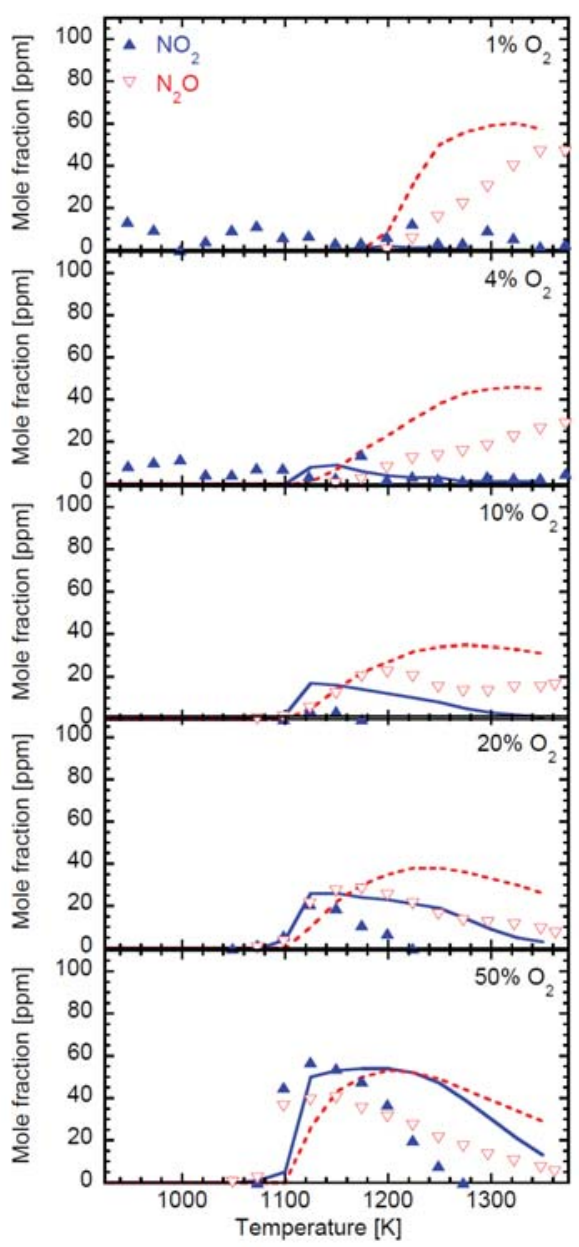

Figure 34: Comparison of experimental data [280] and modeling predictions for formation of $\mathrm{NO}_{2}$ and $\mathrm{N}_{2} \mathrm{O}$ in the reduction of $\mathrm{NO}$ by $\mathrm{NH}_{3}$ in a quartz flow reactor: effect of $\mathrm{O}_{2}$ concentration. Symbols denote experimental data, while solid lines denote modeling predictions. Conditions are the same as in Fig. 33. Inlet concentrations: $\mathrm{NH}_{3}=1000 \pm 60 \mathrm{ppm}, \mathrm{NO}=500 \pm 30 \mathrm{ppm}, \mathrm{H}_{2} \mathrm{O}=5 \%$, balance $\mathrm{N}_{2}$. Residence time $(\mathrm{s})=88.0 / \mathrm{T}(\mathrm{K})$. The reactor surface/volume ratio was $7.8 \mathrm{~cm}^{-1}$.

$$
\mathrm{NO}+\mathrm{HO}_{2} \rightleftarrows \mathrm{NO}_{2}+\mathrm{OH}
$$

Formation of $\mathrm{HO}_{2}$, and thereby $\mathrm{NO}_{2}$, is then replenished through the reactions,

$$
\mathrm{NH}_{2}+\mathrm{NO}_{2} \rightleftarrows \mathrm{H}_{2} \mathrm{NO}+\mathrm{NO}
$$




$$
\begin{gathered}
\mathrm{H}_{2} \mathrm{NO}+\mathrm{O}_{2} \rightleftarrows \mathrm{HNO}+\mathrm{HO}_{2} \\
\mathrm{HNO}+\mathrm{O}_{2} \rightleftarrows \mathrm{NO}+\mathrm{HO}_{2}
\end{gathered}
$$

The competition between reactions of $\mathrm{HNO}$ and $\mathrm{H}_{2} \mathrm{NO}$ with $\mathrm{O}_{2}$ (neither of which are well characterized) and with the radical pool is important for the peak concentration of $\mathrm{NO}_{2}$, as well as the width of the $\mathrm{NO}_{2}$ formation window [19].

The formation of $\mathrm{N}_{2} \mathrm{O}$ is a complex function of temperature and oxygen concentration. The $\mathrm{N}_{2} \mathrm{O}$ peak shifts from high temperature to low temperature as $\left[\mathrm{O}_{2}\right]$ increases. At $10 \% \mathrm{O}_{2}$, a double peak in $\mathrm{N}_{2} \mathrm{O}$ can be detected, indicating that two mechanisms of $\mathrm{N}_{2} \mathrm{O}$ formation are active. The two sources of $\mathrm{N}_{2} \mathrm{O}$ are the reactions $[187,188]$

$$
\mathrm{NH}_{2}+\mathrm{NO}_{2} \rightleftarrows \mathrm{N}_{2} \mathrm{O}+\mathrm{H}_{2} \mathrm{O}
$$

active predominantly at lower temperatures and larger $\left[\mathrm{O}_{2}\right]$ where $\mathrm{NO}_{2}$ is readily available, and

$$
\mathrm{NH}+\mathrm{NO} \rightleftarrows \mathrm{N}_{2} \mathrm{O}+\mathrm{H}
$$

which competes with $\mathrm{NH}+\mathrm{O}_{2}$ at higher temperatures and lower values of $\left[\mathrm{O}_{2}\right]$. The predictions with the current mechanism agree qualitatively with the measured profiles, but the model overpredicts $\mathrm{N}_{2} \mathrm{O}$ under conditions where the $\mathrm{NH}+\mathrm{NO}$ reaction is the main source.

Presence of combustibles such as $\mathrm{H}_{2}$ or $\mathrm{CO}$ shifts the window for NO removal towards lower temperatures by replenishing the radical pool. Furthermore, it leads to a narrowing of the process window, because the enhanced radical levels cause oxidation of $\mathrm{NH}_{3}$ to $\mathrm{NO}$ to compete more efficiently with the NO removal reactions. These effects are illustrated in Fig. 35, which compares modeling predictions for the effect of CO addition on Thermal DeNO $\mathrm{x}_{\mathrm{x}}$ with the experimental results of Alzueta et al. [281]. Both the shift in onset temperature and the narrowing of the temperature window are captured quite well by the model. 


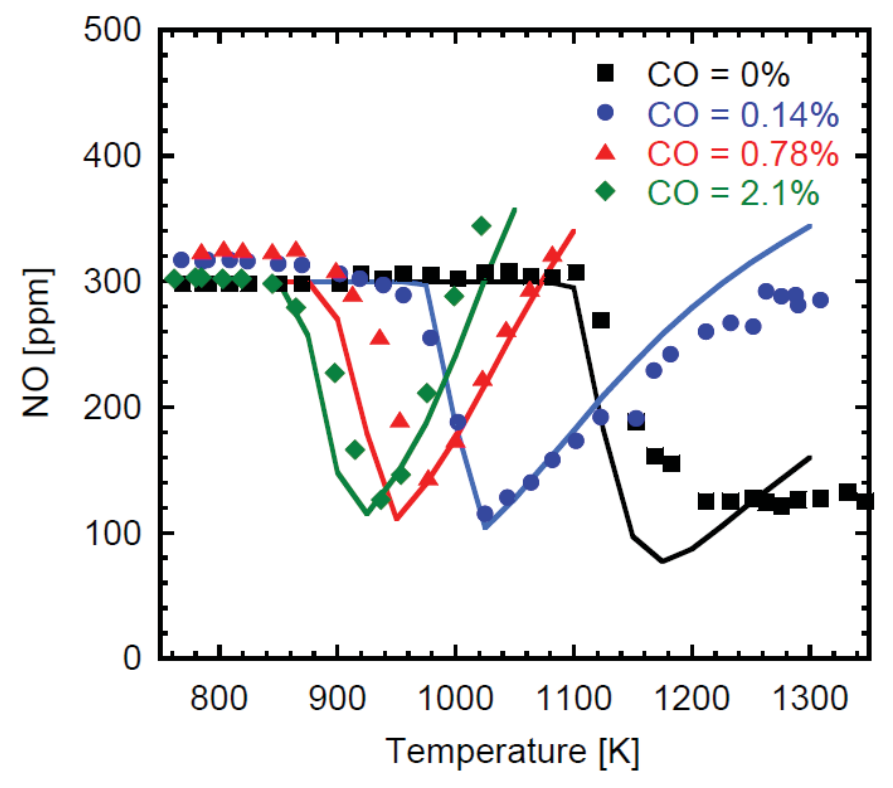

Figure 35: Comparison of experimental data [281] and modeling predictions for reduction of $\mathrm{NO}$ by $\mathrm{NH}_{3}$ in a quartz flow reactor: effect of $\mathrm{CO}$ concentration. Symbols denote experimental data, while solid lines denote modeling predictions. Inlet concentrations: $300 \mathrm{ppm} \mathrm{NH} 3,300 \mathrm{ppm} \mathrm{NO}, 4.0 \% \mathrm{O}_{2}, 4.5 \% \mathrm{H}_{2} \mathrm{O}$; balance $\mathrm{N}_{2}$. Pressure is $1.1 \mathrm{~atm}$. Residence time at $1200 \mathrm{~K}$ (constant molar rate) is about $150 \mathrm{~ms}$. The reactor surface/volume ratio was $4.4 \mathrm{~cm}^{-1}$.

Even though the Thermal DeNO $\mathrm{x}_{\mathrm{x}}$ mechanism is now well understood and the main features of the process are predicted satisfactorily by the model, quantitative modeling predictions over a wider range of conditions are still elusive. As discussed in section 3.6.1, the rate constants and branching fractions of some of the key reactions were re-evaluated in the present work, most importantly the $\mathrm{NH}_{2}+\mathrm{NO}$ reaction (R65, R66). This reaction is probably one of the best characterized reactions in combustion chemistry, with rate constants for the two product channels determined very accurately from both experiment and theory. Still, this level of accuracy $( \pm 10 \%)$ is not sufficient to guarantee a good prediction of $\mathrm{NO}$ in the Thermal DeNO $\mathrm{x}_{\mathrm{x}}$ process. A small lowering of the branching fraction from 0.37 (best theoretical value [191]) to 0.34 (lower end of experimental range) at $1200 \mathrm{~K}$ considerably improves predictions for the process by 
increasing the onset temperature for reaction by $25-50 \mathrm{~K}$. It is probably a unique feature of nitrogen chemistry - due to the selectivity in products $\left(\mathrm{NO}, \mathrm{N}_{2}, \mathrm{~N}_{2} \mathrm{O}\right.$, etc.) - that such a small correction has a major impact on predictions. The accuracy of modeling predictions for Thermal $\mathrm{DeNO}_{\mathrm{x}}$ is limited also by uncertainties in other reactions, for instance at increased oxygen concentrations the steps $\mathrm{HNO}+\mathrm{O}_{2}$ and $\mathrm{H}_{2} \mathrm{NO}+\mathrm{O}_{2}$. 


\subsubsection{SNCR with Cyanuric Acid (RapReNO $\left.{ }_{x}\right)$}

Cyanuric acid, (HOCN) $)_{3}$, is an alternative to ammonia and urea as an SNCR agent. Above $600 \mathrm{~K}$, cyanuric acid decomposes to isocyanic acid (HNCO), which at sufficiently high temperature initiates a reaction sequence that can take out NO [152]. The process was discovered by Perry [282] and termed RapReNO ${ }_{\mathrm{x}}$. Compared to the Thermal DeNO ${ }_{x}$ process, RapReNO ${ }_{x}$ is efficient at slightly higher temperatures, due to the self-inhibiting nature of HNCO oxidation discussed in section 3.5. A concern with the process is the formation and possible emission of nitrous oxide, $\mathrm{N}_{2} \mathrm{O}$.

A number of flow reactor studies of the reduction of NO by HNCO have been performed in order to investigate the characteristics of this process [158-160,181, 283]. The most comprehensive data were obtained by Caton and Siebers [158] who investigated the effect of temperature and exhaust gas composition on the process. Modeling studies for the RapReNO $\mathrm{x}_{\mathrm{x}}$ process have been reported by Miller and Bowman [1,152], Lyon and Cole [160], and Glarborg et al. [159]. These studies have provided an overall understanding of the reduction of NO by HNCO, but details of the chemistry remain uncertain.

The subset used in the present work for studying the RapReNO $\mathrm{x}_{\mathrm{x}}$ is the same as that discussed in sections 3.4 and 3.5 for oxidation of $\mathrm{HCN}$ and $\mathrm{HNCO}$, respectively. In the modeling, cyanuric acid is assumed to decompose instantaneously at the temperatures relevant for the process. The key reaction for removing NO is $\mathrm{NCO}+\mathrm{NO}$, which has two product channels,

$$
\begin{aligned}
& \mathrm{NCO}+\mathrm{NO} \rightleftarrows \mathrm{N}_{2} \mathrm{O}+\mathrm{CO} \\
& \mathrm{NCO}+\mathrm{NO} \rightleftarrows \mathrm{N}_{2}+\mathrm{CO}_{2}
\end{aligned}
$$

The overall rate constant has been measured over a wide range of temperature $[161,284,285]$ and the main uncertainty relates to the branching ratio for the 
reaction. We have adopted the recommendation of Baulch et al. [26], which is based on the theoretical work by Zhu and Lin [153]. The nitrous oxide formed in reaction (R42) may be emitted from the process and it is a concern for RapReNO ${ }_{x}$.

For model validation, we compare predictions with the flow reactor data of Caton and Siebers [158]. They systematically investigated the effect of the initial concentrations of $\mathrm{CO}, \mathrm{H}_{2} \mathrm{O}$, and $\mathrm{O}_{2}$. Their data are characterized by a high $\mathrm{HNCO} / \mathrm{NO}$ ratio and long reaction times, promoting $\mathrm{NO}$ reduction and widening the temperature window for the process. However, uncertainties related to the mixing conditions, the temperature profile, and the decomposition of cyanuric acid imply that their results should be used with caution for model evaluation purposes [152].

Figure 36 shows the effect of adding water vapor and carbon monoxide to the process. In the absence of $\mathrm{H}_{2} \mathrm{O}$ and $\mathrm{CO}$, the process window occurs at temperatures above $1300 \mathrm{~K}$. Under these conditions, atomic oxygen is the main radical, and the $\mathrm{HNCO}+\mathrm{O}$ reaction yields both $\mathrm{NCO}$ (R47) and NH (R46). The subsequent $\mathrm{NCO}+\mathrm{NO}$ reaction $(\mathrm{R} 42, \mathrm{R} 43)$ is chain terminating. Even though the reaction removes NO, it serves to limit NO reduction, shifting the process to higher temperatures. In addition, the sequence $\mathrm{NO}+\mathrm{O}(+\mathrm{M}) \rightarrow \mathrm{NO}_{2}(+\mathrm{M})$, $\mathrm{NO}_{2}+\mathrm{O} \rightarrow \mathrm{NO}+\mathrm{O}_{2}$ is chain terminating and slows down reaction. The NH radical is consumed primarily by reaction with $\mathrm{O}_{2}$ and $\mathrm{NO}$ in chain propagating reactions; the $\mathrm{NH}+\mathrm{NO}$ reaction makes a considerable contribution to reducing NO under dry conditions.

Addition of $\mathrm{H}_{2} \mathrm{O}$ shifts the window approximately $50 \mathrm{~K}$ towards lower temperatures. The presence of water vapor causes a shift from $\mathrm{O}$ to $\mathrm{OH}$ as the major chain carrier due to the reaction $\mathrm{O}+\mathrm{H}_{2} \mathrm{O} \rightarrow \mathrm{OH}+\mathrm{OH}$, diminishing the importance of the chain terminating sequence involving $\mathrm{NO}_{2}$. Also, the direct reaction between $\mathrm{HNCO}$ and $\mathrm{H}_{2} \mathrm{O}$ serves to promote reaction, even though it is slow. 


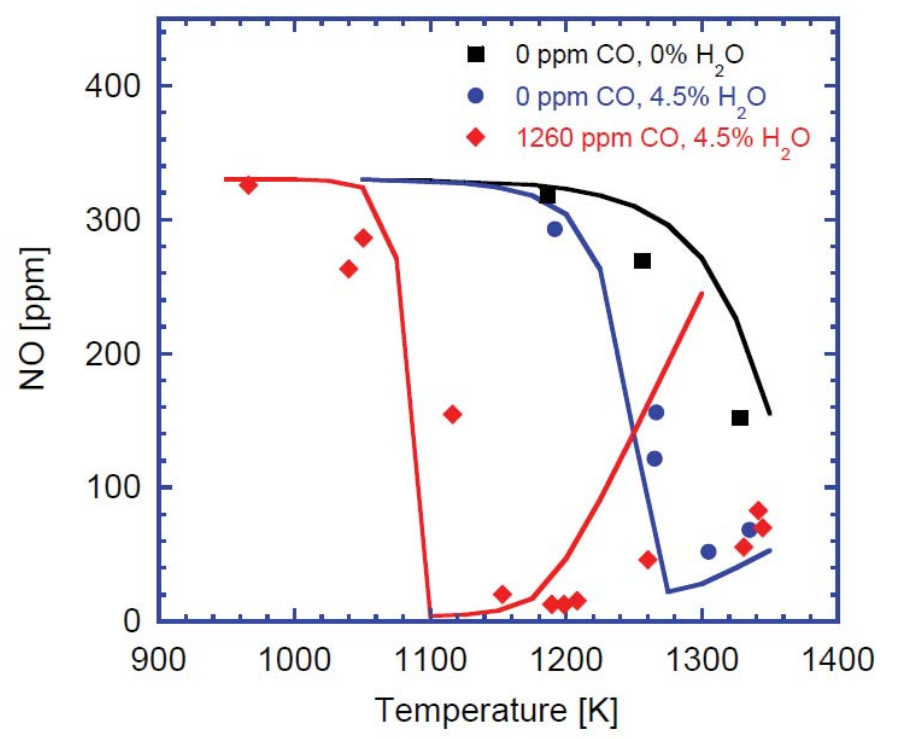

Figure 36: Comparison of modeling predictions and experimental data for the RapReNO $\mathrm{N}_{\mathrm{x}}$ process in a quartz flow reactor: effect of the initial mole fractions of $\mathrm{CO}$ and $\mathrm{H}_{2} \mathrm{O}$. The experimental data, taken from Caton and Siebers [158], are shown as symbols, modeling predictions as lines. Inlet mole fractions: $(\mathrm{HOCN})_{3}$ $=470 \mathrm{ppm}, \mathrm{NO}=330 \mathrm{ppm}, \mathrm{CO}=0$ or $1260 \mathrm{ppm}, \mathrm{O}_{2}=12.3 \%, \mathrm{H}_{2} \mathrm{O}=0$ or $4.5 \%$, balance $\mathrm{N}_{2}$. Reaction time $=0.72 \mathrm{~s}$ at $1200 \mathrm{~K}$ (constant mass flow). The surface to volume ratio was 1.2. In the calculations, it is assumed that $(\mathrm{HOCN})_{3}$ is instantaneously converted to HNCO (1410 ppm).

When $\mathrm{CO}$ is added as a combustible, the temperature window is lowered further, with onset of reaction occurring below 1100 K. Figure 37 shows comparison of experimental data and modeling predictions for $\mathrm{HNCO}, \mathrm{NO}, \mathrm{N}_{2} \mathrm{O}, \mathrm{CO}$, and $\mathrm{CO}_{2}$ for these conditions. Due to the large excess of HNCO compared to NO, as well as the long residence time, the temperature window for the process is unusually wide, extending from $1100 \mathrm{~K}$ to beyond $1350 \mathrm{~K}$. A significant fraction of the $\mathrm{NO}$ is converted to $\mathrm{N}_{2} \mathrm{O}$; only at the highest investigated temperature of $1350 \mathrm{~K}$ is $\mathrm{N}_{2} \mathrm{O}$ depleted.

Despite the uncertainties in the subset for $\mathrm{HNCO}$, the model describes the data of Caton and Siebers satisfactorily, particularly in the presence of combustibles. Nitric oxide is generally overpredicted in the higher end of the temperature 


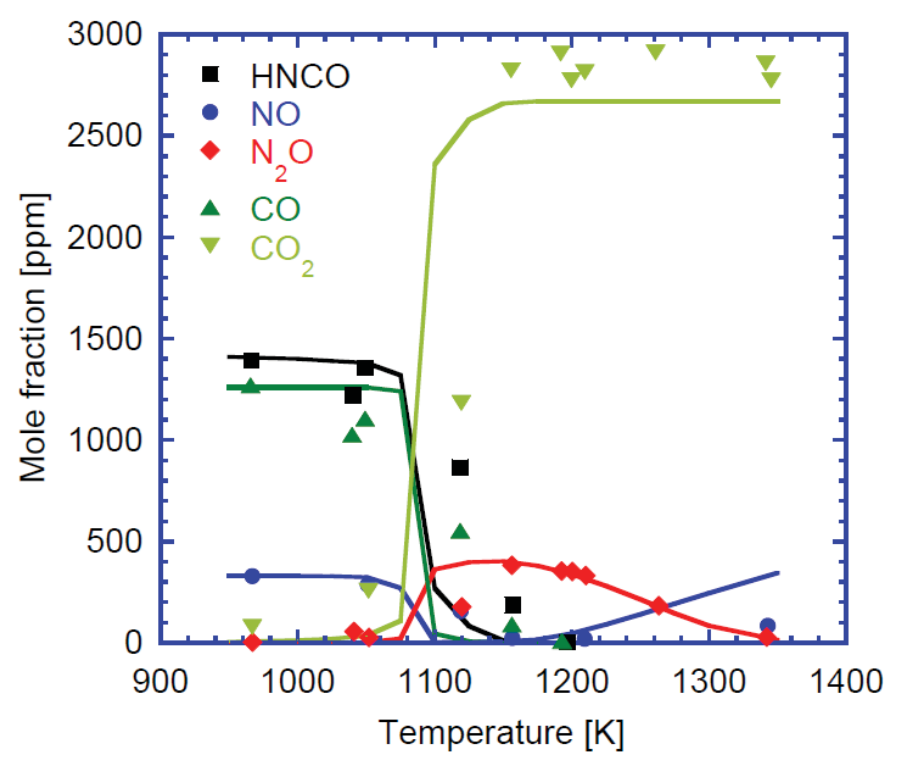

Figure 37: Comparison of modeling predictions and experimental data for the RapReNO $\mathrm{x}_{\mathrm{x}}$ process in a quartz flow reactor. The experimental data, taken from Caton and Siebers [158], are shown as symbols, modeling predictions as lines. Inlet mole fractions: $(\mathrm{HOCN})_{3}=470 \mathrm{ppm}, \mathrm{NO}=330 \mathrm{ppm}, \mathrm{CO}=1260 \mathrm{ppm}, \mathrm{O}_{2}$ $=12.3 \%, \mathrm{H}_{2} \mathrm{O}=4.5 \%$, balance $\mathrm{N}_{2}$. Reaction time $=0.72 \mathrm{~s}$ at $1200 \mathrm{~K}$ (constant mass flow). In the calculations, it is assumed that $(\mathrm{HOCN})_{3}$ is instantaneously converted to HNCO (1410 ppm).

window, but $\mathrm{N}_{2} \mathrm{O}$ is predicted well. However, the availability of reliable experimental data for RapReNO ${ }_{\mathrm{x}}$ is limited and it is difficult to fully assess the predictive capabilities of the model. 


\subsubsection{SNCR with urea $\left(\mathrm{NO}_{\mathrm{x}} \mathrm{Out}\right)$}

Selective non-catalytic reduction of NO using urea as a reducing agent was proposed by Muzio and coworkers [286] who termed the process $\mathrm{NO}_{\mathrm{x}} \mathrm{Out}$. At high temperatures, urea decomposes rapidly to $\mathrm{NH}_{3}$ and $\mathrm{HNCO}$ [158], and thus the chemistry of the process shares important similarities with both Thermal $\mathrm{DeNO}_{\mathrm{x}}$ and RapReNO $\mathrm{x}_{\mathrm{x}}$. Compared to ammonia, the use of urea has the advantage of easier handling and reduced safety hazards. In addition, the urea SNCR process has a slightly wider temperature window than SNCR with $\mathrm{NH}_{3}$. A disadvantage of the process is that, similarly to RapReNO ${ }_{x}, \mathrm{~N}_{2} \mathrm{O}$ will be formed and may be emitted from the process.

The urea SNCR process is not as well characterized as Thermal DeNO $\mathrm{x}$, even though its commercial impact is similar. Experimental data for $\mathrm{NO}_{\mathrm{x}} \mathrm{Out}$, obtained under well-defined conditions in the laboratory, are limited, partly because urea is typically added to the reactor either in solid form or dissolved in water. In laboratory scale, flow reactor experiments have been reported by Alzueta et al. [287] and Lee et al. [288], while Rota et al. [289,290] conducted experiments in a jet-stirred reactor.

Chemical kinetic models for the $\mathrm{NO}_{\mathrm{x}}$ Out process have been reported by several groups $[287,289,291]$. The reaction mechanism involves reactions for urea decomposition, along with the $\mathrm{H} / \mathrm{N} / \mathrm{O}$ subset for Thermal $\mathrm{DeNO}_{\mathrm{x}}$ and the HNCO subset for RapReNO ${ }_{x}$. Data for urea decomposition at high temperatures and high heating rates representative of the SNCR process are limited, but results indicate that it is fast [291,292]; we assume it to happen instantaneously. When urea is added in an aqueous solution or as a solid, the decomposition presumably happens in condensed phase; reported activation energies of 15-20 kcal $\mathrm{mol}^{-1}$ [292] seem to be too low to be compatible with a gas-phase dissociation. Details of the condensed phase decomposition of urea still need to be verified, but a preliminary reaction mechanism has been proposed based on TGA exper- 
iments [293].

Figure 38 compares modeling predictions to the experimental data from Alzueta et al. [287], obtained in a laminar flow reactor, and from Rota et al. [289], measured in a jet-stirred reactor. Despite differences in reactor configuration and urea/NO molar ratio, the two data sets agree fairly well. The onset of reaction (in the absence of combustibles) occurs at around $1150 \mathrm{~K}$, with the highest NO reduction observed at about $1250 \mathrm{~K}$.

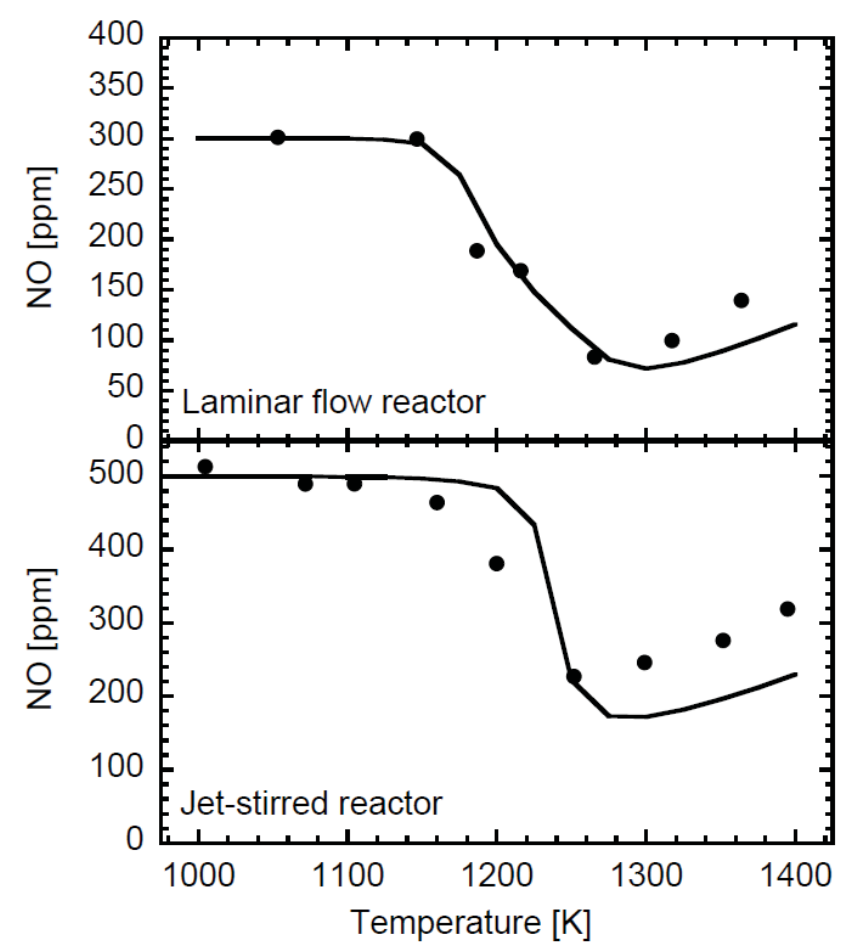

Figure 38: Comparison of experimental data $[287,289]$ and modeling predictions for reduction of NO by urea. Symbols denote experimental data, while solid lines denote modeling predictions. Upper figure (laminar flow quartz reactor $(\mathrm{S} / \mathrm{V}=2.3)$ [287]): Inlet concentrations: urea $=150 \mathrm{ppm}, \mathrm{NO}=300 \mathrm{ppm}, \mathrm{O}_{2}=4.0 \%, \mathrm{H}_{2} \mathrm{O}=4 \%$, balance $\mathrm{N}_{2}$. Residence time $(s)=200 / T(K)$. Lower figure (jet-stirred reactor [289]): Inlet concentrations: urea = $300 \mathrm{ppm}, \mathrm{NO}=500 \mathrm{ppm}, \mathrm{O}_{2}=4.0 \%, \mathrm{H}_{2} \mathrm{O}=19 \%$, balance $\mathrm{N}_{2}$. Nominal residence time $(\mathrm{s})$ $=200 / \mathrm{T}(\mathrm{K})$.

The model captures the trends well and the agreement with experiment is satisfactory. The minimum in NO is predicted at slightly higher temperatures than 
observed and the level of reduction is overpredicted at higher temperatures, but the differences are not large.

Similar to the situation for $\operatorname{RapReNO}$, the availability of experimental data for $\mathrm{NO}_{\mathrm{x}}$ Out is limited and the predictive capability of the model is difficult to assess. However, conceivably the uncertainty in predictions is similar to that for Thermal $\mathrm{DeNO}_{\mathrm{x}}$, since this subset, in particular the choice of rate constants for the $\mathrm{NH}_{2}+\mathrm{NO}$ reaction and $\mathrm{NNH}$ dissociation, controls the temperature window for the process. 


\subsection{Reburning}

Sixty years ago Myerson et al. [294] discovered that hydrocarbon radicals react fast with NO. A low- $\mathrm{NO}_{\mathrm{x}}$-technique that exploits this reaction was outlined by Wendt et al. [295], who termed the method reburning. In reburning NO is removed from the combustion products by using fuel as reducing agent. By adding part of the fuel and combustion air to the post flame region instead of the main combustion zone a three stage combustion process is obtained. The first stage, where around $80 \%$ of the heat is released, is normally run with stoichiometric or excess air. The reburn fuel, which usually constitutes 10-20\% of the total fuel, is added after the primary combustion zone to form a fuel-rich second stage where NO is reduced. Downstream of the reburn zone secondary combustion air is added to secure complete burnout.

The reburning process has been studied extensively, both experimentally and through modeling work [296]. The reported experimental work includes data from flow reactors [21, 23, 265-267, 297, 298], jet-stirred reactors [100, 268, 270, 272], and low-pressure flames [299-303]. The stages in the reburn process involves mixing of the reburn fuel into the flue gas from the primary zone, decomposition of the reburn fuel and formation of flame radicals to react with NO, and conversion of the formed cyano and amine species to molecular nitrogen. The reburn chemistry is quite complex, sharing similarities with both prompt NO and fuel-NO chemistry. Despite this complexity, reported modeling studies for reburning $[1,21,23,24,262,266,268-273]$ have generally provided satisfactory results, at least for smaller hydrocarbons.

\subsubsection{Reaction subset for reburning}

Table 10 lists selected reactions from the reburning subset of the model. Significant progress has been made in characterizing the reactions that reduce NO. 
In the $1200-1500 \mathrm{~K}$ range typical of the reburn process it is primarily the reactions $\mathrm{HCCO}+\mathrm{NO}, \mathrm{CH}_{3}+\mathrm{NO}$ and ${ }^{3} \mathrm{CH}_{2}+\mathrm{NO}$ that are active in reducing NO [21,23]. At higher temperatures, for instance in well-stirred reactors or flames, $\mathrm{NO}$ is primarily reduced by smaller hydrocarbon radicals, i.e., ${ }^{3} \mathrm{CH}_{2}$, $\mathrm{CH}$, and $\mathrm{C}[1]$. Many of these steps are complex, multi-step reactions.

\begin{tabular}{|c|c|c|c|c|c|}
\hline & & A & $\beta$ & $\mathrm{E}$ & Source \\
\hline 74. & $\mathrm{CH}_{3}+\mathrm{NO} \rightleftarrows \mathrm{HCN}+\mathrm{H}_{2} \mathrm{O}$ & $1.5 \mathrm{E}-1$ & 3.520 & 3950 & {$[304]$} \\
\hline 75. & $\mathrm{CH}_{3}+\mathrm{NO} \rightleftarrows \mathrm{H}_{2} \mathrm{CN}+\mathrm{OH}$ & $1.5 \mathrm{E}-1$ & 3.520 & 3950 & {$[304]$} \\
\hline 76. & ${ }^{3} \mathrm{CH}_{2}+\mathrm{NO} \rightleftarrows \mathrm{HCNO}+\mathrm{H}$ & $3.1 \mathrm{E} 12$ & 0.000 & -378 & {$[305,306]$} \\
\hline 77. & ${ }^{3} \mathrm{CH}_{2}+\mathrm{NO} \rightleftarrows \mathrm{HCN}+\mathrm{OH}$ & $3.9 \mathrm{E} 11$ & 0.000 & -378 & {$[305,306]$} \\
\hline 78. & ${ }^{1} \mathrm{CH}_{2}+\mathrm{NO} \rightleftarrows \mathrm{HCN}+\mathrm{OH}$ & $2.0 \mathrm{E} 13$ & 0.000 & 0 & est \\
\hline 79. & ${ }^{1} \mathrm{CH}_{2}+\mathrm{NO} \rightleftarrows{ }^{3} \mathrm{CH}_{2}+\mathrm{NO}$ & 1.0E14 & 0.000 & 0 & {$[307]$} \\
\hline 80. & $\mathrm{CH}+\mathrm{NO} \rightleftarrows \mathrm{CO}+\mathrm{NH}$ & $9.1 \mathrm{E} 12$ & 0.000 & 0 & {$[26]$} \\
\hline 81. & $\mathrm{CH}+\mathrm{NO} \rightleftarrows \mathrm{NCO}+\mathrm{H}$ & $1.8 \mathrm{E} 13$ & 0.000 & 0 & {$[26]$} \\
\hline 82. & $\mathrm{CH}+\mathrm{NO} \rightleftarrows \mathrm{HCN}+\mathrm{O}$ & $7.9 \mathrm{E} 13$ & 0.000 & 0 & {$[26]$} \\
\hline 83. & $\mathrm{CH}+\mathrm{NO} \rightleftarrows \mathrm{CN}+\mathrm{OH}$ & 1.1E12 & 0.000 & 0 & {$[26]$} \\
\hline 84. & $\mathrm{CH}+\mathrm{NO} \rightleftarrows \mathrm{HCO}+\mathrm{N}$ & $6.8 \mathrm{E} 12$ & 0.000 & 0 & {$[26]$} \\
\hline 85. & $\mathrm{C}+\mathrm{NO} \rightleftarrows \mathrm{CN}+\mathrm{O}$ & $2.0 \mathrm{E} 13$ & 0.000 & 0 & {$[307]$} \\
\hline 86. & $\mathrm{C}+\mathrm{NO} \rightleftarrows \mathrm{CO}+\mathrm{N}$ & $2.8 \mathrm{E} 13$ & 0.000 & 0 & {$[307]$} \\
\hline 87. & $\mathrm{C}_{2} \mathrm{H}_{3}+\mathrm{NO} \rightleftarrows \mathrm{HCN}+\mathrm{CH}_{2} \mathrm{O}$ & $7.0 \mathrm{E} 21$ & -3.382 & 1025 & {$[308]$} \\
\hline 88. & $\mathrm{C}_{2} \mathrm{H}+\mathrm{NO} \rightleftarrows \mathrm{HCN}+\mathrm{CO}$ & $4.6 \mathrm{E} 13$ & 0.000 & 570 & {$[309,310]$} \\
\hline 89. & $\mathrm{C}_{2} \mathrm{H}+\mathrm{NO} \rightleftarrows \mathrm{CN}+\mathrm{HCO}$ & $1.4 \mathrm{E} 13$ & 0.000 & 570 & {$[309,310]$} \\
\hline 90. & $\mathrm{C}_{2}+\mathrm{NO} \rightleftarrows \mathrm{C}_{2} \mathrm{O}+\mathrm{N}$ & $2.3 \mathrm{E} 13$ & 0.000 & 8640 & {$[311]$} \\
\hline 91. & $\mathrm{HCCO}+\mathrm{NO} \rightleftarrows \mathrm{HCNO}+\mathrm{CO}$ & $7.5 \mathrm{E} 12$ & 0.000 & -676 & {$[312-314$} \\
\hline 92. & $\mathrm{HCCO}+\mathrm{NO} \rightleftarrows \mathrm{HCN}+\mathrm{CO}_{2}$ & $2.1 \mathrm{E} 12$ & 0.000 & -676 & {$[312-314$} \\
\hline 93. & $\mathrm{C}_{2} \mathrm{O}+\mathrm{NO} \rightleftarrows \mathrm{CO}+\mathrm{NCO}$ & $1.0 \mathrm{E} 14$ & 0.000 & 670 & {$[315]$} \\
\hline 94. & $\mathrm{HCNO}+\mathrm{H} \rightleftarrows \mathrm{HCN}+\mathrm{OH}$ & $7.2 \mathrm{E} 10$ & 0.841 & 8612 & {$[316]$} \\
\hline 95. & $\mathrm{HCNO}+\mathrm{O} \rightleftarrows \mathrm{HCO}+\mathrm{NO}$ & $6.3 \mathrm{E} 13$ & 0.000 & 0 & {$[317]$} \\
\hline 96. & $\mathrm{HCNO}+\mathrm{O} \rightleftarrows \mathrm{NCO}+\mathrm{OH}$ & $7.0 \mathrm{E} 12$ & 0.000 & 0 & {$[316]$} \\
\hline 97. & $\mathrm{HCNO}+\mathrm{OH} \rightleftarrows \mathrm{CO}+\mathrm{H}_{2} \mathrm{NO}$ & $1.0 \mathrm{E} 13$ & 0.000 & -1490 & {$[318]$} \\
\hline 98. & $\mathrm{HCNO}+\mathrm{OH} \rightleftarrows \mathrm{HCO}+\mathrm{HNO}$ & $6.0 \mathrm{E} 12$ & 0.000 & -1490 & $318]$ \\
\hline
\end{tabular}

Table 10: Selected reactions in the reburn subset. Parameters for use in the modified Arrhenius expression $\mathrm{k}=\mathrm{AT}^{\beta} \exp (-\mathrm{E} /[\mathrm{RT}])$. Units are mol, $\mathrm{cm}, \mathrm{s}$, cal.

The reaction between $\mathrm{CH}_{3}$ and $\mathrm{NO}$ has three product channels:

$$
\mathrm{CH}_{3}+\mathrm{NO}(+\mathrm{M}) \rightleftarrows \mathrm{CH}_{3} \mathrm{NO}(+\mathrm{M})
$$




$$
\begin{aligned}
& \mathrm{CH}_{3}+\mathrm{NO} \rightleftarrows \mathrm{HCN}+\mathrm{H}_{2} \mathrm{O} \\
& \mathrm{CH}_{3}+\mathrm{NO} \rightleftarrows \mathrm{H}_{2} \mathrm{CN}+\mathrm{OH}
\end{aligned}
$$

It has been studied extensively, both at low temperatures, where only the recombination reaction is competitive, and at high temperatures, where cyanides are formed (R74, R75). In the temperature range of the present work, the $\mathrm{CH}_{3} \mathrm{NO}$ complex dissociates rapidly, and only reactions R74 and R75 serve to remove NO. The overall rate for these two steps is fairly well established. We use a rate constant for the overall reaction derived theoretically by Miller et al. [304], which is in good agreement with high temperature experimental data $[319,320]$, together with a branching fraction of $50 \%$ [21].

The reaction between ${ }^{3} \mathrm{CH}_{2}$ and NO has two major product channels, presumably

$$
\begin{gathered}
{ }^{3} \mathrm{CH}_{2}+\mathrm{NO} \rightleftarrows \mathrm{HCNO}+\mathrm{H} \\
{ }^{3} \mathrm{CH}_{2}+\mathrm{NO} \rightleftarrows \mathrm{HCN}+\mathrm{OH}
\end{gathered}
$$

Despite a number of experimental studies [305,321-323] both reaction rate and product channels for this reaction remain uncertain. In particular, the static reactor laser photolysis measurements of Atakan et al. [305] deviate significantly from the shock tube results of Bauerle et al. [323] at the overlapping temperature of $1000 \mathrm{~K}$, both in the overall rate constant and in the contribution of an $\mathrm{OH}$ producing channel. Following Mendiara and Glarborg [23], we adopt the overall rate constant from Atakan et al., using the branching fraction reported by Fikri et al. [306]. The reaction of singlet $\mathrm{CH}_{2}$ with $\mathrm{NO}$ yields primarily inter-system crossing to triplet $\mathrm{CH}_{2}$, with a possible minor channel forming $\mathrm{HCN}$ [21]. For the reaction of $\mathrm{CH}$ with $\mathrm{NO}$ that appears to have five product channels (R80-R84), we rely on the recommendations of Baulch et al. [26].

The reaction between ketenyl and NO,

$$
\mathrm{HCCO}+\mathrm{NO} \rightleftarrows \mathrm{HCNO}+\mathrm{CO}
$$




$$
\mathrm{HCCO}+\mathrm{NO} \rightleftarrows \mathrm{HCN}+\mathrm{CO}_{2}
$$

has been characterized experimentally in a number of studies [312-314,324-328] and both the overall rate constant and the branching fraction is fairly well established. Measurements of the branching fraction indicate that the HCNO + CO channel (R91) dominates, with reported yields of $64-88 \%[313,314,326$, 327]. We have combined the total rate coefficient measurement of Carl et al. [312] with the reported branching fraction, which appears to be independent of temperature $[313,314]$, to arrive at the rate coefficients used in the present work.

The reactions between hydrocarbon radicals and NO mostly feed into the cyanide pool, forming mainly hydrogen cyanide; the cyanide chemistry is discussed in section 3.4. However, both $\mathrm{HCCO}+\mathrm{NO}(\mathrm{R} 76)$ and ${ }^{3} \mathrm{CH}_{2}+\mathrm{NO}(\mathrm{R} 91)$ form $\mathrm{HCNO}$ and the fate of this intermediate is important for the NO reduction efficiency. In earlier reburn modeling work [21], it was assumed that the reactions of $\mathrm{HCNO}$ with $\mathrm{O}$ and $\mathrm{OH}$ were fast and that both of them produced $\mathrm{NO}$ as the major product. Later, Miller et al. [316] proposed NCO as an alternative product for the $\mathrm{HCNO}+\mathrm{OH}$ reaction. However, recent experimental [318] and theoretical [329] work indicate that the $\mathrm{HCNO}+\mathrm{OH}$ reaction forms mainly $\mathrm{H}_{2} \mathrm{NO}$ (R97) and HNO (R98). Thereby the reactions of HCNO with O (R95) and $\mathrm{OH}$ (R97, R98) largely recycle $\mathrm{HCNO}$ back to NO, and consequently the reactions that form $\mathrm{HCNO}$ have only a minor impact on the NO reduction efficiency.

\subsubsection{Modeling reburning}

Even though the reburning process has been studied extensively, experimental data obtained under well-controlled conditions in laboratory scale are limited. For the present purposes, we have selected data from well-stirred reactor and flow reactor experiments. 
Chen and Malte [330] studied combustion of $\mathrm{CH}_{4} / \mathrm{O}_{2} / \mathrm{N}_{2}$-mixtures doped with NO in a jet-stirred flow reactor. They measured the emissions of NO, HCN and $\mathrm{NH}_{3}$ as a function of fuel-air equivalence ratio and temperature. Figure 39 shows comparison between their measurements and modeling predictions for reactor temperatures of $1580 \mathrm{~K}$ and $1800 \mathrm{~K}$.

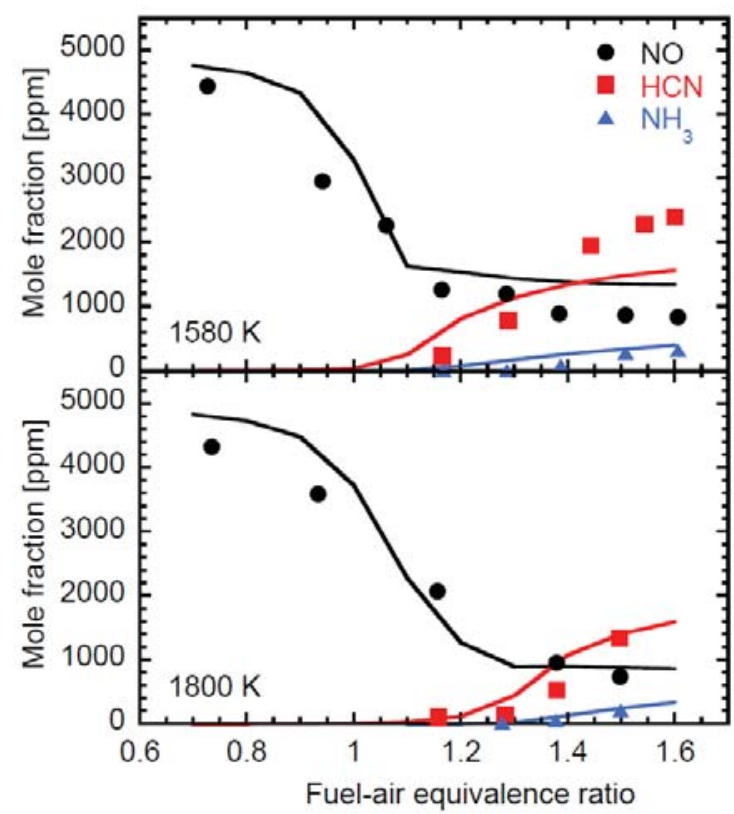

Figure 39: Comparison of measured [330] and predicted emissions of fixed nitrogen species in combustion of methane doped with $5000 \mathrm{ppm}$ NO in a well-stirred reactor. The symbols denote experimental data, while the solid lines denote calculated values. Reactor conditions: temperatures of $1580 \mathrm{~K}$ or $1800 \mathrm{~K}$, nominal residence time $9.0 \mathrm{~ms}$, and pressure $1.0 \mathrm{~atm}$.

The behavior of the reburning system is similar at the two investigated temperatures. Under lean conditions $60-100 \%$ of the NO is emitted, while under fuel-rich conditions the emission of NO is considerably lower, constituting less than $20 \%$ of the inlet NO at fuel-air equivalence ratios larger than 1.4. Here, a major part of the NO is converted to cyanides, with minor amounts of ammonia formed. There is a minimum in total fixed nitrogen (TFN), taken here as the sum $\mathrm{HCN}+\mathrm{NH}_{3}+\mathrm{NO}$, as a function of the equivalence ratio. The minimum 
at $1580 \mathrm{~K}$ occurs at a fuel-air equivalence ratio below 1.2 , while at $1800 \mathrm{~K}$ the minimum is observed at more reducing conditions, $\phi \approx 1.3$. The agreement between experimental data and modeling predictions is good. Both NO, HCN and $\mathrm{NH}_{3}$ are predicted well over the whole range of equivalence ratios, in particular at the higher temperature.

The importance of competing reaction pathways depends strongly on the actual reburn conditions, particularly reburn fuel, temperature, and stoichiometry. However, the results can all be interpreted in terms of three most important overall steps:

- Decomposition of the reburn fuel and formation of hydrocarbon radicals

- Fast reaction of hydrocarbon radicals with NO, forming cyanide species

- Comparatively slow conversion of cyanide species via isocyanic and amine species partly to $\mathrm{N}_{2}$ and partly back to $\mathrm{NO}$

Figure 40 shows a reaction path diagram for the reburn chemistry, for methane as a reburn fuel. Nitric oxides are converted into cyanides and isocyanides by reactions with a wide range of hydrocarbon radicals, mainly $\mathrm{CH}_{3},{ }^{3} \mathrm{CH}_{2}, \mathrm{CH}$, $\mathrm{C}$, and $\mathrm{HCCO}$. At high radical concentrations (high temperatures and/or jetstirred reactor conditions), the smaller hydrocarbon radicals are most active in reducing NO, while in a less reactive environment (lower temperatures and/or flow reactor conditions) reactions of $\mathrm{NO}$ with $\mathrm{CH}_{3}$ and $\mathrm{HCCO}$ dominate.

The cyanide pool is oxidized in a sequence of reactions similar to that discussed for prompt-NO formation (section 3.2) and HCN oxidation (section 3.4). Under high-temperature, reducing conditions a significant fraction of the $\mathrm{HCN}$ is converted through the isomer $\mathrm{HNC}$ in the sequence $\mathrm{HCN} \stackrel{+\mathrm{M}, \mathrm{H}}{\longrightarrow} \mathrm{HNC} \stackrel{\mathrm{OH}}{\longrightarrow} \mathrm{HNCO}$ $\stackrel{\mathrm{H}}{\longrightarrow} \mathrm{NH}_{2} \stackrel{\mathrm{H}, \mathrm{OH}}{\longrightarrow} \mathrm{NH}$. This sequence is shown as a single dashed line in Fig. 40.

Reactions of ${ }^{3} \mathrm{CH}_{2}$ and $\mathrm{HCCO}$ with NO yield HCNO, which becomes an important nitrogen intermediate under certain conditions. The HCNO is partly con- 


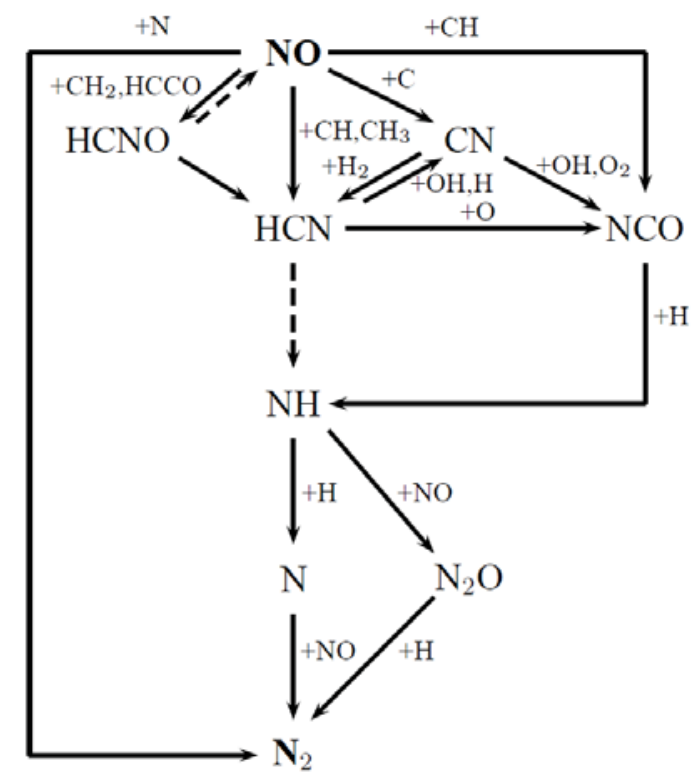

Figure 40: Reaction path diagram for NO reduction by reburning with methane. Dashed lines denote multi-step pathways (see discussion).

verted to $\mathrm{HCN}$ by reaction with atomic hydrogen and possibly also by thermal dissociation. However, a significant fraction of the HCNO is recycled directly or indirectly (via $\mathrm{HNO}$ and $\mathrm{H}_{2} \mathrm{NO}$ ) to $\mathrm{NO}$ through reaction with $\mathrm{OH}(\mathrm{R} 97, \mathrm{R} 98$ ) and $\mathrm{O}$ (R95); these recycling pathways are shown in Fig. 40 as a single dashed line.

Figure 41 shows sensitivity coefficients for NO for the conditions of the Chen and Malte experiments for fuel-air equivalence ratios of 1.1 and 1.3. The analysis shows that the reactions of importance for NO removal depends on the stoichiometry, but there are some common trends. Nitric oxide is consumed by mainly hydrocarbon radicals and prediction of NO is sensitive to these steps, in particular $\mathrm{CH}_{3}+\mathrm{NO}(\mathrm{R} 74, \mathrm{R} 75),{ }^{3} \mathrm{CH}_{2}+\mathrm{NO}(\mathrm{R} 76)$, and $\mathrm{CH}+\mathrm{NO}$ (R82). Consequently, also reactions promoting formation of $\mathrm{CH}_{\mathrm{n}}$ exhibit negative sensitivity coefficients; these steps include $\mathrm{CH}_{3}+\mathrm{H}$ (R99, R100b), $\mathrm{CH}_{3}+\mathrm{OH}(\mathrm{R} 103)$ and ${ }^{3} \mathrm{CH}_{2}+\mathrm{H}$ (R106). Oxidation of hydrocarbon radicals to oxygenated in- 
termediates inhibits NO removal; this takes place mainly through the reactions $\mathrm{CH}_{3}+\mathrm{O}$ (R101), ${ }^{3} \mathrm{CH}_{2}+\mathrm{OH}(\mathrm{R} 107), \mathrm{CH}+\mathrm{H}_{2} \mathrm{O}$ (R115), and $\mathrm{CH}+\mathrm{CO}_{2}$ (R116). Nitric oxide may also be reduced by reaction with amine radicals, NH $+\mathrm{NO}(\mathrm{R} 17)$ and $\mathrm{N}+\mathrm{NO}(\mathrm{R} 1)$, or reformed by the reaction $\mathrm{N}+\mathrm{OH}(\mathrm{R} 3)$.

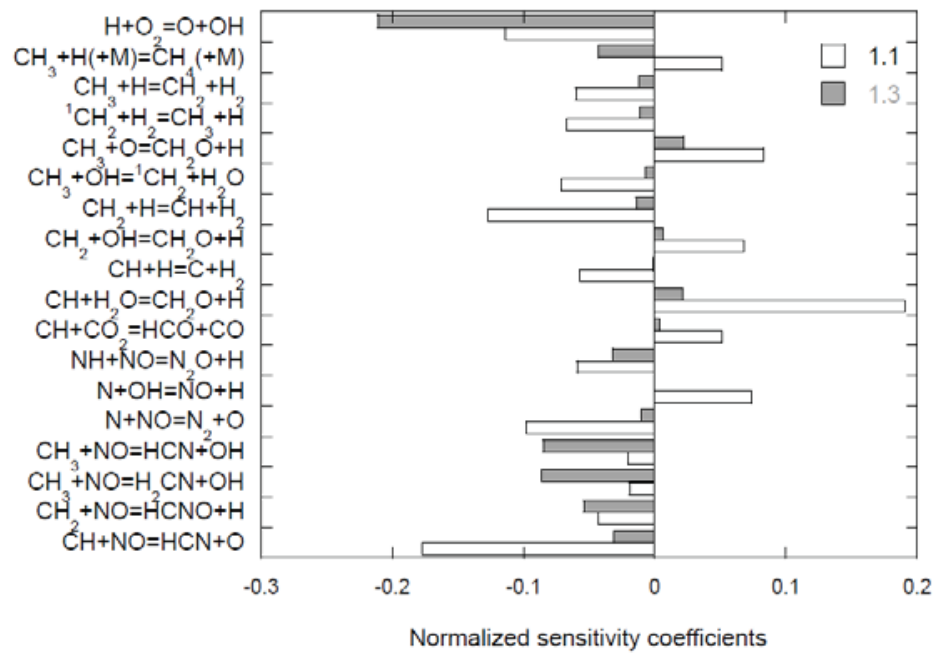

Figure 41: Sensitivity coefficients for prediction of NO under the conditions of the Chen and Malte reburn experiments [330] at $1580 \mathrm{~K}$ as a function of the stoichiometry ( $\phi=1.1$ or 1.3$)$.

Figure 42 shows a comparison between the flow reactor data of Myerson [297] and calculations for combustion of methane in a simulated flue gas containing $\mathrm{CO}, \mathrm{CO}_{2}, \mathrm{O}_{2}$ and $\mathrm{N}_{2}$, together with $1150 \mathrm{ppm}$ NO. The figure shows the effect of oxygen concentration on the emission of total fixed nitrogen $(\mathrm{NO}+\mathrm{HCN}+$ $\mathrm{NH}_{3}$ ) from the reactor. Myerson observed significant temperature gradients in the reactor and the reported temperature of $1423 \mathrm{~K}$ was only accurate within $\pm 70 \mathrm{~K}$.

Myerson showed that for a variety of fuels, there was a most effective molar ratio between the oxygen and the reburn fuel at which a minimum TFN could be obtained. The observed minimum for methane occurs at an $\mathrm{O}_{2} / \mathrm{CH}_{4}-$ ratio of 1.0 (Figure 42). The agreement between experimental data and calculations 


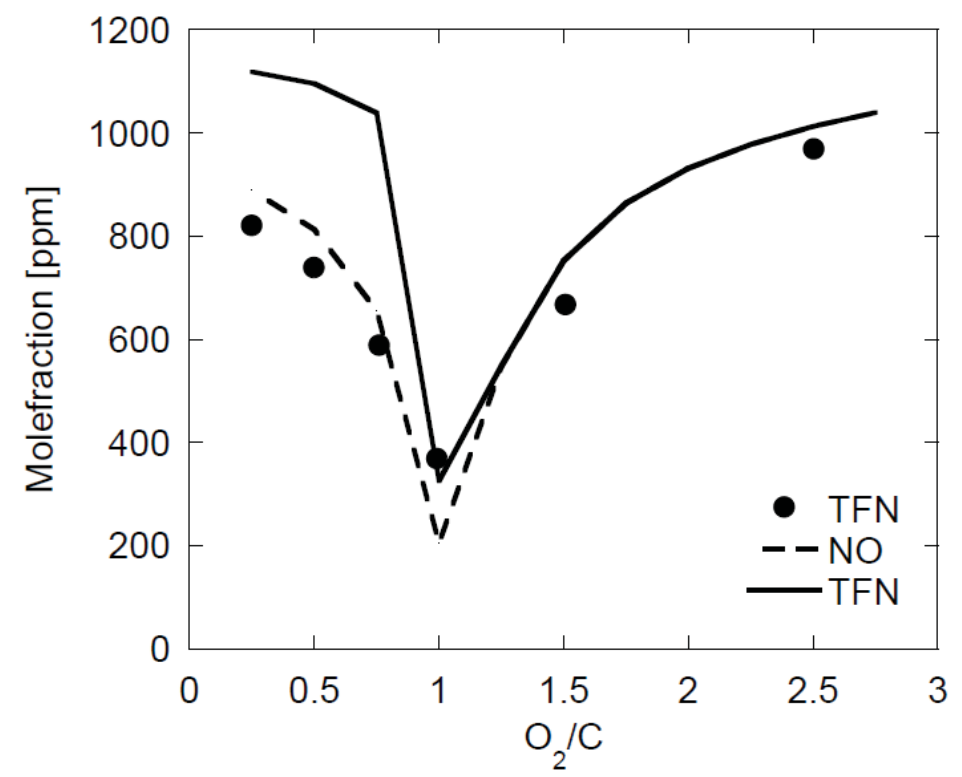

Figure 42: Comparison of measured [297] and predicted emissions of total fixed nitrogen species $\left(\mathrm{HCN}+\mathrm{NH}_{3}+\mathrm{NO}\right)$ for reaction of methane with a simulated flue gas in a flow reactor (mullite or alumina). The symbols denote experimental data, while the solid line denotes calculated values. The dashed line denotes the predicted NO emission. Reactor conditions: temperature $1423 \pm 70 \mathrm{~K}$ (assumed $1450 \mathrm{~K}$ in calculations), residence time $189 \mathrm{~ms}$, and pressure $1.0 \mathrm{~atm}$. Inlet mole fractions: $0.46 \% \mathrm{CH}_{4}, 1.0 \% \mathrm{CO}, 13.2 \% \mathrm{CO}_{2}, 0.115 \% \mathrm{NO} 0.0012, \mathrm{O}_{2}$ varying; $\mathrm{N}_{2}$ balance.

is good, except at very reducing conditions $\left(\mathrm{O}_{2} / \mathrm{CH}_{4}<1.0\right)$ where the concentration of total fixed nitrogen is overpredicted. Both modeling predictions and experimental data indicate that the fixed nitrogen under these conditions consists almost entirely of $\mathrm{NO}$ and $\mathrm{HCN}$; only negligible amounts of $\mathrm{NH}_{3}$ are formed.

Alzueta and coworkers $[21,267]$ studied the reburn chemistry for different hydrocarbon fuels in flow reactor experiments under reducing conditions. In Fig. 43 a comparison is shown between their data and calculations for NO in combustion of methane and $\mathrm{C}_{2}$-hydrocarbons as a function of temperature.

The results show that the ability to remove NO varies significantly between the 
investigated hydrocarbons. Under the conditions of the experiments, $\mathrm{CH}_{4}$ is only active above $1350 \mathrm{~K}$, reducing NO by about 30\%. A simulated natural gas (methane with about $10 \%$ of ethane) is more efficient in reducing NO and with a lower onset temperature, about $1300 \mathrm{~K}$. Among the $\mathrm{C}_{2}$-hydrocarbons, acetylene and ethylene behave similarly, with an NO reduction of up to about $50 \%$ from $1150 \mathrm{~K}$. Ethane is able to reduce NO above $1100 \mathrm{~K}$, with the efficiency increasing with temperature. Nitric oxide is partly converted to hydrogen cyanide for all fuels, but the HCN concentrations are comparatively low.

The modeling predictions capture the trends well and are mostly in good agreement with the experimental results. The only major discrepancy is seen for reburning with ethane, where both the reduction of NO and the formation of $\mathrm{HCN}$ is underpredicted. Part of this difference may be attributed to mixing effects in the reactor, as discussed by Glarborg et al. [21].

Prediction of the potential of reburning for reducing NO relies on the ability of the model to describe the chemistry in the reducing zone, where hydrocarbon radicals are formed and act to reduce NO, and at the rich-lean transition, where the formed cyanides and amines are converted to $\mathrm{NO}$ and $\mathrm{N}_{2}$. The accuracy in predicting the fuel-derived radical concentrations is still in discussion, even for oxidation of methane (see section 3.2 and App. B). However, since most of the $\mathrm{C}_{1}$ and $\mathrm{C}_{2}$ radicals typically participate in removing $\mathrm{NO}$ and the radical + NO reactions generally are fairly well characterized, the model would be expected to predict the NO consumption in the reducing zone perhaps within $30 \%$ for methane, with a slightly higher uncertainty for other hydrocarbons. The burnout chemistry at the rich-lean transition, which is discussed in more detail by Kristensen et al. [182], involves oxidation of $\mathrm{HCN}$ and $\mathrm{NH}_{3}$ in the presence of the remaining combustibles as well as of NO. It shares similarities with selective non-catalytic reduction of NO (see section 4.1). The radical generation in the burnout region is controlled by oxidation of $\mathrm{CO}$ and $\mathrm{H}_{2}$ rather than by the nitrogen chemistry, and the selectivity for forming $\mathrm{NO}$ and $\mathrm{N}_{2}$ from the reactive 
nitrogen species would be expected to be captured well by the model. 


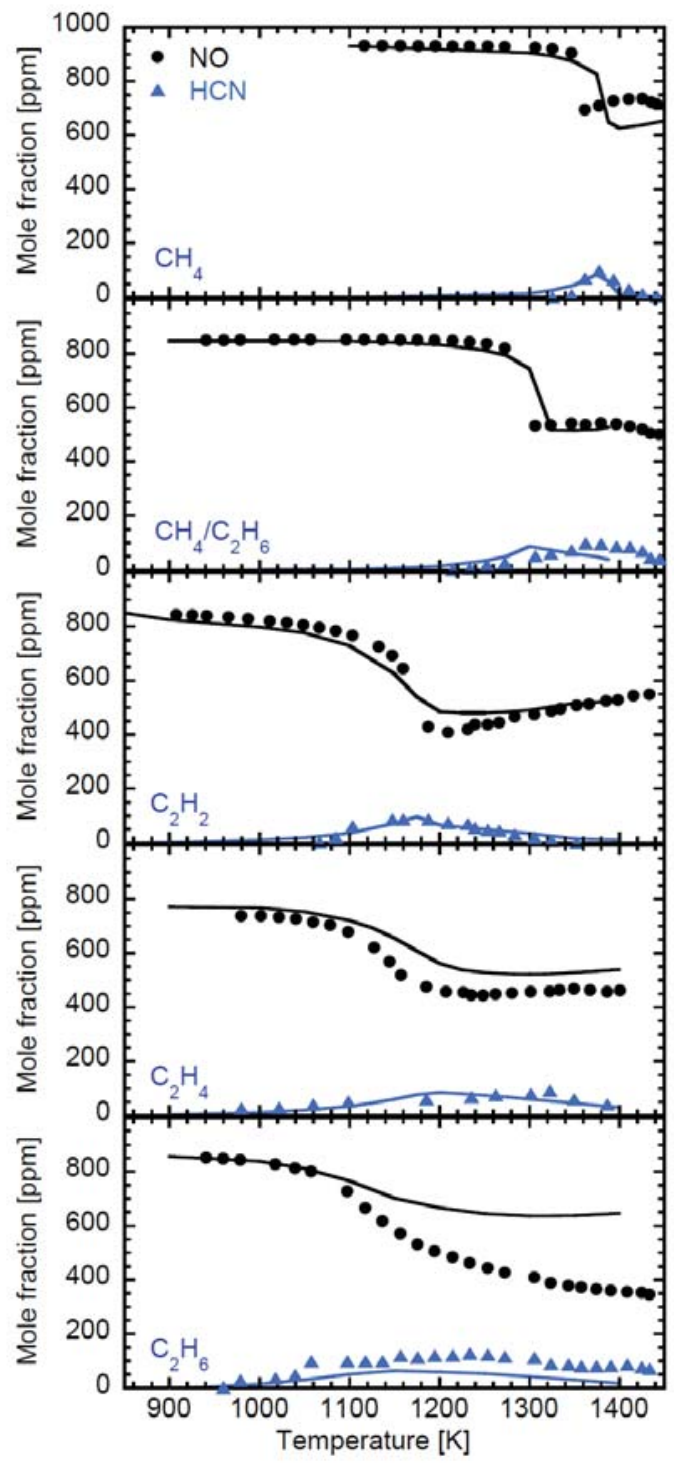

Figure 43: Comparison of experimental data $[21,267]$ and modeling predictions for reduction of $\mathrm{NO}$ by hydrocarbons under reburning conditions in a quartz flow reactor. Symbols denote experimental data, while solid lines denote modeling predictions. Inlet concentrations: $\mathrm{CH}_{4}=2800 \mathrm{ppm}, \mathrm{O}_{2}=4830 \mathrm{ppm}, \mathrm{NO}=$ $920 \mathrm{ppm}(\tau=181[\mathrm{~K}] / \mathrm{T}) ; \mathrm{CH}_{4}=2770 \mathrm{ppm}, \mathrm{C}_{2} \mathrm{H}_{6}=260 \mathrm{ppm}, \mathrm{O}_{2}=4885 \mathrm{ppm}$, $\mathrm{NO}=850 \mathrm{ppm}(\tau=170[\mathrm{~K}] / \mathrm{T}) ; \mathrm{C}_{2} \mathrm{H}_{2}=890 \mathrm{ppm}, \mathrm{O}_{2}=1700 \mathrm{ppm}, \mathrm{NO}=835$ $\operatorname{ppm}(\tau=162[\mathrm{~K}] / \mathrm{T}) ; \mathrm{C}_{2} \mathrm{H}_{4}=1020 \mathrm{ppm}, \mathrm{O}_{2}=2015 \mathrm{ppm}, \mathrm{NO}=790 \mathrm{ppm}(\tau=$ $165[\mathrm{~K}] / \mathrm{T}) ; \mathrm{C}_{2} \mathrm{H}_{6}=1530 \mathrm{ppm}, \mathrm{O}_{2}=3970 \mathrm{ppm}, \mathrm{NO}=870 \mathrm{ppm}(\tau=167[\mathrm{~K}] / \mathrm{T})$. All experiments were conducted with $2 \% \mathrm{H}_{2} \mathrm{O}$, balance $\mathrm{N}_{2}$, at $1.05 \mathrm{~atm}$. 


\section{Concluding remarks}

Close to thirty years ago, Miller and Bowman published their epochal review on nitrogen chemistry in combustion. They concluded that future changes to their proposed mechanism were likely to be quantitative rather than qualitative. Since then, our knowledge of the thermochemistry and rate constants important for formation and destruction of nitrogen oxides has increased considerably, facilitated by the development of high-level theoretical tools. However, to a large extent the statement of Miller and Bowman has turned out to be accurate. The subsets describing formation of $\mathrm{NO}$ by the thermal mechanism, via $\mathrm{N}_{2} \mathrm{O}$, or from oxidation of cyanides and amines are now more reliable due to advances in our knowledge of specific reactions, but qualitatively they are similar to those proposed by Miller and Bowman. The same applies for the reburn type chemistry that serves to destroy NO in staged combustion. Major discoveries post Miller and Bowman concern the formation of prompt NO, where the products of the rate controlling reaction between $\mathrm{CH}$ and $\mathrm{N}_{2}$ is now known to be $\mathrm{NCN}$ $+\mathrm{H}$ rather than $\mathrm{HCN}+\mathrm{N}$, and the Thermal $\mathrm{DeNO}_{\mathrm{x}}$ process, where the predicted lifetime of $\mathrm{NNH}$ has been reduced from $10^{-4} \mathrm{~s}$ to $10^{-9} \mathrm{~s}$, so reaction now is restrained by the branching fraction $\alpha$ of the $\mathrm{NH}_{2}+\mathrm{NO}$ reaction rather than by reaction of $\mathrm{NNH}$ with $\mathrm{NO}$ or $\mathrm{O}_{2}$. Despite the advances in the accuracy of specific rate constants, there are still subsets of the nitrogen chemistry where modeling predictions are less reliable than desired; these include primarily prompt NO formation and selective non-catalytic reduction of NO (SNCR). However, overall the present non-optimized model offers reliable predictions for formation and destruction of $\mathrm{NO}$ over a wide range of conditions and can be used with a significant degree of confidence in engineering calculations for industrial processes.

Future challenges in nitrogen chemistry include extension of the model to more complicated fuels (emphasizing, for instance, formation of hydrocarbon radicals that may interact with nitrogen species), more complex nitrogen compounds 
such as cyclic species, and, not least, extension to the high pressures encountered in engines and gas turbines.

\section{Acknowledgments}

The work is part of the CHEC (Combustion and Harmful Emission Control) research program. The work at DTU (P.G.) was financially supported by Innovation Fund Denmark. The work at Argonne National Laboratory (B.R., S.J.K.) was supported by the U.S. Department of Energy, Office of Science, Office of Basic Energy Sciences, Division of Chemical Sciences, Geosciences and Biosciences, under Contract No. DE-AC02-06CH11357, with the contribution from J.A.M. supported through the Argonne-Sandia Consortium on High-Pressure Combustion Chemistry (ANL FWP 59044). Finally, the authors would like to thank Tamas Turanyi for a careful reading of the manuscript and the reviewers for very useful comments. 


\section{References}

[1] J.A. Miller and C.T. Bowman. Mechanism and modeling of nitrogen chemistry in combustion. Prog. Energy Combust. Sci., 15:287-338, 1989.

[2] C.T. Bowman. Control of combustion-generated nitrogen oxide emissions: technology driven by regulation. Symp. (Int.) Combust., 24:859-878, 1992.

[3] P. Glarborg, A.D. Jensen, and J.E. Johnsson. Fuel nitrogen conversion in solid fuel fired systems. Prog. Energy Combust. Sci., 29:89-113, 2003.

[4] P. Glarborg. Hidden interactions - trace species governing combustion and emissions. Proc. Combust. Inst., 31:77-98, 2007.

[5] J.E. Johnsson. Formation and Reduction of Nitrogen Oxides in FluidizedBed Combustion. Fuel, 73:1398-1415, 1994.

[6] S.C. Hill and L.D. Smoot. Modeling of nitrogen oxides formation and destruction in combustion systems. Prog. Energy Combust. Sci., 26:417458,2000 .

[7] F.L. Dryer, F.M. Haas, J. Santner, T.I. Farouk, and M. Chaos. Interpreting chemical kinetics from complex reaction-advection-diffusion systems: Modeling of flow reactors and related experiments. Prog. Energy Combust. Sci., 44:19-39, 2014.

[8] B. Ruscic, R.E. Pinzon, M.L. Morton, G. von Laszewski, S. Bittner, S.G. Nijsure, K.A. Amin, M. Minkoff, and A.F. Wagner. Introduction to Active Thermochemical Tables: Several "key" enthalpies of formation revisited. J. Phys. Chem. A, 108:9979-9997, 2004.

[9] B. Ruscic, R.E. Pinzon, G. von Laszewski, D. Kodeboyina, A. Burcat, D. Leahy, D. Montoya, and A.F. Wagner. Active Thermochemical Tables: thermochemistry for the 21st century. J. Phys. Conf. Ser., 16:561-570, 2005. 
[10] B. Ruscic. Active Thermochemical Tables: Sequential bond dissociation Enthalpies of methane, ethane, and methanol and the related thermochemistry. J. Phys. Chem. A, 119:7810-7837, 2015.

[11] B. Ruscic and D. H. Bross. Active Thermochemical Tables (ATcT) values based on ver. 1.122 of the Thermochemical Network. (available at ATcT.anl.gov), 2016.

[12] T. L. Nguyen, J. H. Baraban, B. Ruscic, and J. F. Stanton. On the HCN - HNC energy difference. J. Phys. Chem. A, 119:10929-10934, 2015.

[13] S.J. Klippenstein, L.B. Harding, and B. Ruscic. Ab initio computations and Active Thermochemical Tables hand in hand: Heats of formation of core combustion species. J. Phys. Chem. A, 121:6580-6602, 2017.

[14] B. J. McBride and S. Gordon. Properties and coefficients, computer program for calculating and fitting thermodynamic functions. National Aeronautics and Space Administration, Glenn Research Center, Cleveland, OH, 1999.

[15] E. Goos, A. Burcat, , and B. Ruscic. Ideal gas thermochemical database with updates from Active Thermochemical Tables. (<ftp://ftp. technion. ac. il/pub/supported/aetdd/thermodynamics $>$ mirrored at $<$ http://garfield. chem. elte. hu/burcat/burcat. html>, 2016.

[16] H. Hashemi, J.M. Christensen, S. Gersen, H. Levinsky, S.J. Klippenstein, and P. Glarborg. High-pressure oxidation of methane. Combust. Flame, 172:349-364, 2016.

[17] J. Gimenez-Lopez, C. T. Rasmussen, H. Hashemi, M.U. Alzueta, Y. Gao, P. Marshall, C.F. Goldsmith, and P. Glarborg. Experimental and kinetic modeling study of $\mathrm{C}_{2} \mathrm{H}_{2}$ oxidation at high pressure. Int. J. Chem. Kinet., 48:724-738, 2016. 
[18] H. Hashemi, J. G. Jacobsen, C. T. Rasmussen, J. M. Christensen, P. Glarborg, S. Gersen, M. van Essen, H.B. Levinsky, and S.J. Klippenstein. High-pressure oxidation of ethane. Combust. Flame, 182:150-166, 2017.

[19] S.J. Klippenstein, L.B. Harding, P. Glarborg, and J.A. Miller. The role of NNH in NO formation and control. Combust. Flame, 158:774-789, 2011.

[20] P. Dagaut, P. Glarborg, and M.U. Alzueta. The oxidation of hydrogen cyanide and related chemistry. Prog. Energy Combust. Sci., 34:1-46, 2008.

[21] P. Glarborg, M.U. Alzueta, K. Dam-Johansen, and J.A. Miller. Kinetic modeling of hydrocarbon/nitric oxide interactions in a flow reactor. Combust. Flame, 115:1-27, 1998.

[22] T. Mendiara and P. Glarborg. Ammonia chemistry in oxy-fuel combustion of methane. Combust. Flame, 156:1937-1949, 2009.

[23] T. Mendiara and P. Glarborg. NO reduction in oxy-fuel combustion of methane. Energy Fuels, 23:3565-3572, 2009.

[24] P. Glarborg, J.A. Miller, and R.J. Kee. Kinetic modeling and sensitivity analysis of nitrogen oxide formation in well-stirred reactors. Combust. Flame, 65:177-202, 1986.

[25] Y.B. Zeldovich. The oxidation of nitrogen in combustion and explosions. Acta. Physicochem. USSR, 21:577-628, 1946.

[26] D.L. Baulch, C.T. Bowman, C.J. Cobos, R.A. Cox, T. Just, J.A. Kerr, M.J. Pilling, D. Stocker, J. Troe, W. Tsang, R.W. Walker, and J. Warnatz. Evaluated kinetic data for combustion modeling: Supplement II. J. Phys. Chem. Ref. Data, 34:757-1397, 2005.

[27] J.P. Monat, R.K. Hanson, and C.H. Kruger. Shock tube determination of the rate coefficient for the reaction $\mathrm{N}_{2}+\mathrm{O} \rightarrow \mathrm{NO}+\mathrm{N}$. Symp. (Int.) Combust., 17:543-552, 1979. 
[28] K. Thielen and P. Roth. Resonance absorption measurements of $\mathrm{N}$ and $\mathrm{O}$ atoms in high temperature NO dissociation and formation kinetics. Symp. (Int.) Combust., 20:685-693, 1984.

[29] C.P. Fenimore. Formation of nitric oxide in premixed hydrocarbon flames. Symp. (Int.) Combust., 13:373-380, 1971.

[30] J.B. Livesey, A.L. Roberts, and A. Williams. The formation of oxides of nitrogen in some oxy-propane flames. Combust. Sci. Technol., 4:9-15, 1971.

[31] F. Bachmaier, K.H. Eberius, and Th. Just. The formation of nitric oxide and the detection of $\mathrm{HCN}$ in premixed hydrocarbon-air flames at 1 atmosphere. Combust. Sci. Technol., 7:77-84, 1973.

[32] D. Iverach, K.S. Basden, and N.Y. Kirov. Formation of nitric oxide in fuel-lean and fuel-rich flames. Symp. (Int.) Combust., 14:767-775, 1973.

[33] R.J. Harris, M. Nasralla, and A. Williams. Formation of oxides of nitrogen in high-temperature $\mathrm{CH}_{4}-\mathrm{O}_{2}-\mathrm{N}_{2}$ flames. Combust. Sci. Technol., 14:85-94, 1976.

[34] P.V. Heberling. Prompt NO measurements at high pressures. Symp. (Int.) Combust., 16:159-166, 1977.

[35] J. Blauwens, B. Smets, and J. Peeters. Mechanism of prompt NO formation in hydrocarbon flames. Symp. (Int.) Combust., 16:1055-1064, 1976.

[36] M.F. Zabielski and D.J. Seery. The direct measurement of the rate of nitric oxide formation in a high temperature, oxygen enriched methane flame. ASME Fossil Fuels Combust. Symp., 25:91-94, 1989.

[37] M.A.A. Clyne and B.A. Thrush. Kinetics of reactions of active nitrogen with oxygen and with nitric oxide. Proc. $R$. Soc. London A, 261:259-273, 1961. 
[38] M.A.A. Clyne and I.S. McDermid. Mass-spectrometric determinations of rates of elementary reactions of $\mathrm{NO}$ and of $\mathrm{NO}_{2}$ with ground-state $\mathrm{N}$ atoms. J. Chem. Soc. Faraday Trans. 1, 71:2189-2202, 1975.

[39] C.T. Cheah and M.A.A. Clyne. Reactions forming electronically-excited free-radicals. 2. Formation of $\mathrm{N} 4 \mathrm{~s}, \mathrm{~N}_{2} \mathrm{~d}$ and $\mathrm{N}_{2} \mathrm{p}$ atoms in the $\mathrm{H}+\mathrm{NF}_{2}$ reaction, and N-atom reactions. J. Chem. Soc. Faraday Trans. 2, 76:1543$1560,1980$.

[40] J. Brunning and M.A.A. Clyne. Elementary reactions of the SF radical. Part 1. Rate constants for the reactions $\mathrm{F}+\mathrm{OCS} \rightarrow \mathrm{SF}+\mathrm{CO}$ and $\mathrm{SF}+$ $\mathrm{SF} \rightarrow \mathrm{SF}_{2}+$ S. J. Chem. Soc. Faraday Trans. 2, 80:1001-1014, 1984.

[41] J.H. Lee, J.V. Michael, W.A. Payne, and L.J. Stief. Absolute rate of the reaction of $\mathrm{N}$ with NO from 196-400 K with DF-RF and FP-RF techniques. J. Chem. Phys., 69:3069-3076, 1978.

[42] M. Koshi, M. Yoshimura, K. Fukuda, H. Matsui, K. Saito, M. Watanabe, A. Imamura, and C. Chen. Reactions of $\mathrm{N}$ atoms with $\mathrm{NO}$ and $\mathrm{H}_{2} . J$. Chem. Phys., 93:8703-8708, 1990.

[43] D.F. Davidson and R.K. Hanson. High-temperature reaction-rate coefficients derived from $\mathrm{N}$-atom ARAS measurements and excimer photolysis of NO. Int. J. Chem. Kinet., 22:843-861, 1990.

[44] J.V. Michael and K.P. Lim. Rate constants for the $\mathrm{N}_{2} \mathrm{O}$ reaction system - thermal-decomposition of $\mathrm{N}_{2} \mathrm{O}, \mathrm{N}+\mathrm{NO} \rightarrow \mathrm{N}_{2}+\mathrm{O}$ and implications for $\mathrm{O}+\mathrm{N}_{2} \rightarrow \mathrm{NO}+\mathrm{N}$. J. Chem. Phys., 97:3228-3234, 1992.

[45] H.J. Mick, H. Matsui, and P. Roth. High-temperature kinetics of Si atom oxidation by $\mathrm{NO}$ based on $\mathrm{Si}, \mathrm{N}$, and $\mathrm{O}$ atom measurements. J. Phys. Chem., 97:6839-6842, 1993.

[46] M. Abian, M.U. Alzueta, and P. Glarborg. Formation of NO from $\mathrm{N}_{2} / \mathrm{O}_{2}$ mixtures in a flow reactor: Towards an accurate prediction of Thermal NO. Int. J. Chem. Kinet., 47:518-532, 2015. 
[47] P. Gamallo, M. Gonzalez, and R. Says. Ab initio study of the two lowest triplet potential energy surfaces involved in the $\mathrm{N}+\mathrm{NO}$ reaction. $J$. Chem. Phys., 118:10602-10610, 2003.

[48] O. Skreiberg, P. Kilpinen, and P. Glarborg. Ammonia chemistry under fuel-rich conditions in a flow reactor. Combust Flame, 136:501-518, 2004.

[49] A. Fernandez, A. Goumri, and A. Fontijn. Kinetics of the reactions of N atoms with $\mathrm{O}_{2}$ and $\mathrm{CO}_{2}$ over wide temperature ranges. J. Phys. Chem. A, 102:168-172, 1998.

[50] A.A. Konnov. On the relative importance of different routes forming NO in hydrogen flames. Combust Flame, 134:421-424, 2003.

[51] A. Frassoldati, T. Faravelli, and E. Ranzi. A wide range modeling study of $\mathrm{NO}_{\mathrm{x}}$ formation and nitrogen chemistry in hydrogen combustion. Int. J. Hydrogen Energy, 31:2310-2328, 2006.

[52] N. Arai, T. Higashi, M. Hasatani, and S. Sugiyama. Formation of thermal $\mathrm{NO}_{\mathrm{x}}$ in a binary system of nitrogen and oxygen. Int. Chem. Eng., 18:661$665,1978$.

[53] J.B. Homer and M.M. Sutton. Nitric oxide formation and radical overshoot in premixed hydrogen flames. Combust Flame, 20:71-76, 1973.

[54] A.N. Hayhurst and I.M. Vince. Nitric-oxide formation from $\mathrm{N}_{2}$ in flames - the importance of prompt NO. Prog. Energy Combust. Sci., 6:35-51, 1980.

[55] M.R. Roomina and R.W. Bilger. Conditional moment closure (CMC) predictions of a turbulent methane-air jet flame. Combust. Flame, 125:11761195, 2001.

[56] L. Cui, K. Morokuma, J.M. Bowman, and S.J. Klippenstein. The spinforbidden reaction $\mathrm{CH}+\mathrm{N}_{2} \rightarrow \mathrm{HCN}+\mathrm{N}$ revisited. II. Nonadiabatic transition state theory and application. J. Chem. Phys., 110:9469-9482, 1999. 
[57] L.V. Moskaleva and M.C. Lin. The spin-conserved reaction $\mathrm{CH}+\mathrm{N}_{2} \rightarrow \mathrm{H}$ + NCN: A major pathway to prompt NO studied by quantum/statistical theory calculations and kinetic modeling of rate constant. Proc. Combust. Inst., 28:2393-2401, 2000.

[58] S. Xu and M. C. Lin. Ab initio chemical kinetics for singlet $\mathrm{CH}_{2}$ reaction with $\mathrm{N}_{2}$ and the related decomposition of diazomethane. J. Phys. Chem. A, 114:5195-5204, 2010.

[59] B.A. Williams and J.W. Fleming. Experimental and modeling study of NO formation in 10 torr methane and propane flames: Evidence for additional prompt-NO precursors. Proc. Combust. Inst., 31:1109-1117, 2007.

[60] J.A. Sutton and J.W. Fleming. Towards accurate kinetic modeling of prompt NO formation in hydrocarbon flames via the NCN pathway. Combust. Flame, 154:630-636, 2008.

[61] A.A. Konnov. Implementation of the NCN pathway of prompt-NO formation in the detailed reaction mechanism. Combust. Flame, 156:2093-2105, 2009.

[62] N. Lamoureux, P. Desgroux, A. El Bakali, and J.F. Pauwels. Experimental and numerical study of the role of NCN in prompt-NO formation in lowpressure $\mathrm{CH}_{4}-\mathrm{O}_{2}-\mathrm{N}_{2}$ and $\mathrm{C}_{2} \mathrm{H}_{2}-\mathrm{O}_{2}-\mathrm{N}_{2}$ flames. Combust. Flame, 157:19291941, 2010.

[63] R. S. Zhu, S. C. Xu, and M. C. Lin. Ab initio chemical kinetics for the reactions of $\mathrm{N}_{2}$ with singlet and triplet $\mathrm{C}_{2} \mathrm{O}$ radicals. Chem. Phys. Lett., 488:121-125, 2010.

[64] T. Sommer, T. Kruse, P. Roth, and H. Hippler. Perturbation study on the reaction of $\mathrm{C}_{2}$ with $\mathrm{N}_{2}$ in high-temperature $\mathrm{C}_{60} / \mathrm{Ar}+\mathrm{N}_{2}$ mixtures. $J$. Phys. Chem. A, 101:3720-3725, 1997. 
[65] Yu. A. Kolbanovskii and Yu. A. Borisov. Quantum chemical calculations on the mechanism of the reaction between dicarbene $\mathrm{C}_{2}$ and molecular nitrogen. Russ J. Phys. Chem. B, 9:29-35, 2015.

[66] M. Köhler, A. Brockhinke, M. Braun-Unkhoff, and K. Kohse-Höinghaus. Quantitative laser diagnostic and modeling study of $\mathrm{C}_{2}$ and $\mathrm{CH}$ chemistry in combustion. J. Phys. Chem. A, 114:4719-4734, 2010.

[67] A. el Bakali, L. Pillier, P. Desgroux, B. Lefort, L. Gasnot, J.F. Pauwels, and I. da Costa. NO prediction in natural gas flames using GDF-Kin3.0 mechanism NCN and HCN contribution to prompt-NO formation. Fuel, 85:896-909, 2006.

[68] I.G. Zsely, J. Zador, and T. Turanyi. Uncertainty analysis of NO production during methane combustion. Int. J. Chem. Kinet., 40:754-768, 2008.

[69] S. Gersen, A.V. Mokhov, and H.B. Levinsky. Diode laser absorption measurement and analysis of $\mathrm{HCN}$ in atmospheric-pressure, fuel-rich premixed methane/air flames. Combust. Flame, 155:267-276, 2008.

[70] J.A. Sutton, B.A. Williams, and J.W. Fleming. Investigation of NCN and prompt-NO formation in low-pressure $\mathrm{C}_{1}-\mathrm{C}_{4}$ alkane flames. Combust. Flame, 159:562-576, 2012.

[71] E. Goos, C. Sickfeld, F. Mauss, L. Seidel, B. Ruscic, A. Burcat, and T. Zeuch. Prompt NO formation in flames: The influence of NCN thermochemistry. Proc. Combust. Inst., 34:657-666, 2013.

[72] N. Lamoureux, H. El Merhubi, L. Pillier, S. de Persis, and P. Desgroux. Modeling of NO formation in low pressure premixed flames. Combust. Flame, 163:557-575, 2016.

[73] E.P. Clifford, P.G. Wenthold, W.C. Lineberger, G.A. Petersson, and G.B. Ellison. Photoelectron spectroscopy of the NCN- and HNCN- ions. $J$. Phys. Chem. A, 101:4338-4345, 1997. 
[74] R.T. Bise, H. Choi, and D.M. Neumark. Photodissociation dynamics of the singlet and triplet states of the NCN radical. J. Chem. Phys., 111:4923-4932, 1999.

[75] R.T. Bise, A.A. Hoops, and D.M. Neumark. Photodissociation and photoisomerization pathways of the HNCN free radical. J. Chem. Phys., 114:9000-9011, 2001.

[76] S. Canneaux, A. Wallet, M. Ribaucour, and F. Louis. A theoretical study of the NCN biradical thermochemical properties: Implications for combustion chemistry. Comput. Theo. Chem., 967:67-74, 2011.

[77] L.B. Harding, S.J. Klippenstein, and J.A. Miller. Kinetics of $\mathrm{CH}+\mathrm{N}_{2}$ revisited with multireference methods. J. Phys. Chem. A, 112:522-532, 2008.

[78] N. Fassheber, J. Dammeier, and G. Friedrichs. Direct measurements of the total rate constant of the reaction $\mathrm{NCN}+\mathrm{H}$ and implications for the product branching ratio and the enthalpy of formation of NCN. Phys. Chem. Chem. Phys., 16:11647-11657, 2014.

[79] B. Ruscic. Active Thermochemical Tables (ATcT) values based on ver. 1.112 of the Thermochemical Network. (available at ATcT.anl.gov), 2013.

[80] B. Ruscic. Active Thermochemical Tables (ATcT) values based on ver. 1.118 of the Thermochemical Network. (available at ATcT.anl.gov), 2015.

[81] B. Ruscic, D. Feller, and K. A. Peterson. Active Thermochemical Tables: Dissociation energies of several homonuclear first-row diatomics and related thermochemical values. Theor. Chem. Acc., 133:1415/1-12, 2014.

[82] S. J. Klippenstein, M. Pfeifle, A.W. Jasper, and P. Glarborg. Theory and Modeling of Relevance to Prompt-NO Formation at High Pressure. submitted for publication. 
[83] J. Dammeier, N. Fassheber, and G. Friedrichs. Direct measurements of the high temperature rate constants of the reactions $\mathrm{NCN}+\mathrm{O}, \mathrm{NCN}+$ NCN, and NCN + M. Phys. Chem. Chem. Phys., 14:1030-1037, 2012.

[84] R.S. Zhu and M.C. Lin. Ab initio study on the oxidation of NCN by $\mathrm{O}$ : prediction of the total rate constant and product branching ratios. $J$. Phys. Chem. A, 111:6766-6771, 2007.

[85] N. Fassheber and G. Friedrichs. Shock tube Measurements of the rate constant of the reaction $\mathrm{NCN}+\mathrm{O}_{2}$. Int. J. Chem. Kinet., 47:586-595, 2015 .

[86] J. Dammeier and G. Friedrichs. Direct measurements of the rate constants of the reactions $\mathrm{NCN}$ plus $\mathrm{NO}$ and $\mathrm{NCN}+\mathrm{NO}_{2}$ behind shock waves. $J$. Phys. Chem. A, 115:14382-14390, 2011.

[87] A.J. Dean, R.K. Hanson, and C.T. Bowman. High temperature shock tube study of reactions of $\mathrm{CH}$ and C-atoms with $\mathrm{N}_{2}$. Symp. (Int.) Combust., 23:259-265, 1991.

[88] V. Vasudevan, R.K. Hanson, C.T. Bowman, D.M. Golden, and D.F. Davidson. Shock tube study of the reaction of $\mathrm{CH}$ with $\mathrm{N}_{2}$ : Overall rate and branching ratio. J. Phys. Chem. A, 111:11818-11830, 2007.

[89] J.A. Miller and S.P. Walch. Prompt NO: Theoretical prediction of the high-temperature rate coefficient for $\mathrm{CH}+\mathrm{N}_{2} \rightarrow \mathrm{HCN}+\mathrm{N}$. Int. J. Chem. Kinet., 29:253-259, 1997.

[90] J.A. Miller, M.J. Pilling, and J. Troe. Unravelling combustion mechanisms through a quantitative understanding of elementary reactions. Proc. Combust. Inst., 30:43-88, 2005.

[91] D. Lindackers, M. Burmeister, and P. Roth. Prturbation studies of high temperature $\mathrm{C}$ and $\mathrm{CH}$ reactions with $\mathrm{N}_{2}$ and NO. Symp. (Int.) Combust., 23:251-257, 1991. 
[92] W.-S. Teng, L.V. Moskaleva, H.-L. Chen, and M.C. Lin. Ab initio chemical kinetics for $\mathrm{H}+\mathrm{NCN}$ : Prediction of NCN heat of formation and reaction product branching via doublet and quartet surfaces. J. Phys. Chem. A, 117:5775-5784, 2013.

[93] R.S. Zhu, H.M.T. Nguyen, and M.C. Lin. Ab initio study on the oxidation of $\mathrm{NCN}$ by $\mathrm{OH}$ : Prediction of the individual and total rate constants. $J$. Phys. Chem. A, 113:298-304, 2009.

[94] R.S. Zhu and M.C. Lin. Ab initio study of the oxidation of $\mathrm{NCN}$ by $\mathrm{O}_{2}$. Int. J. Chem. Kinet., 37:593-598, 2005.

[95] P.A. Berg, D.A. Hill, A.R. Noble, G.P. Smith, J.B. Jeffries, and D.R. Crosley. Absolute $\mathrm{CH}$ concentration measurements in low-pressure methane flames: Comparisons with model results. Combust. Flame, 121:223-235, 2000.

[96] N. Lamoureux, X. Mercier, C. Western, J.F. Pauwels, and P. Desgroux. NCN quantitative measurement in a laminar low pressure flame. Proc. Combust. Inst., 32:937-944, 2009.

[97] N. Lamoureux, P. Desgroux, A. El Bakali, and J.F. Pauwels. Experimental and numerical study of the role of NCN in the prompt-NO formation in low pressure $\mathrm{CH}_{4} / \mathrm{O}_{2} / \mathrm{N}_{2}$ and $\mathrm{C}_{2} \mathrm{H}_{2} / \mathrm{O}_{2} / \mathrm{N}_{2}$ flames. Combust. Flame, 160:745-746, 2013.

[98] N. Lamoureux, C.M. Western, X. Mercier, and P. Desgroux. Reinvestigation of the spectroscopy of the $\AA^{3} \Pi_{u}$ - $\mathrm{X}^{3} \Sigma_{g}$-transition of the NCN radical at high temperature: application to quantitative NCN measurement in flames. Combust. Flame, 160:755-765, 2013.

[99] N. Lamoureux, H. El Merhubi, L. Gasnot, C. Schoemaecker, and P. Desgroux. Measurements and modelling of $\mathrm{HCN}$ and $\mathrm{CN}$ species profiles in laminar $\mathrm{CH}_{4} / \mathrm{O}_{2} / \mathrm{N}_{2}$ low pressure flames using LIF/CRDS techniques. Proc. Combust. Inst., 35:745-752, 2015. 
[100] W. Bartok, V. S. Engleman, R. Goldstein, and E. G. del Valle. Basic kinetic studies and modeling of nitrogen oxide formation in combustion processes. AIChE Symp. Ser., 126 (68):30-38, 1972.

[101] P. Malte and D.T. Pratt. Measurements of atomic oxygen and nitrogen oxides in jet-stirred combustion. Symp. (Int.) Combust., 15:1061-1070, 1975 .

[102] J.W. Bozzelli and A.M. Dean. O + NNH: A possible new route for $\mathrm{NO}_{\mathrm{x}}$ formation in flames. Int. J. Chem. Kinet., 27:1097-1109, 1995.

[103] M.S. Day, J.B. Bell, X. Gao, and P. Glarborg. Numerical simulation of nitrogen oxide formation in lean premixed turbulent $\mathrm{H}_{2} / \mathrm{O}_{2} / \mathrm{N}_{2}$ flames. Proc. Combust. Inst., 33:1591-1599, 2011.

[104] N.E. Meagher and W.R. Anderson. Kinetics of the $\mathrm{O}(3 \mathrm{P})+\mathrm{N}_{2} \mathrm{O}$ reaction. 2. Interpretation and recommended rate coefficients. J. Phys. Chem. A, 104:6013-6031, 2000.

[105] P. Marshall, A. Fontijn, and C.F. Melius. High-temperature photochemistry and BAC-MP4 studies of the reaction between ground-state H-atoms and $\mathrm{N}_{2} \mathrm{O}$. J. Chem. Phys., 86:5540-5549, 1987.

[106] H. Lillich, A. Schuck, H-R. Volpp, J. Wolfrum, and P.D. Naik. Kinetic studies of the reactions $\mathrm{NH}+\mathrm{NO}$ and $\mathrm{NH}+\mathrm{O}_{2}$ at elevated temperatures. Symp. (Int.) Combust., 25:993-1001, 1994.

[107] H.J. Romming and H.G. Wagner. A kinetic study of the reactions of NH with $\mathrm{O}_{2}$ and NO in the temperature range from 1200 to $2200 \mathrm{~K}$. Symp. (Int.) Combust., 26:559-566, 1996.

[108] K. Yokoyama, Y. Sakane, and T. Fueno. Formations of OH in the reaction of NH with NO in incident shock waves. Bull. Chem. Soc. Jpn., 64:1738$1742,1991$. 
[109] J. D. Mertens, A. Y. Chang, R. K. Hanson, and C. T. Bowman. A shock tube study of the reactions of $\mathrm{NH}$ with $\mathrm{NO}, \mathrm{O}_{2}$, and $\mathrm{O}$. Int. J. Chem. Kinet., 23:173-196, 1991.

[110] J.L. Durant. Product branching fractions in the reaction of NH (ND) with NO. J. Phys. Chem., 98:518-521, 1994.

[111] S. Okada, A. Tezaki, A. Miyoshi, and H. Matsui. Product branching fractions in the reactions of NH with NO. J. Chem. Phys., 101:95829588, 1994.

[112] R. W. Quandt and J. F. Hershberger. Product branching ratios of the NH $+\mathrm{NO}$ and $\mathrm{NH}+\mathrm{NO}_{2}$ reactions. J. Phys. Chem., 99:16939-16944, 1995.

[113] S. Gordon, W. Mulac, and P. Nangia. Pulse radiolysis of ammonia gas. II. Rate of disappearance of the $\mathrm{NH}_{2}$ radical. J. Phys. Chem., 75:2087-2093, 1971.

[114] I. Hansen, K. Hoinghaus, C. Zetzsch, and F. Stuhl. Detection of NH by resonance fluorescence in the pulsed vacuum UV photolysis of $\mathrm{NH}_{3}$ and its application to reactions of NH radicals. Chem. Phys. Lett., 42:370-372, 1976.

[115] J.A. Harrison, A.R. Whyte, and L.F. Phillips. Kinetics of reactions of NH with $\mathrm{NO}$ and $\mathrm{NO}_{2}$. Chem. Phys. Lett., 129:346-352, 1986.

[116] W. Hack, H.Gg. Wagner, and A. Zaspypkin. Elementary reactions of NH with N, O and NO. Ber. Bunsenges. Phys. Chem., 98:156-164, 1994.

[117] H. Geiger, P. Wiesen, and K.H. Becker. A product study of the reaction of $\mathrm{CH}$ radicals with nitric oxide at 298 K. Phys. Chem. Chem. Phys., 1:5601-5606, 1999.

[118] A.A. Konnov, G. Colson, and J. De Ruyck. The new route forming NO via NNH. Combust. Flame, 121:548-550, 2000. 
[119] A.A. Konnov, I.V. Dyakov, and J. De Ruyck. Nitric oxide formation in premixed flames of $\mathrm{H}_{2}+\mathrm{CO}+\mathrm{CO}_{2}$ and air. Proc. Combust. Inst., 29:2171$2177,2002$.

[120] N.L. Haworth, J.C. Mackie, and G.B. Bacskay. An ab initio quantum chemical and kinetic study of the $\mathrm{NNH}+\mathrm{O}$ reaction potential energy surface: How important is this route to NO in combustion? J. Phys. Chem. A, 107:6792-6803, 2003.

[121] D.L. Baulch, D.D. Drysdale, D.G. Horne, and A.C. Lloyd. Evaluated kinetic data for high temperature reactions. Vol 2, Homogeneous gas phase reactions of the $\mathrm{H}_{2}-\mathrm{N}_{2}-\mathrm{O}_{2}$ system. Butterworths, London, 1973.

[122] R.K. Hanson and S. Salimian. Combustion chemistry of nitrogen. In Jr. W.C. Gardiner, editor, Combustion chemistry. Springer-Verlag, New York, 1984.

[123] F. Kaufman, N.J. Gerri, and R.E. Bowman. Role of nitric oxide in the thermal decomposition of nitrous oxide. J. Chem. Phys., 25:106-115, 1956.

[124] H. Dindi, H.-M. Tsai, and M.C. Branch. Combustion mechanism of carbon monoxide-nitrous oxide flames. Combust. Flame, 87:13-20, 1991.

[125] M. Rohrig, E. L. Petersen, D. F. Davidson, and R. K. Hanson. The pressure dependence of the thermal decomposition of $\mathrm{N}_{2} \mathrm{O}$. Int. J. Chem. Kinet., 28:599-608, 1996.

[126] M. Gonzalez, R. Sayos, and R. Valero. Ab initio and kinetics study of the ground potential energy surface of the $\mathrm{O}(\mathrm{D}-1)+\mathrm{N}_{2} \mathrm{O} \rightarrow 2 \mathrm{NO}, \mathrm{N}_{2}+\mathrm{O}_{2}$ reactions. Chem. Phys. Lett., 355:123-132, 2002.

[127] A.N. Hayhurst and E.M. Hutchinson. Evidence for a new way of producing NO via NNH in fuel-rich flames at atmospheric pressure. Combust. Flame, 114:274-279, 1998. 
[128] A.A. Konnov and J. De Ruyck. Temperature-dependent rate constant for the reaction $\mathrm{NNH}+\mathrm{O} \rightarrow \mathrm{NH}+\mathrm{NO}$. Combust. Flame, 125:1258-1264, 2001.

[129] J.E. Harrington, G.P. Smith, P.A. Berg, A.B. Noble, J.B. Jeffries, and D.R. Crosley. Evidence for a new NO production mechanism in flames. Symp. (Int.) Combust., 26:2133-2138, 1996.

[130] R. Steele, P. Malte, D. Nicol, and J. Kramlich. $\mathrm{NO}_{\mathrm{x}}$ and $\mathrm{N}_{2} \mathrm{O}$ in leanpremixed jet stirred flames. Combust. Flame, 100:440-449, 1995.

[131] A. Lucassen, K. Zhang, J. Warkentin, K. Moshammer, P. Glarborg, P. Marshall, and K. Kohse-Höinghaus. Fuel-nitrogen conversion in the combustion of small amines using dimethylamine and ethylamine as biomass-related model fuels. Combust. Flame, 159:2254-2279, 2012.

[132] Murakami N., Tokunaga K., and Sakai M. Formation of NO by the oxidation of HCN. Nenryo Kyokaishi, 61:759-769, 1982.

[133] T. Higashihara, K. Saito, and I. Murakami. Oxidation of hydrogencyanide in shock-waves - formation of nitrogen monoxide. J. Phys. Chem., 87:3707-3712, 1983.

[134] J.A. Miller, M.C. Branch, W.J. McLean, Chandler D.W., M.D. Smooke, and Kee R.J. The conversion of $\mathrm{HCN}$ to $\mathrm{NO}$ and $\mathrm{N}_{2}$ in $\mathrm{H}_{2}-\mathrm{O}_{2}-\mathrm{HCN}-\mathrm{Ar}$ flames at low pressure. Proc. Combust. Inst., 20:673-684, 1984.

[135] K. Thielen and P. Roth. Resonance absorption measurements of N, O, and $\mathrm{H}$ atoms in shock heated $\mathrm{HCN} / \mathrm{O}_{2} / \mathrm{Ar}$ mixtures. Combust. Flame, 69:141-154, 1987.

[136] T. Hulgaard and K. Dam-Johansen. Homogeneous nitrous oxide formation and destruction under combustion conditions. AIChE J., 39:1342-1354, 1993. 
[137] P. Glarborg and J.A. Miller. Mechanism and modeling of hydrogen cyanide oxidation in a flow reactor. Combust. Flame, 99:475-483, 1994.

[138] P. Dagaut, F. Lecomte, S. Chevailler, and M. Cathonnet. Mutual sensitization of the oxidation of nitric oxide and simple fuels over an extended temperature range: experimental and detailed kinetic modeling. Combust Sci Technol, 148:27-57, 1999.

[139] P. Dagaut, F. Lecomte, S. Chevailler, and M. Cathonnet. The oxidation of $\mathrm{HCN}$ and reactions with nitric oxide: Experimental and detailed kinetic modeling. Combust. Sci. Technol., 155:105-127, 2000.

[140] V. J. Wargadalam, G. Löffler, F. Winter, and H. Hofbauer. Homogeneous formation of $\mathrm{NO}$ and $\mathrm{N}_{2} \mathrm{O}$ from the oxidation of $\mathrm{HCN}$ and $\mathrm{NH}_{3}$ at 600 $1000^{\circ}$ C. Combust. Flame, 120:465-478, 2000.

[141] J. Gimenez-Lopez, A. Millera, R. Bilbao, and M.U. Alzueta. HCN oxidation in an $\mathrm{O}_{2} / \mathrm{CO}_{2}$ atmosphere: An experimental and kinetic modeling study. Combust. Flame, 157:267-276, 2010.

[142] J. Gimenez-Lopez, A. Millera, R. Bilbao, and M. U. Alzueta. Interactions of $\mathrm{HCN}$ with $\mathrm{NO}$ in a $\mathrm{CO}_{2}$ Atmosphere Representative of Oxy-fuel Combustion Conditions. Energy Fuels, 29:6593-6597, 2015.

[143] P. Glarborg and P. Marshall. Importance of the HNC isomer in modeling HCN oxidation in combustion. Energy Fuels, 31:2156-2163, 2017.

[144] J.A. Miller, C. Parrish, , and N..J. Brown. A statistical-theoretical investigation of the thermal rate coefficient and branching ratio for the reaction $\mathrm{O}+\mathrm{HCN} \rightarrow$ products. J. Phys. Chem., 90:3339-3345, 1986.

[145] J.A. Miller and C.F. Melius. A theoretical analysis of the reaction between hydroxyl and hydrogen cyanide at high temperature. Symp. (Int.) Combust., 21:919-927, 1986. 
[146] A.M. Dean and J.W. Bozzelli. Combustion chemistry of nitrogen. In W.C. Gardiner, editor, Gas phase combustion chemistry, chapter 2. SpringerVerlag, 2000.

[147] S.T. Wooldridge, R.K. Hanson, and C.T. Bowman. Simultaneous laserabsorption measurements of $\mathrm{CN}$ and $\mathrm{OH}$ in a shock-tube study of $\mathrm{HCN}+\mathrm{OH} \rightarrow$ products. Int. J. Chem. Kinet., 27:1075-1087, 1995.

[148] R. Sumathi and M.T. Nguyen. A theoretical study of the $\mathrm{CH}_{2} \mathrm{~N}$ system: Reactions in both lowest lying doublet and quartet states. J. Phys. Chem. A, 102:8013-8020, 1998 .

[149] A.J.C. Bunkan, Y. Tang, S.R. Sellevag, and C.J. Nielsen. Atmospheric gas phase chemistry of $\mathrm{CH}_{2}=\mathrm{NH}$ and HNC. A first-principles approach. J. Phys. Chem. A, 118:5279-5288, 2014.

[150] W. Feng and J. F. Hershberger. Reinvestigation of the branching ratio of the $\mathrm{CN}+\mathrm{O}_{2}$ reaction. J. Phys. Chem. A, 113:3523-3527, 2009.

[151] Y. Gao and G. MacDonald. Determination of the rate constant for the $\mathrm{NCO}+\mathrm{O}$ reaction at 292 K. J. Phys. Chem. A, 107:4625-4635, 2003.

[152] J. A. Miller and C. T. Bowman. Kinetic modeling of the reduction of nitric oxide in combustion products by isocyanic acid. Int. J. Chem. Kinet., 23:289-313, 1991.

[153] R. S. Zhu and M. C. Lin. The NCO + NO reaction revisited: Ab inito $\mathrm{MO} /$ VRRKM calculations for total rate constant and product branching ratios. J. Phys. Chem. A, 104:10807-10811, 2000.

[154] M.C. Lin, Y. He, and C.F. Melius. Communication - implications of the $\mathrm{HCN} \rightarrow \mathrm{HNC}$ process to high-temperature nitrogen-containing fuel chemistry. Int. J. Chem. Kinet., 24:1103-1107, 1992.

[155] F. Mohammad, V.R. Morris, W.H. Fink, and W.M. Jackson. On the mechanism and branching ratio of the $\mathrm{CN}+\mathrm{O}_{2} \rightarrow \mathrm{CO}+\mathrm{NO}$ reaction channel 
using transient IR emission spectroscopy. J. Phys. Chem., 97:11590-11598, 1993.

[156] K.T. Rim and J.F. Hershberger. Temperature dependence of the product branching ratio of the $\mathrm{CN}+\mathrm{O}_{2}$ reaction. J. Phys. Chem. A, 103:3721-3725, 1999.

[157] B. S. Haynes. The oxidation of hydrogen cyanide in fuel-rich flames. Combust. Flame, 28:113-121, 1977.

[158] J. A. Caton and D. L. Siebers. Comparison of nitric oxide removal by cyanuric acid and ammonia. Combust. Sci. Technol., 65:277-293, 1989.

[159] P. Glarborg, P.G. Kristensen, S.H. Jensen, and K. Dam-Johansen. A flow reactor study of HNCO oxidation chemistry. Combust. Flame, 98:241-258, 1994.

[160] R.K. Lyon and J.A. Cole. A reexamination of the RapreNO $\mathrm{N}_{\mathrm{x}}$ process. Combust. Flame, 82:435-443, 1990.

[161] R.A. Perry. Kinetics of the reactions of NCO radicals with $\mathrm{H}_{2}$ and NO using laser photolysis-laser induced fluorescence. J. Chem. Phys., 82:5485$5488,1985$.

[162] F.P. Tully, R.A. Perry, L.R. Thorne, and M.D. Allendorf. Free-radical oxidation of isocyanic acid. Symp. (Int.) Combust., 22:1101-1106, 1988.

[163] C. H. Wu, H. T. Wang, M. C. Lin, and R. A. Fifer. Kinetics of CO and $\mathrm{H}$ atom production from the decomposition of HNCO in shock-waves. $J$. Phys. Chem., 94:3344-3347, 1990.

[164] Y. He, X.P. Liu, M.C. Lin, and C.F. Melius. The thermal reaction of HNCO at moderate temperatures. Int. J. Chem. Kinet., 23:1129-1149, 1991.

[165] Y. He, M. C. Lin, C. H. Wu, and C. F. Melius. The reaction of HNCO with $\mathrm{NO}_{2}$ in shock waves. Symp. (Int.) Combust., 24:711-717, 1992. 
[166] Y. He, X.P. Liu, M.C. Lin, and C.F. Melius. Thermal-reaction of HNCO with $\mathrm{NO}_{2}$ at moderate temperatures. Int. J. Chem. Kinet., 25:845-863, 1993.

[167] J. D. Mertens, A. Y. Chang, R. K. Hanson, and C. T. Bowman. Reactionkinetics of $\mathrm{NH}$ in the shock-tube pyrolysis of HNCO. Int. J. Chem. Kinet., 21:1049-1067, 1989 .

[168] J. D. Mertens, A. Y. Chang, R. K. Hanson, and C. T. Bowman. A shocktube study of $\mathrm{H}+\mathrm{HNCO} \rightarrow \mathrm{NH}_{2}+\mathrm{CO}$. Int. J. Chem. Kinet., 23:655-668, 1991.

[169] J. D. Mertens, R. K. Hanson, and C. T. Bowman. A shock-tube study of reactions of atomic oxygen with isocyanic acid. Int. J. Chem. Kinet., 24:279-295, 1992.

[170] S.T. Wooldridge, R.K. Hanson, and C.T. Bowman. A shock tube study of $\mathrm{CO}+\mathrm{OH} \rightarrow \mathrm{CO}_{2}+\mathrm{H}$ and $\mathrm{HNCO}+\mathrm{OH} \rightarrow$ products via simultaneous laser adsorption measurements of $\mathrm{OH}$ and $\mathrm{CO}_{2}$. Int. J. Chem. Kinet, 28:361-372, 1995 .

[171] J.A. Miller and C.F. Melius. A theoretical analysis of the reaction between hydrogen atoms and isocyanic acid. Int. J. Chem. Kinet., 24:421-432, 1992.

[172] D. Sengupta and M. T. Nguyen. Mechanism of $\mathrm{NH}_{2}+\mathrm{CO}_{2}$ formation in $\mathrm{OH}+\mathrm{HNCO}$ reaction: Rate constant evaluation via ab initio calculations and statistical theory. J. Chem. Phys., 106:9703-9707, 1997.

[173] X.-G. Wei, X.-M. Sun, X.-P. Wu, S. Geng, Y. Ren, N.-B. Wong, and W.K. Li. Cooperative effect of water molecules in the self-catalyzed neutral hydrolysis of isocyanic acid: a comprehensive theoretical study. J. Mol. Model., 17:2069-2082, 2011. 
[174] X. Cheng, Y. Zhao, W. Zhu, and Y. Liu. Theoretical investigation on the synthesis mechanism of cyanuric acid from $\mathrm{NH}_{3}$ and $\mathrm{CO}_{2}$. J. Mol. Model., 19:5037-5043, 2013.

[175] W.L. Feng, Y. Wang, and S.-W. Zhang. Theoretical study of the mechanism and rate constant of the dimerization of isocyanic acid. J. Mol. Structure (Theochem), 342:147-151, 1995.

[176] N. Borduas, B. Place, G. R. Wentworth, J. P. D. Abbatt, and J. G. Murphy. Solubility and reactivity of HNCO in water: insights into HNCO's fate in the atmosphere. Atmos. Chem. Phys., 16:703-714, 2016.

[177] A. Zabardasti and M. Solimannejad. Theoretical study and aim analysis of hydrogen bonded clusters of water and isocyanic acid. J. Mol. Structure THEOCHEM, 819:52-59, 2007.

[178] A. Nicolle, S. Cagnina, and T. de Bruin. First-principle based modeling of urea decomposition in aqueous solutions. Chem. Phys. Lett., 664:149-153, 2016.

[179] A.M. Mebel, A. Luna, M.C. Lin, and K. Morokuma. A density functional study of the global potential energy surfaces of the [HCNO] system in singlet and triplet states. J. Chem. Phys., 105:6439-6454, 1996.

[180] J. Cao, Z.X. Wang, L.J. Gao, and F. Fu. Water-assisted isomerization of the [H,C,N,O] system. J. Mol. Model., 21:66, 1-8, 2015.

[181] B. G. Wicke, K. A. Grady, and J. W. Ratcliffe. Cyanuric acid + nitric oxide reaction at $700^{\circ} \mathrm{C}$ and the effects of oxygen. Combust. Flame, $78: 249-255,1989$.

[182] P.G. Kristensen, P. Glarborg, and K. Dam-Johansen. Nitrogen chemistry during burnout in fuel-staged combustion. Combust. Flame, 107:211-222, 1996. 
[183] J. A. Miller, M. D. Smooke, R. M. Green, and R. J. Kee. Kinetic modeling of the oxidation of ammonia in flames. Combust. Sci. Technol., 34:149$176,1983$.

[184] R. P. Lindstedt, F. C. Lockwood, and M. A. Selim. A detailed kinetic study of ammonia oxidation. Combust. Sci. Technol., 108:231-254, 1995.

[185] O. Mathieu and E.L. Petersen. Experimental and modeling study on the high-temperature oxidation of Ammonia and related $\mathrm{NO}_{\mathrm{x}}$ chemistry. Combust. Flame, 162:554-570, 2015.

[186] P. Glarborg, K. Dam-Johansen, J.A. Miller, R.J. Kee, and M.E. Coltrin. Modeling the Thermal DeNO ${ }_{\mathrm{x}}$ process in flow reactors. Surface effects and nitrous oxide formation. Int. J. Chem. Kinet., 26:421-436, 1994.

[187] J. A. Miller and P. Glarborg. Modeling the formation of $\mathrm{N}_{2} \mathrm{O}$ and $\mathrm{NO}_{2}$ in the Thermal De-NO ${ }_{x}$ process. Springer Ser. Chem. Phys., 61:318-333, 1996.

[188] J. A. Miller and P. Glarborg. Modeling the Thermal DeNO $\mathrm{x}$ process: Closing in on a final solution. Int. J. Chem. Kinet., 31:757-765, 1999.

[189] Z. Tian, Y. Li, L. Zhang, P. Glarborg, and F. Qi. An experimental and kinetic modeling study of premixed $\mathrm{NH}_{3} / \mathrm{CH}_{4} / \mathrm{O}_{2} /$ Ar flames at low pressure. Combust. Flame, 156:1413-1426, 2009.

[190] J. A. Miller and S. J. Klippenstein. Theoretical considerations in the $\mathrm{NH}_{2}$ + NO reaction. J. Phys. Chem. A, 104:2061-2069, 2000.

[191] S. J. Klippenstein. From theoretical reaction dynamics to chemical modeling of combustion. Proc. Combust. Inst., 36:77-111, 2017.

[192] S. J. Klippenstein, L. B. Harding, P. Glarborg, Y. Gao, and P. Marshall. Rate constant and branching fraction for the $\mathrm{NH}_{2}+\mathrm{NO}_{2}$ reaction. $J$. Phys. Chem. A, 117:9011-9022, 2013. 
[193] S.J. Klippenstein, L.B. Harding, B. Ruscic, R. Sivaramakrishnan, N.K. Srinivasan, M.-C. Su, and J.V. Michael. Thermal decomposition of $\mathrm{NH}_{2} \mathrm{OH}$ and subsequent reactions: $\mathrm{Ab}$ initio transition state theory and reflected shock tube experiments. J. Phys. Chem. A, 113:10241-10259, 2009.

[194] G. Altinay and R. G. Macdonald. Determination of the rate constants for the $\mathrm{NH}_{2}\left(\mathrm{X}^{2} \mathrm{~B}_{1}\right)+\mathrm{NH}_{2}\left(\mathrm{X}^{2} \mathrm{~B}_{1}\right)$ and $\mathrm{NH}_{2}\left(\mathrm{X}^{2} \mathrm{~B}_{1}\right)+\mathrm{H}$ recombination reactions in $\mathrm{N}_{2}$ as a function of temperature and pressure. J. Phys. Chem. A, 119:7593-7610, 2015.

[195] J. V. Michael, J. W. Sutherland, and R. B. Klemm. Rate constant for the reaction $\mathrm{H}+\mathrm{NH}_{3}$ over the temperature range 750-1777 K. J. Phys. Chem., 90:497-500, 1986.

[196] J. W. Sutherland, P. M. Patterson, and R. B. Klemm. Flash photolysisshock tube kinetic investigation of the reaction of $\mathrm{O}(3 \mathrm{P})$ atoms with ammonia. J. Phys. Chem., 94:2471-2475, 1990.

[197] S. Salimian, R. K. Hanson, and C. H. Kruger. High-temperature study of the reactions of $\mathrm{O}$ and $\mathrm{OH}$ with $\mathrm{NH}_{3}$. Int. J. Chem. Kin., 16:725-739, 1984.

[198] R. Sumathi and S. D. Peyerimhoff. A Quantum Statistical Analysis of the Rate Constant for the $\mathrm{HO}_{2}+\mathrm{NH}_{2}$ Reaction. Chem. Phys. Lett., 263:742$748,1996$.

[199] A. Fontijn, S.M. Shamsuddin, D. Crammond, P. Marshall, and W.R. Anderson. Kinetics of the $\mathrm{NH}$ reaction with $\mathrm{H}_{2}$ and reassesment of $\mathrm{HNO}$ formation from $\mathrm{NH}+\mathrm{CO}_{2}, \mathrm{H}_{2} \mathrm{O}$. Combust. Flame, 145:543-551, 2006.

[200] S. Xu and M. C. Lin. Ab initio chemical kinetics for the $\mathrm{NH}_{2}+\mathrm{HNO}_{\mathrm{x}}$ reactions, Part I: Kinetics and mechanism for $\mathrm{NH}_{2}+$ HNO. Int. J. Chem. Kin., 41:667-677, 2009. 
[201] S. Song, R. K. Hanson, C. T. Bowman, and D. M. Golden. Shock tube determination of the overall rate of $\mathrm{NH}_{2}+\mathrm{NO} \rightarrow$ products in the Thermal De- $\mathrm{NO}_{\mathrm{x}}$ temperature window. Int. J. Chem. Kinet., 33:715-721, 2001.

[202] J.A. Miller and C.F Melius. The reactions of imidogen with nitric oxide and molecular oxygen. Symp. (Int.) Combust., 24:719-726, 1992.

[203] D.-C. Fang, L.B. Harding, S.J. Klippenstein, and J.A. Miller. A direct transition state theory analysis of the branching in $\mathrm{NH}_{2}+\mathrm{NO}$. Faraday Disc. Royal Soc. Chem., 119:207-222, 2001.

[204] S. Song, R. K. Hanson, C. T. Bowman, and D. M. Golden. A shock tube study of the product branching ratio of the $\mathrm{NH}_{2}+\mathrm{NO}$ reaction at high temperatures. J. Phys. Chem. A, 106:9233-9235, 2002.

[205] J. A. Silver and C. E. Kolb. Kinetic measurements for the reaction of $\mathrm{NH}_{2}+\mathrm{NO}$ over the temperature range 294-1215 K. J. Phys. Chem., $86: 3240-3246,1982$.

[206] L. J. Stief, W. D. Brobst, D. F. Nava, R. P. Borkowski, and J. V. Michael. Rate constant for the reaction $\mathrm{NH}_{2}+\mathrm{NO}$ from $216 \mathrm{~K}$ to $480 \mathrm{~K}$. J. Chem. Soc. Faraday Trans. 2, 78:1391-1401, 1982.

[207] B. Atakan, A. Jacobs, M. Wahl, R. Weller, and J. Wolfrum. Kinetic measurements and product branching ratio for the reaction $\mathrm{NH}_{2}+\mathrm{NO}$ at 294-1027 K. Chem. Phys. Lett., 155:609-613, 1989.

[208] M. Wolf, D. L. Yang, and D. L. Durant. Kinetic studies of $\mathrm{NH}_{\mathrm{x}}$ radical reactions. J. Photochem. Photobiol. A: Chem., 80:85-93, 1994.

[209] M. Wolf, D. L. Yang, and D. L. Durant. A comprehensive study of the reaction $\mathrm{NH}_{2}+\mathrm{NO} \rightarrow$ products: Reaction rate coefficients, product branching fractions, and ab initio calculations. J. Phys. Chem. A, 101:6243-6251, 1997. 
[210] J. Park and M. C. Lin. Direct determination of product branching for the $\mathrm{NH}_{2}+\mathrm{NO}$ reaction at temperatures between 302 and 1060 K. J. Phys. Chem., 100:3317-3319, 1996.

[211] J. Park and M. C. Lin. Product branching ratios in the $\mathrm{NH}_{2}+\mathrm{NO}$ reaction: A re-evaluation. J. Phys. Chem. A, 103:8906-8907, 1999.

[212] P. Glarborg, P. G. Kristensen, K. Dam-Johansen, and J.A. Miller. The branching fraction of the $\mathrm{NH}_{2}+\mathrm{NO}$ reaction between 1210 and $1370 \mathrm{~K} . J$. Phys. Chem. A, 101:3741-3745, 1997.

[213] M. Votsmeier, S. Song, R. K. Hanson, and C. T. Bowman. A shock tube study of the product branching ratio for the reaction $\mathrm{NH}_{2}+\mathrm{NO}$ using frequency-modulation detection of $\mathrm{NH}_{2}$. J. Phys. Chem. A, 103:15661571, 1999.

[214] V. P. Bulatov, A. A. Ioffe, V. A. Lozovsky, and O. M. Sarkisov. On the reaction of the $\mathrm{NH}_{2}$ radical with $\mathrm{NO}_{2}$ at 295-620 K. Chem. Phys. Lett., 161:141-146, 1989.

[215] C. J. Howard. Kinetic study of the equilibrium $\mathrm{HO}_{2}+\mathrm{NO} \rightleftharpoons \mathrm{OH}+\mathrm{NO}_{2}$ and the thermochemistry of $\mathrm{HO}_{2}$. J. Am. Chem. Soc., 102:6937-6941, 1980.

[216] N.K. Srinivasan, M.-C. Su, J.W. Sutherland, J.V. Michael, and B. Ruscic. Reflected shock tube studies of high-temperature rate constants for $\mathrm{OH}$ $+\mathrm{NO}_{2} \rightarrow \mathrm{HO}_{2}+\mathrm{NO}$ and $\mathrm{OH}+\mathrm{HO}_{2} \rightarrow \mathrm{H}_{2} \mathrm{O}+\mathrm{O}_{2}$. J. Phys. Chem. A, 110:6602-6607, 2006.

[217] W. Hack, H. Schacke, M. Schröter, and H. Gg. Wagner. Reaction rates of $\mathrm{NH}_{2}$-radicals with $\mathrm{NO}, \mathrm{NO}_{2}, \mathrm{C}_{2} \mathrm{H}_{2}, \mathrm{C}_{2} \mathrm{H}_{4}$ and other hydrocarbons. Symp. (Int.) Combust., 17:505-513, 1979.

[218] H. Kurasawa and R. Lesclaux. Kinetics of the reaction of $\mathrm{NH}_{2}$ with $\mathrm{NO}_{2}$. Chem. Phys. Lett., 66:602-607, 1979. 
[219] A. R. Whyte and L. F. Phillips. Rates of reactions of $\mathrm{NH}_{2}$ with $\mathrm{NO}$ and $\mathrm{NO}_{2}$. Chem. Phys. Lett., 102:451-454, 1983.

[220] T. X. Xiang, L. M. Torres, and W. A. Guillory. State-selected reaction and relaxation of $\mathrm{NH}_{2}$ radicals and $\mathrm{NO}_{2}$. J. Chem. Phys., 83:1623-1629, 1985.

[221] V. P. Bulatov, A. A. Ioffe, V. A. Lozovsky, and O. M. Sarkisov. On the reaction of the $\mathrm{NH}_{2}$ radical with $\mathrm{NO}_{2}$ at 295-620 K. Chem. Phys. Lett., 159:171-174, 1989.

[222] P. Pagsberg, B. Sztuba, E. Ratajczak, and A. Sillesen. Spectrokinetic studies of the gas-phase reactions $\mathrm{NH}_{2}+\mathrm{NO}_{\mathrm{x}}$ initiated by pulse-radiolysis. Acta Chem. Scand., 45:329-334, 1991.

[223] P. Glarborg, K. Dam-Johansen, and J.A. Miller. The reaction of ammonia with nitrogen dioxide in a flow reactor: Implications for the $\mathrm{NH}_{2}+\mathrm{NO}_{2}$ reaction. Int. J. Chem. Kinet., 27:1207-1220, 1995.

[224] H. Meunier, P. Pagsberg, and A. Sillesen. Kinetics and branching ratios of the reactions $\mathrm{NH}_{2}+\mathrm{NO}_{2} \rightarrow \mathrm{N}_{2} \mathrm{O}+\mathrm{H}_{2} \mathrm{O}$ and $\mathrm{NH}_{2}+\mathrm{NO}_{2} \rightarrow \mathrm{H}_{2} \mathrm{NO}$ + NO studied by pulse radiolysis combined with time-resolved infrared diode laser spectroscopy. Chem. Phys. Lett., 261:277-282, 1996.

[225] J. Park and M. C. Lin. A mass spectrometric study of the $\mathrm{NH}_{2}+\mathrm{NO}_{2}$ reaction. J. Phys. Chem. A, 101:2643-2647, 1997.

[226] S. Song, D. M. Golden, R. K. Hanson, and C. T. Bowman. A shock tube study of the $\mathrm{NH}_{2}+\mathrm{NO}_{2}$ reaction. Proc. Combust. Inst., 29:2163-2170, 2002.

[227] J. Park and M. C. Lin. Mass-spectrometric determination of product branching probabilities for the $\mathrm{NH}_{2}+\mathrm{NO}_{2}$ reaction at temperatures between 300 and 990 K. Int. J. Chem. Kinet., 28:879-883, 1996. 
[228] R. W. Quandt and J. F. Hershberger. Diode laser study of the product branching ratio of the $\mathrm{NH}_{2}+\mathrm{NO}_{2}$ reaction. J. Phys. Chem., 100:9407$9411,1996$.

[229] N. Lindholm and J. F. Hershberger. Product branching ratios of the $\mathrm{NH}_{2}$ $+\mathrm{NO}_{2}$ reaction. J. Phys. Chem. A, 101:4991-4995, 1997.

[230] M. Yumura and T. Asaba. Rate constants of chemical reactions in the high temperature pyrolysis of ammonia. Symp. (Int.) Combust., 18:863-872, 1981.

[231] D.F. Davidson, K. Kohse-Hoinghaus, A.Y. Chang, and R.K. Hanson. A pyrolysis mechanism for ammonia. Int. J. Chem. Kinet., 22:513-535, 1990.

[232] M. Rohrig and H.G. Wagner. The reactions of NH with the water gas components $\mathrm{CO}_{2}, \mathrm{H}_{2} \mathrm{O}$, and $\mathrm{H}_{2}$. Symp. (Int.) Combust., 25:975-981, 1994.

[233] M.-K. Bahng and R.G. Macdonald. Determination of the rate constants for the radical-radical reactions $\mathrm{NH}_{2}+\mathrm{NH}$ and $\mathrm{NH}_{2}+\mathrm{H}_{2}$ at $293 \mathrm{~K}$. J. Phys. Chem. A, 113:2415-2423, 2009.

[234] P. Dransfeld, W. Hack, H. Kurzke, F. Temps, and H.G. Wagner. Direct studies of elementary reactions of $\mathrm{NH}_{2}$-radicals in the gas phase. Symp. (Int.) Combust., 20:655-663, 1972.

[235] J.D. Adamson, S.K. Farhat, C.L. Morter, G.P. Glass, R.F. Curl, and L.F. Phillips. The reaction of $\mathrm{NH}_{2}$ with O. J. Phys. Chem., 98:5665-5669, 1994.

[236] S. Inomata and N. Washida. Rate constants for the reactions of $\mathrm{NH}_{2}$ and HNO with atomic oxygen at temperatures between 242 and $473 \mathrm{~K}$. $J$. Phys. Chem. A, 103:5023-5031, 1999.

[237] Y. Song, H. Hashemi, J.M. Christensen, C. Zou, P. Marshall, and P. Glarborg. Ammonia oxidation at high pressure. Fuel, 181:358-365, 2016. 
[238] C. P. Fenimore and G. W. Jones. Oxidation of ammonia in flames. $J$. Phys. Chem., 65:298-303, 1961.

[239] D. I. MacLean and H. Gg. Wagner. The structure of the reaction zones of ammonia-oxygen and hydrazine decomposition flames. Symp. (Int.) Combust., 11:871-878, 1967.

[240] R. J. Blint and C. J. Dasch. Formation of $\mathrm{NO}$ and $\mathrm{N}_{2}$ from $\mathrm{NH}_{3}$ in flames. ACS Symp. Series, 249:87-101, 1984.

[241] C. J. Dasch and R. J. Blint. A mechanistic and experimental study of ammonia in flames. Combust. Sci. Technol., 41:223-244, 1984.

[242] A. M. Dean, M.-S. Chou, and D. Stern. Nitrogen chemistry in flames. Observations and detailed chemistry. ACS Symp Series, 249:71-86, 1984.

[243] A.M. Dean, M.-S. Chou, and D. Stern. Kinetics of rich ammonia flames. Int. J. Chem. Kinet., 16:633-653, 1984.

[244] J. Bian, J. Vandooren, and P.J. van Tiggelen. Experimental study of the structure of an ammonia-oxygen flame. Symp. (Int.) Combust., 21:953963, 1986.

[245] C. Duynslaegher, H. Jeanmart, and J. Vandooren. Flame structure studies of premixed ammonia/hydrogen/oxygen/argon flames: Experimental and numerical investigation. Proc. Combust. Inst., 32:1277-1284, 2009.

[246] T. Takeyama and H. Miyama. Kinetic studies of ammonia oxidation in shock waves II. The rate of ammonia consumption. Bull. Chem. Soc. Japan, 39:2352-2355, 1966.

[247] T. Takeyama and H. Miyama. A shock-tube study of the ammonia-oxygen reaction. Symp. (Int.) Combust., 11:845-852, 1967.

[248] D. C. Bull. A shock tube study of the oxidation of ammonia. Combust. Flame, 12:603-610, 1968. 
[249] H. Miyama. Kinetic studies of ammonia oxidation in ahock waves IV. Comparison of induction periods for the ignition of $\mathrm{NH}_{3}-\mathrm{O}_{2}-\mathrm{N}_{2}$ with those for $\mathrm{NH}_{3}-\mathrm{O}_{2}$-Ar mixtures. Bull Chem Soc Japan, 41:1761-1765, 1968.

[250] H. Miyama. Ignition of ammonia-oxygen mixtures by shock waves. $J$. Chem. Phys., 48:1421-1422, 1968.

[251] J.N. Bradley, R.N. Butlin, and D. Lewis. Oxidation of ammonia in shock waves. Trans. Faraday Soc., 64:71-78, 1968.

[252] L. J. Drummond. High Temperature Oxidation of Ammonia. Combust. Sci. Technol., 5:175-182, 1972.

[253] N. Fujii, H. Miyama, M. Koshi, and T. Asaba. Kinetics of ammonia oxidation in shock waves. Symp. (Int.) Combust., 18:873-883, 1981.

[254] A. M. Dean, J. E. Hardy, and R. K. Lyon. Kinetics and mechanism of $\mathrm{NH}_{3}$ oxidation. Symp. (Int.) Combust., 19:97-105, 1982.

[255] T. Hasegawa and M. Sato. Study of ammonia removal from coal-gasified fuel. Combust. Flame, 114:246-258, 1998.

[256] E. Vilas and P. Glarborg. The selective non-catalytic reduction of NO with ammonia at high oxygen concentration. Technical Report CHEC R0410, DTU Chemical Engineering, 2004.

[257] R. K. Lyon and D. J. Benn. Kinetics of the $\mathrm{NO}-\mathrm{NH}_{3}-\mathrm{O}_{2}$ reaction. Symp. (Int.) Combust., 17:601-610, 1979.

[258] R.K. Lyon. $\mathrm{NH}_{3}-\mathrm{NO}-\mathrm{O}_{2}$ reaction. Int. J. Chem. Kinet., 8:315-318, 1976.

[259] R. K. Lyon and J. E. Hardy. Discovery and development of the thermal DeNO ${ }_{x}$ process. Ind. Eng. Chem. Fundam., 25:19-24, 1986.

[260] S. L. Chen, J. M. McCarthy, W. D. Clark, M. P. Heap, W. R. Seeker, and D. W. Pershing. Bench and pilot scale process evaluation of reburning for in-furnace $\mathrm{NO}_{\mathrm{x}}$ reduction. Symp. (Int.) Combust., 21:1159-1169, 1986. 
[261] R. Mechenbier and H. Kremer. Brennstoffstufung kohlenstaub/methan zur minderung brennstoffbedingter $\mathrm{NO}_{\mathrm{x}}$-emissionen. VDI-Ber., 645:8798, 1987.

[262] P. Kilpinen, P. Glarborg, and M. Hupa. Reburning chemistry - A kinetic modeling study. Ind. Eng. Chem. Res., 31:1477-1490, 1992.

[263] A. Kicherer, H. Spliethoff, H. Maier, and K. R. G. Hein. The effect of different reburning fuels on $\mathrm{NO}_{\mathrm{x}}$-reduction. Fuel, 73:1443-1446, 1994.

[264] R. Bilbao, A. Millera, and M. U. Alzueta. Influence of the temperature and oxygen concentration on $\mathrm{NO}_{\mathrm{x}}$ reduction in the natural-gas reburning process. Ind. Eng. Chem. Res., 33:2846-2852, 1994.

[265] R. Bilbao, M. U. Alzueta, and A. Millera. Experimental study of the influence of the operating variables on natural gas reburning efficiency. Ind. Eng. Chem. Res., 34:4531-4539, 1995.

[266] R. Bilbao, A. Millera, M.U. Alzueta, and L. Prada. Evaluation of the use of different hydrocarbon fuels for gas reburning. Fuel, 76:1401-1407, 1997.

[267] M. U. Alzueta, P. Glarborg, and K. Dam-Johansen. Low temperature interactions between hydrocarbons and nitric oxide: An experimental study. Combust. Flame, 109:25-36, 1997.

[268] P. Dagaut, F. Lecomte, S. Chevailler, and M. Cathonnet. Experimental and detailed kinetic modeling of nitric oxide reduction by a natural gas blend in simulated reburning conditions. Combust. Sci. Technol., 139:329$363,1998$.

[269] E.B. Ledesma, P.F. Nelson, and J.C. Mackie. An experimental and kinetic modeling study of the reduction of NO by coal volatiles in a flow reactor. Proc. Combust. Inst., 28:2345-2351, 2000.

[270] P. Dagaut, J. Luche, and M. Cathonnet. The kinetics of $\mathrm{C}_{1}$ to $\mathrm{C}_{4}$ hydrocarbons/NO interactions in relation with reburning. Proc. Combust. Inst., 28:2459-2465, 2000. 
[271] P. Glarborg, P.G. Kristensen, K. Dam-Johansen, M.U. Alzueta, A. Millera, and R. Bilbao. Nitric oxide reduction by non-hydrocarbon fuels. Energy Fuels, 14:828-838, 2000.

[272] P. Dagaut and F. Lecomte. Experiments and kinetic modeling study of NO-reburning by gases from biomass pyrolysis in a JSR. Energy Fuels, 17:608-613, 2003.

[273] A. Frassoldati, T. Faravelli, and E. Ranzi. Kinetic modeling of the interactions between NO and hydrocarbons at high temperature. Combust. Flame, 135:97-112, 2003.

[274] S. L. Chen, J. C. Kramlich, W. R. Seeker, and D. W. Pershing. Advanced $\mathrm{NO}_{\mathrm{x}}$ reduction processes using $-\mathrm{NH}$ and $-\mathrm{CN}$ compounds in conjunction with staged air addition. J. Air Waste Manage. Assoc., 39:1375-1379, 1989.

[275] J. A. Miller, M. C. Branch, and R. J. Kee. A chemical kinetic model for the selective reduction of nitric oxide by ammonia. Combust. Flame, 43:81-98, 1981 .

[276] R. Rota, D. Antos, E.F. Zanoelo, and S. Carra. Experimental study and kinetic modelling of nitric oxide reduction with ammonia. Combust. Sci. Technol., 163:25-47, 2001.

[277] Z.-M. Lu and J.-D. Lu. Influences of $\mathrm{O}_{2}$ concentration on NO reduction and $\mathrm{N}_{2} \mathrm{O}$ formation in Thermal DeNO $\mathrm{x}$ process. Combust. Flame, 156:1303-1315, 2009.

[278] W. Duo. Kinetic studies of the reactions involved in selective non-catalytic reduction of nitric oxide. PhD thesis, DTU Chemical Engineering, Technical University of Denmark, 1990.

[279] J.W. Stephens, C.L. Morter, S.K. Farhat, G.P. Glass, and R.F. Curl. Branching ratio of the reaction amidogen + nitric oxide at elevated temperatures. J. Phys. Chem., 97:8944-8951, 1993. 
[280] F. Kasuya, P. Glarborg, and K. Dam-Johansen. The Thermal DeNO process: Influence of partial pressures and temperature. Chem. Eng. Sci., 50:1455-1466, 1995 .

[281] M. U. Alzueta, H. Røjel, P.G. Kristensenand, P. Glarborg, and K. DamJohansen. Laboratory study of the $\mathrm{CO} / \mathrm{NH}_{3} / \mathrm{NO} / \mathrm{O}_{2}$ system: Implications for hybrid reburn/SNCR Strategies. Energy Fuels, 11:716-723, 1997.

[282] R.A. Perry amd D.L. Siebers. Rapid reduction of nitrogen oxides in exhaust gas streams. Nature, 324:657-658, 1986.

[283] D. L. Siebers and J. A. Caton. Removal of nitric oxide from exhaust gas with cyanuric acid. Combust. Flame, 79:31-46, 1990.

[284] B. Atakan and J. Wolfrum. Kinetic studies of the reactions of NCO radicals with $\mathrm{NO}$ and $\mathrm{O}_{2}$ in the temperature range between 294 and $1260 \mathrm{~K}$. Chem. Phys. Lett., 178:157-162, 1991.

[285] J. D. Mertens, A.J. Dean, R. K. Hanson, and C. T. Bowman. A shock tube study of reactions of $\mathrm{NCO}$ with $\mathrm{O}$ and $\mathrm{NO}$ using $\mathrm{NCO}$ laser absorption. Symp. (Int.) Combust., 24:701-710, 1992.

[286] L.J. Muzio, J.K. Arand, and D.P. Teixeira. Gas phase decomposition of nitric oxide in combustion products. Symp. (Int.) Combust., 16:199-208, 1977.

[287] M.U. Alzueta, R. Bilbao, A. Millera, M. Oliva, and J. C. Ibanez. Interactions between nitic oxide and urea under flow reactor conditions. Energy Fuels, 12:1001-1007, 1998.

[288] S. Lee, K. Park, J.W. Park, and B.H. Kim. Characteristics of reducing NO using urea and alkaline additives. Combust. Flame, 141:200-203, 2005.

[289] R. Rota, D. Antos, E.F. Zanoelo, and M. Morbidello. Experimental and modeling analysis of the $\mathrm{NO}_{\mathrm{x}} \mathrm{OUT}$ process. Chem. Eng. Sci., 57:27-38, 2002. 
[290] R. Rota and E.F. Zanoelo. Influence of oxygenated additives on the $\mathrm{NO}_{\mathrm{x}} \mathrm{OUT}$ process efficiency. Fuel, 82:765-770, 2003.

[291] MU Alzueta, R Bilbao, A Millera, M Oliva, and JC Ibanez. Impact of new findings concerning urea thermal decomposition on the modeling of the urea-SNCR process. Energy Fuels, 14:509-510, 2000.

[292] H. Aoki, T. Fujiwara, Y. Morozumi, and T. Miura. Measurement of urea thermal decomposition reaction rate for NO selective non-catalytic reduction. Fifth international conference on technologies and combustion for a clean environment, 1:115-118, 1999.

[293] Wolfgang Brack, Barbara Heine, Felix Birkhold, Matthias Kruse, Gunter Schoch, and Olaf Deutschmann Steffen Tischer. Kinetic modeling of urea decomposition based on systematic thermogravimetric analyses of urea and its most important by-products. Chem. Eng. Sci., 106:1-8, 2014.

[294] A.L. Myerson, F.R. Taylor, and B.G Faunce. Ignition limits and products of the multistage flames of propane-nitrogen dioxide mixtures. Symp. (Int.) Combust., 6:154-163, 1957.

[295] J. O. L. Wendt, C. V. Sternling, and M. A. Matovich. Reduction of sulfur trioxide and nitrogen oxides by secondary fuel injection. Symp. (Int.) Combust., 14:897-904, 1973.

[296] LD Smoot, SC Hill, and $\mathrm{H} \mathrm{Xu}$. $\mathrm{NO}_{\mathrm{x}}$ control through reburning. Prog. Energy Combust. Sci., 24:385-408, 1998.

[297] A.L. Myerson. The reduction of nitric oxide in simulated combustion effluents by hydrocarbon-oxygen mixtures. Symp. (Int.) Combust., 15:1085$1092,1975$.

[298] J. Gimenez-Lopez, V. Aranda, A. Millera, R. Bilbao, and M. U. Alzueta. An experimental parametric study of gas reburning under conditions of interest for oxy-fuel combustion. Fuel Process. Technol., 92:582-589, 2011. 
[299] Thorne L.R., M.C. Branch, Chandler D.W., Kee R.J., and J.A. Miller. Hydrocarbon/nitric oxide interactions in low-pressure flames. Proc. Combust. Inst., 21:965-977, 1986.

[300] A. Garo, C. Hilaire, and D. Puechberty. Experimental-study of methane oxygen flames doped with nitrogen oxide or ammonia - comparison with modeling. Combust. Sci. Technol., 86:87-103, 1992.

[301] T. Etzkorn, S. Muris, J. Wolfrum, C. Dembny, H. Bockhorn, P. F. Nelson, A. Attia-Shahin, and J. Warnatz. Destruction and formation of NO in low pressure stoichiometric $\mathrm{CH}_{4} / \mathrm{O}_{2}$ flames. Symp. (Int.) Combust., 24:925$932,1992$.

[302] B. A. Williams and J. W. Fleming. Comparative species concentrations in $\mathrm{CH}_{4} / \mathrm{O}_{2} /$ Ar flames doped with $\mathrm{N}_{2} \mathrm{O}$, NO, and $\mathrm{NO}_{2}$. Combust. Flame, 93:98-106, 1994.

[303] W. Juchmann, H. Latzel, D. I. Shin, G. Peiter, T. Dreier, H. R. Volpp, J. Wolfrum, R. P. Lindstedt, and K. M. Leung. Absolute radical concentration measurements and modeling of low-pressure $\mathrm{CH}_{4} / \mathrm{O}_{2} / \mathrm{NO}$ flames. Symp. (Int.) Combust., 27:469-476, 1998.

[304] J. A. Miller, C. F. Melius, and P. Glarborg. The $\mathrm{CH}_{3}+\mathrm{NO}$ rate coefficient at high temperatures: Theoretical analysis and comparison with experiment. Int. J. Chem. Kinet., 30:223-228, 1998.

[305] B. Atakan, D. Kocis, J. Wolfrum, and P. Nelson. Direct investigations of the kinetics of the reactions of $\mathrm{CN}$ radicals with $\mathrm{N}$ atoms and ${ }^{3} \mathrm{CH}_{2}$ radicals with NO. Symp. (Int.) Combust., 24:691-699, 1992.

[306] M. Fikri, S. Meyer, J. Roggenbuck, and F. Temps. An experimental and theoretical study of the product distribution of the reaction $\mathrm{CH}_{2}+\mathrm{NO}$. Faraday Discuss., 119:223-242, 2001.

[307] D.L. Baulch, C.J. Cobos, R.A. Cox, P. Frank, G. Hayman, Th. Just, J.A. Kerr, T. Murrels, M.J. Pilling, J. Troe, R.W. Walker, and J. Warnatz. 
Evaluated kinetic data for combustion modeling: Supplement I. J. Phys. Chem. Ref. Data, 23:847-1033, 1994.

[308] F. Stribel, L.E. Jusinski, A. Fahr, J.B. Halpern, S.J. Klippenstein, and C.A. Taatjes. Kinetics of the reaction of vinyl radicals with NO: Ab initio theory, master equation predictions, and laser absorption measurements. Phys. Chem. Chem. Phys., 6:2216-2223, 2004.

[309] J. Peeters, H. van Look, and B. Ceursters. Absolute rate coefficients of the reactions of $\mathrm{C} 2 \mathrm{H}$ with $\mathrm{NO}$ and $\mathrm{H}_{2}$ between 295 and $440 \mathrm{~K}$. J. Phys. Chem., 100:15124-15129, 1996.

[310] W. Feng and J.F. Hershberger. Experimental and theoretical study of the product channels of the $\mathrm{C}_{2} \mathrm{H}+\mathrm{NO}$ reaction. J. Phys. Chem. A, 117:3585-3592, 2013.

[311] T. Kruse and P. Roth. High-temperature reaction of $\mathrm{C}_{2}$ with NO including product channel measurements. Int. J. Chem. Kinet., 31:11-21, 1999.

[312] S.A. Carl, Q. Sun, L. Vereecken, and J. Peeters. Absolute rate coefficient of the HCCO plus NO reaction over the range $\mathrm{T}=297-802 \mathrm{~K}$. J. Phys. Chem. A, 106:12242-12247, 2002.

[313] W. Boullart, M.T. Nguyen, and J. Peeters. Experimental investigation of the reaction between nitric oxide and ketenyl radicals $(\mathrm{HCCO}+\mathrm{NO})-$ Rate coefficients at $\mathrm{T}=290-670 \mathrm{~K}$ and product distribution at $700 \mathrm{~K}$. J. Phys. Chem., 98:8036-8043, 1994.

[314] J.P. Meyer and J.F. Hershberger. Product channels of the HCCO + NO reaction. J. Phys. Chem. B, 109:8363-8366, 2005.

[315] W. D. Thweat, M.A. Erickson, and J. F. Hershberger. Kinetics of the $\mathrm{CCO}+\mathrm{NO}$ and $\mathrm{CCO}+\mathrm{NO}_{2}$ reactions. J. Phys. Chem. A, 108:74-79, 2004 . 
[316] J. A. Miller, S. J. Klippenstein, and P. Glarborg. A kinetic issue in reburning: The fate of HCNO. Combust. Flame, 135:357-362, 2003.

[317] J. A. Miller, J.L. Durant, and P. Glarborg. Some chemical kinetics issues in reburning: The branching fraction of the $\mathrm{HCCO}+\mathrm{NO}$ reaction. Symp. (Int.) Combust., 27:235-243, 1998.

[318] W. H. Feng, J. P. Meyer, and J. F. Hershberger. Kinetics of the OH plus HCNO reaction. J. Phys. Chem. A, 110:4458-4464, 2006.

[319] M. Braun-Unkhoff, C. Naumann, K. Wintergest, and P. Frank. Untersuchung der reaktionen von $\mathrm{NO}$ und $\mathrm{O}_{2}$ mit $\mathrm{CH}_{3}$ bei hohen temperaturen. VDI Ber., 1090:287-294, 1993.

[320] G. Hennig and H.Gg. Wagner. Investigation of the $\mathrm{CH}_{3}+\mathrm{NO}$ reaction in shock-waves. Ber. Bunsenges. Phys. Chem., 98:749-753, 1994.

[321] C. Vinckier and W. Debruyn. Temperature-dependence of the reactions of methylene with oxygen atoms, oxygen, and nitric oxide. J. Phys. Chem., 83:2057-2062, 1979.

[322] V. Seidler, F. Temps, H.Gg. Wagner, and M. Wolf. Kinetics of the reactions of $\mathrm{CH}_{2}$ (X3B1) radicals with $\mathrm{NO}$ and $\mathrm{NO}_{2}$. J. Phys. Chem., 93:1070$1073,1989$.

[323] S. Bauerle, M. Klatt, and H.Gg. Wagner. Investigation of the reaction of $\mathrm{CH}_{2}$ with $\mathrm{NO}$ at high temperatures. Ber. Bunsenges. Phys. Chem., 99:97-104, 1995.

[324] H.G. Unfried, G.P. Glass, and R.F. Curl. Infrared flash kinetic spectroscopy of the ketenyl radical. Chem. Phys. Lett., 177:33-38, 1991.

[325] F. Temps, H.Gg. Wagner, and M. Wolf. Some experiments concerning the reactions of $\mathrm{HCCO}$ with $\mathrm{C}_{2} \mathrm{H}_{2}, \mathrm{O}_{2}, \mathrm{NO}$, and $\mathrm{NO}_{2}$. Z . Phys. Chem., 176:27-39, 1992. 
[326] U. Eickhoff and F. Temps. FTIR study of the products of the reaction between HCCO and NO. Phys. Chem. Chem. Phys., 1:243-251, 1999.

[327] K.T. Rim and J.F. Hershberger. Product branching ratio of the HCCO plus NO reaction. J. Phys. Chem. A, 104:293-296, 2000.

[328] L. Vereecken, R. Sumathy, S.A. Carl, and J. Peeters. NO $\mathrm{N}_{\mathrm{x}}$ reduction by reburning: theoretical study of the branching ratio of the HCCO plus NO reaction. Chem. Phys. Lett., 344:400-406, 2001.

[329] H. M. T. Nguyen and T. N. Nguyen. Calculations on the complex mechanism of the HCNO plus OH reaction. Chem. Phys. Lett., 599:15-22, 2014.

[330] A.T. Chen and P.C. Malte. paper WSS/CI 84-86 presented at the 1984 Fall Meeting of Western States Section, The Combustion Institute, October 22-23, Stanford, California, 1984.

[331] C. N. Hinshelwood and R. E. Burk. The thermal decomposition of ammonia upon various surfaces. J. Chem. Soc. Trans., 127:1105-1117, 1925.

[332] K. F. Roenigk and K. F. Jensen. Low-pressure CVD of silicon nitride. J. Electrochem. Soc., 134:1777-1785, 1987.

[333] J. Suhlmann and G. Rotzoll. The influence of quartz glass surfaces on the reduction of $\mathrm{NO}$ with $\mathrm{NH}_{3}$ at high-temperatures. Chem.-Ing.-Tech., 64:580-581, 1992.

[334] B. Lewis and G. von Elbe. Combustion and flames and explosions of gases. Academic Press, second edition, 1987.

[335] M. Balat-Pichelin, J. M. Badie, R. Berjoan, and P. Boubert. Recombination coefficient of atomic oxygen on ceramic materials under earth re-entry conditions by optical emission spectroscopy. Chem. Phys., 291:181-194, 2003. 
[336] Y. C. Kim and M. Boudart. Recombination of O, N, and H-atoms on silica - kinetics and mechanism. Langmuir, 7:2999-3005, 1991.

[337] B. Gordiets, C. M. Ferreira, J. Nahorny, D. Pagnon, M. Touzeau, and M. Vialle. Surface kinetics of $\mathrm{N}$ and $\mathrm{O}$ atoms in $\mathrm{N}_{2}-\mathrm{O}_{2}$ discharges. J. Phys. D Appl. Phys., 29:1021-1031, 1996.

[338] G. Cartry, L. Magne, and G. Cernogora. Atomic oxygen recombination on fused silica: experimental evidence of the surface state influence. $J$. Phys. D Appl. Phys., 32:L53-56, 1999.

[339] P. Macko, P. Veis, and G. Cernogora. Study of oxygen atom recombination on a Pyrex surface at different wall temperatures by means of time-resolved actinometry in a double pulse discharge technique. Plasma Sources Sci. Technol., 13:251-262, 2004.

[340] L. Bedra, M. Rutigliano, M. Balat-Pichelin, and M. Cacciatore. Atomic oxygen recombination on quartz at high temperature: Experiments and molecular dynamics simulation. Langmuir, 22:7208-7216, 2006.

[341] W.V. Smith. The surface recombination of $\mathrm{H}$ atoms and $\mathrm{OH}$ radicals. $J$. Chem. Phys., 11:110-125, 1943.

[342] W. Hack, A. W. Preuss, F. Temps, and H. Gg. Wagner. Reaction $\mathrm{O}+\mathrm{HO}_{2}$ $\rightarrow \mathrm{OH}+\mathrm{O}_{2}$ studied with a LMR-ESR spectrometer. Ber. Bunsenges. Phys. Chem., 83:1275-1279, 1979.

[343] A. Garo, D. Puechberty, and M. Ledoux. Recombination kinetics of oh radicals on a quartz wall in a propane oxygen flame at 25 torr. Combust. Flame, 56:307-316, 1984.

[344] K. A. Sahetchian, A. Heiss, and R. Rigny. Evidence of the formation of hydrogen by the bimolecular recombination reaction of $\mathrm{HO}_{2}$ radicals low-temperature heterogeneous reaction of $\mathrm{HO}_{2}$ radicals. Can. J. Chem., 60:2896-2902, 1982. 
[345] V. B. Rozhenshtein, Y.M. Gershenzon, S.D. Ilin, O. P. Kishkovich, and R.T. Malkhasyan. Study of reactions of $\mathrm{HO}_{2}$ radicals by means of combined electron-spin-resonance LMR spectrometer - destruction on surface. Kinet. Cat., 26:460-466, 1985.

[346] A. Zh. Arutyunyan, G. L. Grigoryan, and A. B. Nalbandyan. Electronspin-resonance study of the heterogeneous radical decomposition of hydrogen-peroxide vapor on glass and silica. Kinet. Cat., 26:678-682, 1985.

[347] C.A. Bank and E. A. Th. Verdurmen. On the catalytic reaction of carbon monoxide and oxygen at a quartz surface. J. Phys. Chem., 67:2869-2871, 1963.

[348] V. Guerra. Theoretical investigation of the influence of the wall temperature on the probability for surface atomic recombination of a single species. Jap. J. Appl. Phys., 45:8200-8203, 2006.

[349] A. A. Buchachenko, V. L. Kovalev, and A. A. Krupnov. Closed model of oxygen recombination on an $\mathrm{Al}_{2} \mathrm{O}_{3}$ surface. Russ. J. Phys. Chem. B, 32:86-94, 2013.

[350] P. G. Kristensen. Nitrogen Burnout Chemistry. PhD thesis, Department of Chemical Engineering and Technical University of Denmark, 1995.

[351] P. G. Kristensen, P. Glarborg, and K. Dam-Johansen. Verification of a quartz flow reactor system for homogeneous combustion chemistry. Technical Report CHEC Report 9511, DTU Chemical Engineering, 1995.

[352] A.W. Jasper, S.J. Klippenstein, L.B. Harding, and B. Ruscic. Kinetics of the reaction of methyl radical with hydroxyl radical and methanol decomposition. J. Phys. Chem. A, 111:3932-3950, 2007.

[353] C. Wilson and G.G. Balint-Kurti. New pathway for the $\mathrm{CH}_{3}+\mathrm{OH} \rightarrow$ $\mathrm{CH}_{2}+\mathrm{H}_{2} \mathrm{O}$ reaction on a triplet surface. J. Phys. Chem. A, 102:16251631, 1998. 
[354] P.-F. Lee, H. Matsui, and N.-S. Wang. Study on the Reaction of $\mathrm{CH}_{2}$ with $\mathrm{H}_{2}$ at High Temperature. J. Phys. Chem. A, 116:1891-1896, 2012.

[355] J.M. Preses, C. Fockenberg, and G.W. Flynn. A measurement of the yield of carbon monoxide from the reaction of methyl radicals and oxygen atoms. J. Phys. Chem. A, 104:6758-6763, 2000.

[356] F. Hayes, W.D. Lawrance, W.S. Staker, and K.D. King. Temperature dependences of singlet methylene removal rates. J. Phys. Chem., 100:1131411318,1996

[357] A.W. Jasper, S.J. Klippenstein, and L.B. Harding. Secondary kinetics of methanol decomposition: Theoretical rate coefficients for ${ }^{3} \mathrm{CH}_{2}+\mathrm{OH}$, ${ }^{3} \mathrm{CH}_{2}+{ }^{3} \mathrm{CH}_{2}$, and ${ }^{3} \mathrm{CH}_{2}+\mathrm{CH}_{3}$. J. Phys. Chem. A, 111:8699-8707, 2007.

[358] M. Rohrig, E.L. Petersen, D.F. Davidson, R.K. Hanson, and C.T. Bowman. Measurement of the rate coefficient of the reaction $\mathrm{CH}+\mathrm{O}_{2}$ : products in the temperature range 2200 to $2600 \mathrm{~K}$. Int. J. Chem. Kinet, 29:781-789, 1997.

[359] P. Glarborg and L.L.B. Bentzen. Chemical effects of a high $\mathrm{CO}_{2}$ concentration in oxy-fuel combustion of methane. Energy Fuels, 22:291-296, 2008.

[360] D. Husain and L.J. Kirsch. Reactions of atomic carbon C by kinetic absorption spectroscopy in vacuum ultra-violet. Trans. Faraday Soc., 67:2025-2035, 1971.

[361] J. Grebe and K.H. Homann. Kinetics of the species $\mathrm{OH}$ and $\mathrm{CH}$ in the system $\mathrm{C}_{2} \mathrm{H}_{2}-\mathrm{O}-\mathrm{H}$. Ber. Bunsenges. Phys. Chem., 86:581-587, 1982.

[362] T. Bohland and F. Temps. Direct determination of the rate-constant for the reaction $\mathrm{CH}_{2}+\mathrm{H} \rightarrow \mathrm{CH}+\mathrm{H}_{2}$. Ber. Bunsenges. Phys. Chem., 88:459-461, 1984. 
[363] T. Bohland, F. Temps, and H.Gg. Wagner. A direct study of the reactions of $\mathrm{CH}_{2}$ radicals with $\mathrm{H}$ and D atoms. J. Phys. Chem., 91:1205-1209, 1987.

[364] W. Boullart and J. Peeters. Product distributions of the $\mathrm{C}_{2} \mathrm{H}_{2}+\mathrm{O}$ and $\mathrm{HCCO}+\mathrm{H}$ reactions - rate-constant of $\mathrm{CH}_{2}+$ H. J. Phys. Chem., 96:9810$9816,1992$.

[365] K. Devriendt, W. van Poppel, W. Boullart, and J. Peeters. Kinetic investigation of the ${ }^{3} \mathrm{CH}_{2}+\mathrm{H} \rightarrow \mathrm{CH}+\mathrm{H}_{2}$ reaction in the temperature range $400 \mathrm{~K}<\mathrm{T}<1000$ K. J. Phys. Chem., 99:16953-16959, 1995.

[366] P. Frank, K.A. Bhaskaran, and Th. Just. High-temperature reactions of triplet methylene and ketene with radicals. J. Phys. Chem., 90:2226-2231, 1986.

[367] J. Peeters and G. Mahnen. Reaction mechanisms and rate constants ofelementary steps in methane-oxygen flames. Symp. (Int.) Combust., 14:133146, 1973.

[368] J. Deppe and H. Gg. Wagner. Detection of ${ }^{1} \mathrm{CH}_{2}$ radicals in hydrocarbon pyrolysis behind shock waves using FM spectroscopy. Z. Phys. Chem., 215:1501-1525, 2001.

[369] M.R. Berman and M.C. Lin. Kinetics and mechanisms of the reactions of $\mathrm{CH}$ and $\mathrm{CD}$ with $\mathrm{H}_{2}$ and $\mathrm{D}_{2}$. J. Chem. Phys., 81:5743-5752, 1984.

[370] S. Zabarnick, J.W. Fleming, and M.C. Lin. Kinetic study of the reaction $\mathrm{CH}+\mathrm{H}_{2}=\mathrm{CH}_{2}+\mathrm{H}$ in the temperature range 372 to $675 \mathrm{~K}$. J. Chem. Phys., 85:4373-4376, 1986.

[371] K.H. Becker, R. Kurtenbach, and P. Wiesen. Temperature and pressuredependence of the reaction $\mathrm{CH}+\mathrm{H}_{2}$. J. Phys. Chem., 95:2390-2394, 1991.

[372] R.A. Brownsword, A. Canosa, B.R. Rowe, I.R. Sims, I.W.M. Smith, D.W.A. Stewart, A.C. Symonds, and D. Travers. Kinetics over a wide 
range of temperature (13-744 K): Rate constants for the reactions of $\mathrm{CH}(\nu=0)$ with $\mathrm{H}_{2}$ and $\mathrm{D}_{2}$ and for the removal of $\mathrm{CH}(\nu=1)$ by $\mathrm{H}_{2}$ and D 2 . J. Chem. Phys., 106:7662-7677, 1997.

[373] A.J. Dean, D.F. Davidson, and R.K. Hanson. A shock tube study of reactions of $\mathrm{C}$ atoms with $\mathrm{H}$, and $\mathrm{O}$, using excimer photolysis of $\mathrm{C}_{3} \mathrm{O}_{2}$ and $\mathrm{C}$ atom atomic resonance absorption spectroscopy. J. Phys. Chem., 95:183-191, 1991.

[374] R. van Harrevelt, M.C. van Hemert, and G.C. Schatz. The $\mathrm{CH}+\mathrm{H}$ reaction studied with quantum-mechanical and classical trajectory calculations. $J$. Chem. Phys., 116:6002-6011, 2002.

[375] J. Grebe and K. Homann. Blue-green chemiluminescence in the system $\mathrm{C}_{2} \mathrm{H}_{2}-\mathrm{O}-\mathrm{H}$ - formation of the emitters $\mathrm{CH}, \mathrm{C}_{2}$ and $\mathrm{C}_{2} \mathrm{H}$. Ber. Bunsenges. Phys. Chem., 86:587-597, 1982.

[376] K.H. Becker, B. Engelhardt, P. Wiesen, and K.D. Bayes. Rate constants for $\mathrm{CH}$ reactions at low total pressures. Chem. Phys. Lett., 154:342-348, 1989.

[377] S. Zabarnick, J.W. Fleming, and M.C. Lin. CH Radical Reactions with $\mathrm{H}_{2} \mathrm{O}$ and $\mathrm{CH}_{2} \mathrm{O}$. Symp. (Int.) Combust., 21:713-719, 1986.

[378] M. A. Blitz, M. Pesa, M. J. Pilling, and P. W. Seakins. Reaction of CH with $\mathrm{H}_{2} \mathrm{O}$ : Temperature dependence and isotope effect. J. Phys. Chem. A, 103:5699-5704, 1999.

[379] M. W. Bosnali and Perner D. Reaktionen von pulsradiolytisch erzeugtem CH mit methan und anderen substanzen. Z. Naturforsh., 26:1768-1769, 1971.

[380] A. Bergeat, S. Moisan, R. Mereau, and J.-C. Loison. Kinetics and mechanisms of the reaction of $\mathrm{CH}$ with $\mathrm{H}_{2} \mathrm{O}$. Chem. Phys. Lett., 480:21-25, 2009. 
[381] Kevin M. Hickson, Philippe Caubet, and Jean-Christophe Loison. Unusual low-temperature reactivity of water: The $\mathrm{CH}+\mathrm{H}_{2} \mathrm{O}$ reaction as a source of interstellar formaldehyde? J. Phys. Chem. Lett, 4:2843-2846, 2013.

[382] J. E. Butler, J. W. Fleming, L. P. Goss, and M. C. Lin. Kinetics of CH radical reactions important to hydrocarbon combustion Systems. Am. Chem. Soc. Symp. Ser., 134:397-401, 1980.

[383] M. R. Berman, J. W. Fleming, A. B. Harvey, and M. C. Lin. Temperature dependence of $\mathrm{CH}$ radical reactions with $\mathrm{O}_{2}, \mathrm{NO}, \mathrm{CO}$ and $\mathrm{CO}_{2}$. Symp. (Int.) Combust., 19:73-79, 1982.

[384] C. Mehlmann, M. J. Frost, D. E. Heard, B. J. Orr, and P. F. Nelson. Rate constants for removal of $\mathrm{CH}(\mathrm{D})(\nu=0$ and 1$)$ by collisions with $\mathrm{N}_{2}, \mathrm{CO}$, $\mathrm{O}_{2}, \mathrm{NO}$ and $\mathrm{NO}_{2}$ at $298 \mathrm{~K}$ and with $\mathrm{CO}_{2}$ at 296-873 K. J. Chem. Soc. Faraday Trans., 92:2335-2341, 1996.

[385] M. W. Markus, P. Roth, and T. Just. A shock tube study of the reactions of $\mathrm{CH}$ with $\mathrm{CO}_{2}$ and $\mathrm{O}_{2}$. Int. J. Chem. Kinet., 28:171-179, 1996.

[386] R.J. Hennessy, C. Robinson, and D.B. Smith. A comparative study of methane and ethane flame chemistry by experiment and detailed modeling. Symp. (Int) Combust., 21:761-772, 1986.

[387] T. Etzkorn, J. Fitzer, S. Muris, and J. Wolfrum. Determination of absolute methyl radical and hydroxyl radical concentrations in a low-pressure methane oxygen flame. Chem. Phys. Lett., 208:307-310, 1993.

[388] S. Cheskis, I. Derzy, V.A. Lozovsky, A. Kachanov, and F. Stoeckel. Intracavity laser absorption spectroscopy detection of singlet $\mathrm{CH}_{2}$ radicals in hydrocarbon flames. Chem. Phys. Lett., 277:423-429, 1997.

[389] V. A. Lozovsky, I. Derzy, and S. Cheskis. Radical concentration profiles in a low-pressure methane-air flame measured by intracavity laser absorption and cavity ring-down spectroscopy. Symp. (Int.) Combust., 27:445-452, 1998. 
[390] A. McIlroy. Direct measurement of ${ }^{1} \mathrm{CH}_{2}$ in flames by cavity ringdown laser absorption spectroscopy. Chem. Phys. Lett., 296:151-158, 1998.

[391] I. Derzy and S. Cheskis V.A. Lozovsky. Absorption cross-section and absolute concentration of singlet methylene in methane/air flames. Chem. Phys. Lett., 313:121-128, 1999.

[392] A. McIlroy. Laser studies of small radicals in rich methane flames: $\mathrm{OH}$, $\mathrm{HCO}$, and ${ }^{1} \mathrm{CH}_{2}$. Israel $J$ Chem, 39:55-62, 1999.

[393] R. Evertsen, J. A. van Oijen, R. T. E. Hermanns, L. P. H. de Goey, and J. J. ter Meulen. Measurements of the absolute concentrations of $\mathrm{HCO}$ and ${ }^{1} \mathrm{CH}_{2}$ in a premixed atmospheric flat flame by cavity ring-down spectroscopy. Combust. Flame, 135:57-64, 2003.

[394] A. Fomin, T. Zavlev, V. A. Alekseev, I. Rahinov, S. Cheskis, and A. A. Konnov. Experimental and modelling study of ${ }^{1} \mathrm{CH}_{2}$ in premixed very rich methane flames. Combust. Flame, 171:198-210, 2016.

[395] D.E. Heard, J.B. Jeffries, G.P. Smith, and D.R. Crosley. LIF measurements in methane air flames of radicals important in prompt-NO formation. Combust. Flame, 88:137-148, 1992.

[396] J. Luque, G. P. Smith, and D. R. Crosley. Quantitative CH determinations in low-pressure flames. Symp. (Int.) Combust., 26:959-966, 1996.

[397] D. R. Crosley, J. B. Jeffries, and G. P. Smith. Absolute concentration measurements of chemically-important flame radicals. Israel J. Chem., 39:41-48, 1999 .

[398] L. Gasnot, P. Desgroux, J. F. Pauwels, and L.R. Sochet. Detailed analysis of low-pressure premixed flames of $\mathrm{CH}_{4}+\mathrm{O}_{2}+\mathrm{N}_{2}$ : A study of promptNO. Combust. Flame, 117:291-306, 1999.

[399] I Derzy, VA Lozovsky, and S Cheskis. Absolute CH concentration in flames measured by cavity ring-down spectroscopy. Chem. Phys. Lett., 306:319-324, 1999. 
[400] R. Evertsen, R.L. Stolk, and J.J. Ter Meulen. Investigations of cavity ring down spectroscopy applied to the detection of $\mathrm{CH}$ in atmospheric flames. Combust. Sci. Technol., 149:19-34, 1999.

[401] J. Luque, R.J.H. Klein-Douwel, J.B. Jeffries, P. Smith, and D.R. Crosley. Quantitative laser-induced fluorescence of $\mathrm{CH}$ in atmospheric pressure flames. Appl. Phys. B - Lasers Optics, 75:779-790, 2002.

[402] R. Evertsen, J. A. van Oijen, R. T. E. Hermanns, L. P. H. de Goey, and J. J. ter Meulen. Measurements of absolute concentrations of $\mathrm{CH}$ in a premixed atmospheric flat flame by cavity ring-down spectroscopy. Combust. Flame, 132:34-42, 2003.

[403] J. Luque, P.A. Berg, J.B. Jeffries, G.P. Smith, D.R. Crosley, and J.J. Scherer. Cavity ring-down absorption and laser-induced fluorescence for quantitative measurements of $\mathrm{CH}$ radicals in low-pressure flames. Appl. Phys. B-Lasers Optics, 78:93-102, 2004.

[404] L Pillier, A El Bakali, X Mercier, A Rida, JF Pauwels, and P Desgroux. Influence of C-2 and C-3 compounds of natural gas on NO formation: an experimental study based on LIF/CRDS coupling. Proc. Combust. Inst., 30:1183-1191, 2005.

[405] P. Versailles, G. M. G. Watson, A. C. A. Lipardi, and J. M. Bergthorson. Quantitative $\mathrm{CH}$ measurements in atmospheric-pressure, premixed flames of $\mathrm{C}_{1}-\mathrm{C}_{4}$ alkanes. Combust. Flame, 165:109-124, 2016.

[406] R.G. Joklik, J.W. Daily, and W.J. Pitz. Measurements of ch radical concentrations in an acetylene/oxygen flame and comparisons to modeling calculations. Symp. (Int.) Combust., 21:895-904, 1986.

[407] J. Luque and D. R. Crosley. Absolute CH concentrations in low-pressure flames measured with laser-induced fluorescence. Appl. Phys. B - Lasers Optics, 63:91-98, 1996. 


\section{Appendices}

\section{A: Surface reactions in quartz reactors.}

A significant fraction of the experimental data on nitrogen chemistry in combustion is obtained in atmospheric pressure, laminar flow quartz reactors. While these data benefit from well-characterized experimental conditions, the potential impact of surface reactions on the reactor walls introduces an uncertainty in data interpretation. Heterogeneous reactions may involve decomposition of fuel components, promoting reaction, or loss of radicals, inhibiting reaction.

Some nitrogen species, in particular ammonia [186,331,332], are known to decompose on quartz surfaces. Dean et al. [254] observed that heterogeneous effects affected induction times for oxidation of ammonia. For Thermal DeNO $\mathrm{x}$, Lyon and Benn [257] found little impact of surfaces, consistent with the modeling study of Glarborg et al. [186] who concluded that surface decomposition of $\mathrm{NH}_{3}$ was not important for $\mathrm{SNCR}$ in low $\mathrm{S} / \mathrm{V}$ quartz reactors. However, Suhlmann and Rotzoll [333] reported that for high surface/volume ratios, presence of quartz surfaces widened the temperature window for the process.

Radical recombination on $\mathrm{SiO}_{2}$ surfaces (quartz, Pyrex, etc.) has been studied extensively, due to its importance for reaction in reactors (e.g., explosion limits [334]) and on heat shields for space vehicles in earth reentry [335]. The radical recombination at the surface is usually described in terms of an apparent recombination efficiency $\gamma$. Data are available for $\mathrm{H}$ [336], O [335-340], $\mathrm{OH}[215,341-343], \mathrm{HO}_{2}[215,342,344-346]$ and $\mathrm{N}$ [337].

It can be expected that the impact of the surface will depend on the concentration of water vapor in the system. In flow reactor experiments, the dominating radicals are $\mathrm{O}$ (dry conditions) or $\mathrm{OH}$ (moist conditions), provided the mixture is not too fuel-rich. In addition to controlling the main chain carrier, the pres- 
ence of water vapor has been reported to alter the surface condition, for instance inhibiting oxidation of $\mathrm{CO}$ on a quartz surface [347].

In a dry system, where the silica surface may be more active, atomic oxygen is the dominating chain carrier under oxidizing conditions. The recombination probability for $\mathrm{O}$ on quartz is found to be a complex function of temperature [336], but in the $700-1430 \mathrm{~K}$ range results are consistent, indicating an activation energy for the apparent recombination efficiency of 4.2 $\mathrm{kcal} \mathrm{mol}^{-1}[335,336]$. At these temperatures, it is likely that both Eley-Rideal and Langmuir-Hinshelwood recombination mechanisms contribute to the radical loss $[340,348,349]$.

It is of interest whether a radical loss mechanism can explain the difference between measured and predicted temperatures for the onset of reaction in SNCR experiments conducted under dry conditions (see section 4.1.1 and Fig. 30). Figure 44 compares experimental results for the $\mathrm{NH}_{3} / \mathrm{NO} / \mathrm{O}_{2}$ system obtained under dry conditions [278] with modeling predictions with and without heterogeneous removal of $\mathrm{O}$. The sink of atomic oxygen on the quartz surface is represented in the mechanism by a pseudo-first-order reaction with an activation energy set to the value reported by Kim and Boudart [336] and the A-factor adjusted to predict the observed onset of reaction for the conditions of Fig. 44. Addition of this pseudo-reaction to the mechanism shifts the predicted window for the process towards higher temperature, providing a good agreement between modeling and experiments. However, results in literature on the impact of surface reactions on ammonia oxidation and Thermal $\mathrm{DeNO}_{\mathrm{x}}$ in dry systems indicate that heterogeneous radical loss is insignificant. Lyon and Benn [257] reported that reaction rates for the $\mathrm{NH}_{3} / \mathrm{O}_{2} / \mathrm{NO}$ system was reproducible within $6 \%$ when varying the surface to volume ratio by a factor of two in a dry system. Furthermore, Dean et al. [254] varied the S/V ratio from $4 \mathrm{~cm}^{-1}$ to $20 \mathrm{~cm}^{-1}$ without observing significant changes in the post-induction time $\mathrm{NH}_{3}$ oxidation rate. 


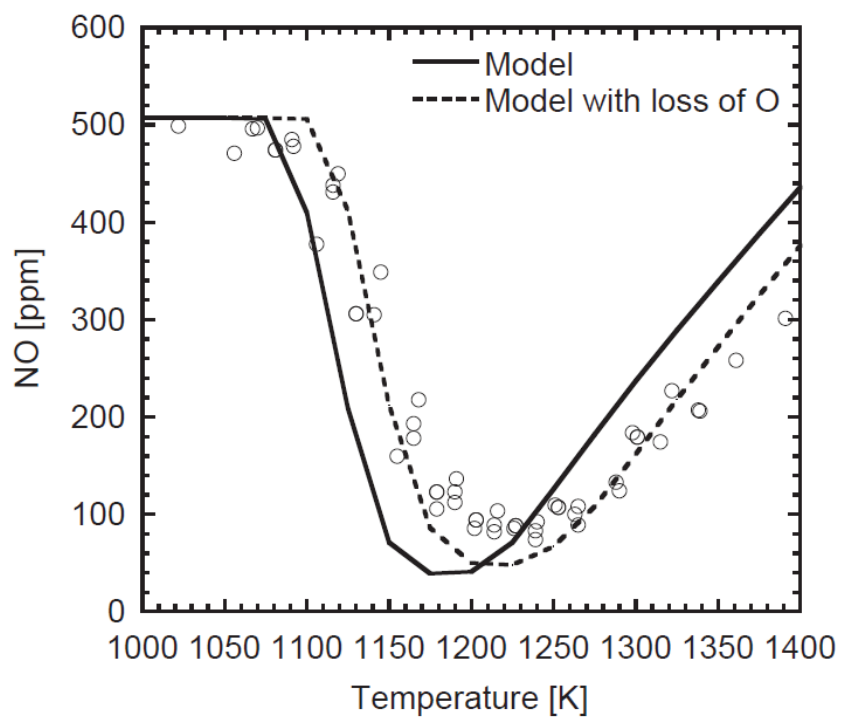

Figure 44: Comparison of experimental data [278] and modeling predictions for reduction of $\mathrm{NO}$ by $\mathrm{NH}_{3}$ under dry conditions. Symbols denote experimental data, while lines denote modeling predictions. Inlet concentrations: $\mathrm{NH}_{3}=832$ ppm, $\mathrm{NO}=507 \mathrm{ppm}, \mathrm{O}_{2}=4.0 \%$, balance $\mathrm{N}_{2}$. Residence time $(\mathrm{s})=92.7 / \mathrm{T}(\mathrm{K})$. The dashed line denotes modeling predictions conducted with surface loss of atomic $\mathrm{O}$ corresponding to a pseudo-first-order reaction with a rate constant $\mathrm{k}_{\mathrm{O}, \text { surf }}=20 \cdot \frac{\mathrm{S}}{\mathrm{V}} \cdot \mathrm{T}^{0.5} \exp (-2110 / \mathrm{T}) \mathrm{s}^{-1}$.

Loss of radicals on the surfaces of quartz flow reactors in moist systems was discussed by Kristensen and coworkers [350,351]. Figure 45 shows their results for moist $\mathrm{CO}$ oxidation in quartz reactors of varying size. The moist $\mathrm{CO}$ oxidation experiments had good reproducibility, independent of time and among reactors of varying size. The results indicate that under moist conditions loss of radicals on the quartz surface of aged reactors is negligible. Modeling predictions conducted with loss of $\mathrm{O}$ atoms on the surface with the rate constant derived above (assuming it to be proportional to the surface/volume ratio of the reactor) shows an impact of reactor size not observed experimentally.

Based on this evidence, we conclude that surface loss of radicals in quartz reactors is generally insignificant at temperatures relevant to combustion. However, surface decomposition or oxidation of reactive species could conceivably play a 


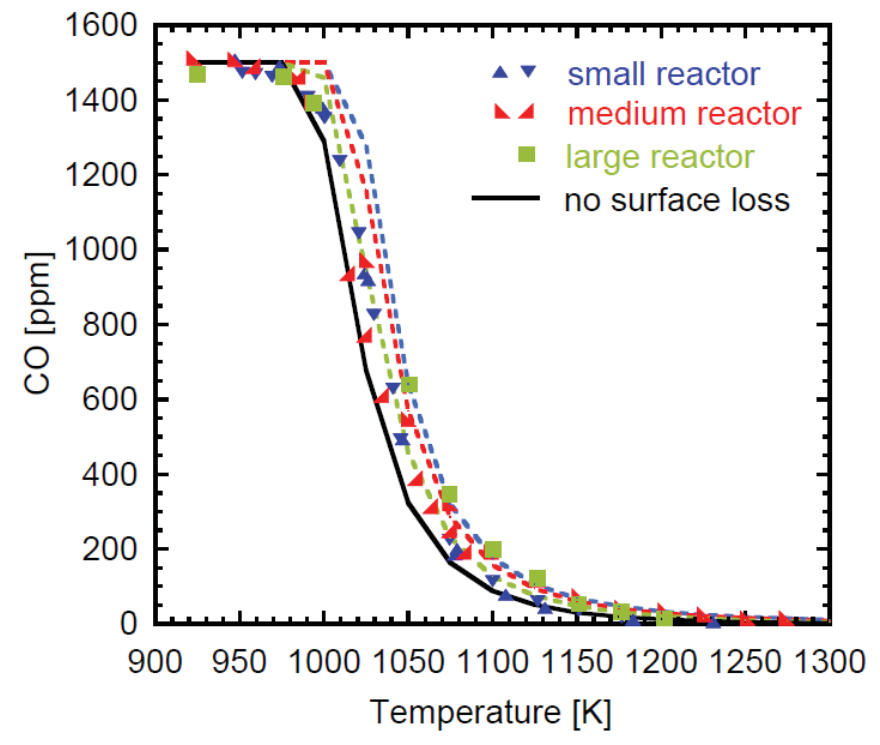

Figure 45: Comparison of experimental data [350] and modeling predictions for moist oxidation of $\mathrm{CO}$ in a flow reactor: effect of quartz reactor size. Symbols denote experimental data, while solid lines denote modeling predictions. Reactor surface to volume ratios are $10 \mathrm{~cm}^{-1}$ (small), $7.8 \mathrm{~cm}^{-1}$ (medium), and $4.4 \mathrm{~cm}^{-1}$ (large). Inlet concentrations: $1468-1520$ (1500) ppm CO, $2.1 \% \mathrm{O}_{2}, 2.0 \% \mathrm{H}_{2} \mathrm{O}$, balance $\mathrm{N}_{2}$. The residence times are $64 / \mathrm{T}[\mathrm{K}] \mathrm{s}$ (small or medium reactor) and $69 / \mathrm{T}[\mathrm{K}] \mathrm{s}$ (large reactor). Pressure is $1.05 \mathrm{~atm}$. The modeling predictions are conducted with (dashed lines, color same as corresponding experimental data) and without (solid line) surface loss of atomic $\mathrm{O}$ corresponding to a pseudofirst-order reaction with a rate constant $\mathrm{k}_{\mathrm{O} \text {, surf }}=20 \cdot \frac{\mathrm{S}}{\mathrm{V}} \cdot \mathrm{T}^{0.5} \exp (-2110 / \mathrm{T}) \mathrm{s}^{-1}$.

role, and data from flow reactor or batch reactor experiments on systems that react slowly (such as $\mathrm{HNCO}$ oxidation) or are sensitive to initiation (e.g, $\mathrm{NH}_{3}$ oxidation) must be interpreted with caution. 


\section{B: Formation and consumption of hydrocarbon radicals.}

Table 11 lists important reactions in the $\mathrm{CH}_{\mathrm{n}}$ subset $(\mathrm{n}=0-3)$. Formation of methylene in its triplet $\left({ }^{3} \mathrm{CH}_{2}\right)$ and singlet $\left({ }^{1} \mathrm{CH}_{2}\right)$ states from methyl occurs mainly by reactions involving $\mathrm{H}$ and $\mathrm{OH}$. In the present mechanism, the rate constant for $\mathrm{CH}_{3}+\mathrm{H}$ to form ${ }^{3} \mathrm{CH}_{2}+\mathrm{H}_{2}$ (R99) is drawn from Klippenstein (unpublished work), while the channel to ${ }^{1} \mathrm{CH}_{2}+\mathrm{H}_{2}$ (R100b), represented by the reverse step, was adopted from the evaluation of Baulch et al. [26]. The rate constants for the $\mathrm{CH}_{3}+\mathrm{OH}$ reactions (R103, R104) were based on the theoretical work of Jasper et al. [352]. The calculated rate constant $\mathrm{k}_{103}$ for abstraction on the triplet surface is in good agreement with the measurement of Wilson and Balint-Kurti [353]. Singlet $\mathrm{CH}_{2}$ formed in (R100b) and (R104) is mostly converted to its triplet state by the rapid collisionally induced intersystem crossing (R105).

The $\mathrm{CH}$ radical is formed from methylene by the reactions $\mathrm{CH}_{2}+\mathrm{H} \rightarrow \mathrm{CH}$ $+\mathrm{H}_{2}$ (R106) and $\mathrm{CH}_{2}+\mathrm{OH} \rightarrow \mathrm{CH}+\mathrm{H}_{2} \mathrm{O}$ (R108). The rate constants for both of these steps have been in question. Low temperature data for reaction R106 [361-365] are in good agreement, indicating a fast reaction with a rate constant of around $10^{14} \mathrm{~mol} \mathrm{~cm} \mathrm{~cm}^{-3} \mathrm{~s}^{-1}$. However, the extrapolation to high temperatures is uncertain. Early high-temperature data from shock tubes [366] and flames [367] indicated that the reaction is not faster than $10^{13} \mathrm{~mol} \mathrm{~cm}^{-3}$ $\mathrm{s}^{-1}$ at $2000 \mathrm{~K}$, while more recent shock tube work of Rohrig et al. [358] and Deppe and Wagner [368] suggested a fast rate even at high temperature.

Measurements [369-372] of the rate constant of the reverse reaction, $\mathrm{CH}+\mathrm{H}_{2}$ $\rightarrow \mathrm{CH}_{2}+\mathrm{H}$ (R106b), support the findings of Rohrig et al. and Deppe and Wagner that the $\mathrm{CH}_{2}+\mathrm{H}$ rate constant is largely independent of temperature. Figure 46 compares the available data for $\mathrm{k}_{106}$, both from direct measurements of the forward reaction and from converting data for $\mathrm{k}_{106 \mathrm{~b}}$ through the equilibrium constant. Values of $\mathrm{k}_{106}$ derived from reaction $\mathrm{R} 106 \mathrm{~b}$ are generally larger, 


\begin{tabular}{|c|c|c|c|c|c|}
\hline 99 . & $\mathrm{CH}_{3}+\mathrm{H} \rightleftarrows{ }^{3} \mathrm{CH}_{2}+\mathrm{H}_{2}$ & $1.2 \mathrm{E} 06$ & 2.43 & 11941 & $a$ \\
\hline 100. & ${ }^{1} \mathrm{CH}_{2}+\mathrm{H}_{2} \rightleftarrows \mathrm{CH}_{3}+\overrightarrow{\mathrm{H}}$ & $7.6 \mathrm{E} 13$ & 0.00 & 0 & {$[354]$} \\
\hline 101. & $\mathrm{CH}_{3}+\mathrm{O} \rightleftarrows \mathrm{CH}_{2} \mathrm{O}+\mathrm{H}$ & $6.9 \mathrm{E} 13$ & 0.00 & 0 & {$[26,355]$} \\
\hline 102. & $\mathrm{CH}_{3}+\mathrm{O} \rightleftarrows \mathrm{CO}+\mathrm{H}_{2}+\mathrm{H}$ & $1.5 \mathrm{E} 13$ & 0.00 & 0 & {$[26,355]$} \\
\hline 103. & $\mathrm{CH}_{3}+\mathrm{OH} \rightleftarrows{ }^{3} \mathrm{CH}_{2}+\mathrm{H}_{2} \mathrm{O}$ & $4.3 \mathrm{E} 04$ & 2.568 & 3997 & {$[352]$} \\
\hline \multirow[t]{3}{*}{104.} & $\mathrm{CH}_{3}+\mathrm{OH} \rightleftarrows{ }^{1} \mathrm{CH}_{2}+\mathrm{H}_{2} \mathrm{O}$ & $2.2 \mathrm{E} 14$ & -0.53832 & -220 & {$[352], 0.013$ bar } \\
\hline & & $1.2 \mathrm{E} 15$ & -0.72747 & 600 & $0.13 \mathrm{bar}$ \\
\hline & & $4.3 \mathrm{E} 15$ & -0.85972 & 1888 & $1.3 \mathrm{bar}$ \\
\hline 105. & ${ }^{1} \mathrm{CH}_{2}+\mathrm{M} \rightleftarrows \mathrm{CH}_{2}+\mathrm{M}$ & $1.3 \mathrm{E} 13$ & 0.00 & 400 & {$[356]\left(\mathrm{N}_{2}\right)$} \\
\hline 106. & ${ }^{3} \mathrm{CH}_{2}+\mathrm{H} \rightleftarrows \mathrm{CH}+\mathrm{H}_{2}$ & 1.6E14 & 0.000 & 0 & See text \\
\hline 107. & ${ }^{3} \mathrm{CH}_{2}+\mathrm{OH} \rightleftarrows \mathrm{CH}_{2} \mathrm{O}+\mathrm{H}$ & $2.9 \mathrm{E} 13$ & 0.1228 & -162 & {$[357]$} \\
\hline 108. & ${ }^{3} \mathrm{CH}_{2}+\mathrm{OH} \rightleftarrows \mathrm{CH}+\mathrm{H}_{2} \mathrm{O}$ & 8.6Е05 & 2.019 & 6776 & {$[357]$} \\
\hline 109. & ${ }^{3} \mathrm{CH}_{2}+\mathrm{O}_{2} \rightleftarrows \mathrm{CO}_{2}+\mathrm{H}+\mathrm{H}$ & 2.1E09 & 0.9929 & -269 & $a$ \\
\hline 110. & ${ }^{3} \mathrm{CH}_{2}+\mathrm{O}_{2} \rightleftarrows \mathrm{CH}_{2} \mathrm{O}+\mathrm{O}$ & 1.3E06 & 2.4202 & 1604 & $a$ \\
\hline 111. & $\mathrm{CH}+\mathrm{H} \rightleftarrows \mathrm{C}+\mathrm{H}_{2}$ & $1.2 \mathrm{E} 14$ & 0.000 & 0 & {$[26]$} \\
\hline 112. & $\mathrm{CH}+\mathrm{OH} \rightleftarrows \mathrm{HCO}+\mathrm{H}$ & $3.0 \mathrm{E} 13$ & 0.000 & 0 & {$[21]$} \\
\hline 113. & $\mathrm{CH}+\mathrm{O}_{2} \rightleftarrows \mathrm{HCO}+\mathrm{O}$ & $9.7 \mathrm{E} 13$ & 0.000 & 0 & [358] \\
\hline 114. & $\mathrm{CH}+\mathrm{OH} \rightleftarrows \mathrm{C}+\mathrm{H}_{2} \mathrm{O}$ & 4.0Е07 & 2.000 & 3000 & {$[21]$} \\
\hline 115. & $\mathrm{CH}+\mathrm{H}_{2} \mathrm{O} \rightleftarrows \mathrm{CH}_{2} \mathrm{O}+\mathrm{H}$ & 8.5E08 & 1.144 & -2051 & $a$ \\
\hline 116. & $\mathrm{CH}+\mathrm{CO}_{2} \rightleftarrows \mathrm{HCO}+\mathrm{CO}$ & 8.8E06 & 1.750 & -1040 & [359] \\
\hline 117. & $\mathrm{C}+\mathrm{OH} \rightleftarrows \mathrm{CO}+\mathrm{H}$ & $5.0 \mathrm{E} 13$ & 0.000 & 0 & est \\
\hline 118. & $\mathrm{C}+\mathrm{O}_{2} \rightleftarrows \mathrm{CO}+\mathrm{O}$ & $2.0 \mathrm{E} 13$ & 0.000 & 0 & {$[360]$} \\
\hline
\end{tabular}

$a$ : Rate constant calculated by S.J. Klippenstein (unpublished work).

Table 11: Selected reactions involved in formation and consumption of hydrocarbon radicals. Parameters for use in the modified Arrhenius expression $\mathrm{k}=$ $\mathrm{AT}^{\beta} \exp (-\mathrm{E} /[\mathrm{RT}])$. Units are mol, cm, s, cal. In reactions $\mathrm{R} 102$ and $\mathrm{R} 109$ a significant fraction of the initial bimolecular products dissociate prior to their thermalization. In this instance, the proper phenomenological rate model for that directly dissociative fraction involves a description of the reactions as producing three separate molecular products.

perhaps due to interference from the competing step $\mathrm{CH}+\mathrm{H}_{2}(+\mathrm{M}) \longrightarrow \mathrm{CH}_{3}$ $(+\mathrm{M})$. In the present work we have applied a rate constant of $1.6 \cdot 10^{14} \mathrm{~cm}^{3}$ $\mathrm{mol}^{-1} \mathrm{~s}^{-1}$, slightly faster than the recommendation of Baulch et al. [26]. However, there is significant scatter in the data and an accurate determination of $\mathrm{k}_{106}$ over a wide temperature range is desirable. 


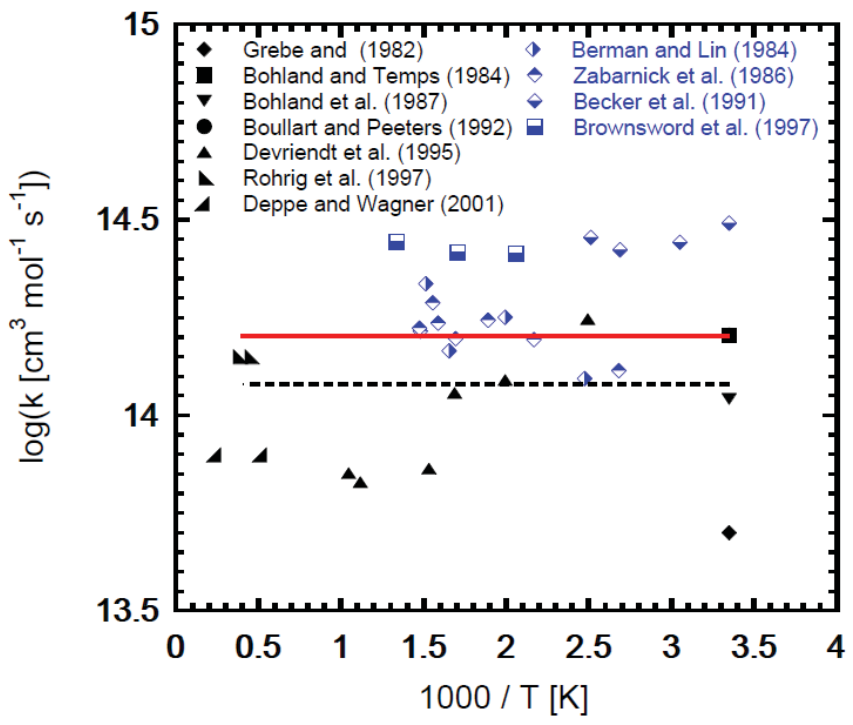

Figure 46: Arrhenius plot for the reaction $\mathrm{CH}_{2}+\mathrm{H} \rightleftarrows \mathrm{CH}+\mathrm{H}_{2}$ (R106). The closed symbols denote measurements in the forward reaction while the open symbols denote data obtained from measurements of the reverse step, converted using the thermodynamic properties of the present work. Data for $\mathrm{k}_{106}$ : Grebe and Homann [361], Bohland and Temps [362], Bohland et al. [363], Boullart et al. [364], Devriendt et al. [365], Rohrig et al. [358] and Deppe and Wagner [368]. Data derived from measurements of $\mathrm{k}_{106 \mathrm{~b}}$ : Berman and Lin [369], Zabarnick et al. [370], Becker et al. [371], Brownsword et al. [372]. The solid line shows the value used in the present model while the dashed line denotes the recommendation of Baulch et al. [26].

For the reaction of $\mathrm{CH}_{2}$ with $\mathrm{OH}(\mathrm{R} 107, \mathrm{R} 108)$ we rely on the theoretical work of Jasper et al. [357]. Reactions R106 and R108 that form CH compete with steps involving $\mathrm{O}, \mathrm{OH}$, and $\mathrm{O}_{2}$ that form oxygenated species and serve to diminish the $\mathrm{CH}_{\mathrm{n}}$ radical pool.

The most important $\mathrm{CH}$-consuming step under reducing conditions is the reaction with atomic hydrogen:

$$
\mathrm{CH}+\mathrm{H} \rightleftarrows \mathrm{C}+\mathrm{H}_{2}
$$

Baulch et al. [26] recommend a value of $\mathrm{k}_{108}$ of $1.2 \cdot 10^{14} \mathrm{~cm}^{3} \mathrm{~mol}^{-1} \mathrm{~s}^{-1}$, based 
on shock tube results for reaction R111b by Dean et al. [373]. The fast rate is supported by theory [374], but conflicts with measurements at room temperature $[375,376]$. Reaction R111 competes with other consumption steps of $\mathrm{CH}$, including reactions with $\mathrm{O}, \mathrm{OH}, \mathrm{O}_{2}$, and $\mathrm{H}_{2} \mathrm{O}$. Even though they are much slower than the radical-radical reactions, reactions of $\mathrm{CH}$ with $\mathrm{H}_{2} \mathrm{O}$ and $\mathrm{CO}_{2}$ may become important under conditions with high concentrations of combustion products. The reaction between $\mathrm{CH}$ and $\mathrm{H}_{2} \mathrm{O}$ yields formaldehyde,

$$
\mathrm{CH}+\mathrm{H}_{2} \mathrm{O} \rightleftarrows \mathrm{CH}_{2} \mathrm{O}+\mathrm{H}
$$

Figure 47 shows an Arrhenius plot for the reaction. Previous modeling studies have relied on the measurements of Zabarnick et al. [377] (298-669 K) and Blitz et al. [378] (291-673 K), which show a negative temperature dependence of reaction R115, making it comparatively slow under most combustion conditions. Recently, Klippenstein (unpublished work) studied the reaction at a high level of theory. He calculated a rate constant with a minimum at approximately 800 $\mathrm{K}$ and a slow increase with temperature above this value. His rate constant, which was adopted in the present model, results in a reaction which is more competitive at combustion temperatures and consequently a faster predicted consumption of $\mathrm{CH}$.

The rate constant for the reaction between $\mathrm{CH}$ and $\mathrm{CO}_{2}$ (R14) has been measured over a wider temperature range (298-3500 K) [382-385]. The data, which show a strong curvature in the Arrhenius expression, are well described by the rate constant proposed by Glarborg and Bentzen [359].

\subsubsection{Modeling the $\mathrm{CH}_{n}$ radical pool in flames}

Hydrocarbon radical concentrations reported from low-pressure, premixed methane flames include data for methyl [303,386,387], triplet methylene [386], and singlet methylene [388-394]. Most data are available for methylidyne (CH), which 


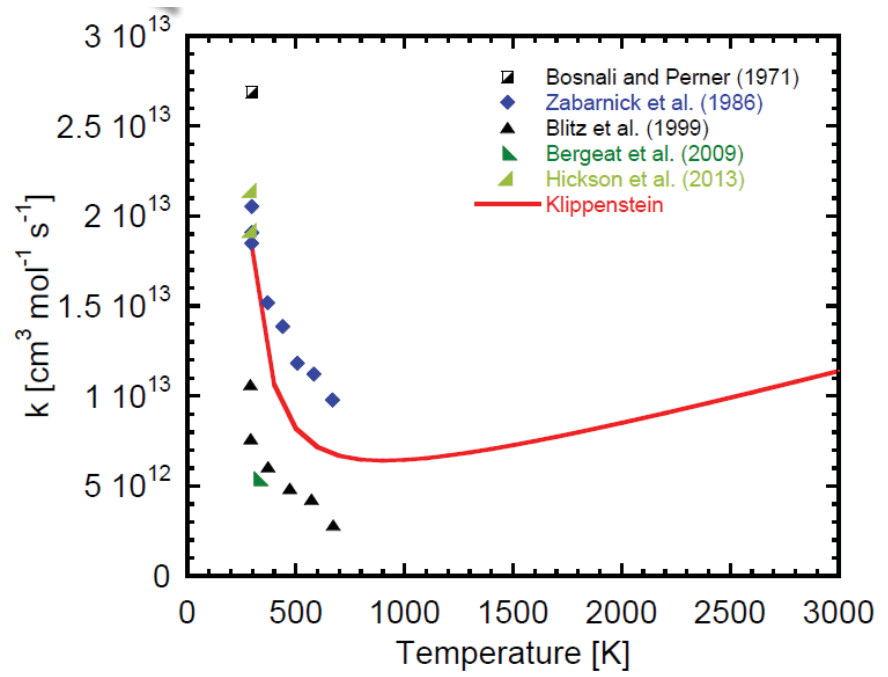

Figure 47: Arrhenius plot for the reaction $\mathrm{CH}+\mathrm{H}_{2} \mathrm{O} \rightarrow \mathrm{CH}_{2} \mathrm{O}+\mathrm{H}$ (R115). The symbols denote measurements while the solid line denotes a theoretical determination. Data were drawn from the following sources: Bosnali and Perner [379], Zabarnick et al. [377], Blitz et al. [378], Bergeat et al. [380], Hickson et al. [381], and Klippenstein (unpublished).

has been detected in methane flames [62, 70, 95, 97, 303, 395-405], as well as in flames of $\mathrm{C}_{2} \mathrm{H}_{2}[62,97,406], \mathrm{C}_{2} \mathrm{H}_{4}$ [35], $\mathrm{C}_{2} \mathrm{H}_{6}$ [70, 405], $\mathrm{C}_{3} \mathrm{H}_{6}$ [66], and $\mathrm{C}_{3} \mathrm{H}_{8}[70,396,405,407]$.

Figure 11 shown in section 3.2.3 compared the measured and calculated CHprofiles from two sets of low-pressure methane flames, obtained over a range of fuel-air equivalence ratios. Modeling predictions were generally in satisfactory agreement with measurements, capturing the $\mathrm{CH}$ concentration within a a factor of two under all conditions. Here we compare modeling predictions with measured profiles for a wider range of $\mathrm{CH}_{n}$ radicals, obtained by molecular beam sampling and mass spectrometry.

In Fig. 48, modeling predictions are compared to data from Hennessy et al. [386] for a low-pressure, premixed methane/oxygen/argon flame. The structure of this flame is well predicted by the model; all major species (including $\mathrm{CH}_{4}$ 
shown) are captured precisely. The peak concentrations of $\mathrm{CH}_{3}$ and ${ }^{3} \mathrm{CH}_{2}$ are predicted within a factor of two, but the methylene peak is shifted by about 1.5 $\mathrm{mm}$ compared to the measured profile.

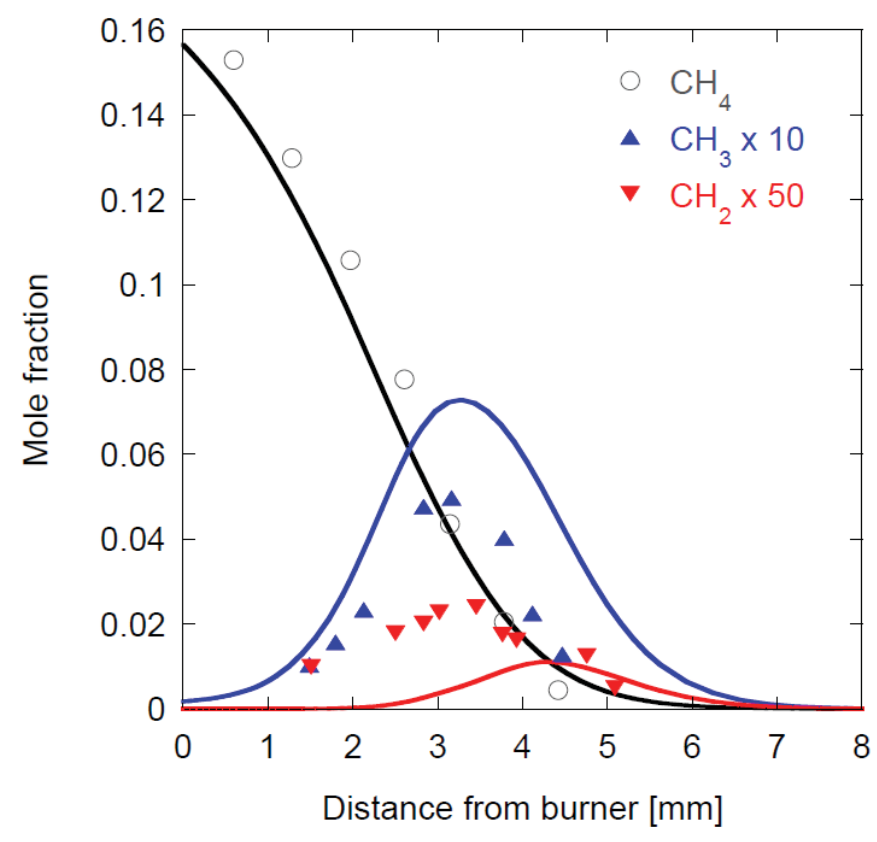

Figure 48: Comparison of measured [386] and predicted mole fractions of $\mathrm{CH}_{4}$, $\mathrm{CH}_{3}$, and ${ }^{3} \mathrm{CH}_{2}$ for a low-pressure premixed methane/air flame. The symbols denote experimental data, while the solid lines denote calculated values. Conditions: pressure of 20 torr, inlet composition $19 \% \mathrm{CH}_{4}, 38 \% \mathrm{O}_{2}$; balance $\mathrm{Ar}$. The maximum flame temperature was about $2300 \mathrm{~K}$ and the velocity of the unburnt gas mixture was $119 \mathrm{~cm} / \mathrm{s}$.

Figure 49 compares measured and predicted profiles of ${ }^{3} \mathrm{CH}_{2}, \mathrm{CH}$, and $\mathrm{C}$ for the low-pressure, premixed ethylene $/ \mathrm{O}_{2} / \mathrm{N}_{2}$ flame from Blauwens et al. [35]. The flame was operated under near-stoichiometric conditions. While $\mathrm{CH}$ is calculated quite accurately, the model overpredicts the ${ }^{3} \mathrm{CH}_{2}$ and $\mathrm{C}$ concentrations by factors of two and three, respectively.

The uncertainties in the measured radical concentrations in the flames of Hennesy et al. and Blauwens et al. were reported to be factors of three and two, 


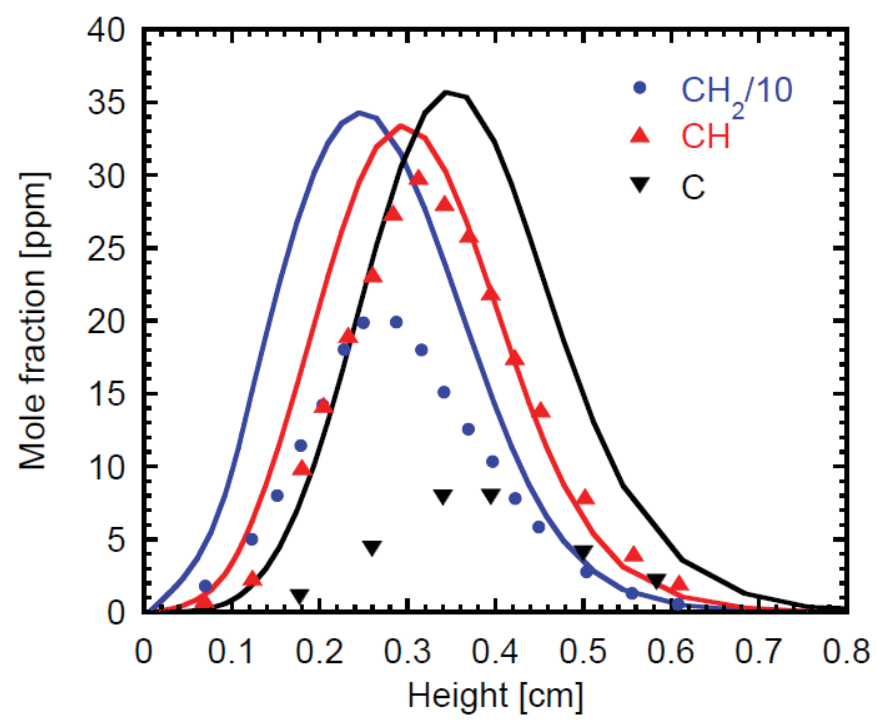

Figure 49: Comparison of measured [35] and predicted mole fractions of ${ }^{3} \mathrm{CH}_{2}$, $\mathrm{CH}, \mathrm{C}$, and NO for a low-pressure premixed ethylene/air flame. The symbols denote experimental data, while the solid lines denote calculated values. Conditions: pressure of 18.5 torr, fuel-air equivalence ratio of $\phi=0.97\left(11.2 \% \mathrm{C}_{2} \mathrm{H}_{4}\right.$ in $\mathrm{O}_{2} / \mathrm{N}_{2}$ mixture) and a velocity of the unburnt gas mixture of $169 \mathrm{~cm} / \mathrm{s}$.

respectively. Lamoureux et al. [72] and Berg et al. [95] measured CH concentrations by laser diagnostics with an estimated accuracy of $20 \%$ (see section 3.2.3). We estimate that modeling predictions of the $\mathrm{CH}_{\mathrm{n}}$ radical concentrations in combustion of small hydrocarbons are mostly accurate within a factor of two.

For larger hydrocarbons, formation and consumption of fuel-derived radicals are more complicated. Sutton et al. [70] compared modeling predictions to flame measurements for different fuels and stoichiometries and concluded that the tested mechanisms were not able to predict the $\mathrm{CH}$ concentration accurately over a wider range of fuels and conditions. Also, for more complex fuels larger hydrocarbon radicals, such as propargyl $\left(\mathrm{C}_{3} \mathrm{H}_{3}\right)$, may become important in interacting with the nitrogen chemistry. More work is desirable in this area, but it is outside the scope of the present review. 